\title{
Adapting CMMI for Acquisition Organizations: A Preliminary Report
}

CMU/SEI-2006-SR-005

Improving processes for better products

Kathryn M. Dodson, EDS

Dr. Hubert F. Hofmann, General Motors

Gowri S. Ramani, Hewlett Packard

Deborah K. Yedlin, General Motors

Edited by

Dr. Matthew J. Fisher, Software Engineering Institute Keith Kost, Software Engineering Institute 
This work is sponsored by General Motors Corporation and was created under collaborative agreement 0500199-CA-000 between General Motors Corporation and the Software Engineering Institute.

The Software Engineering Institute is a federally funded research and development center sponsored by the U.S. Department of Defense. The ideas and findings in this report should not be construed as an official DoD position. It is published in the interest of scientific and technical information exchange.

Copyright 2006 Carnegie Mellon University.

NO WARRANTY

THIS CARNEGIE MELLON UNIVERSITY AND SOFTWARE ENGINEERING INSTITUTE MATERIAL IS FURNISHED ON AN "AS-IS" BASIS. CARNEGIE MELLON UNIVERSITY MAKES NO WARRANTIES OF ANY KIND, EITHER EXPRESSED OR IMPLIED, AS TO ANY MATTER INCLUDING, BUT NOT LIMITED TO, WARRANTY OF FITNESS FOR PURPOSE OR MERCHANTABILITY, EXCLUSIVITY, OR RESULTS OBTAINED FROM USE OF THE MATERIAL. CARNEGIE MELLON UNIVERSITY DOES NOT MAKE ANY WARRANTY OF ANY KIND WITH RESPECT TO FREEDOM FROM PATENT, TRADEMARK, OR COPYRIGHT INFRINGEMENT.

Use of any trademarks in this report is not intended in any way to infringe on the rights of the trademark holder.

Internal use. Permission to reproduce this document and to prepare derivative works from this document for internal use is granted, provided the copyright and "No Warranty" statements are included with all reproductions and derivative works.

External use. Requests for permission to reproduce this document or prepare derivative works of this document for external and commercial use should be addressed to the SEI Licensing Agent.

This work was created in the performance of Federal Government Contract Number FA8721-05-C-0003 with Carnegie Mellon University for the operation of the Software Engineering Institute, a federally funded research and development center. The Government of the United States has a royalty-free government-purpose license to use, duplicate, or disclose the work, in whole or in part and in any manner, and to have or permit others to do so, for government purposes pursuant to the copyright license under the clause at 252.227-7013.

For information about purchasing paper copies of SEI reports, please visit the publications portion of our Web site (http://www.sei.cmu.edu/publications/pubweb.html).

The following service marks and registered marks are used in this document:

Capability Maturity Model $^{\circledR}$

$\mathrm{CMM}^{\circledR}$

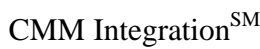

$\mathrm{CMMI}^{\circledR}$

IDEAL $^{\text {SM }}$

SCAMPI $^{\text {SM }}$

CMMI, CMM, and Capability Maturity Model are registered in the U.S. Patent and Trademark Office. CMM Integration, SCAMPI, and IDEAL are service marks of Carnegie Mellon University. 


\section{Preface}

$\mathrm{CMMI}^{\circledR}$ (Capability Maturity Model ${ }^{\circledR}$ Integration) is a collection of best practices that helps organizations improve their processes. It was initially developed by a product team from Industry, U.S. government and the Software Engineering Institute for application to process improvement in the development of products and services covering the entire product life cycle from conceptualization through maintenance and disposal. Following the success of CMMI models for development organizations, the need was identified for a CMMI model addressing the acquisition environment. This need was reinforced and gained further attention due to similar needs expressed by General Motors (GM), which acquires information technology (IT) solutions. Aligned with GM's strategy, GM projects or programs develop requirements and design constraints and oversee multiple suppliers that develop IT solutions and then deploy the resulting products and services into one or more of GM's business units. This approach parallels the acquisition processes used in many government organizations.

General Motors, in collaboration with the SEI and with approval of the CMMI Sponsors and Steering Group, sponsored the development of an initial draft CMMI for Acquisition (CMMI-ACQ) constellation, which will lead to a CMMI-based acquisition model formally accepted by both government and industry after piloting of the initial draft CMMI-ACQ has been completed. This draft is based on the CMMI Version 1.2 architecture and framework which incorporates the concept of constellations, which are groupings of components to support a specific model application such as Development (DEV) or Acquisition (ACQ).

The Office of the Secretary of Defense (OSD) has recognized the value of using this initial draft CMMI-ACQ as a basis for piloting and further development to create a final validated acquisition model useful to both government and industry.

This document presents the initial draft CMMI-ACQ, which adapts CMMI for acquisition organizations. The initial draft CMMI-ACQ is a collection of best practices that is generated from the CMMI v1.2 Architecture and Framework and acquisition best practices from government and industry. 
The CMMI Architecture and Framework supports the CMMI Product Suite by allowing multiple models, called constellations, and training courses to be generated that support specific areas of interest.

The initial draft CMMI-ACQ is based on the CMMI Model Foundation (i.e., 16 process areas that cover project management, organizational and support process areas; the generic goals and practices; and glossary), the CMMI Acquisition Module, and the prior Software Acquisition Capability Maturity Model (SA-CMM). It also incorporates attempts by several acquisition organizations to adapt the CMMI for Development (CMMI-DEV) constellation for an acquisition organization.

The initial draft CMMI-ACQ provides guidance for the application of the CMMI framework to the acquirer or acquisition discipline. The practices focus on activities required for supplier sourcing, initiating and awarding supplier agreements and managing acquisition of products and services through a set of standard metrics, acceptance criteria, and supplier deliverables. The initial draft CMMI-ACQ integrates bodies of knowledge that are essential for an acquirer. Supplier activities are not addressed in the initial draft CMMI-ACQ.

By integrating these bodies of knowledge, the initial draft CMMI-ACQ provides a comprehensive solution for acquirers as they work with suppliers to develop and maintain products and services. CMMI-DEV may be treated as a reference for supplier executed activities for systems engineering, software development, and hardware design work in an acquisition initiative.

Many talented people were involved in developing the initial draft CMMI-ACQ: the primary development team, the review participants, and the CMMI Steering Group.

The primary development team wrote, reviewed, revised, discussed, and agreed on the structure and technical content of the initial draft CMMI-ACQ, including the application of the CMMI architecture, the framework, and models. 
Review teams took drafts of the content and gave substantive feedback to the development team, which was then incorporated into subsequent versions of the draft. This feedback came from their knowledge of the CMMI model construct, as well as from their own practical experiences as acquirers or suppliers. Piloting of this content will occur in 2006, and the piloting team will plan and manage piloting activities. This team will identify candidate organizations to participate in piloting, will prepare pilot materials, help with training activities, and consolidate and summarize pilot results. A representative sample of possible audiences for the eventual acquisition model will be selected in order to fully test the applicability of the initial draft CMMI-ACQ.

Members of these groups, who were involved in developing the initial draft CMMI-ACQ, are listed in Appendix C.

\section{Audience}

The audience for the initial draft CMMI-ACQ includes anyone interested in process improvement in an acquisition environment. Whether you are familiar with the concept of Capability Maturity Models or whether you are seeking information to get started on your improvement efforts, the initial draft CMMI-ACQ will be useful to you. This document is also intended for people who want to use it for an appraisal. ${ }^{1}$

The document is organized into three main parts:

- Part One-About Adapting CMMI for Acquisition Organizations

- Part Two-Generic Goals and Practices, and the Process Areas

- Part Three-The Appendices and Glossary

Part One, "About Adapting CMMI for Acquisition Organizations," consists of five chapters:

- Chapter 1, "Introduction," offers a broad view of CMMI and the eventual CMMI for Acquisition constellation. It is an introduction to the concepts of process improvement and describes the history of models used for process improvement and different process improvement approaches.

- Chapter 2, "Process Area Components," describes all of the components of the Adapting CMMI for Acquisition Organizations process areas.

${ }^{1}$ An appraisal is an examination of one or more processes by a trained team of professionals using a reference model (e.g., CMMI) as the basis for determining strengths and weaknesses. 
- Chapter 3, "Tying It All Together," assembles the model components and explains the concepts of maturity level and capability level.

- Chapter 4, "Using CMMI Models," describes paths to adoption and use of CMMI (and the initial draft CMMI-ACQ) for process improvement and benchmarking.

Part Two, "Generic Goals and Practices, and the Process Areas," contains the required and expected components for the potential acquisition constellation. It also contains related informative components, including subpractices, notes, and typical work products.

To make these process areas easy to find, they are organized alphabetically by process area acronym. Each section contains descriptions of goals, best practices, and examples.

Part Three, "Appendices," consists of the following sections:

- Appendix A, "References," provides a list of references used in development of the document

- Appendix B, "Acronyms," defines the acronyms used in this document.

- Appendix C, "Adapting CMMI for Acquisition Organizations Project Participants"

- Appendix D, the "Glossary" defines many of the terms used in $\mathrm{CMMI}$ and in this document.

Whether you are new to process improvement, new to CMMI, or already familiar with CMMI, Part One can help you understand why the initial draft CMMI-ACQ is the guide to use for improving your acquisition processes.

\section{Readers New to Process Improvement}

If you are new to process improvement or new to the $\mathrm{CMM}^{\circledR}$ concept, we suggest that you read chapter 1, "Introduction," first. Chapter 1 will give you an overview of process improvement and explain what CMMI is all about.

Next, skim Part Two, including generic goals and practices as well as specific goals and practices, to get a feel for the scope of the best practices contained in the initial draft CMMI-ACQ. Pay close attention to the purpose and introductory notes at the beginning of each process area. 
In Part Three, look through the references in Appendix A and select additional sources you think would be beneficial to read before moving forward with using the initial draft CMMI-ACQ. Read through the acronyms and glossary to become familiar with the language of CMMI. Then, go back and read the details of Part Two.

\section{Readers Experienced with Process Improvement}

If you are new to CMMI but have experience with other processimprovement models, such as the Software CMM (version 1.1) or the Systems Engineering Capability Model (i.e., EIA 731), you will immediately recognize many similarities [SEI 1995, EIA 1998].

We recommend that you read Part One to understand how CMMI is different from other process-improvement models, but you may want to read some of the sections more quickly than others. Read Part Two with an eye open for best practices you recognize from the models you have already tried. Identifying familiar material gives you a feel for what is new and what has been carried over from the model you already know.

Next, review the glossary to understand how some terminology may differ from that used in the process-improvement model you know. Many concepts will be repeated, but they may be called something different.

\section{Readers Familiar with CMMI}

If you have reviewed or used a CMMI model before, you will quickly recognize the CMMI concepts discussed and the best practices presented.

\section{Additional Information and Reader Feedback}

You can find additional information from various other sources about CMMI, such as the background and history of the CMMI models, as well as the benefits of using CMMI models. Many of these sources are listed in Appendix A and are also documented on the CMMI Web sitehttp://www.sei.cmu.edu/cmmi/.

Suggestions for improving CMMI are welcome. For information on how to provide feedback, see the CMMI Web site at http://www.sei.cmu.edu/cmmi/models/change-requests.html [SEI 2]. If you have questions about CMMI, send an e-mail to cmmicomments@sei.cmu.edu. 
Adapting CMMI for Acquisition Organizations: A Preliminary Report

Preface 


\section{Table of Contents}

Preface $\quad$ i

Purpose

Acknowledgement ii

Audience iii

Organization of This Document iii

How to Use This Document iv

Readers New to Process Improvement iv

Readers Experienced with Process Improvement $\quad \mathrm{V}$

Readers Familiar with CMMI $\quad v$

Additional Information and Reader Feedback v

About Adapting CMMI for Acquisition Organizations 1

1 Introduction 2

About Capability Maturity Models $\quad 4$

Evolution of CMMI $\quad 6$

CMMI for Acquisition $\quad 8$

The Scope of CMMI for Acquisition $\quad 8$

2 Process Area Components 9

Required, Expected, and Informative Components 9

Required Components 9

Expected Components 9

Informative Components 10

$\begin{array}{ll}\text { Components Associated with Part Two } & 10\end{array}$

Process Areas 11

Purpose Statements 11

Introductory Notes $\quad 12$

Related Process Areas $\quad 12$

Specific Goals $\quad 12$

Generic Goals $\quad 12$

Specific Goal and Practice Summary 13

Specific Practices 13

Typical Acquirer Work Products 13

Typical Supplier Deliverables $\quad 13$

Subpractices 14

Generic Practices 14

Supporting Informative Components $\quad 14$

Notes 15

Examples 15 
Adapting CMMI for Acquisition Organizations: A Preliminary Report

$\begin{array}{ll}\text { Amplifications } & 15\end{array}$

References 15

Numbering Scheme $\quad 16$

Typographical Conventions 16

$3 \quad$ Tying It All Together 19

Understanding Levels $\quad 19$

Understanding Capability Levels $\quad 20$

Understanding Maturity Levels $\quad 21$

Maturity Level 1: Initial $\quad 21$

Maturity Level 2: Managed $\quad 22$

Maturity Level 3: Defined 24

Maturity Level 4: Quantitatively Managed 27

Maturity Level 5: Optimizing 27

Relating the Two Representations 28

Process Area Categories $\quad 29$

$4 \quad$ Using CMMI Models $\quad 32$

Adopting CMMI $\quad 32$

Your Process Improvement Program 33

Selections That Influence Your Program 33

CMMI Models 34

Using CMMI Appraisals $\quad 35$

Appraisal Requirements for CMMI $\quad 35$

SCAMPI Appraisal Methods $\quad 36$

Appraisal Considerations $\quad 36$

$\begin{array}{ll}\text { CMMI-Related Training } & 37\end{array}$

Generic Goals and Practices, and the Process Areas 39

Generic Goals and Practices $\quad 40$

Overview $\quad 40$

Process Institutionalization $\quad 40$

Performed Process $\quad 41$

Managed Process $\quad 41$

Defined Process 41

Quantitatively Managed Process $\quad 43$

Optimizing Process 44

Relationships among Processes $\quad 45$

Generic Goals and Generic Practices $\quad 46$

Applying Generic Practices $\quad 60$

Process Areas That Support Generic Practices 60

$\begin{array}{ll}\text { Acquisition Management } & 67\end{array}$

Acquisition Requirements Development $\quad 77$

$\begin{array}{ll}\text { Acquisition Technical Solution } & 90\end{array}$

$\begin{array}{ll}\text { Acquisition Validation } & 98\end{array}$ 
$\begin{array}{ll}\text { Acquisition Verification } & 106\end{array}$

Causal Analysis and Resolution $\quad 114$

Configuration Management 123

Decision Analysis and Resolution 135

Integrated Project Management 143

Measurement and Analysis 158

Organizational Innovation and Deployment 177

Organizational Process Definition 193

Organizational Process Focus 205

Organizational Process Performance 218

Organizational Training 229

Project Monitoring and Control 240

Project Planning 255

Process and Product Quality Assurance $\quad 281$

Quantitative Project Management $\quad 289$

Requirements Management 310

Risk Management $\quad 318$

Solicitation and Supplier Agreement Development 335

The Appendices and Glossary 357

Appendix A: References 358

Publicly Available Sources $\quad 358$

Regularly Updated Sources $\quad 360$

Appendix B: Acronyms $\quad 361$

Appendix C: Adapting CMMI for Acquisition Organizations

Project Participants 365

Primary Development Team $\quad 365$

Reviewers $\quad 365$

Steering Group $\quad 368$

Appendix D: Glossary 370 
Adapting CMMI for Acquisition Organizations: A Preliminary Report 


\section{PART ONe \\ About Adapting CMMI for Acquisition Organizations}




\section{Introduction}

Now more than ever, organizations are increasingly becoming acquirers $^{2}$ of technology solutions by obtaining development and maintenance services from suppliers, and developing less and less technology solutions in-house. The intent of this widely adopted business strategy is to improve an organization's operational efficiencies by leveraging a supplier's capabilities to deliver quality solutions rapidly, at lower cost, with the most appropriate technology. [ACQ]

Acquisition of technology solutions is challenging because acquirers must take overall accountability for solution delivery, while allowing the supplier to perform the tasks necessary to develop and maintain the solution. [ACQ]

According to Dun and Bradstreet ${ }^{3}, 20$ percent to 25 percent of large information technology (IT) acquisition projects fail within two years and 50 percent fail within five years. Mismanagement, inability to articulate customer needs, poor requirements definition, inadequate vendor selection and contracting processes, insufficient technology selection procedures, and uncontrolled requirements changes are all factors that contribute to project failure. The onus for these disturbing statistics does not sit exclusively with the supplier, but also with the acquirer. The majority of project failures could be avoided if organizations learned how to properly prepare for, engage with, and manage suppliers. [ACQ]

In addition to the challenges cited above, an overall key to a successful acquirer-supplier relationship is communication. [AcQ]

Unfortunately, many organizations have not invested in the capabilities necessary to effectively manage projects in an acquisition environment. Too often acquirers disengage from the project once the supplier is hired to develop the technology solution. Too late they discover that the project is not on schedule, deadlines will not be met, technology selected is not viable, and the project has failed. [ACQ]

\footnotetext{
${ }^{2}$ In the initial draft CMMI-ACQ, the term project refers to the acquisition project; the term organization refers to the acquisition organization; the term acquirer refers to acquisition projects.

${ }^{3}$ Other studies have reported similar findings, e.g., Stronger Management Practices are needed to Improve DoD’s Software Intensive Weapons Acquisitions, GAO-04-393 (March 2004).
} 
The acquirer has a focused set of major objectives. These include the requirement to maintain a relationship with the business to fully comprehend its needs. In addition, the relationship with the supplier through the supplier agreement and the acquirer's supplier management activities gives the acquirer the scope and execution direction to deliver to the business. The acquirer owns the project, executes overall project management, and is accountable for delivering solutions to the business. [ACQ]

In the current marketplace, there are maturity models, standards, methodologies, and guidelines that can help an organization improve the way it does business. However, most available improvement approaches focus on a specific part of the business and do not take a systemic approach to the problems that most organizations are facing. By focusing on improving one area of a business, these models have unfortunately perpetuated the stovepipes and barriers that exist in organizations.

Capability Maturity Mode ${ }^{\circledR}$ Integration $\left(\mathrm{CMMI}^{\circledR}\right.$ ) provides an opportunity to avoid or eliminate these stovepipes and barriers through integrated models that transcend disciplines.

This document provides guidance for the application of the CMMI framework to the acquirer or acquisition discipline. ${ }^{4}$ [ACQ]

The initial draft CMMI for Acquisition (CMMI-ACQ) contains 16 "core" process areas that cover project management, process management and support process areas. In addition, four process areas outside of these core process areas are further modified or adapted to the acquisition discipline. Two acquisition unique process areas are also included. These six process areas address unique acquisition practices addressing solicitation and supplier agreement development, acquisitions management, acquisition requirements development, acquisitions technical solution, acquisition validation, and acquisition verification. [ACQ]

The practices in all process areas focus on activities of the acquirer. Those activities include supplier sourcing, developing and awarding contracts (supplier agreements), and managing acquisition of solutions where solutions include both products and services. Supplier activities are not addressed in this document. For suppliers, CMMI for Development (CMMI-DEV) may be treated as a reference model for those suppliers developing products and services. [ACQ]

\footnotetext{
${ }^{4}$ The terms outsourcing and acquisition as disciplines are used interchangeably in this report.
} 
The initial draft CMMI-ACQ will be reviewed by additional government and industry stakeholders and be used in pilot appraisals before it will be submitted to the CMMI Steering Group for final approval. The intended use of the initial draft CMMI-ACQ is to provide organizations with a resource of effective and proven practices to support acquisition process improvement. This document can also be used by the supplier community to better understand the expectations of its customers. [ACO]

The SEI has found several dimensions that an organization can focus on to improve its business. Figure 1.1 illustrates the three critical dimensions that organizations typically focus on: people, procedures and methods, and tools and equipment. [ACQ]

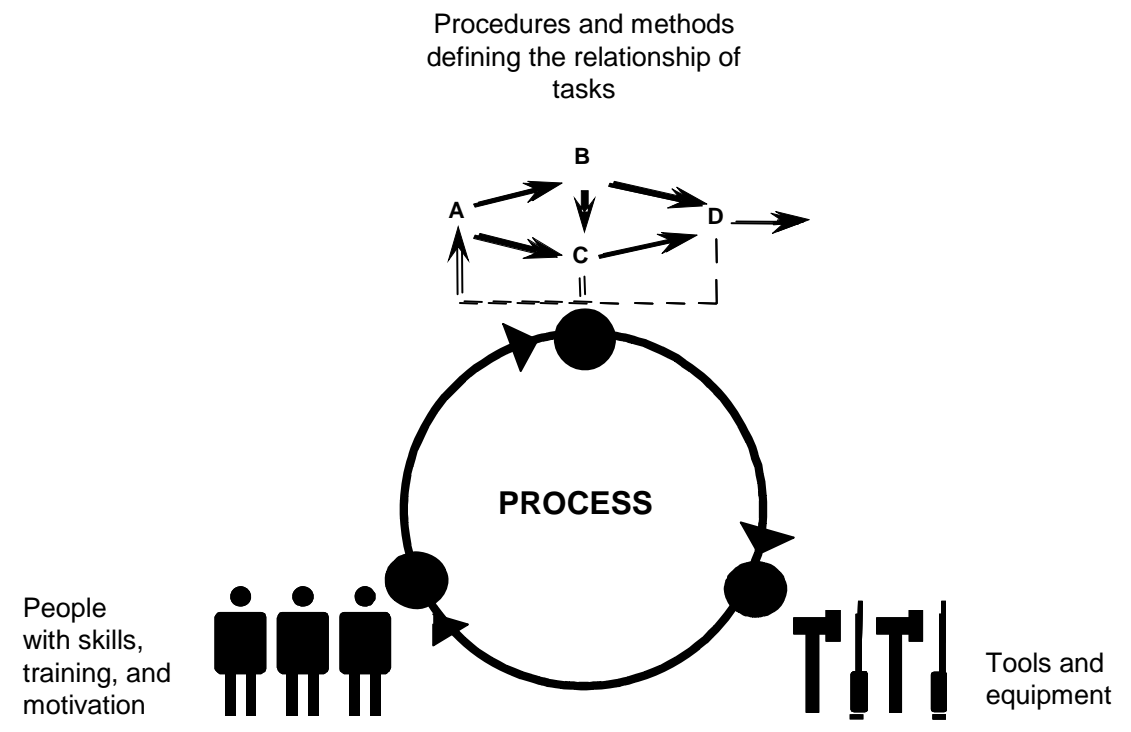

Figure 1.1: The Three Critical Dimensions

But what holds everything together? It is the processes used in your organization. Processes allow you to align the way you do business. They allow you to address scalability and provide a way to incorporate knowledge of how to do things better. Processes allow you to leverage your resources and to examine business trends.

This is not to say that people and technology are not important. We are living in a world where technology is changing by an order of magnitude every ten years. Similarly, people typically work for many companies throughout their careers. We live in a dynamic world. A focus on process provides the infrastructure necessary to deal with an everchanging world, and to maximize the productivity of personnel and the use of technology to be more competitive. 
Manufacturing has long recognized the importance of process effectiveness and efficiency. Today, many organizations in manufacturing and service industries recognize the importance of quality processes. Process helps an organization's workforce meet business objectives by helping them work smarter, not harder, and with improved consistency. Effective processes also provide a vehicle for introducing and using new technology in a way that best meets the business objectives of the organization.

In the 1930s, Walter Shewhart began work in process improvement with his principles of statistical quality control [Shewhart 1931]. These principles were refined by W. Edwards Deming [Deming 1986] and Joseph Juran [Juran 1988]. Watts Humphrey, Ron Radice, and others extended these principles even further and began applying them to software in their work at IBM and the SEI. Humphrey's book Managing the Software Process [Humphrey 1989] provides a description of the basic principles and concepts on which many of the capability maturity models are based.

The SEI has taken the process-management premise, "the quality of a system or product is highly influenced by the quality of the process used to develop and maintain it," and defined capability maturity models that embody this premise. The belief in this premise is seen worldwide in quality movements, as evidenced by the International Organization for Standardization/International Electrotechnical Commission (ISO/IEC) body of standards.

Capability maturity models (CMMs) focus on improving processes in an organization. They contain the essential elements of effective processes for one or more disciplines and describe an evolutionary improvement path from ad hoc, immature processes to disciplined, mature processes with improved quality and effectiveness.

Mark Paulk and others at the Software Engineering Institute created the first capability maturity model designed for software organizations and published it in a book, The Capability Maturity Model: Guidelines for Improving the Software Process [SEI 1995]. The value of this process improvement approach has been confirmed over time. Organizations have experienced increased productivity and quality, improved cycle time, and more accurate and predictable schedules and budgets ${ }^{5}$

\footnotetext{
${ }^{5}$ From the forthcoming SEI technical report, Performance Results of CMMI-Based Process Improvement by Diane L. Gibson, Dennis R. Goldenson, and Keith Kost.
} 
Since 1991, CMMs have been developed for a myriad of disciplines. Some of the most notable include models for systems engineering, software engineering, software acquisition, workforce management and development, and integrated product and process development.

Although these models have proved useful to many organizations in different industries, the use of multiple models has been problematic. Many organizations would like their improvement efforts to span different groups in their organizations. However, the differences among these discipline-specific models used by each group, including their architecture, content, and approach, have limited these organizations' ability to broaden their improvements successfully. Further, applying multiple models that are not integrated within and across an organization is costly in terms of training, appraisals, and improvement activities.

The CMM Integration project was formed to sort out the problem of using multiple CMMs. The CMMI Product Team's initial mission was to combine three source models:

1. The Capability Maturity Model for Software (SW-CMM) v2.0 draft C [SEI 1997b]

\section{The Systems Engineering Capability Model (SECM) [EIA 1998]}

3. The Integrated Product Development Capability Maturity Model (IPDCMM) v 0.98 [SEI 1997a]

The combination of these models into a single improvement framework was intended for use by organizations in their pursuit of enterprise-wide process improvement.

These three source models were selected because of their widespread adoption in the software and systems engineering communities and because of their different approaches to improving processes in an organization.

Using information from these popular and well-regarded models as source material, the CMMI Product Team created a cohesive set of integrated models that can be adopted by those currently using the source models, as well as by those new to the CMM concept. Hence, CMMI is a result of the evolution of the SW-CMM, the SECM, and the IPD-CMM. 
Developing a set of integrated models involved more than simply adding existing model materials together. Using processes that promote consensus, the CMMI Product Team built a framework that accommodates multiple disciplines and is flexible enough to support the different approaches of the source models.

Since the release of CMMI v1.1, which is focused on product and service development, we have seen that this improvement framework can be applied to other areas of interest. To apply to multiple areas of interest, the framework groups best practices into what we call "constellations." A constellation is a collection of CMMI components that are used to build models, training materials, and appraisal documents. Currently there are three constellations planned to be supported by the Version 1.2 model framework: development, services, and acquisition. Figure 1.2 illustrates the history of how CMMI was developed and has grown. [ACQ]

\section{History of CMMs}

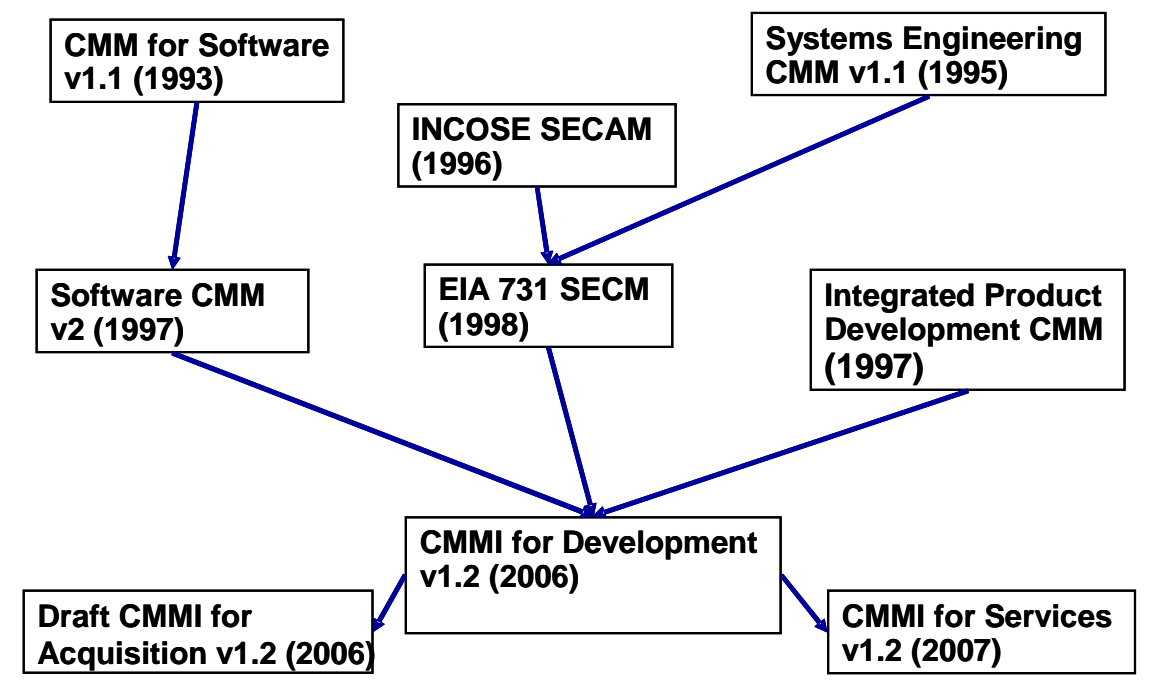

Figure 1.2: The History of CMMs [ACQ]

Recently, the CMMI model architecture was improved to support multiple constellations and the sharing of best practices among constellations and their member models. The CMMI models that have been available in the community prior to $\mathbf{2 0 0 6}$ are now considered part of the CMMI for Development constellation. 
General Motors partnered with the SEI to create the initial draft CMMI for Acquisition described in this document. An organization should use professional judgment and common sense to interpret this document for its organization. That is, although the process areas described here depict behaviors considered best practice for most organizations, all process areas and practices are to be interpreted using an in-depth knowledge of the CMMI model (including the initial draft CMMI-ACQ) being used, organizational constraints, the business environment, and other circumstances involved. [ACQ]

Practices essential for executing acquisition processes are performed slightly differently or with differing roles when focused either on the acquirer or the interaction with the supplier. These differences are particularly apparent in activities such as monitoring, directing, or overseeing a supplier, which occur after a source selection or authorization for a supplier to begin work is accomplished. [ACQ]

This document is to be considered as an initial draft CMMI-ACQ for the Acquisition constellation. The best practices contained in the initial draft CMMI-ACQ have gone through an extensive review process. The Product Team evaluated more than 1,000 comments and change requests from acquisition organizations as well as suppliers to create the initial draft CMMI-ACQ. [ACQ]

This document describes a draft reference model that covers the acquisition of technical solutions. There are acquirers of technology solutions from many industries including aerospace, banking, computer hardware, software, defense, automobile manufacturing, and telecommunications that can use CMMI for Acquisition. [ACQ]

The initial draft CMMI-ACQ contains unique acquisition practices in six process area that cover solicitation and supplier agreement development, acquisitions management, acquisition requirements development, acquisitions technical solution, acquisition validation, and acquisition verification. The six processes areas are supplemented by 16 process areas that cover project management, organizational and support process areas. These 16 processes are necessary but not sufficient to executing as a successful acquirer. [ACQ] 


\section{Process Area Components}

This chapter describes the components that comprise each process area, generic goal, and generic practice of the initial draft CMMI-ACQ. Understanding the meaning of these components is critical to using the information in Part Two effectively. If you are unfamiliar with Part Two, you may want to skim the Generic Goals and Practices section and a couple of process area sections to get a general feel for the content and layout before reading this chapter. [ACQ]

Required, Expected, and Informative Components

Model components are grouped into three categories-required, expected, and informative - that reflect how to interpret them.

\section{Required Components}

Required components describe what an organization must achieve to satisfy a process area. This achievement must be visibly implemented in an organization's processes. The required components in CMMI are the specific and generic goals. Goal satisfaction is used in appraisals as the basis for deciding if a process area has been achieved and satisfied.

\section{Expected Components}

Expected components describe what an organization will typically implement to achieve a required component. Expected components guide those who implement improvements or perform appraisals. Expected components include the specific and generic practices.

Before goals can be considered satisfied, either the practices as described or acceptable alternatives to them are present in the planned and implemented processes of the organization. 


\section{Informative Components}

Informative components provide details that help organizations get started in thinking about how to approach the required and expected components. Subpractices, typical acquirer work products, typical supplier deliverables, amplifications, goal and practice titles, goal and practice notes, and references are all informative model components. [ACQ]

The CMMI glossary of terms is not a required, expected, or informative element of CMMI models. The terms in the glossary should be interpreted in the context of the model component in which they appear.

The model components associated with Part Two can be summarized to illustrate their relationships, as in Figure 2.1. Within Part 2, generic goals and practices are described separately from the individual process areas, but they apply to all process areas. [ACQ]

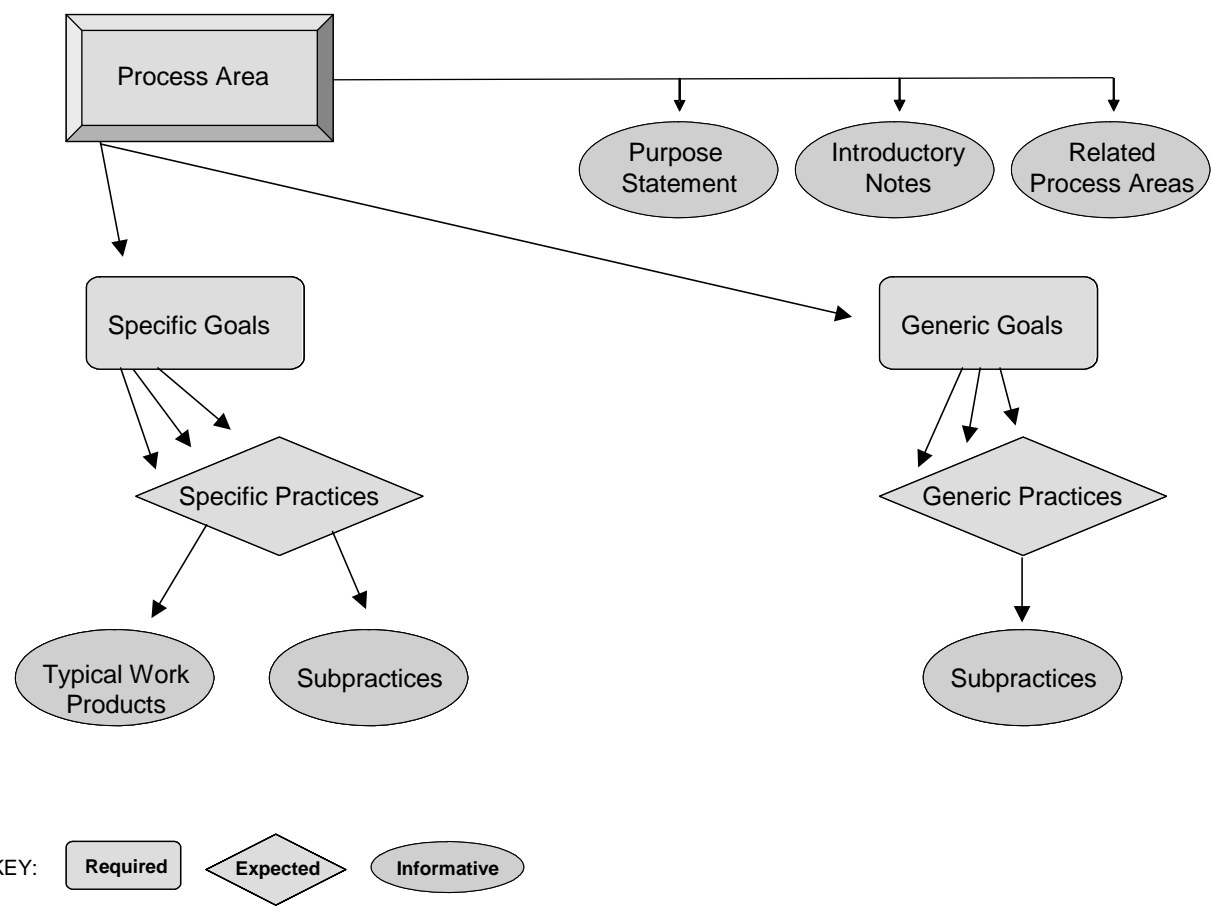

Figure 2.1: CMMI Model Components

The following sections provide detailed descriptions of the model components. 
A process area is a cluster of related practices in an area that, when implemented collectively, satisfies a set of goals considered important for making significant improvement in that area.

There are twenty-two process areas, presented in alphabetical order by acronym: [ACQ]

- Acquisition Management (AM)

- Acquisition Requirements Development (ARD)

- Acquisition Technical Solution (ATS)

- Acquisition Validation (AVAL)

- Acquisition Verification (AVER)

- Causal Analysis and Resolution (CAR)

- Configuration Management (CM)

- Decision Analysis and Resolution (DAR)

- Integrated Project Management (IPM)

- Measurement and Analysis (MA)

- Organizational Innovation and Deployment (OID)

- Organizational Process Definition (OPD)

- Organizational Process Focus (OPF)

- Organizational Process Performance (OPP)

- Organizational Training (OT)

- Project Monitoring and Control (PMC)

- Project Planning (PP)

- Process and Product Quality Assurance (PPQA)

- Quantitative Project Management (QPM)

- Requirements Management (REQM)

- $\quad$ Risk Management (RSKM)

- Solicitation and Supplier Agreement Development (SSAD)

Purpose Statements

The purpose statement describes the purpose of the process area and is an informative component.

For example, the purpose statement of the Organizational Process Definition process area is "The purpose of Organizational Process Definition (OPD) is to establish and maintain a usable set of organizational process assets and work environment standards." [ACQ] 


\section{Introductory Notes}

The introductory notes section of the process area describes the major concepts covered in the process area and is an informative component.

An example from the introductory notes of the Project Planning process area is "Planning begins with requirements that define the product and project."

\section{Related Process Areas}

The related process areas section lists references to related process areas and reflects the high-level relationships among the process areas. The related process area section is an informative component.

An example of a reference found in the related process areas section of the Project Planning process area is "Refer to the Risk Management process area for more information about identifying and managing risks."

\section{Specific Goals}

A specific goal describes the unique characteristics that must be present to satisfy the process area. A specific goal is a required model component and is used in appraisals to help determine whether a process area is satisfied.

For example, a specific goal from the Configuration Management process area is "Integrity of baselines is established and maintained."

Only the statement of the specific goal is a required model component. The title of a specific goal (preceded by the goal number) and any notes associated with the goal are considered informative model components.

\section{Generic Goals}

Generic goals appear in Part Two as a separate section and are called "generic" because all generic goal statements apply to all process areas. A generic goal describes the characteristics that must be present to institutionalize the processes that implement a process area. A generic goal is a required model component and is used in appraisals to determine whether a process area is satisfied. (See Generic Goals and Practices section in Part Two for a more detailed description of generic goals.) [ACQ]

An example of a generic goal is "The process is institutionalized as a defined process." 
Only the statement of the generic goal is a required model component. The title of a generic goal (preceded by the goal number) and any notes associated with the goal are considered informative model components.

\section{Specific Goal and Practice Summary}

The specific goal and practice summary provides a high-level summary of the specific goals that are required components and the specific practices that are expected components. The specific goal and practice summary is an informative component.

\section{Specific Practices}

A specific practice is the description of an activity that is considered important in achieving the associated specific goal. The specific practices describe the activities that are expected to result in achievement of the specific goals of a process area. A specific practice is an expected model component.

For example, a specific practice from the Project Monitoring and Control process area is "Monitor commitments against those identified in the project plan."

Only the statement of the specific practice is an expected model component. The title of a specific practice (preceded by the practice number) and any notes associated with the specific practice are considered informative model components.

\section{Typical Acquirer Work Products}

The typical acquirer work products section lists sample outputs from a specific practice. These examples are called "typical acquirer work products" because there are often other work products that are just as effective but are not listed. [ACQ]

For example, a typical acquirer work product for the specific practice "Establish and maintain verification procedures and criteria for the selected work products" in the Acquisition Verification process area is "verification criteria." [ACQ]

\section{Typical Supplier Deliverables}

To aid the acquirer, typical supplier deliverables examples are also provided. These deliverables represent artifacts that are input to or support the acquirer's implementation of the practice. All deliverables required by the acquirer are to be included in the supplier agreement. [ACQ] 
For example, a typical supplier deliverable for the specific practice "Select the work products to be verified and the verification methods that will be used for each" in the Acquisition Verification process area is "list of supplier deliverables." [ACQ]

\section{Subpractices}

A subpractice is a detailed description that provides guidance for interpreting and implementing a specific or generic practice. Subpractices may be worded as if prescriptive, but are actually an informative component meant only to provide ideas that may be useful for process improvement.

For example, a subpractice for the specific practice "Take corrective action on identified issues" in the Project Monitoring and Control process area is "Determine and document the appropriate actions needed to address the identified issues."

\section{Generic Practices}

Generic practices appear with generic goals in a section Part Two and are called "generic" because all generic practice statements apply to all process areas. A generic practice is the description of an activity that is considered important in achieving the associated generic goal. A generic practice is an expected model component. [ACQ]

For example, a generic practice for the generic goal "The process is institutionalized as a managed process" is "Provide adequate resources for performing the process, developing the work products, and providing the services of the process."

Only the statement of the generic practice is an expected model component. The title of a generic practice (preceded by the practice number) and any notes associated with the practice are considered informative model components.

\section{Supporting Informative Components}

There are many places where further information is needed to describe a concept. This informative material is provided in the form of the following components:

- Notes

- Examples

- Amplifications

- References 


\section{Notes}

A note is text that can accompany nearly any other model component. It may provide detail, background, or rationale. A note is an informative model component.

For example, a note that accompanies the specific practice "Implement the selected action proposals that were developed in causal analysis" in the Causal Analysis and Resolution process area is "Only changes that prove to be of value should be considered for broad implementation."

\section{Examples}

An example is a component comprising text and often a list of items, usually in a box, that can accompany nearly any other component and provides one or more examples to clarify a concept or described activity. An example is an informative model component.

The following is an example that accompanies the subpractice "Document noncompliance issues when they cannot be resolved within the project" under the specific practice "Communicate quality issues and ensure resolution of noncompliance issues with the staff and managers."

\section{Amplifications}

There are two types of amplifications: those that apply to disciplines and those that apply to additions. An amplification is informative material that is relevant to a particular discipline or addition. Each amplification is labeled with a tag [ACQ] that indicates this amplification applies to the acquisition discipline. [ACQ]

\section{References}

A reference is a pointer to additional or more detailed information in related process areas and can accompany nearly any other model component. A reference is an informative model component.

For example, a reference that accompanies the specific practice "Select the subprocesses that compose the project's defined process based on historical stability and capability data" in the Quantitative Project Management process area is "Refer to the Organizational Process Definition process area for more information about the organization's process asset library, which might include a process element of known and needed capability." 
Specific and generic goals are numbered sequentially. Each specific goal begins with the prefix SG (e.g., SG 1). Each generic goal begins with the prefix GG (e.g., GG 2).

Each specific practice begins with the prefix SP, followed by a number in the form $x . y$ (e.g., SP 1.1). The $x$ is the same number as the goal the specific practice maps to. The $y$ is the sequence number of the specific practice under the specific goal.

An example of specific practice numbering is in the Project Planning process area. The first specific practice is numbered SP 1.1 and the second is SP 1.2.

Each generic practice begins with the prefix GP, followed by a number in the form x.y (e.g., GP 1.1).

The $x$ corresponds to the number of the generic goal. The $y$ is the sequence number of the generic practice under the generic goal. For example, the first generic practice associated with GG 2 is numbered GP 2.1.

The typographical conventions used in this document were designed to enable you to select what you need and use it effectively. We present model components in formats that allow you to find them quickly on the page. [ACQ]

Figures 2.2 through 2.3 are sample pages from process areas in Part Two; they show the different process area components, labeled so that you can identify them. Notice that components differ typographically so that you can easily identify each one. 


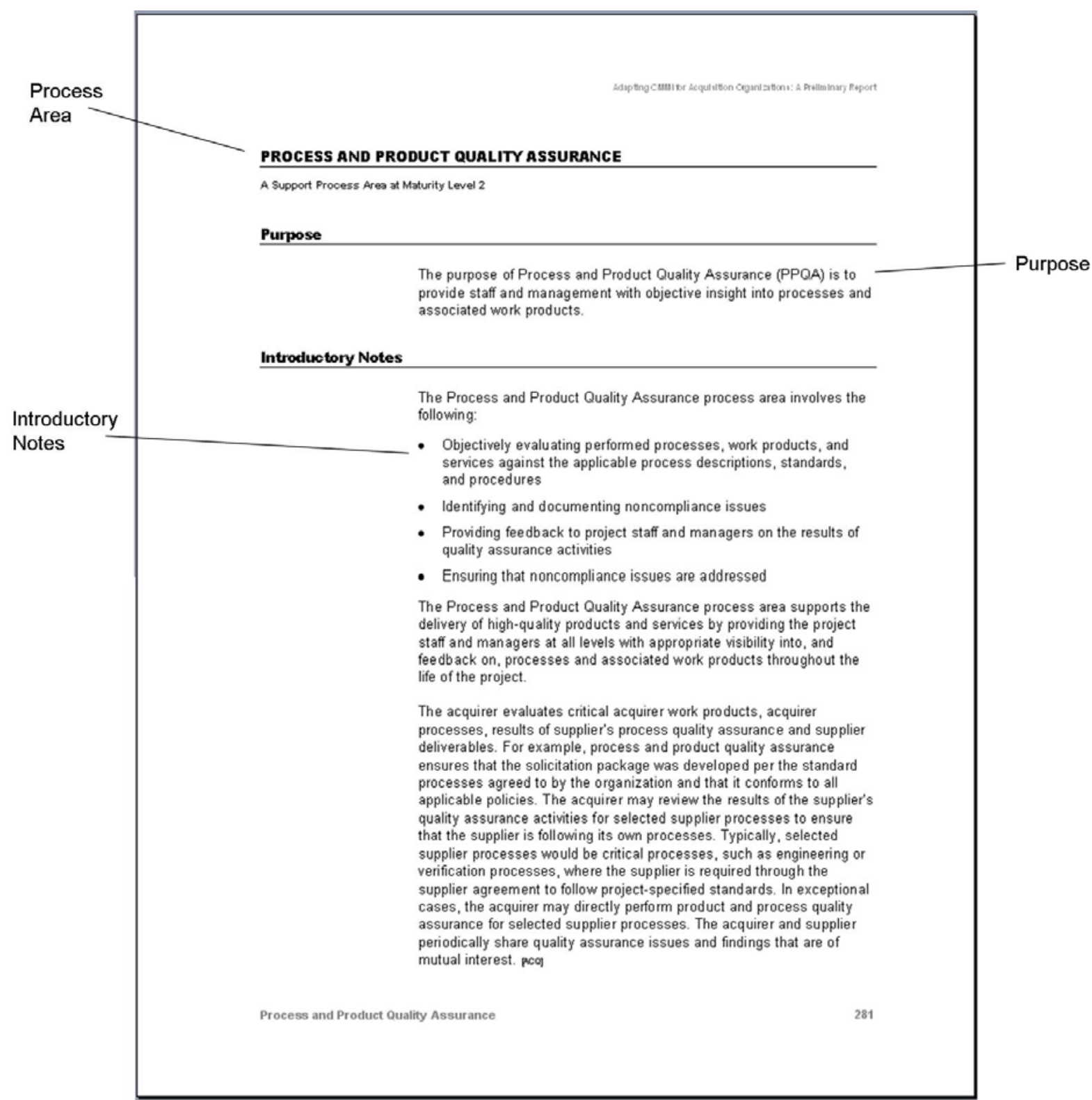

Figure 2.2: Sample Page from Process and Product Quality Assurance [ACQ] 


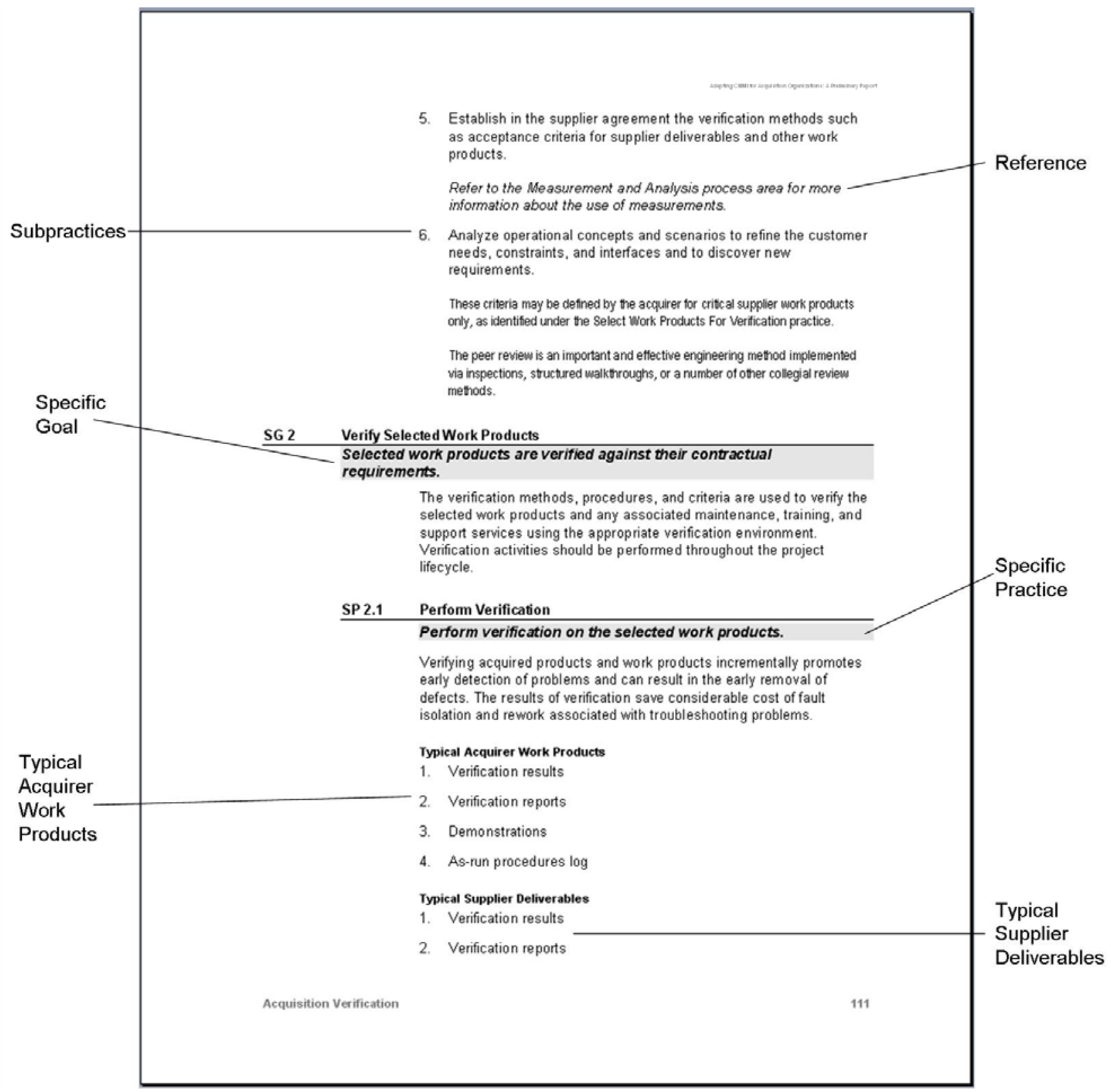

Figure 2.3: Sample Page from Acquisition Verification [AcQ] 


\section{Tying It All Together}

Now that you have been introduced to the components of $\mathrm{CMMI}^{\circledR}$ models, you need to understand how they all fit together to meet your process improvement needs. This chapter introduces the concept of levels and shows how the process areas are organized and used.

The initial draft CMMI-ACQ does not specify that a project or acquirer follows a particular acquisition process flow or that a certain number of "deliverables per day" or specific performance targets are achieved only that they have processes in place for adequately addressing acquisition-related practices. To determine whether this is so, a project or organization maps its processes to the process areas contained in this document. [ACQ]

The mapping of its processes to process areas allows an acquirer to track progress to the initial draft CMMI-ACQ as incremental process improvement or innovations are successfully deployed. It is not intended that every process area of the initial draft CMMI-ACQ maps one to one with a given organization's or project's processes. [AcQ]

Levels are used in CMMI to describe an evolutionary path recommended for an organization that wants to improve the processes it uses to acquire its products and services. Levels can also be the outcome of the rating activity of appraisals. ${ }^{6}$ Appraisals can apply to organizations that comprise entire companies, or to smaller groups such as a small group of projects or a division within a company. [ACQ]

CMMI supports two improvement approaches. The first utilizes what is called the continuous representation; the continuous representation is based on capability levels. The second utilizes what is called the staged representation; the staged representation is based on maturity levels. [ACQ]

\footnotetext{
${ }^{6}$ For more information about appraisals, see the forthcoming Appraisal Requirements for CMMI and the Standard CMMI Appraisal Method for Process Improvement Method Definition Document.
} 
To support those using the continuous representation, all CMMI models reflect capability levels in their design and content. A capability level consists of a generic goal and its related generic practices for a process area that can improve the organization's processes associated with that process area. As you satisfy the generic goal and its generic practices at each capability level, you reap the benefits of process improvement for that process area.

The six capability levels, designated by the numbers 0 through 5 , are

0. Incomplete

1. Performed

2. Managed

3. Defined

4. Quantitatively Managed

5. Optimizing

The fact that capability levels 2 through 5 use the same terms as generic goals 2 through 5 is intentional because each of these general goals and practices reflects the meaning of the capability levels in terms of goals and practices you can implement. (See the Generic Goals and Practices section in Part Two for more information about generic goals and practices.)

The five capability levels are described as follows ${ }^{7}$ : [ACQ]

- Achieving CL 1 ("Performed") means you have satisfied all the specific goals of the process area; otherwise you are CL 0 ("Not Performed") relative to that process area.

- Achieving CL 2 ("Managed") relative to a process area means you have achieved CL 1 in that process area and in addition have satisfied generic goal 2 and all its associated generic practices.

- Achieving CL 3 ("Defined") relative to a process area means you have achieved CL 2 in that process area and in addition have satisfied generic goal 3 and all its associated generic practices.

${ }^{7}$ The initial draft CMMI-ACQ was designed to support those seeking to apply the staged rather than continuous representation-based improvement approach. As a result, the description of capability levels has been shortened. Those seeking to use the continuous representation are encouraged to consult the Generic Goals and Practices section in Part Two for the subsection that describes generic practice and process area interactions, which are important to understand when selecting which process areas to implement first. Also, chapters 3 and 4 of the CMMI for Development, v1.2 provide additional information. 
- Achieving CL 4 ("Quantitatively Managed") relative to a process area means you have achieved CL 3 in that process area and in addition have satisfied generic goal 4 and all its associated generic practices.

- Achieving CL 5 ("Optimizing") relative to a process area means you have achieved CL 4 in that process area and in addition have satisfied generic goal 5 and all its associated generic practices.

\section{Understanding Maturity Levels}

If you do not know where to start and which processes to choose to improve, the staged representation is a good choice for you. It gives you a specific set of processes to start improving as an acquirer of technology solutions. The following sections will describe the process areas contained in each maturity level. There are five maturity levels, each a layer in the foundation for ongoing process improvement, designated by the numbers 1 through 5: [ACQ]
1. Initial
2. Managed
3. Defined
4. Quantitatively Managed
5. Optimizing

Maturity Level 1: Initial

At maturity level 1, processes are usually ad hoc and chaotic. The organization usually does not provide a stable environment to support the processes. Success in these organizations depends on the competence and heroics of the people in the organization and not on the use of proved processes. In spite of this chaotic environment, maturity level 1 organizations acquire products and services that often work; however, they frequently exceed the budget and schedule documented in their plans. [ACQ]

Maturity level 1 organizations are characterized by a tendency to overcommit, abandonment of processes in a time of crisis, and an inability to repeat their successes. 
At maturity level 2 , projects establish the foundation for an organization to become an effective acquirer of technology solutions by institutionalizing basic project management and supplier agreement management practices. The acquirer ensures that processes are planned and executed in accordance with policy, employ skilled people who have adequate resources to produce controlled outputs, and involve relevant stakeholders; that projects are monitored and controlled; and that selected work products and processes are objectively evaluated for adherence to their process descriptions. The process discipline reflected by maturity level 2 helps to ensure that existing practices are retained during times of stress. [ACQ]

At maturity level 2, requirements, processes, work products, and services are managed. The status of the work products and the delivery of services are visible to management at defined points (for example, at major milestones and at the completion of major tasks). Commitments are established among relevant stakeholders and are revised as needed. Work products are reviewed with stakeholders and are controlled. The work products and services satisfy their specified requirements, standards, and objectives. [ACQ]

Figure 3.1 provides an overview of the maturity level 2 process areas and some of their more significant interactions. The relationships shown are notional and are not intended to portray all possible interactions or all required interactions. [ACQ] 


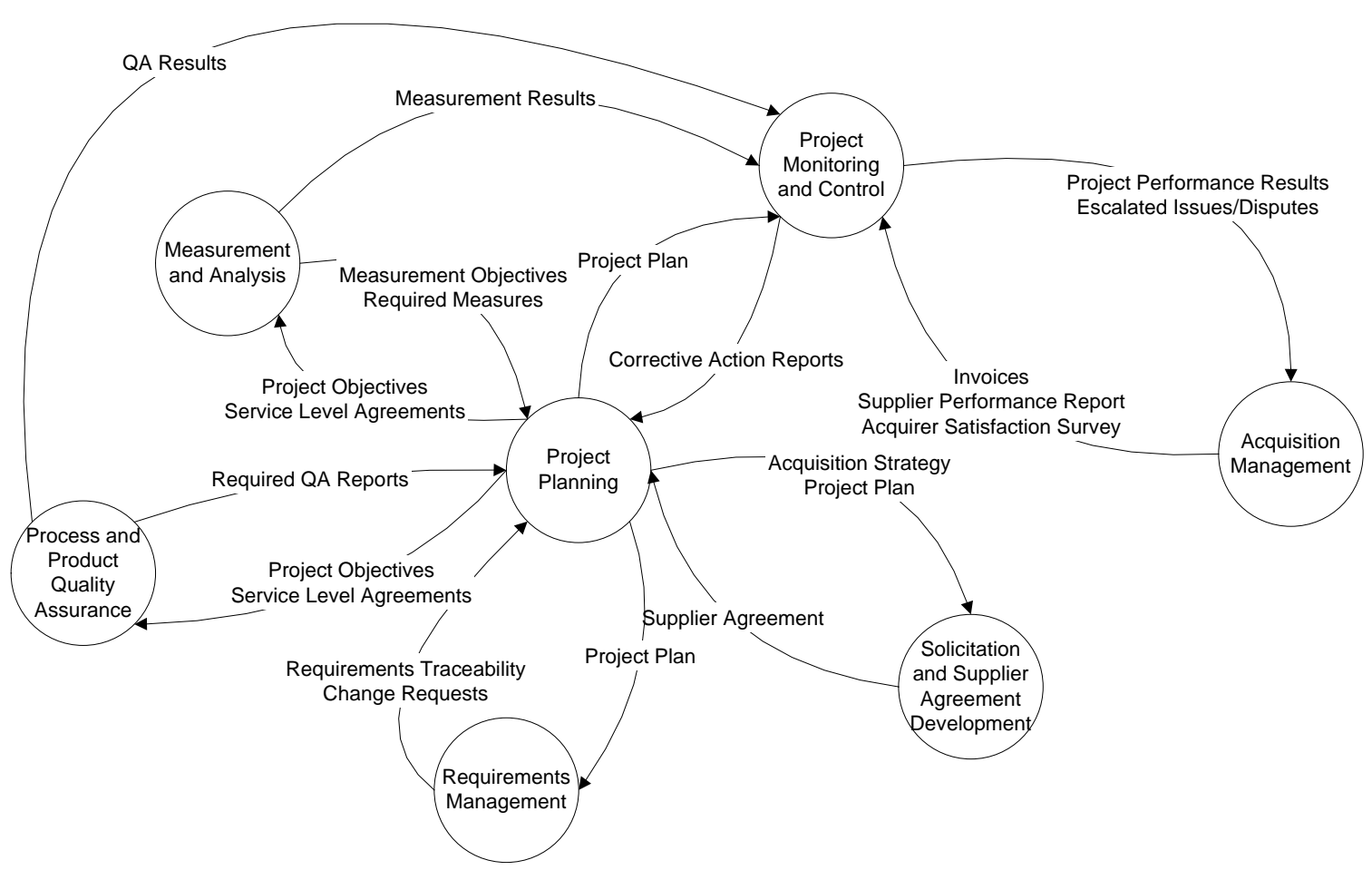

Figure 3.1: Maturity Level 2 Process Areas [ACQ]

The Solicitation and Supplier Agreement Development process area defines practices to prepare a solicitation package, to select a capable supplier and to establish the supplier agreement. Acquisition Management focuses on maintaining the supplier agreement including dispute resolution and managing the relationship with the supplier. This includes managing payments to suppliers and ongoing communications with suppliers. [ACQ]

Project planning establishes and maintains plans that define project activities. This includes planning for transition of the product into operations and support. After a supplier is selected and a supplier agreement is established, the acquirer continues to apply Requirements Management practices to manage the customer and contractual requirements, while the selected supplier is managing the refined product and product component requirements. The Project Monitoring and Control process area is concerned with monitoring and control of acquirer activities and overseeing the progress and performance of the supplier's execution according to the project plans. [ACQ] 
An acquirer uses the Measurement and Analysis process area practices to support the information needs of the business, organization and project. Some of this information may be needed from the acquirer, some from the supplier, and some from all parts of a project. All information required from the supplier must be designated in the supplier agreement. The Process and Product Quality Assurance process area objectively evaluates selected acquirer work products and processes. [ACQ]

Configuration Management (not depicted in Figure 3.1) establishes and maintains the integrity of work products such as solicitation packages using configuration identification, configuration control, configuration status accounting, and configuration audits. In addition, configuration management of acquired products (both final and interim products) created by the suppliers require monitoring to ensure that project goals are met. [ACQ]

At maturity level 3, acquirers are using defined processes for establishing and managing standard supplier agreements, and they embed tenets of project management and engineering best practices, such as requirements development and establishing design constraints, into the standard process set. These processes are well characterized and understood, and are described in standards, procedures, tools, and methods. [ACQ]

The organization's set of standard processes, which is the basis for maturity level 3 , is established and improved over time. These standard processes are used to establish consistency across the organization. Projects establish their defined processes by tailoring the organization's set of standard processes according to tailoring guidelines.

A critical distinction between maturity levels 2 and 3 is the scope of standards, process descriptions, and procedures. At maturity level 2 , the standards, process descriptions, and procedures may be quite different in each specific instance of the process (e.g., on a particular project). At maturity level 3 , the standards, process descriptions, and procedures for a project are tailored from the organization's set of standard processes to suit a particular project or organizational unit and therefore are more consistent except for the differences allowed by the tailoring guidelines. 
Another critical distinction is that at maturity level 3, processes are typically described more rigorously than at maturity level 2. A defined process clearly states the purpose, inputs, entry criteria, activities, roles, measures, verification steps, outputs, and exit criteria. At maturity level 3 , processes are managed more proactively using an understanding of the interrelationships of the process activities and detailed measures of the process, its work products, and its services.

At maturity level 3 , the organization must further mature the maturity level 2 process areas. The generic practices associated with Generic Goal 3 that were not addressed at maturity level 2 are applied to achieve maturity level 3.

Figure 3.2 provides an overview of the maturity level 3 process areas and some of their more significant interactions. The relationships shown are notional and are not intended to portray all possible interactions or all required interactions. [ACQ]

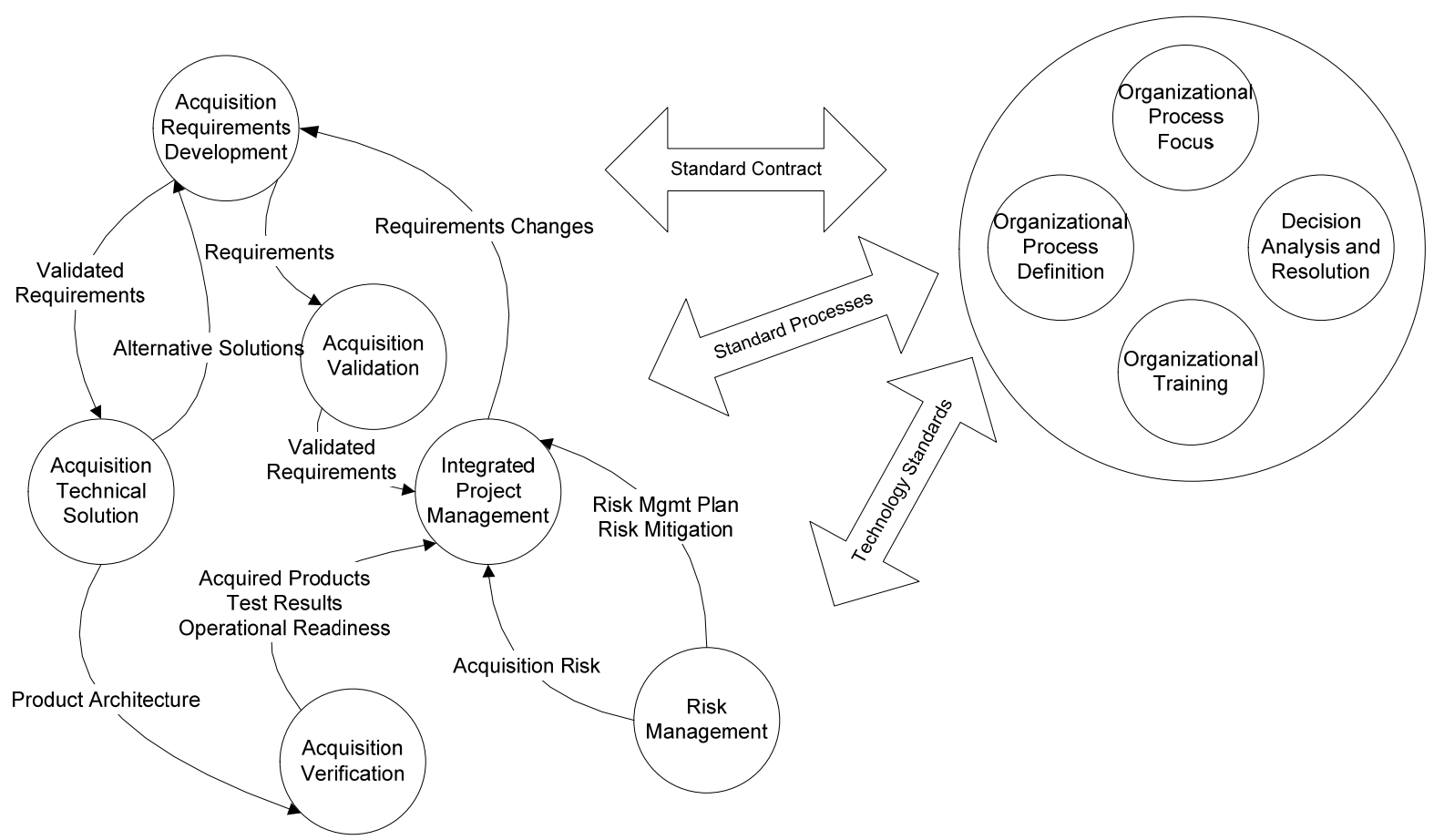

Figure 3.2: Maturity Level 3 Process Areas [AcQ]

Due to the acquirer-supplier relationship, the need for an early and aggressive detection of risk is compounded by the complexity of projects acquiring products or services. The purpose of Risk Management is to identify and assess project risks during the project planning process and managing these risks throughout the project. [ACQ] 
The acquirer has a dual role: first, to assess and manage overall project risks for the duration of the project, and second, to assess and manage risks associated with the performance of the supplier. As the acquisition progresses to the selection of a supplier, the risk specific to the supplier's technical and management approach becomes important to the success of the acquisition. [ACQ]

The acquirer applies Integrated Project Management practices to establish and manage the project and the involvement of the relevant stakeholders according to an integrated and defined process that is tailored from the organization's set of standard processes. A repeatable Decision Analysis and Resolution process is important for an acquirer, both while making the critical decisions that define and guide the acquisition process and later when critical decisions are made with the selected supplier. [ACQ]

Acquisition Requirements Development focuses on specifying customer and contractual requirements that express customer value. The acquirer uses Acquisition Validation processes to ensure that the products or services received from the supplier will fulfill the relevant stakeholders' intentions and needs. [AcQ]

The acquirer provides design constraints to the supplier. The product or service are designed and implemented by the supplier consistent with the acquirer's design constraints. Acquisition Technical Solution covers developing design constraints and verifying the technical solution of the supplier. The acquirer applies Acquisition Verification processes to address whether the acquired product, intermediate acquirer work products, and supplier deliverables meet their contractual requirements. [ACQ]

Organizational Process Definition focuses on establishing and maintaining a usable set of organizational process assets and work environment standards. The acquirer's set of standard processes may also describe standard interactions with suppliers. Supplier interactions are typically identified in terms of deliverables expected from suppliers, acceptance criteria applicable to those deliverables, standards (e.g., architecture and technology standards), and standard milestone and progress reviews. [ACQ]

The acquirer defines in the supplier agreement how changes to organizational process assets that impact the supplier (e.g., standard supplier deliverables, acceptance criteria) have to be deployed. The acquirer encourages participation of suppliers in process improvement activities (Organizational Process Focus). Suppliers may be involved in developing the process action plans if the processes that define interfaces between acquirer and supplier are targeted for improvement. [ACQ] 
The purpose of Organizational Training is to develop the skills and knowledge of people so they can perform their roles effectively and efficiently. [ACQ]

Maturity Level 4: Quantitatively Managed

At maturity level 4, acquirers control variation in their results through quantitative management. That is, acquirers examine the business system being used to meet the needs of the end customer, identifying constraints that significantly impede overall business performance. These constraints are understood using statistical and other quantitative techniques so that an acquirer can make the appropriate process refinements including adjustments to its supplier interactions to better achieve business objectives. Focusing on these critical constraints, the acquirer can use process performance models to predict how to best maximize the flow of work through the project and/or the organization. [ACQ]

Specific measures of process performance are collected and statistically analyzed. When selecting the processes or subprocesses for analyses, it is critical to understand the relationships between different processes and subprocesses and their impact on the acquirer's and supplier's performance relative to delivering the product specified by the customer. Such an approach will help ensure that quantitative and statistical management is applied to where it will have the most overall value to the business. Supplier process performance is analyzed as it interfaces with acquirer processes, through data and measures submitted by the supplier. Performance models are used to set performance objectives for the suppliers, and to help suppliers achieve these objectives. [ACQ]

A critical distinction between maturity levels 3 and 4 is the predictability of process performance. At maturity level 4 , the performance of processes is controlled using statistical and other quantitative techniques, and is quantitatively predictable. At maturity level 3 , processes are typically only qualitatively predictable.

At maturity level 5, an organization continually improves its processes based on a quantitative understanding of the common causes of variation inherent in processes. Maturity level 5 focuses on continually improving process performance through incremental and innovative process and technological improvements that enhance the acquirer's and its suppliers' ability to meet the acquirer's quality and processperformance objectives. [AcQ] 
Quantitative process-improvement objectives for the organization are established, continually revised to reflect changing business objectives, and used as criteria in managing process improvement. The effects of deployed process improvements are measured and evaluated against the quantitative process-improvement objectives. Both the defined processes and the organization's set of standard processes are targets of measurable improvement activities.

The acquirer typically achieves its quality and performance objectives through coordination with its suppliers. The acquirer typically focuses on capabilities differentiation along with collaborative supplier management. Achievement of these objectives also depends on being able to effectively evaluate and deploy proposed improvements to the processes and technologies. All members of the acquirer-supplier network participate in the acquirer's process- and technologyimprovement activities. This participation can be facilitated if suppliers are willing to open up their processes for inspection to the acquirer and other suppliers of the acquirer. Their process improvement proposals are systematically gathered and addressed. [ACQ]

A critical distinction between maturity levels 4 and 5 is the type of process variation addressed. At maturity level 4 , the organization is concerned with addressing special causes of process variation and providing statistical predictability of the results. Although processes may produce predictable results, the results may be insufficient to achieve the established objectives. At maturity level 5 , the organization is concerned with addressing common causes of process variation and changing the process (to shift the mean of the process performance or reduce the inherent process variation experienced) to improve process performance and to achieve the established quantitative processimprovement objectives.

The continuous representation enables the organization or projects to choose the focus of its process improvement efforts by choosing those process areas, or sets of interrelated process areas, that best benefit the acquirer and its business objectives. Once you select the process areas, you must also select how much you would like to mature the processes associated with those process areas (i.e., select the appropriate capability level). This selection is typically described through a target profile. A target profile defines all of the process areas to be addressed and the targeted capability level for each. This profile then governs which goals and practices the organization will address in its process-improvement efforts. [AcQ] 
Organizations that target capability levels higher than 1 will concentrate on the institutionalization of the selected processes in the organization by implementing the associated generic goals and practices. Target staging is a sequence of target profiles that describes the path of process improvement to be followed by the organization. When building target profiles, the organization should pay attention to the dependencies between generic practices and process areas. If a generic practice depends on a certain process area, either to carry out the generic practice or to provide a prerequisite product, the generic practice may be much less effective when the process area is not implemented. [ACQ]

The staged representation enables the organization or projects to use designated sets of process areas to follow a defined improvement path or maturity levels for an acquirer. The staged representation provides a predetermined path of improvement from maturity level 1 to maturity level 5. As acquirers improve they may follow different improvement approaches. [ACQ]

Equivalent staging enables an organization using the continuous representation for an appraisal to convert a capability level profile to the associated maturity level rating. The most effective way to depict equivalent staging is to provide a sequence of target profiles, each of which is equivalent to a maturity level rating of the staged representation. [ACQ]

The following rules summarize equivalent staging:

- To achieve maturity level 2 , all process areas assigned to maturity level 2 must achieve capability level 2 or higher.

- To achieve maturity level 3, all process areas assigned to maturity levels 2 and 3 must achieve capability level 3 or higher.

- To achieve maturity level 4 , all process areas assigned to maturity levels 2, 3, and 4 must achieve capability level 3 or higher.

- To achieve maturity level 5, all process areas must achieve capability level 3 or higher.

While all process areas have dependencies with all other process areas, some process areas have similar or closely-related purposes. This similarity in purpose is a basis for categorizing the process areas into process area categories. [ACQ]

Process areas can be grouped into four categories: [ACQ]

- Process Management 
- Project Management

- Acquisition

- Support

Understanding these process area categories will help users of the initial draft CMMI-ACQ recognize closely-allied process areas. Users are encouraged to take the time needed to understand the interdependencies within and across process area categories when planning organizational process improvement. [ACQ]

Process Management process areas contain the cross-project activities related to defining, planning, deploying, implementing, monitoring, controlling, appraising, measuring, and improving processes. [ACQ]

The Process Management process areas are as follows: [AcQ]

- Organizational Innovation and Deployment

- Organizational Process Definition

- Organizational Process Focus

- Organizational Process Performance

- Organizational Training

Project Management process areas cover the project management activities related to planning, monitoring, and controlling the project. [ACQ]

The Project Management process areas are as follows: [ACQ]

- Integrated Project Management

- Project Monitoring and Control

- Project Planning

- Quantitative Project Management

- Requirements Management ${ }^{8}$

- Risk Management

Acquisition process areas cover the activities related to the acquisition of products and services from suppliers. [ACQ]

The Acquisition process areas are as follows: [AcQ]

- Acquisition Management

- Acquisition Requirements Development

- Acquisition Technical Solution

${ }^{8}$ The Requirements Management process area is instead categorized as belonging to the Engineering process area category within the CMMI for Development, v1.2. As there is no such process area category in the initial draft CMMI-ACQ, it is categorized as belonging to the Project Management process area category. 
- Acquisition Validation

- Acquisition Verification

- Solicitation and Supplier Agreement Development

Support process areas address processes that are used in the context of performing other processes. In general, the Support process areas address processes that are targeted toward the project, and may address processes that apply more generally to the organization. For example, Process and Product Quality Assurance can be used with all the process areas to provide an objective evaluation of the processes and work products described in these process areas. [ACQ]

The Support process areas of CMMI are as follows: [ACQ]

- Causal Analysis and Resolution

- Configuration Management

- Decision Analysis and Resolution

- Measurement and Analysis

- Process and Product Quality Assurance 


\section{Using CMMI Models}

The complexity of today's products demands an integrated view of how organizations do business. CMMI can reduce the cost of process improvement across enterprises that depend on multiple functions or groups to produce products and services.

To achieve this integrated view, the CMMI Framework includes common terminology, common model components, common appraisal methods, and common training materials. This chapter describes how organizations can use the CMMI Product Suite for not only improving their quality, reducing their costs, and optimizing their schedules, but also gauging how well their process improvement program is doing.

Research has shown that the most powerful initial step to process improvement is to build strong organizational support through strong senior management sponsorship. To gain senior management sponsorship, it is often beneficial to expose senior management to the performance results experienced by others who have used CMMI to improve their processes.

For more information about CMMI performance results, see the SEI Web site at http://www.sei.cmu.edu/cmmi/results.html [SEI 3].

The senior manager, once committed as the process improvement sponsor, must be actively involved in the CMMI-based process improvement effort. Activities performed by the senior management sponsor include, but are not limited to the following:

- influence the organization to adopt CMMI

- choose the best people to manage the process improvement effort

- monitor the process improvement effort personally

- be a visible advocate and spokesperson for the process improvement effort

- ensure that adequate resources are available to enable the process improvement effort to be successful. 
Given sufficient senior management sponsorship, the next step is establishing a strong, technically competent process group that represents relevant stakeholders to guide process-improvement efforts.

For an organization with a mission to develop software-intensive systems, the process group might include engineers representing the different technical disciplines across the organization, and other selected members based on the business needs driving improvement. For example, a systems administrator may focus on informationtechnology support, whereas a marketing representative may focus on integrating customers' needs. Both members could make powerful contributions to the process group.

Once your organization has decided to adopt CMMI, planning can begin with an improvement approach such as the IDEAL ${ }^{\text {SM }}$ (Initiating, Diagnosing, Establishing, Acting, Learning) model [SEI 2]. For more information about the IDEAL model, see the Software Engineering Institute Web site at: http://www.sei.cmu.edu/ideal/ideal.html [SEI 1]

Your Process Improvement Program

Use the CMMI Product Suite to help establish your organization's process improvement program. Using the product suite for this purpose can be a relatively informal process that involves understanding and applying CMMI best practices to your organization. Or, it can be a formal process that involves extensive training, creation of a process improvement infrastructure, appraisals, and more.

Selections That Influence Your Program

There are three selections you must make to apply CMMI to your organization for process improvement: (1) select the part of the organization, (2) select the model (3) select a representation.

Selecting the projects to be involved in your process improvement program is critical. If you select a group that is too large, it may be too much for the initial improvement effort. The selection should also consider how homogeneous the group is (i.e., are they all software engineers, do they all work on the same product or business line).

Selecting the model to be used depends on the areas your organization is interested in improving. Not only must you select a constellation (e.g., Development, Acquisition, or Services), you must also decide whether to include any additions (e.g., IPPD). 
Selecting the representation to be used has some guidelines because of how CMMI models are built. If your organization likes the idea of maturity levels and the staged representation, your improvement roadmap is already defined. If your organization likes the continuous representation, you can select nearly any process area or group of process areas to guide improvement, although dependencies among process areas should be considered when making such a selection.

As the process improvement plans and activities progress, other important selections must be made, including: (1) which appraisal method should be used, (2) which projects should be appraised, (3) how should training for personnel be secured, (4) which personnel should be trained.

CMMI models describe what have been determined to be best practices that organizations have found to be productive and useful to achieving business objectives. Regardless of your type of organization, to apply CMMI practices, you must use professional judgment to interpret them for your situation, needs, and business objectives. Although process areas depict the characteristics of an organization committed to process improvement, you must interpret the process areas using an in-depth knowledge of CMMI, your organization, the business environment, and the specific circumstances involved.

As you begin using a CMMI model for improving your organization's processes, map your real-world processes to a CMMI model's process areas. This mapping enables you to initially judge and later track your organization's level of conformance to the CMMI model you are using and to identify opportunities for improvement.

To interpret practices, it is important to consider the overall context in which these practices are used and to determine how well the practices satisfy the goals of a process area in that context. CMMI models do not explicitly prescribe nor imply particular processes that are right for any organization or project. Instead, CMMI describes minimal criteria necessary to plan and implement processes selected by the organization for improvement based on business objectives.

CMMI practices purposely use nonspecific phrases such as "relevant stakeholders," "as appropriate," and "as necessary" to accommodate the needs of different organizations and projects. The specific needs of a project may also differ at various points during its life. 
Many organizations find value in measuring their progress by conducting an appraisal and thus earning a maturity level rating or a capability level achievement profile. These appraisals are typically conducted for one or more of the following reasons:

- To determine how well the organization's processes compare to CMMI best practices and identify areas where improvement can be made

- To inform external customers and suppliers about how well the organization's processes compare to CMMI best practices

- To meet the contract requirements of one or more customers

Appraisals or organizations using a CMMI model must conform to the requirements defined in the Appraisal Requirements for CMMI (ARC) document. These appraisals focus on identifying improvement opportunities and comparing the organization's processes to CMMI best practices. Appraisal teams use a CMMI model and ARC-conformant appraisal method to guide their evaluation of the organization as well as how they report their conclusions. The appraisal results are then used (by a process group, for example) to plan improvements for the organization. [Ahern 2005].

\section{Appraisal Requirements for CMMI}

The Appraisal Requirements for CMMI (ARC) document describes the requirements for several types of appraisals. A full benchmarking class of appraisal is defined as a Class A appraisal. Less formal methods are defined as Class B or C methods. The ARC document was designed to help improve consistency across appraisal methods, and to help appraisal method developers, sponsors, and users understand the tradeoffs associated with various methods. ${ }^{9}$

Depending on the purpose of the appraisal and the nature of the circumstances, one class may be preferred over the others. Sometimes self-assessments, initial appraisals, quick-look or mini-appraisals, incremental appraisals, or external appraisals are appropriate; whereas at other times a formal benchmarking appraisal is appropriate.

A particular appraisal method is declared an ARC Class A, B, or C appraisal method based on the sets of $A R C$ requirements that the method developer has addressed when designing the method.

More information about the ARC is available on the Software Engineering Institute's Web site at http://www.sei.cmu.edu/cmmi/appraisals/appraisals.html.

${ }^{9}$ See the forthcoming Appraisal Requirements for CMMI. 
The SCAMPI appraisal methods are the generally accepted methods used for conducting appraisals using CMMI models. The SCAMPI Method Definition Document (MDD) defines rules for ensuring the consistency of appraisal ratings. For benchmarking against other organizations, appraisals must ensure consistent ratings. The achievement of a specific maturity level or the satisfaction of a process area must mean the same thing for different appraised organizations.

The SCAMPI family of appraisals includes Class A, B, and C appraisal methods. SCAMPI $A$ is the most rigorous method and the only method that can result in a rating. SCAMPI B provides options in model scope, but the characterization of practices is fixed to one scale and is performed on implemented practices. SCAMPI $C$ provides a wide range of options, including characterization of planned approaches to process implementation according to a scale defined by the user.

More information about SCAMPI methods is available on the Software Engineering Institute Web site at the following URL:

http://www.sei.cmu.edu/cmmi/appraisals/appraisals.html. ${ }^{10}$

Choices that affect a CMMI-based appraisal include the following:

- Establishing the appraisal scope, including the organizational unit to be appraised, the CMMI process areas to be investigated, and the maturity level or capability level(s) to be appraised

- Selecting the appraisal method

- Selecting the appraisal team members

- Selecting appraisal participants from the appraisal entities to be interviewed

- Establishing appraisal outputs (e.g., ratings, instantiation-specific findings)

- Establishing appraisal constraints (e.g., time spent on site)

The SCAMPI Method Definition Document allows the selection of predefined options for use in an appraisal. These appraisal options are designed to help organizations align CMMI with their business needs and objectives.

\footnotetext{
${ }^{10}$ See the forthcoming Standard CMMI Appraisal Method for Process Improvement Method Definition
} Document. 
Documentation of CMMI appraisal plans and results must always include a description of the appraisal options, model scope, and organizational scope selected. This documentation confirms whether an appraisal meets the requirements for benchmarking.

For organizations that wish to appraise multiple functions or groups, CMMI's integrated approach enables some economy of scale in model and appraisal training. One appraisal method can provide separate or combined results for multiple functions.

The appraisal principles for the CMMI Product Suite ${ }^{11}$ remain the same as those used in appraisals for other process-improvement models. Those principles are listed below:

- Senior management sponsorship ${ }^{12}$

- A focus on the organization's business objectives

- Confidentiality for interviewees

- Use of a documented appraisal method

- Use of a process reference model (e.g., a CMMI model) as a base

- A collaborative team approach

- A focus on actions for process improvement

Whether your organization is new to process improvement or is already familiar with process-improvement models, training is a key element in the ability of organizations to adopt CMMI. An initial set of courses is provided by the SEI and its Partners ${ }^{13}$, but your organization may wish to supplement these courses with internal instruction. This approach allows your organization to focus on the areas that provide the greatest business value.

${ }^{11}$ See the glossary for the definition of CMMI Product Suite.

${ }^{12}$ Experience has shown that the most critical factor influencing successful process improvement and appraisals is senior management sponsorship.

${ }^{13}$ Courses covering acquisition will gradually become available; initial training will be available to support using the initial draft CMMI-ACQ. 
Adapting CMMI for Acquisition Organizations: A Preliminary Report

Current information about CMMI-related training is available on the Software Engineering Institute Web site at:

http://www.sei.cmu.edu/cmmi/training/training.html. 


\section{PART TWo \\ Generic Goals and Practices, and the Process Areas}


This chapter describes, in detail, all the generic goals and generic practices-model components that directly address process institutionalization.

The text of the generic goals and generic practices is not repeated in the process areas. As you address each process area, refer to this chapter for the details of all generic practices. [AcQ]

"Institutionalization" is an important concept in process improvement. When mentioned in the generic goal and generic practice descriptions, institutionalization implies that the process is ingrained in the way the work is performed and there is commitment and consistency to performing the process.

An institutionalized process is more likely to be retained during times of stress. When the requirements and objectives for the process change, however, the implementation of the process may also need to change to ensure that it remains effective. The generic practices describe activities that address these aspects of institutionalization.

The degree of institutionalization is embodied in the generic goals and expressed in the names of the processes associated with each goal as indicated in Table 5.1.

Table 5.1: Generic Goals and Process Names

\begin{tabular}{ll}
\hline Generic Goal & Progression of Processes \\
\hline GG 1 & Performed process \\
GG 2 & Managed process \\
GG 3 & Defined process \\
GG 4 & Quantitatively managed process \\
GG 5 & Optimizing process \\
\hline
\end{tabular}

The progression of process institutionalization is described in the following descriptions of each process. 
A performed process is a process that accomplishes the work necessary to produce work products. The specific goals of the process area are satisfied.

\section{Managed Process}

A managed process is a performed process that is planned and executed in accordance with policy; employs skilled people who have adequate resources to produce controlled outputs; involves relevant stakeholders; is monitored, controlled, and reviewed; and is evaluated for adherence to its process description. The process may be instantiated by a project, group, or organizational function. Management of the process is concerned with institutionalization and the achievement of other specific objectives established for the process, such as cost, schedule, and quality objectives. The control provided by a managed process helps ensure that the established process is retained during times of stress.

The requirements and objectives for the process are established. The status of the work products and delivery of the services are visible to management at defined points (e.g., at major milestones and completion of major tasks). Commitments are established among those performing the work and the relevant stakeholders and are revised as necessary. Work products are reviewed with relevant stakeholders and are controlled. The work products and services satisfy their specified requirements.

A critical distinction between a performed process and a managed process is the extent to which the process is managed. A managed process is planned (the plan may be part of a more encompassing plan) and the performance of the process is managed against the plan. Corrective actions are taken when the actual results and performance deviate significantly from the plan. A managed process achieves the objectives of the plan and is institutionalized for consistent performance.

\section{Defined Process}

A defined process is a managed process that is tailored from the organization's set of standard processes according to the organization's tailoring guidelines; has a maintained process description; and contributes work products, measures, and other process improvement information to the organizational process assets. 
The organizational process assets are artifacts that relate to describing, implementing, and improving processes. These artifacts are assets because they are developed or acquired to meet the business objectives of the organization, and they represent investments by the organization that are expected to provide current and future business value.

The organization's set of standard processes, which are the basis of the defined process, are established and improved over time. Standard processes describe the fundamental process elements that are expected in the defined processes. Standard processes also describe the relationships (e.g., the ordering and the interfaces) among these process elements. The organization-level infrastructure to support current and future use of the organization's set of standard processes is established and improved over time. (See the definition of "standard process" in the glossary.)

A project's defined process provides a basis for planning, performing, and improving the project's tasks and activities. A project may have more than one defined process (e.g., one for developing the product and another for testing the product).

A defined process clearly states the following:

- Purpose

- Inputs

- Entry criteria

- Activities

- Roles

- Measures

- Verification steps

- Outputs

- Exit criteria

A critical distinction between a managed process and a defined process is the scope of application of the process descriptions, standards, and procedures. For a managed process, the process descriptions, standards, and procedures are applicable to a particular project, group, or organizational function. As a result, the managed processes of two projects in one organization may be different. 
Another critical distinction is that a defined process is described in more detail and performed more rigorously than a managed process. This means that improvement information is easier to understand, analyze, and use. Finally, management of the defined process is based on the additional insight provided by an understanding of the interrelationships of the process activities and detailed measures of the process, its work products, and its services.

\section{Quantitatively Managed Process}

A quantitatively managed process is a defined process that is controlled using statistical and other quantitative techniques. The product quality, service quality, and process performance attributes are measurable and controlled throughout the project.

Quantitative objectives are established based on the capability of the organization's set of standard processes; the organization's business objectives; and the needs of the customer, end users, organization, and process implementers, subject to available resources. The people performing the process are directly involved in quantitatively managing the process.

Quantitative management is performed on the overall set of processes that produces a product or provides a service. The subprocesses that are significant contributors to overall process performance are statistically managed. For these selected subprocesses, detailed measures of process performance are collected and statistically analyzed. Special causes of process variation are identified and, where appropriate, the source of the special cause is addressed to prevent its recurrence.

The quality and process performance measures are incorporated into the organization's measurement repository to support future fact-based decision making.

Activities for quantitatively managing the performance of a process include the following:

- Identifying the subprocesses that are to be brought under statistical management

- Identifying and measuring product and process attributes that are important contributors to quality and process performance

- Identifying and addressing special causes of subprocess variations (based on the selected product and process attributes and subprocesses selected for statistical management)

- Managing each of the selected subprocesses, with the objective of bringing their performance within natural bounds (i.e., making the 
subprocess performance statistically stable and predictable based on the selected product and process attributes)

- $\quad$ Predicting the ability of the process to satisfy established quantitative quality and process-performance objectives

- Taking appropriate corrective actions when it is determined that the established quantitative quality and process-performance objectives will not be satisfied

These corrective actions include changing the objectives or ensuring that relevant stakeholders have a quantitative understanding of, and have agreed to, the performance shortfall.

A critical distinction between a defined process and a quantitatively managed process is the predictability of the process performance. The term "quantitatively managed" implies using appropriate statistical and other quantitative techniques to manage the performance of one or more critical subprocesses so that the performance of the process can be predicted. A defined process provides only qualitative predictability.

\section{Optimizing Process}

An optimizing process is a quantitatively managed process that is changed and adapted to meet relevant current and projected business objectives. An optimizing process focuses on continually improving process performance through both incremental and innovative technological improvements. Process improvements that address common causes of process variation, root causes of defects and other problems, and those that would measurably improve the organization's processes are identified, evaluated, and deployed as appropriate. These improvements are selected based on a quantitative understanding of their expected contribution to achieving the organization's process-improvement objectives versus the cost and impact to the organization. The process performance of the organization's processes is continually improved.

Selected incremental and innovative technological process improvements are systematically managed and deployed into the organization. The effects of the deployed process improvements are measured and evaluated against the quantitative process-improvement objectives.

In a process that is optimized, common causes of process variation are addressed by changing the process in a way that will shift the mean or decrease variation when the process is restabilized. These changes are intended to improve process performance and achieve the organization's established process-improvement objectives. 
A critical distinction between a quantitatively managed process and an optimizing process is that the optimizing process is continuously improved by addressing common causes of process variation. A quantitatively managed process is concerned with addressing special causes of process variation and providing statistical predictability of the results. Although the process may produce predictable results, the results may be insufficient to achieve the organization's processimprovement objectives.

\section{Relationships among Processes}

The generic goals evolve so that each goal provides a foundation for the next. Therefore the following conclusions can be made:

- A managed process is a performed process.

- A defined process is a managed process.

- A quantitatively managed process is a defined process.

- An optimizing process is a quantitatively managed process.

Thus, applied sequentially and in order, the generic goals describe a process that is increasingly institutionalized, from a performed process to an optimizing process.

Achieving GG 1 for a process area is equivalent to saying you achieve the specific goals of the process area.

Achieving GG 2 for a process area is equivalent to saying you manage the performance of processes associated with the process area. There is a policy that indicates you will perform it. There is a plan for performing it. There are resources provided, responsibilities assigned, training on how to perform it, selected work products from performing the process are controlled, and so on. In other words, the process is planned and monitored just like any project or support activity.

Achieving GG 3 for a process area assumes that an organizational standard process exists that can be tailored to result in the process you will use. Tailoring might result in making no changes to the standard process. In other words, the process used and the standard process may be identical. Using the standard process "as is" is tailoring because the choice is made that no further modification is required.

Each process area describes multiple activities, some of which are repeatedly performed. You may need to tailor the way one of these activities is performed to account for new capabilities or circumstances. For example, you may have a standard for developing or obtaining organizational training that does not consider Web-based training. When preparing to develop or obtain a Web-based course, you may need to tailor that standard process to account for the particular challenges and benefits of Web-based training. 
Achieving GG 4 or GG 5 for a process area is conceptually feasible but may not be economical except, perhaps, in situations where the product domain has become stable for an extended period or in situations in which the process area or domain is a critical business driver.

\section{Generic Goals and Generic Practices}

This section describes all of the generic goals and generic practices, as well as their associated subpractices, notes, examples, and references. The generic goals are organized in numerical order, GG 1 through GG 5 . The generic practices are also organized in numerical order under the generic goal they support.

As mentioned earlier in this chapter, the text of the generic practices is not repeated in the process areas; the text for each generic goal and generic practice is found only here. [ACQ]

GG 1 Achieve Specific Goals

The process supports and enables achievement of the specific goals of the process area by transforming identifiable input work products to produce identifiable output work products.

GP 1.1 Perform Specific Practices

Perform the specific practices of the process area to develop work products and provide services to achieve the specific goals of the process area.

The purpose of this generic practice is to produce the work products and deliver the services that are expected by performing the process. These practices may be done informally, without following a documented process description or plan. The rigor with which these practices are performed depends on the individuals managing and performing the work and may vary considerably.

GG 2 Institutionalize a Managed Process

The process is institutionalized as a managed process.

GP 2.1 Establish an Organizational Policy

Establish and maintain an organizational policy for planning and performing the process.

The purpose of this generic practice is to define the organizational expectations for the process and make these expectations visible to those in the organization who are affected. In general, senior management is responsible for establishing and communicating guiding principles, direction, and expectations for the organization. 
Not all direction from senior management will bear the label "policy." The existence of appropriate organizational direction is the expectation of this generic practice, regardless of what it is called or how it is imparted.

This policy establishes organizational expectations for planning and performing the process; including not only the elements of the process addressed directly by the acquirer, but also the interactions of the acquirer with suppliers. [ACQ]

\section{GP 2.2 Plan the Process}

\section{Establish and maintain the plan for performing the process.}

The purpose of this generic practice is to determine what is needed to perform the process and to achieve the established objectives, to prepare a plan for performing the process, to prepare a process description, and to get agreement on the plan from relevant stakeholders.

The practical implications of applying a generic practice vary for each process area. Consider these variances as they relate to planning the process.

For example, the planning described by this generic practice as applied to the Project Monitoring and Control process area may be carried out in full by the processes associated with the Project Planning process area. However, this generic practice when applied to the Project Planning process area, sets an expectation that the project planning process itself be planned. It is important to be aware of the extent to which this generic practice may either reinforce expectations set elsewhere in CMMI or set new expectations that should be addressed.

Establishing a plan includes documenting the plan and providing a process description. Maintaining the plan includes changing it, as necessary, in response to either corrective actions or to changes in requirements and objectives for the process.

The plan for performing the process typically includes the following:

- Process description

- Standards and requirements for the work products and services of the process

- Specific objectives for the performance of the process (e.g., quality, time scale, cycle time, and resource usage)

- Dependencies among the activities, work products, and services of the process

- Resources (including funding, people, and tools) needed to perform the process 
- Assignment of responsibility and authority

- Training needed for performing and supporting the process

- Work products to be controlled and the level of control to be applied

- Measurement requirements to provide insight into the performance of the process, its work products, and its services

- Involvement of identified stakeholders

- Activities for monitoring and controlling the process

- Objective evaluation activities of the process

- Management review activities for the process and the work products

Subpractices

1. Define and document the plan for performing the process.

This plan may be a stand-alone document, embedded in a more comprehensive document, or distributed across multiple documents. In the case of the plan being distributed across multiple documents, ensure that a coherent picture of who does what is preserved. Documents may be hardcopy or softcopy.

2. Define and document the process description.

The process description, which includes relevant standards and procedures, may be included as part of the plan for performing the process or may be included in the plan by reference.

3. Review the plan with relevant stakeholders and get their agreement.

This includes reviewing that the planned process satisfies the applicable policies, plans, requirements, and standards to provide assurance to relevant stakeholders.

4. Revise the plan as necessary.

\section{GP 2.3 Provide Resources}

Provide adequate resources for performing the process, developing the work products, and providing the services of the process.

The purpose of this generic practice is to ensure that the resources necessary to perform the process as defined by the plan are available when they are needed. Resources include adequate funding, appropriate physical facilities, skilled people, and appropriate tools.

The interpretation of the term adequate depends on many factors and can change over time. Inadequate resources may be addressed by increasing resources or by removing requirements, constraints, and commitments. 
Assign responsibility and authority for performing the process, developing the work products, and providing the services of the process.

The purpose of this generic practice is to ensure that there is accountability for performing the process and achieving the specified results throughout the life of the process. The people assigned must have the appropriate authority to perform the assigned responsibilities.

Responsibility can be assigned using detailed job descriptions or in living documents, such as the plan for performing the process. Dynamic assignment of responsibility is another legitimate way to perform this generic practice, as long as the assignment and acceptance of responsibility are ensured throughout the life of the process.

\section{Subpractices}

1. Assign overall responsibility and authority for performing the process.

2. Assign responsibility and authority for performing the specific tasks of the process.

3. Confirm that the people assigned to the responsibilities and authorities understand and accept them.

\section{GP 2.5 Train People}

Train the people performing or supporting the process as needed.

The purpose of this generic practice is to ensure that the people have the necessary skills and expertise to perform or support the process.

Appropriate training is provided to the people who will be performing the work. Overview training is provided to orient people who interact with those performing the work.

Examples of methods for providing training include self-study; selfdirected training; self-paced, programmed instruction; formalized onthe-job training; mentoring; and formal and classroom training.

Training supports the successful performance of the process by establishing a common understanding of the process and by imparting the skills and knowledge needed to perform the process.

Experience may be substituted for training and means, for example, having participated in a project with responsibility for managing some of the acquisition processes. [ACQ] 
Examples of training topics include the following: [ACO]

- Development of a solicitation package

- Negotiation skills

- Risk identification and management

- Supplier agreement development

- Acquisition management

- Acquisition requirements development

Refer to the Organizational Training process area for more information on training the people performing or supporting the process.

GP 2.6 Manage Configurations

Place designated work products of the process under appropriate levels of control.

The purpose of this generic practice is to establish and maintain the integrity of the designated work products of the process (or their descriptions) throughout their useful life.

The designated work products are specifically identified in the plan for performing the process, along with a specification of the appropriate level of control.

Different levels of control are appropriate for different work products and for different points in time. For some work products, it may be sufficient to maintain version control (i.e., the version of the work product in use at a given time, past or present, is known and changes are incorporated in a controlled manner). Version control is usually under the sole control of the work product owner (which may be an individual, a group, or a team).

Sometimes, it may be critical that work products be placed under formal or "baseline" configuration management. This type of control includes defining and establishing baselines at predetermined points. These baselines are formally reviewed and agreed on, and serve as the basis for further development of the designated work products.

Refer to the Configuration Management process area for more information on placing work products under configuration management.

Additional levels of control between version control and formal configuration management are possible. An identified work product may be under various levels of control at different points in time.

The acquirer is responsible for establishing and maintaining baselines and ensures designated acquirer work products and supplier deliverables are placed under appropriate levels of control. [ACQ] 
Examples of acquirer work products and supplier deliverables placed under control

include the following: $[\mathrm{ACQ}]$

- Project plans

- Solicitation packages

- Measures

- Product documentation

GP 2.7 Identify and Involve Relevant Stakeholders Identify and involve the relevant stakeholders as planned.

The purpose of this generic practice is to establish and maintain the expected involvement of stakeholders during the execution of the process.

Involve relevant stakeholders as described in an appropriate plan for stakeholder involvement. Involve them appropriately in activities such as the following:

- Planning

- Decisions

- Commitments

- Communications

- Coordination

- Reviews

- Appraisals

- Requirements definitions

- Resolution of problems/issues

Refer to the Project Planning process area for information on the project planning for stakeholder involvement.

The objective of planning the stakeholder involvement is to ensure that interactions necessary to the process are accomplished, while not allowing excessive numbers of affected groups and individuals to impede process execution.

Relevant stakeholders include the suppliers who develop the product and any suppliers who may be affected by the product. [AcQ] 
Examples of activities for supplier involvement as stakeholders include the following:

[ACQ]

- Corrective action meetings

- Technical reviews and interchanges

- Project status meetings

- Management reviews

Subpractices

1. Identify stakeholders relevant to this process and decide what type of involvement should be practiced.

Relevant stakeholders are identified among the suppliers of inputs to, the users of outputs from, and the performers of the activities within the process. Once the relevant stakeholders are identified, the appropriate level of their involvement in process activities is planned.

2. Share these identifications with project planners or other planners as appropriate.

3. Involve relevant stakeholders as planned.

\section{GP 2.8 Monitor and Control the Process}

Monitor and control the process against the plan for performing the process and take appropriate corrective action.

The purpose of this generic practice is to perform the direct day-to-day monitoring and controlling of the process. Appropriate visibility into the process is maintained so that appropriate corrective action can be taken when necessary. Monitoring and controlling the process involves measuring appropriate attributes of the process or work products produced by the process.

Refer to the Project Monitoring and Control process area for more information about monitoring and controlling the project and taking corrective action.

Refer to the Measurement and Analysis process area for more information about measurement.

The project collects and analyzes measures from the acquirer and from the supplier in order to effectively monitor and control the project. [ACQ]

\section{Subpractices}

1. Measure actual performance against the plan for performing the process.

The measures are of the process, its work products, and its services. 
2. Review accomplishments and results of the process against the plan for performing the process.

3. Review activities, status, and results of the process with the immediate level of management responsible for the process and identify issues. The reviews are intended to provide the immediate level of management with appropriate visibility into the process. The reviews can be both periodic and event driven.

4. Identify and evaluate the effects of significant deviations from the plan for performing the process.

5. Identify problems in the plan for performing the process and in the execution of the process.

6. Take corrective action when requirements and objectives are not being satisfied, when issues are identified, or when progress differs significantly from the plan for performing the process.

There are inherent risks that should be considered before any corrective action is taken.

Corrective action may include the following:

- Taking remedial action to repair defective work products or services

- Changing the plan for performing the process

- Adjusting resources, including people, tools, and other resources

- Negotiating changes to the established commitments

- Securing change to the requirements and objectives that have to be satisfied

- Terminating the effort

7. Track corrective action to closure.

GP 2.9 Objectively Evaluate Adherence

Objectively evaluate adherence of the process against its process description, standards, and procedures, and address noncompliance.

The purpose of this generic practice is to provide credible assurance that the process is implemented as planned and adheres to its process description, standards, and procedures. This purpose is accomplished, in part, by evaluating selected work products of the process. (See the definition of objectively evaluate in the glossary.)

Refer to the Process and Product Quality Assurance process area for more information about objectively evaluating adherence. 
People not directly responsible for managing or performing the activities of the process typically evaluate adherence. In many cases, adherence is evaluated by people within the organization, but external to the process or project, or by people external to the organization. As a result, credible assurance of adherence can be provided even during times when the process is under stress (e.g., when the effort is behind schedule or over budget).

\section{GP 2.10 Review Status with Higher Level Management}

\section{Review the activities, status, and results of the process with} higher level management and resolve issues.

The purpose of this generic practice is to provide higher level management with the appropriate visibility into the process.

Higher level management includes those levels of management in the organization above the immediate level of management responsible for the process. In particular, higher level management includes senior management. These reviews are for managers who provide the policy and overall guidance for the process, not for those who perform the direct day-to-day monitoring and controlling of the process.

Different managers have different needs for information about the process. These reviews help ensure that informed decisions on the planning and performing of the process can be made. Therefore, these reviews are expected to be both periodic and event driven.

Proposed changes to commitments to be made external to the organization, for example, changes to supplier agreements, are typically reviewed with higher level management to ensure that all commitments can be accomplished. [ACQ]

GG 3 Institutionalize a Defined Process

The process is institutionalized as a defined process.

GP 3.1 Establish a Defined Process

Establish and maintain the description of a defined process.

The purpose of this generic practice is to establish and maintain a description of the process that is tailored from the organization's set of standard processes to address the needs of a specific instantiation. The organization should have standard processes that cover the process area, as well as have guidelines for tailoring these standard processes to meet the needs of a project or organizational function. With a defined process, variability in how the processes are performed across the organization is reduced and process assets, data, and learning can be effectively shared. 
Refer to the Organizational Process Definition process area for more information about the organization's set of standard processes and tailoring guidelines.

The descriptions of the defined processes provide the basis for planning, performing, and managing the activities, work products, and services associated with the process.

\section{Subpractices}

1. Select from the organization's set of standard processes those processes that cover the process area and best meet the needs of the project or organizational function.

2. Establish the defined process by tailoring the selected processes according to the organization's tailoring guidelines.

3. Ensure that the organization's process objectives are appropriately addressed in the defined process.

4. Document the defined process and the records of the tailoring.

5. Revise the description of the defined process as necessary.

GP 3.2 Collect Improvement Information

Collect work products, measures, measurement results, and improvement information derived from planning and performing the process to support the future use and improvement of the organization's processes and process assets.

The purpose of this generic practice is to collect information and artifacts derived from planning and performing the process. This generic practice is performed so that the information and artifacts can be included in the organizational process assets and made available to those who are (or who will be) planning and performing the same or similar processes. The information and artifacts are stored in the organization's measurement repository and the organization's process asset library.

Examples of relevant information include the effort expended for the various activities, defects injected or removed in a particular activity, and lessons learned.

Refer to the Organizational Process Definition process area for more information about the organization's measurement repository and process asset library and for more information about the work products, measures, and improvement information that are incorporated into these organizational process assets. 


\section{Subpractices}

1. Store process and product measures in the organization's measurement repository.

The process and product measures are primarily those that are defined in the common set of measures for the organization's set of standard processes.

2. Submit documentation for inclusion in the organization's process asset library.

3. Document lessons learned from the process for inclusion in the organization's process asset library.

4. Propose improvements to the organizational process assets.

GG 4 Institutionalize a Quantitatively Managed Process

The process is institutionalized as a quantitatively managed process.

GP 4.1 Establish Quantitative Objectives for the Process

Establish and maintain quantitative objectives for the process that address quality and process performance based on customer needs and business objectives.

The purpose of this generic practice is to determine and obtain agreement from relevant stakeholders about specific quantitative objectives for the process. These quantitative objectives can be expressed in terms of product quality, service quality, and process performance.

Refer to the Quantitative Project Management process area for information on how quantitative objectives are set for subprocesses of the project's defined process.

The quantitative objectives may be specific to the process or they may be defined for a broader scope (e.g., for a set of processes). In the latter case, these quantitative objectives may be allocated to some of the included processes.

These quantitative objectives are criteria used to judge whether the products, services, and process performance will satisfy the customers, end users, organization management, and process implementers. These quantitative objectives go beyond the traditional end-product objectives. They also cover intermediate objectives that are used to manage the achievement of the objectives over time. They reflect, in part, the demonstrated performance of the organization's set of standard processes. These quantitative objectives should be set to values that are likely to be achieved when the processes involved are stable and within their natural bounds. 


\section{Subpractices}

1. Establish the quantitative objectives that pertain to the process.

2. Allocate the quantitative objectives to the process or its subprocesses.

GP 4.2 Stabilize Subprocess Performance

Stabilize the performance of one or more subprocesses to determine the ability of the process to achieve the established quantitative quality and process-performance objectives.

The purpose of this generic practice is to stabilize the performance of one or more subprocesses of the defined process that are critical contributors to the overall performance using appropriate statistical and other quantitative techniques. Stabilizing selected subprocesses supports predicting the ability of the process to achieve the established quantitative quality and process-performance objectives.

Refer to the Quantitative Project Management process area for information on selecting subprocesses for statistical management, monitoring performance of subprocesses, and other aspects of stabilizing subprocess performance.

A stable subprocess shows no significant indication of special causes of process variation. Stable subprocesses are predictable within the limits established by the natural bounds of the subprocess. Variations in the stable subprocess are due to a constant system of chance causes, and the magnitude of the variations can be small or large.

Predicting the ability of the process to achieve the established quantitative objectives requires a quantitative understanding of the contributions of the subprocesses that are critical to achieving these objectives and establishing and managing against interim quantitative objectives over time.

Selected process and product measures are incorporated into the organization's measurement repository to support process performance analysis and future fact-based decision making.

\section{Subpractices}

1. Statistically manage the performance of one or more subprocesses that are critical contributors to the overall performance of the process.

2. Predict the ability of the process to achieve its established quantitative objectives considering the performance of the statistically managed subprocesses.

3. Incorporate selected process performance measurements into the organization's process performance baselines. 


\section{GP 5.1 Ensure Continuous Process Improvement}

Ensure continuous improvement of the process in fulfilling the relevant business objectives of the organization.

The purpose of this generic practice is to select and systematically deploy process and technology improvements that contribute to meeting established quality and process-performance objectives.

Refer to the Organizational Innovation and Deployment process area for information about selecting and deploying incremental and innovative improvements that measurably improve the organization's processes and technologies.

Optimizing processes that are agile and innovative depends on the participation of an empowered workforce aligned with the business values and objectives of the organization. The organization's ability to rapidly respond to changes and opportunities is enhanced by finding ways to accelerate and share learning. Improvement of the processes is inherently part of everybody's role, resulting in a cycle of continual improvement.

\section{Subpractices}

1. Establish and maintain quantitative process-improvement objectives that support the organization's business objectives.

The quantitative process-improvement objectives may be specific to the individual process or they may be defined for a broader scope (i.e., for a set of processes), with the individual processes contributing to achieving these objectives.

Objectives that are specific to the individual process are typically allocated from quantitative objectives established for a broader scope.

These process-improvement objectives are primarily derived from the organization's business objectives and from a detailed understanding of process capability. These objectives are the criteria used to judge whether the process performance is quantitatively improving the organization's ability to meet its business objectives. These process-improvement objectives are often set to values beyond the current process performance, and both incremental and innovative technological improvements may be needed to achieve these objectives. These objectives may also be revised frequently to continue to drive the improvement of the process (i.e., when an objective is achieved, it may be set to a new value that is again beyond the new process performance).

These process-improvement objectives may be the same as, or a refinement of, the objectives established in the Establish Quantitative Objectives for the Process generic practice, as long as they can serve as both drivers and criteria for successful process improvement. 
2. Identify process improvements that would result in measurable improvements to process performance.

Process improvements include both incremental changes and innovative technological improvements. The innovative technological improvements are typically pursued as efforts that are separately planned, performed, and managed. Piloting is often performed. These efforts often address specific areas of the processes that are determined by analyzing process performance and identifying specific opportunities for significant measurable improvement.

3. Define strategies and manage deployment of selected process improvements based on the quantified expected benefits, the estimated costs and impacts, and the measured change to process performance.

The costs and benefits of these improvements are estimated quantitatively, and the actual costs and benefits are measured. Benefits are primarily considered relative to the organization's quantitative process-improvement objectives. Improvements are made to both the organization's set of standard processes and the defined processes.

Managing deployment of the process improvements includes piloting of changes and implementing adjustments where appropriate, addressing potential and real barriers to deployment, minimizing disruption to ongoing efforts, and managing risks.

\section{GP 5.2 Correct Root Causes of Problems}

\section{Identify and correct the root causes of defects and other problems in the process.}

The purpose of this generic practice is to analyze defects and other problems that were encountered in a quantitatively managed process, to correct the root causes of these types of defects and problems, and to prevent these defects and problems from occurring in the future.

Refer to the Causal Analysis and Resolution process area for more information on identifying and correcting root causes of selected defects. Even though the Causal Analysis and Resolution process area has a project context, it can be applied to processes in other contexts as well.

Root cause analysis can beneficially be applied to processes that are not quantitatively managed. However, the focus of this generic practice is to act on a quantitatively managed process, though the final root causes may be found outside of that process. 
This section helps you to develop a better understanding of the generic practices and provides information for interpreting and applying the generic practices in your organization.

Generic practices are components that are common to all process areas. Think of generic practices as reminders. They serve the purpose of reminding you to do things right, and are expected model components.

For example, when you are achieving the specific goals of the Project Planning process area, you are establishing and maintaining a plan that defines project activities. One of the generic practices that applies to the Project Planning process area is "Establish and maintain the plan for performing the project planning process" (GP 2.2). When applied to this process area, this generic practice reminds you to plan the activities involved in creating the plan for the project.

When you are satisfying the specific goals of the Organizational Training process area, you are developing the skills and knowledge of people in your project and organization so that they can perform their roles effectively and efficiently. When applying the same generic practice (GP 2.2) to the Organizational Training process area, this generic practice reminds you to plan the activities involved in developing the skills and knowledge of people in the organization.

While generic goals and generic practices are the model components that directly address the institutionalization of a process across the organization, many process areas likewise address institutionalization by supporting the implementation of the generic practices. Knowing these relationships will help you effectively implement the generic practices.

Such process areas contain one or more specific practices that when implemented

- may also fully implement a generic practice

- generate a work product that is used in the implementation of a generic practice 
An example is the Configuration Management process area and GP 2.6, "Place designated work products of the process under appropriate levels of control." To implement the generic practice for one or more process areas, you might choose to implement the Configuration Management process area, all or in part, to implement the generic practice.

Another example is the Organizational Process Definition process area and GP 3.1, "Establish and maintain the description of a defined process." To implement this generic practice for one or more process areas, you should first implement the Organizational Process Definition process area, all or in part, to establish the organizational process assets that are needed to implement the generic practice.

Table 5.2 describes (1) the process areas that support the implementation of generic practices, and (2) the recursive relationships between generic practices and their closely related process areas. Both types of relationships are important to remember during process improvement to take advantage of the natural synergies that exist between the generic practices and their related process areas.

Table 5.2: Generic Practice and Process Area Relationships

\begin{tabular}{|c|c|c|}
\hline Generic Practice & $\begin{array}{l}\text { Roles of Process Areas in } \\
\text { Implementation of the Generic Practice }\end{array}$ & $\begin{array}{l}\text { How the Generic Practice Recursively } \\
\text { Applies to its Related Process Area(s) }\end{array}$ \\
\hline $\begin{array}{l}\text { GP } 2.2 \\
\text { Plan the Process }\end{array}$ & $\begin{array}{l}\text { Project Planning: The project planning } \\
\text { process can implement GP } 2.2 \text { in full for } \\
\text { all project-related process areas (except } \\
\text { for Project Planning itself). }\end{array}$ & $\begin{array}{l}\text { GP } 2.2 \text { applied to the project planning } \\
\text { process can be characterized as "plan } \\
\text { the plan" and covers planning the } \\
\text { project planning activities. }\end{array}$ \\
\hline
\end{tabular}

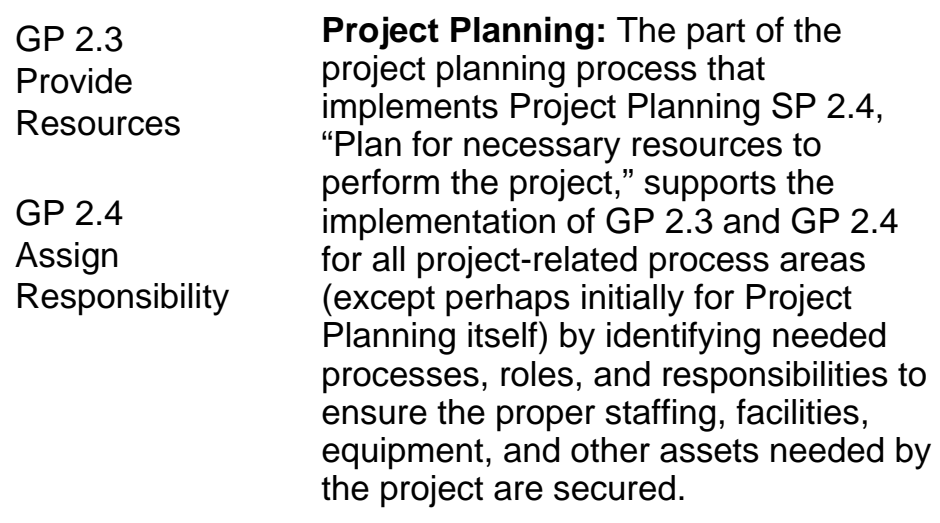

GP 2.3

Provide

GP 2.4

Assign

\footnotetext{
${ }^{14}$ When the relationship between a generic practice and a process area is less direct, the risk of confusion is reduced; therefore, we do not describe all recursive relationships in the table (e.g., for generic practices 2.3, 2.4, and 2.10).
} 


\begin{tabular}{|c|c|}
\hline Generic Practice & $\begin{array}{l}\text { Roles of Process Areas in } \\
\text { Implementation of the Generic Practice }\end{array}$ \\
\hline $\begin{array}{l}\text { GP } 2.5 \\
\text { Train People }\end{array}$ & $\begin{array}{l}\text { Organizational Training: The } \\
\text { organizational training process supports } \\
\text { the implementation of GP } 2.5 \text { as applied } \\
\text { to all process areas by making the } \\
\text { training that addresses strategic or } \\
\text { organization-wide training needs } \\
\text { available to those who will perform or } \\
\text { support the process. } \\
\text { Project Planning: The part of the } \\
\text { project planning process that } \\
\text { implements Project Planning SP } 2.5 \text {, } \\
\text { "Plan for knowledge and skills needed to } \\
\text { perform the project," together with the } \\
\text { organizational training process, supports } \\
\text { the implementation of GP } 2.5 \text { in full for } \\
\text { all project-related process areas. }\end{array}$ \\
\hline
\end{tabular}

\section{GP 2.6}

Manage

Configurations
Configuration Management: The configuration management process can implement GP 2.6 in full for all projectrelated process areas as well as some of the organizational process areas.

Project Planning: The part of the project planning process that implements Project Planning SP 2.6, "Plan the involvement of identified stakeholders," can implement the stakeholder identification part (first two subpractices) of GP 2.7 in full for all project-related process areas.

Project Monitoring and Control: The part of the project monitoring and control process that implements Project Monitoring and Control SP 1.5, "Monitor Stakeholder Involvement," can aid in implementing the third subpractice of GP 2.7 for all project-related process areas.

Integrated Project Management: The part of the integrated project management process that implements Integrated Project Management SP 2.1, "Manage Stakeholder Involvement," can aid in implementing the third subpractice of GP 2.7 for all project-related process areas.
How the Generic Practice Recursively Applies to its Related Process Area(s) ${ }^{14}$

GP 2.5 applied to the organizational training process area covers training for performing the organizational training activities, which addresses the skills required to manage, create, and accomplish the training.

GP 2.6 applied to the configuration management process covers change and version control for the work products produced by configuration management activities.

GP 2.7 applied to the project planning process covers the involvement of relevant stakeholders in project planning activities.

GP 2.7 applied to the project monitoring and control process covers the involvement of relevant stakeholders in project monitoring and control activities.

GP 2.7 applied to the integrated project management process covers the involvement of relevant stakeholders in integrated project management activities. 


\begin{tabular}{|c|c|c|}
\hline Generic Practice & $\begin{array}{l}\text { Roles of Process Areas in } \\
\text { Implementation of the Generic Practice }\end{array}$ & $\begin{array}{l}\text { How the Generic Practice Recursively } \\
\text { Applies to its Related Process Area(s) }\end{array}$ \\
\hline $\begin{array}{l}\text { GP } 2.8 \\
\text { Monitor and } \\
\text { Control the } \\
\text { Process }\end{array}$ & $\begin{array}{l}\text { Project Monitoring and Control: The } \\
\text { project monitoring and control process } \\
\text { can implement GP } 2.8 \text { in full for all } \\
\text { project-related process areas. } \\
\text { Measurement and Analysis: For all } \\
\text { processes, not just project-related } \\
\text { processes, the Measurement and } \\
\text { Analysis process area provides general } \\
\text { guidance about measuring, analyzing, } \\
\text { and recording information that can be } \\
\text { used in establishing measures for } \\
\text { monitoring actual performance of the } \\
\text { process. }\end{array}$ & $\begin{array}{l}\text { GP } 2.8 \text { applied to the project monitoring } \\
\text { and control process covers the } \\
\text { monitoring and controlling of the } \\
\text { project's monitor and control activities. }\end{array}$ \\
\hline $\begin{array}{l}\text { GP } 2.9 \\
\text { Objectively } \\
\text { Evaluate } \\
\text { Adherence }\end{array}$ & $\begin{array}{l}\text { Process and Product Quality } \\
\text { Assurance: The process and product } \\
\text { quality assurance process can } \\
\text { implement GP } 2.9 \text { in full for all process } \\
\text { areas (except perhaps for Process and } \\
\text { Product Quality Assurance itself). }\end{array}$ & $\begin{array}{l}\text { GP } 2.9 \text { applied to the process and } \\
\text { product quality assurance process } \\
\text { covers the objective evaluation of quality } \\
\text { assurance activities. }\end{array}$ \\
\hline $\begin{array}{l}\text { GP } 2.10 \\
\text { Review Status } \\
\text { with Higher Level } \\
\text { Management }\end{array}$ & $\begin{array}{l}\text { Project Monitoring and Control: The } \\
\text { part of the project monitoring and control } \\
\text { process that implements Project } \\
\text { Monitoring and Control SP 1.6, "Conduct } \\
\text { Progress Reviews," and SP 1.7, } \\
\text { "Conduct Milestone Reviews," supports } \\
\text { the implementation of GP } 2.10 \text { for all } \\
\text { project-related process areas, perhaps } \\
\text { in full, depending on higher level } \\
\text { management involvement in these } \\
\text { reviews. }\end{array}$ & \\
\hline $\begin{array}{l}\text { GP } 3.1 \\
\text { Establish a } \\
\text { Defined Process }\end{array}$ & $\begin{array}{l}\text { Integrated Project Management: The } \\
\text { part of the integrated project- } \\
\text { management process that implements } \\
\text { Integrated Project Management SP 1.1, } \\
\text { "Establish and maintain the project's } \\
\text { defined process," can implement GP } 3.1 \\
\text { in full for all project-related process } \\
\text { areas. } \\
\text { Organizational Process Definition: } \\
\text { For all processes, not just project- } \\
\text { related processes, the organizational } \\
\text { process definition process establishes } \\
\text { the organizational process assets } \\
\text { needed to implement GP } 3.1 \text {. }\end{array}$ & $\begin{array}{l}\text { GP } 3.1 \text { applied to the integrated project } \\
\text { management process covers } \\
\text { establishing defined processes for } \\
\text { integrated project management } \\
\text { activities. }\end{array}$ \\
\hline
\end{tabular}




\begin{tabular}{|c|c|c|}
\hline Generic Practice & $\begin{array}{l}\text { Roles of Process Areas in } \\
\text { Implementation of the Generic Practice }\end{array}$ & $\begin{array}{l}\text { How the Generic Practice Recursively } \\
\text { Applies to its Related Process Area(s) }{ }^{14}\end{array}$ \\
\hline $\begin{array}{l}\text { GP } 3.2 \\
\text { Collect } \\
\text { Improvement } \\
\text { Information }\end{array}$ & $\begin{array}{l}\text { Integrated Project Management: The } \\
\text { part of the integrated project- } \\
\text { management process that implements } \\
\text { Integrated Project Management SP 1.6, } \\
\text { "Contribute work products, measures, } \\
\text { and documented experiences to the } \\
\text { organizational process assets," can } \\
\text { implement GP } 3.2 \text { in full for all project- } \\
\text { related process areas. } \\
\text { Organizational Process Focus: The } \\
\text { part of the organizational process focus } \\
\text { process that implements Organizational } \\
\text { Process Focus SP } 2.4, \text { "Incorporate } \\
\text { process-related work products, } \\
\text { measures, and improvement information } \\
\text { derived from planning and performing } \\
\text { the process into the organizational } \\
\text { process assets," can implement GP } 3.2 \\
\text { in part or full for all process areas. } \\
\\
\text { Organizational Process Definition: } \\
\text { For all processes, the organizational } \\
\text { process definition process establishes } \\
\text { the organizational process assets } \\
\text { needed to implement GP } 3.2 \text {. }\end{array}$ & $\begin{array}{l}\text { GP } 3.2 \text { applied to the integrated project } \\
\text { management process covers collecting } \\
\text { improvement information derived from } \\
\text { planning and performing the integrated } \\
\text { project management activities. }\end{array}$ \\
\hline
\end{tabular}




\begin{tabular}{|c|c|}
\hline Generic Practice & $\begin{array}{l}\text { Roles of Process Areas in } \\
\text { Implementation of the Generic Practice }\end{array}$ \\
\hline $\begin{array}{l}\text { GP } 4.1 \\
\text { Establish } \\
\text { Quantitative } \\
\text { Objectives for } \\
\text { the Process }\end{array}$ & $\begin{array}{l}\text { Quantitative Project Management: } \\
\text { The part of the quantitative project- } \\
\text { management process that implements } \\
\text { Quantitative Project Management SP } \\
1.1 \text {, "Establish and maintain the project's } \\
\text { quality and process-performance } \\
\text { objectives," supports the implementation } \\
\text { of GP } 4.1 \text { for all project-related process } \\
\text { areas by providing objectives from which } \\
\text { the objectives for each particular } \\
\text { process can be derived. If these } \\
\text { objectives become established as part } \\
\text { of implementing subpractices } 5 \text { and } 8 \text { of } \\
\text { Quantitative Project Management SP } \\
1.1 \text {, then the quantitative project- } \\
\text { management process implements GP } \\
4.1 \text { in full. } \\
\text { Organizational Process } \\
\text { Performance:The part of the } \\
\text { organizational process performance } \\
\text { process that implements Organizational } \\
\text { Process Performance SP } 1.3 \text {, "Establish } \\
\text { and maintain quantitative objectives for } \\
\text { quality and process performance for the } \\
\text { organization," supports the } \\
\text { implementation of GP } 4.1 \text { for all process } \\
\text { areas. }\end{array}$ \\
\hline
\end{tabular}

GP 4.2

Stabilize

Subprocess

Performance
How the Generic Practice Recursively

Applies to its Related Process Area(s) ${ }^{14}$

GP 4.1 applied to the quantitative project management process covers establishing quantitative objectives for quantitative project management activities.

GP 4.1 applied to the organizational process performance process covers establishing quantitative objectives for organizational process performance activities.

GP 4.2 applied to the quantitative project management process covers the stabilization of selected subprocesses within quantitative project management activities. 


\begin{tabular}{|c|c|c|}
\hline Generic Practice & $\begin{array}{l}\text { Roles of Process Areas in } \\
\text { Implementation of the Generic Practice }\end{array}$ & $\begin{array}{l}\text { How the Generic Practice Recursively } \\
\text { Applies to its Related Process Area(s) }\end{array}$ \\
\hline $\begin{array}{l}\text { GP } 5.1 \\
\text { Ensure } \\
\text { Continuous } \\
\text { Process } \\
\text { Improvement }\end{array}$ & $\begin{array}{l}\text { Organizational Innovation and } \\
\text { Deployment: The organizational } \\
\text { innovation and deployment process can } \\
\text { implement GP } 5.1 \text { in full for all process } \\
\text { areas providing that quality and process- } \\
\text { performance objectives for the } \\
\text { organization have been defined. (The } \\
\text { latter would be the case, say, if the } \\
\text { Organizational Process Performance } \\
\text { process area has been implemented.) }\end{array}$ & $\begin{array}{l}\text { GP } 5.1 \text { applied to the organizational } \\
\text { innovation and deployment process } \\
\text { covers ensuring continuous process } \\
\text { improvement of organizational } \\
\text { innovation and deployment activities. }\end{array}$ \\
\hline $\begin{array}{l}\text { GP } 5.2 \\
\text { Correct Root } \\
\text { Causes of } \\
\text { Problems }\end{array}$ & $\begin{array}{l}\text { Causal Analysis and Resolution: The } \\
\text { causal analysis and resolution process } \\
\text { can implement GP } 5.2 \text { in full for all } \\
\text { project-related process areas. }\end{array}$ & $\begin{array}{l}\text { GP } 5.2 \text { applied to the causal analysis } \\
\text { and resolution process covers } \\
\text { identifying root causes of defects and } \\
\text { other problems in the causal analysis } \\
\text { and resolution activities. }\end{array}$ \\
\hline
\end{tabular}

Given the dependencies that generic practices have on these process areas, and given the more "holistic" view that many of these process areas provide, these process areas are often implemented early, in whole or in part, before or concurrent with implementing the associated generic practices.

There are also a few situations where the result of applying a generic practice to a particular process area would seem to make a whole process area redundant, but, in fact, it does not. It may be natural to think that applying GP 3.1, Establish a Defined Process, to the Project Planning and Project Monitoring and Control process areas gives the same effect as the first specific goal of Integrated Project Management, "The project is conducted using a defined process that is tailored from the organization's set of standard processes."

Although it is true that there is some overlap, the application of the generic practice to these two process areas provides defined processes covering project planning and project monitoring and control activities. These defined processes do not necessarily cover support activities (such as configuration management), other project-management processes (such as project planning), or the engineering processes. In contrast, the project's defined process, provided by the Integrated Project Management process area, covers all appropriate project management, engineering, and support processes. [ACQ] 
The purpose of Acquisition Management (AM) is to ensure that the supplier's performance meets contractual requirements and that the acquirer performs according to the terms of the supplier agreement.

The Acquisition Management process area involves the following:

- Maintaining ongoing communications and mutual understanding with the supplier

- Resolving issues and disputes

- Revising and closing the supplier agreements

- Accepting delivery of acquired products

- Transitioning acquired products to the project

- Managing the payment to the supplier

The legal nature of the acquirer-supplier relationship makes it imperative that the project management team is acutely aware of the legal implications of actions taken when managing any acquisition of products or services.

The supplier agreement is the basis for managing the relationship with the supplier, including resolving issues and disputes. It defines the mechanisms to allow the acquirer to oversee the supplier's activities and evolving products, and to verify compliance with supplier agreement requirements. It also provides the vehicle for mutual understanding between the acquirer and the supplier.

Deviations from the project plan may cause changes to the supplier agreement and significant changes to the supplier agreement may require the project plan to be modified. When the supplier's performance, processes, or products fail to satisfy established criteria as outlined in the supplier agreement, the acquirer may decide to apply legal remedies. 
Refer to the Project Monitoring and Control process area for more information about monitoring projects and taking corrective action.

Refer to the Solicitation and Supplier Agreement Development process area for more information about defining steps for escalation of issues.

Refer to the Decision Analysis and Resolution process area for more information about identifying and analyzing alternatives.

Refer to the Acquisition Validation process area for information about validating products.

Refer to the Acquisition Verification process area for information about verifying supplier deliverables.

Specific Goal and Practice Summary

SG 1 Manage Supplier Agreements

SP 1.1 Manage Supplier Agreement Communications

SP 1.2 Resolve Supplier Agreement Issues and Disputes

SP 1.3 Revise Supplier Agreements

SP 1.4 Close Supplier Agreements

SG 2 Satisfy Supplier Agreements

SP 2.1 Accept the Acquired Product

SP 2.2 Transition Products

SP 2.3 Manage Payments to Suppliers

Specific Practices by Goal

SG 1 Manage Supplier Agreements

Manage changes and revise the supplier agreement if necessary and resolve supplier agreement issues or disputes.

SP 1.1 Manage Supplier Agreement Communications

Manage supplier agreement communications between the acquirer and the supplier about the relationship, performance, results, and impact to the business

Refer to the Project Planning process area for more information about planning stakeholder involvement. 
This specific practice covers communications internally and externally as well as the use of such information by acquirer and supplier to support marketing and public relations. The acquirer manages the relationship with the supplier to maintain effective communication on key issues, for example, change in the acquirer's business, new supplier products and technologies, and changes in the organizational structure.

Typical Acquirer Work Products

1. Marketing and communications material

2. Correspondence between acquirer and supplier

SP 1.2 Resolve Supplier Agreement Issues and Disputes

Resolve issues and disputes associated with the supplier agreement and determine corrective actions necessary to address the issues and disputes.

This specific practice represents the escalation of unresolved issues between the acquirer and supplier through multiple phases of escalation for an issue between acquirer and supplier before possible litigation.

The acquirer collects supplier agreement related issues or disputes and tracks these issues and disputes until resolution. Issues related to the supplier's performance may be escalated from progress or milestone reviews, for example. If the supplier does not comply appropriately with the acquirer's initiation of corrective action, the acquirer escalates and handles the issue as a supplier agreement dispute.

The supplier may also escalate issues related to the agreement, especially those related to the acquirer meeting specified commitments. Each issue is tracked from identification or receipt to resolution according to the escalation process or procedure defined in the supplier agreement. The resolution may require a change to the supplier agreement. Relevant stakeholders, for example, senior managers, contract manager, governance bodies, legal consultants, project manager, suppliers, may be requested to participate in resolution of an issue to prevent the issue becoming the subject of an agreement dispute.

Typical Acquirer Work Products

1. List of escalated issues and disputed issues

2. Corrective action plan

3. Corrective action results

4. Resolution of Agreement issues and disputes (e.g., proposed supplier agreement language) 
5. Correspondence with supplier

Typical Supplier Deliverables

1. List of escalated issues and disputed issues

2. Corrective action plans for supplier issues

3. Corrective action results for supplier issues

4. Correspondence with acquirer

\section{Subpractices}

1. Gather escalated issues associated with the supplier agreement for analysis.

2. Determine and document the appropriate actions need to address the escalated issues.

Collect documentation and backup material relevant to the issue and interpret supplier agreement to compile advantages and disadvantages of various positions for resolution

3. Review escalated issues per the process or procedure in the supplier agreement and resolve if possible.

4. Classify issues not resolved through escalation as disputed issues.

5. Build negotiations team and strategy to resolve the disputed issues.

6. Conduct dispute resolution as required by the supplier agreement.

Communicate proposed dispute resolution to the supplier or analyze supplier's proposed dispute resolution.

7. Monitor escalated issues and disputes for completion.

8. Analyze results of issues and dispute resolution to determine its effectiveness.

9. Document resolution of escalated issues and disputes and communicate as needed.

\section{SP 1.3 Revise Supplier Agreements}

Revise the supplier agreement to reflect changes in conditions where appropriate. 
After award of the supplier agreement, the acquirer may find requirements that are no longer optimal or applicable based on the supplier's progress or environment changes. Examples include availability of new technology, overly burdensome documentation, and reporting requirements. Changes to supplier agreements may also occur when the supplier's processes or products fail to meet agreed to criteria and service levels.

All changes are formally documented and approved by both the acquirer and the supplier before being implemented by this specific practice. Approved change requests can include modifications to the terms and conditions of the supplier agreement, including the statement of work, pricing, and description of products, services, or results to be acquired.

Refer to the Configuration Management process area for information about tracking and controlling changes.

\section{Typical Acquirer Work Products}

1. Revised Supplier Agreement

\section{SP 1.4 Close Supplier Agreements}

\section{Close the supplier agreement after verifying completion of all} supplier requirements.

This practice addresses each supplier agreement applicable to the project or a project phase. Depending on the acquisition life cycle, the term of the supplier agreement may only be applicable to a given phase of the project. In these cases, this specific practice closes the supplier agreement(s) applicable to that phase of the project. When a supplier agreement is applicable to an entire project, this specific practice typically closes the project. Unresolved issues or disputes may be subject to litigation after supplier agreement. The terms and conditions of the supplier agreement can prescribe specific procedures for supplier agreement closure.

Early termination of a supplier agreement is a special case of supplier agreement closure, and can result from a mutual agreement of the acquirer and supplier or from the default of one of the parties. The rights and responsibilities of the acquirer and supplier in the event of an early termination are contained in the termination clause of the supplier agreement.

Typical Acquirer Work Products

1. Supplier agreement file 


\section{Subpractices}

1. Verify with stakeholders that all supplier activities and supplier deliverables specified in the agreement have been received and accepted.

The acquirer verifies, for instance, that any warranty has been completed according to the supplier agreement and that all regulatory requirements have been met. This may also include a final supplier evaluation related to the agreement.

Refer to the Acquisition Verification process area for information about verifying supplier deliverables.

2. Ensure that all records related to the supplier agreement are stored, managed, and controlled for future use.

The acquirer documents the performance of the supplier as a basis for future relationships with the supplier. Supplier performance evaluation by the acquirer is primarily carried out to confirm the competency or lack of competency of the supplier, relative to performing similar work on the project or other projects.

Refer to the Project Monitoring and Control Process area for information about performing progress and milestone reviews.

3. Communicate to appropriate stakeholders that the supplier agreement has been closed.

The acquirer, usually through its authorized supplier agreement or contract administrator, provides the supplier with formal written notice that the supplier agreement has been completed.

SG 2 Satisfy Supplier Agreements

Establish a productive and cooperative environment to meet the goals of the project.

\section{SP 2.1 Manage Payment to Supplier}

Receive, review, approve, and remit invoices provided by the supplier.

This practice handles invoices for any type of charge, for example, onetime, monthly, deliverable-based, pass-through, expenses. It handles invoice errors or disputes, changes to invoices, billing errors, and withholding disputed charges consistent with the terms and conditions of the supplier agreement. The acquirer must adhere to regulatory requirements, for example, tax deductions, in managing payments to the supplier. The acquirer must also ensure that appropriate financial controls are in place. 
The intent of this practice is to ensure that payment terms defined within the supplier agreement are met and that supplier compensation is linked to supplier progress, as defined in the supplier agreement. When accepting supplier deliverables, final payment should not be made to the supplier until it has been certified that all the supplier deliverables meet the contractual requirements and that all acceptance criteria have been satisfied. To the degree that nonperformance is encountered, exercise the contract provisions for withholding or reducing payments to the supplier.

\section{Typical Acquirer Work Products}

1. Invoices Approved for Payment

\section{Typical Supplier Deliverables}

1. Invoices

\section{Subpractices}

1. Review invoice and related supporting material.

Examples of areas of review for invoices and related support material include the
following:
- Volumes for any variable charges
- Pass through expenses
- Regulatory commitments related to payments
- Purchases made by supplier on behalf of acquirer

2. Resolve errors / manage disputes with supplier as required.

3. Process invoice for payment.

SP 2.2 Accept Acquired Product

\section{Ensure that the supplier agreement is satisfied before accepting the acquired product.}

The acquirer ensures that all acceptance criteria have been satisfied and that all discrepancies have been corrected. Requirements for formal deliverable acceptance, and how to address non-conforming deliverables, are usually defined in the supplier agreement. The acquirer should be prepared to exercise all remedies in case the supplier fails to perform.

The acquirer, usually through its authorized supplier agreement or contract administrator, provides the supplier with formal written notice that the supplier deliverables have been accepted or rejected. 
With this specific practice, an authorized representative of the acquirer assumes ownership of existing identified supplier products or deliverables tendered, or approves specific services rendered, as partial or complete performance of the supplier agreement on the part of the supplier.

\section{Typical Acquirer Work Products}

1. Stakeholder approval reports

2. Discrepancy reports

3. Product acceptance review report with approval signatures

Typical Supplier Deliverables

1. Work products as defined in the supplier agreement

\section{Subpractices}

1. Review the validation results, reports, logs, and issues for the acquired product.

Refer to the Acquisition Validation process area for more information about validating products.

2. Confirm that all customer requirements and stakeholder intentions associated with the acquired product are satisfied.

3. Review the verification results, reports, logs, and issues for the acquired product.

Refer to the Acquisition Verification process area for more information about verifying products.

4. Confirm that all contractual requirements associated with the acquired product are satisfied.

This may include confirming that the appropriate license, warranty, ownership, usage, and support or maintenance agreements are in place and that all supporting materials are received.

5. Confirm that all discrepancies have been corrected and that all acceptance criteria have been satisfied.

6. Communicate the product's readiness for transition to operations and support and also the product's status to stakeholders. 
Typically, the supplier integrates and packages the products and prepares for the transition to operations and support, including support for business user acceptance, and the acquirer oversees the supplier activities. These expectations and the acceptance criteria for transition to operations and support are included in the solicitation package and then supplier agreement.

\section{Typical Acquirer Work Products}

1. Transition readiness report

2. Transfer of ownership

3. Transition analysis report

\section{Typical Supplier Deliverables}

1. Transition plans

2. Training reports

3. Pilot results

\section{Subpractices}

1. Ensure the completion of installation of the product in the production environment.

2. Conduct pilot or initial implementation, as appropriate.

The acquirer, following appropriate reviews of the transition activities, makes the product available for use according to the plans for pilot and transition. During this pilot or initial period of production, the acquirer validates that the product is capable and ready for full operational use. During this defined transition or warranty period, for example, 30 days or 90 days, the acquirer oversees activities to make sure the product is operating as planned and identifies any corrective actions required. Although the product is in the operational environment, full responsibility for operations and support is not transitioned until this pilot period is complete and any corrective actions identified have been successfully completed. During this defined transition period, the acquirer ensures support of the product, for example, the supplier may be given responsibility to maintain support during the transition.

Ensure the viability of either dual operations or the capability to back-out the product before transitioning to the production environment

3. Transfer responsibility for operations and support. 
Responsibility for operations and support of the product is transferred by the acquirer to the operations and support organizations, which may be suppliers, only after the operations and support organization demonstrates its capability and capacity to support the product and accept the responsibilities to perform their assigned operations and support processes. The acquirer ensures the operations and support organizations understand post-transition service requirements from the supplier.

The acquirer maintains oversight responsibilities until the transition activities are complete and the transfer of responsibility for operations and support of the product has been accepted. This includes oversight of any supplier activities, based upon the supplier agreement, for the execution of the transition of the product to operations and support.

4. Analyze the results of transition activities.

After the transition is complete and the responsibility transferred to the operational and support organizations (e.g., at the end of the warranty period for a software product), the acquirer reviews and analyzes the results of the transition activities and determines whether any corrective actions must be completed before close.

The following typical reports and logs are used in the analysis by the acquirer:

- Results of transition activities including defects/quality related measures collected during pilot and warranty period

- Problem tracking reports, detailing resolution time, incident response, escalation, and root cause analysis

- Change management reports

- Operation logs to determine that sufficient information is stored to support reconstruction

- Configuration management records

- Violation of security activity reports

- Actual operations costs compared to estimates

- Actual support costs compared to estimates

5. Analyze the actual operations and support cost against the estimated costs.

Follow warranty terms and conditions to resolve problems during period following transition.

6. Ensure that storing, distributing, and using the acquired products are in compliance with the terms and conditions specified in the supplier agreement or license. 
The purpose of Acquisition Requirements Development (ARD) is to produce and analyze customer and contractual requirements.

Requirements are the basis for the selection and for the design or configuration of the acquired product. The development of requirements includes the following activities:

- Elicitation, analysis, validation, and communication of customer needs, expectations, and constraints to obtain customer requirements that constitute an understanding of what will satisfy stakeholders

- Collection and coordination of stakeholder needs

- Development of the life-cycle requirements of the product

- Establishment of the customer requirements

- Establishment of contractual requirements consistent with customer requirements to a level of detail that is sufficient to be included in the solicitation package and supplier agreement

The requirements included in the solicitation package form the basis for evaluating alternate proposals by suppliers and for further negotiations with the suppliers and communication with the customer. The contractual requirements for the supplier are baselined in the supplier agreement.

Requirements are identified and refined throughout the project life cycle. Design decisions, subsequent corrective actions, and feedback during each phase of the project's life cycle are analyzed for impact on contractual requirements.

Requirements analyses aid in understanding, defining, and selecting the requirements at all levels from competing alternatives. Analyses occur recursively at successively more detailed levels until sufficient detail is available to produce contractual requirements and to further refine these, if necessary, while the supplier builds or configures the product. 
Involvement of relevant stakeholders in both requirements development and analyses gives them visibility into the evolution of requirements. Participation continually assures the stakeholders that the requirements are being properly defined.

The Acquisition Requirements Development process area includes three specific goals. The Develop Customer Requirements specific goal addresses eliciting and defining a set of customer requirements. The Develop Contractual Requirements specific goal addresses defining a set of contractual requirements that are based on customer requirements and included in the solicitation package and supplier agreement. The specific practices of the Analyze and Validate Requirements specific goal support the development of the requirements in both the Develop Customer Requirements specific goal and the Develop Contractual Requirements specific goal. The specific practices associated with this specific goal cover analyzing and validating the requirements with respect to the acquirer's intended environment.

The processes associated with the Acquisition Requirements Development process area and those associated with the Acquisition Technical Solution process area may interact recursively with one another, for instance, to iteratively refine requirements.

Related Process Areas

Refer to the Requirements Management process area for more information about managing requirements and changes, obtaining agreement with the requirements provider, obtaining commitments with those implementing the requirements, and maintaining traceability.

Refer to the Acquisition Technical Solution process area for more information about how the outputs of the requirements development processes are used for defining technical constraints.

Refer to the Acquisition Verification process area for more information about verifying that the resulting product meets the contractual requirements.

Refer to the Acquisition Validation process area for more information about how the requirements will be validated against the stakeholder intentions. 


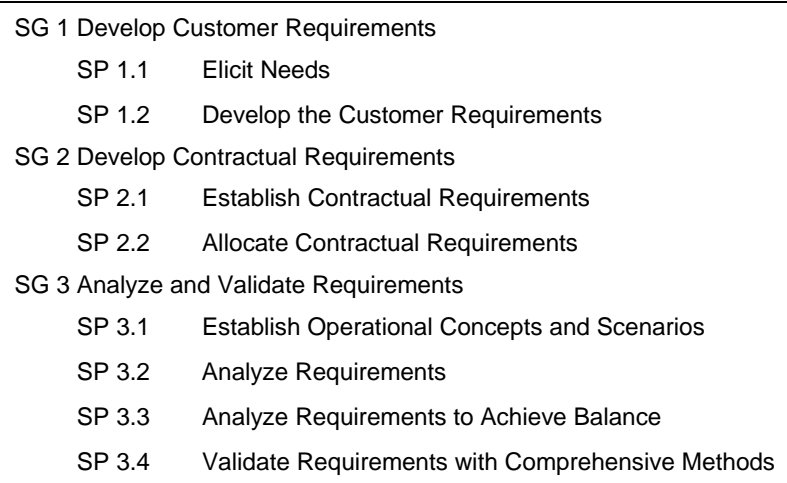

Specific Practices by Goal and translated into customer requirements.

The intentions of stakeholders (e.g., customers, end users, suppliers, supplier agreement management personnel, manufacturers, and logistics support personnel) are the basis for determining requirements. The stakeholder needs, expectations, constraints, interfaces, operational concepts, and product concepts are analyzed, harmonized, refined, and elaborated for translation into a set of customer requirements.

Frequently, the stakeholders' intentions are poorly identified or conflicting. Since the stakeholders' intensions must be clearly identified and understood throughout the project life cycle, an iterative process is used throughout the life of the project to accomplish this objective. To facilitate the required interaction, relevant stakeholders are frequently involved throughout the project life cycle to communicate their needs, expectations, constraints and help resolve conflicts. Environmental, legal, and other constraints should be considered when creating and evolving the set of requirements for acquiring products or services.

\section{SP $1.1 \quad$ Elicit Needs}

\section{Elicit stakeholder needs, expectations, constraints, and interfaces for all phases of the product life cycle.}

Eliciting goes beyond collecting requirements by proactively identifying additional requirements not explicitly provided by the stakeholders. Relevant stakeholders representing all phases of the product's life cycle in the acquirer's intended environment should include business as well as technical functions. In this way, needs for all product-related lifecycle processes are considered concurrently with the concepts for the acquired products. 
Analyses of business processes is a common source of stakeholder needs, expectations, constraints, and interfaces. Additional needs typically address the various project life-cycle activities and their impact on the product.

Examples of techniques to elicit needs for current and potential customers and other stakeholders include the following:

- Questionnaires, interviews, and operational scenarios obtained from end users

- Operational walkthroughs and end-user task analysis

- $\quad$ Prototypes and models

- Observation of existing products, environments, and workflow patterns

- Technology demonstrations

- Interim project reviews

- Brainstorming

- Quality Function Deployment

- Market surveys

- Extraction from sources such as business process documents, standards, or specifications

- Use cases

- Business case analyses

- Reverse engineering (for legacy products)

Examples of sources of requirements that might not be identified by the customer include the following:

- Government regulations

- Policies and standards

- Technology

- Legacy products or product components (for reuse)

Typical Acquirer Work Products

1. Stakeholder intentions

\section{Subpractices}

1. Engage relevant stakeholders using methods for eliciting needs, expectations, constraints, and external interfaces.

\section{SP 1.2 Develop the Customer Requirements}

Transform stakeholder needs, expectations, constraints, and interfaces into customer requirements. 
The customer typically describes requirements as capabilities expressed in broad operational terms concerned with achieving a desired effect under specified standards and regulations. The various inputs from the customer and other stakeholders must be aligned to the organization's strategy, missing information must be obtained, and conflicts must be resolved as the customer requirements are documented (e.g., customer requirements that exist as an output of another project's activities such as a previous project that delivered the initial capability).

Examples of considerations for expressing customer requirements include the following:

- Key characteristics (attributes) of the desired capability with appropriate parameters and measures

- Obstacles to overcome to achieve the capability

- Competitive gap between existing and desired capability

- Supportability of desired capability

- Level of detail of customer requirements so as not to prejudice decisions in favor of a particular means of implementation, but specific enough to evaluate alternative approaches to implement the capability

\section{Typical Acquirer Work Products}

1. Prioritized customer requirements

2. Customer constraints on the conduct of verification

3. Customer constraints on the conduct of validation

\section{Subpractices}

1. Translate the stakeholder needs, expectations, constraints, and interfaces into documented customer requirements.

2. Prioritize customer requirements

3. Define constraints for verification and validation.

Customer requirements are analyzed in conjunction with the development of the operational concept to derive more detailed and precise sets of requirements called contractual requirements to be included in the solicitation package for potential suppliers and eventually in the supplier agreement. The level of detail of contractual requirements is determined based on the acquisition strategy and project characteristics. 
Contractual requirements arise from constraints, consideration of issues implied but not explicitly stated in the customer requirements baseline, and factors introduced by the design constraints and the supplier's capabilities. The requirements are reexamined throughout the project life cycle.

The requirements are allocated to supplier deliverables. The traceability of requirements to supplier deliverables is documented.

Refer to the Maintain Bidirectional Traceability of Requirements specific practice of the Requirements Management process area for more information about maintaining bidirectional traceability.

SP 2.1 Establish Contractual Requirements

\section{Establish and maintain contractual requirements, which are based on the stakeholder requirements.}

The customer requirements may be expressed in the customer's terms and may be non-technical descriptions. The contractual requirements are the expression of these requirements in technical terms that can be used for design decisions. An example of this translation is found in the first House of Quality Functional Deployment, which maps customer desires into technical parameters. For instance, "solid sounding door" might be mapped to size, weight, fit, dampening, and resonant frequencies.

In addition to technical requirements (e.g., requirements specifying interface with other products or applications, functional requirements and their validation, and verification requirements such as product acceptance criteria), contractual requirements also cover non-technical stakeholder needs, expectations, and constraints. 
Examples of considerations for non-technical requirements include the following:

- Frequency and format of supplier reviews

- Standard measures and service levels for the technical solution

- $\quad$ Supplier reports and other communications

- Availability of support to meet levels of business process or product performance.

- Warranty of products provided by a supplier

- Logistics support that sustains both short and long-term readiness

- Minimal total life cycle cost to own and operate (i.e., minimal total ownership cost).

- Maintenance concepts that optimize readiness while drawing upon both acquirer and supplier sources

- Data management and configuration management that facilitates cost-effective product support throughout the product's use by the acquirer.

The modification of requirements due to approved requirement changes is covered by the "maintain" function of this specific practice; whereas, the administration of requirement changes is covered by the Requirements Management process area.

Refer to the Requirements Management process area for more information about managing changes to requirements.

Refer to the Solicitation and Supplier Agreement Development process area for more information about developing solicitation packages and supplier agreements.

Refer to the Acquisition Technical Solution process area for more information about design constraints.

\section{Typical Acquirer Work Products}

1. Contractual requirements

\section{Subpractices}

1. Develop functional requirements necessary for development of alternate solutions and the product by the supplier.

Functional requirements or definition of functionality can include actions, sequence, inputs, outputs, or other information that communicates the manner in which the product will be used. Functionality required may be prioritized as Critical/Must-Have, Good-to-Have, and Optional requirements.

2. Develop interface requirements of the acquired product to other products in the intended environment. 
Requirements for interfaces are defined in terms of origination, destination, stimulus, data characteristics for software, and electrical and mechanical characteristics for hardware.

3. Develop requirements for verification and validation of the product developed by the supplier.

Requirements for verification and validation typically include types and coverage of testing and review to be carried out in the supplier's and acquirer's environment. Testing requirements may include mirroring the production environment by the supplier, type of test data to be used, and simulated testing for interfaces with other products.

Review requirements may include the form of review to be used (e.g., walkthrough, prototype review) and the required participants for reviews.

4. Develop requirements and constraints in technical terms necessary for development of alternate solutions and the product developed by the supplier.

Refer to the Acquisition Technical Solution process area for defining design constraints.

Design constraints express the qualities and performance points that are critical to the success of the product in the acquirer's operational environment. They account for customer requirements in the context of multiple interoperable products. The project needs to identify any dependencies on planned or existing products. This must take project or program constraints into account (e.g., affordability and schedule constraints).

Acquirers may accelerate the development of technical requirements and design constraints by reusing shared or common constraints or requirements and their associated test cases from previous acquisitions or by leveraging the supplier's previous product developments.

5. Establish and maintain relationships between requirements for consideration during change management and requirements allocation.

Relationships between requirements can aid in evaluating the impact of changes. Expected requirements volatility is also a key factor anticipating scope changes and supporting the acquirer's selection of the appropriate acquisition type.

SP 2.2 Allocate Contractual Requirements

\section{Allocate the requirements for each supplier deliverable.}

The requirements for each supplier deliverables are documented. In some cases, this includes allocation of technical requirements to thirdparty products that must be used by the supplier (e.g., commercial off the shelf products). 


\section{Typical Acquirer Work Products}

1. Requirement allocation sheets

\section{Subpractices}

1. Allocate requirements to supplier deliverables.

2. Allocate design constraints to supplier deliverables.

3. Document relationships among allocated requirements and design constraints.

Relationships include dependencies in which a change in one requirement may affect other requirements.

4. Allocate requirements to suppliers.

In situations where multiple suppliers are involved in developing the technical solution, different products or product components may be allocated to different suppliers.

\section{SG 3 Analyze and Validate Requirements}

\section{The requirements are analyzed and validated.}

Analyses are performed to determine what impact the intended operational environment will have on the ability to satisfy the stakeholders' needs, expectations, constraints, and interfaces. Considerations, such as feasibility, mission needs, cost constraints, potential market size, and acquisition strategy, must all be taken into account, depending on the product context.

The objectives of the analyses are to determine candidate requirements for product concepts that will satisfy stakeholder needs, expectations, and constraints; and then to translate these concepts into requirements. In parallel with this activity, the parameters that will be used to evaluate the effectiveness of the product are determined based on customer input and the preliminary product concept.

Requirements are validated to increase the probability that the resulting product will perform as intended in the acquirer's environment.

SP $3.1 \quad$ Establish Operational Concepts and Scenarios

Establish and maintain operational concepts and associated scenarios. 
Operational concepts or concepts of operations give an overall description of the way in which an acquired product is intended to be used or operated, deployed, supported (including maintenance and sustainment), and disposed. For that, the acquirer takes design constraints explicitly into account. For example, the operational concept for a satellite-based communications product is quite different from one based on landlines.

In contrast, an operational scenario is a sequence of events that might occur in the use of the acquired product and that make explicit some stakeholder intentions. Typically, operational scenarios are derived from business process descriptions and operational concepts.

The operational concepts and scenarios are refined as solution decisions are made and more detailed requirements are developed. They are evolved to facilitate the validation of the technical solutions delivered by the supplier.

\section{Typical Acquirer Work Products}

1. Operational concepts

2. Operational scenarios

3. Requirements

\section{Subpractices}

1. Develop operational concepts and scenarios that include functionality, performance, maintenance, support, and disposal as appropriate.

Identify and develop concepts and scenarios, consistent with the level of detail in the stakeholder needs, expectations, and constraints, in which the proposed product is expected to operate.

2. Define the environment the product will operate in, including boundaries and constraints.

3. Review operational concepts and scenarios to refine and discover requirements.

Operational concept and scenario development is an iterative process. The reviews should be held periodically to ensure that they agree with the requirements. The review may be in the form of a walkthrough.

4. Develop a detailed operational concept, as products and product components are developed by the supplier, that defines the interaction of the product, the end user, and the environment, and that satisfies the operational, maintenance, support, and disposal needs. 


\section{Analyze requirements to ensure that they are necessary and} sufficient.

As contractual requirements are defined, their relationship to customer requirements must be understood. In light of the operational concept and scenarios, the contractual requirements are analyzed to determine whether they are necessary and sufficient to meet the customer requirements. The analyzed requirements then provide the basis for more detailed and precise requirements throughout the project life cycle.

One of the other actions is the determination of which key requirements will be used to track technical progress. For instance, the weight of a product or size of a software product may be monitored through development based on its risk.

\section{Typical Acquirer Work Products}

1. Requirements defects reports

2. Proposed requirements changes to resolve defects

3. Key requirements

4. Technical performance measures

\section{Subpractices}

1. Analyze stakeholder needs, expectations, constraints, and external interfaces to remove conflicts and to organize into related subjects.

2. Analyze requirements to determine whether they satisfy the objectives of higher level requirements.

3. Analyze requirements to ensure that they are complete, feasible, realizable, and verifiable.

4. Identify key requirements that have a strong influence on cost, schedule, functionality, risk, or performance.

5. Identify technical performance measures that will be tracked during the acquisition effort.

The total number of performance parameters should be the minimum number needed to characterize the major drivers of the product's performance. The number and specificity of performance parameters may change over time. Early in a project or program the requirements baseline should reflect broadly-defined measures of technology effectiveness or measures of performance to describe needed capabilities. As a program or project matures and requirements become better defined it allows for more detailed technical performance measures, if necessary. Data for technical performance measures is provided by the supplier as specified in the supplier agreement. 
Refer to the Measurement and Analysis process area for more information about the use of measurements.

6. Analyze operational concepts and scenarios to refine the customer needs, constraints, and interfaces and to discover new requirements.

This analysis may result in more detailed operational concepts and scenarios as well as supporting the derivation of new requirements.

SP 3.3 Analyze Requirements to Achieve Balance

Analyze requirements to balance stakeholder needs and constraints.

Stakeholder needs and constraints can address cost, schedule, performance, functionality, reusable components, maintainability, or risk.

Typical Acquirer Work Products

1. Assessment of risks related to requirements

\section{Subpractices}

1. Use proven models, simulations, and prototyping to analyze the balance of stakeholder needs and constraints.

Results of the analyses can be used to reduce the cost of the product and the risk in acquiring and using the product.

2. Perform a risk assessment on the requirements and design constraints.

Refer to the Risk Management process area for information about performing a risk assessment on customer and contractual requirements and the design constraints.

3. Examine product life-cycle concepts for impacts of requirements on risks.

SP 3.4 Validate Requirements with Comprehensive Methods Validate requirements to ensure the resulting product will perform as intended in the user's environment using multiple techniques as appropriate. 
Requirements validation is performed early in the acquisition effort to gain confidence that the requirements are capable of guiding a development that results in successful final validation. This activity should be integrated with risk management activities. Mature organizations will typically perform requirements validation in a more sophisticated way using multiple techniques and will broaden the basis of the validation to include other stakeholder needs and expectations. These organizations will typically perform analyses, simulations, or prototypes to ensure that requirements will satisfy stakeholder needs and expectations.

Examples of techniques used for requirements validation include the following:

- Analysis

- Simulations

- Prototyping

- Demonstrations

Typical Acquirer Work Products

1. Records of analysis methods and results

Typical Supplier Deliverables

1. Requirements and validation methods (e.g., prototypes and simulations)

\section{Subpractices}

1. Analyze the requirements to determine the risk that the resulting product will not perform appropriately in its intended-use environment.

2. Explore the adequacy and completeness of requirements by developing product representations (e.g., prototypes, simulations, models, scenarios, and storyboards) and by obtaining feedback about them from relevant stakeholders.

Refer to the Acquisition Validation process area for information about preparing for and performing validation on products and product components.

3. Assess the product and product components as they are developed by the supplier in the context of the validation environment to identify issues and expose unstated needs and customer requirements. 
The purpose of Acquisition Technical Solution (ATS) is to develop design constraints and to verify the technical solution of the supplier.

The acquirer provides design constraints to the supplier. The product or service are designed and implemented by the supplier consistent with the acquirer's design constraints. The Acquisition Technical Solution process area focuses on the following:

- Developing design constraints for the supplier's technical solution that potentially satisfy an appropriate set of allocated requirements.

- Verify detailed designs for the selected solutions (detailed in the context of containing all the information needed to manufacture, code, or otherwise implement the design as a product or service)

- Analyze and verify the development and implementation of the supplier's technical solution to ensure contractual requirements are met

Typically, these activities interactively support each other. Some level of design, at times fairly detailed, may be needed to select solutions. Prototypes created by the supplier may be used as a means of gaining sufficient knowledge to develop more comprehensive design constraints.

Refer to the Acquisition Requirements Development process area for more information about requirements allocations, establishing an operational concept, and interface requirements definition.

Refer to the Acquisition Verification process area for more information about conducting reviews and verifying that the product and product components meet requirements.

Refer to the Decision Analysis and Resolution process area for more information about formal evaluation. 
Refer to the Requirements Management process area for more information about managing requirements. The specific practices in the Requirements Management process area are performed interactively with those in the Acquisition Technical Solution process area.

Refer to the Organizational Innovation and Deployment process area for more information about improving the organization's technology.

Specific Goal and Practice Summary

SG 1 Develop Technical Constraints

SP 1.1 Establish a Definition of Design Constraints

SP 1.2 Verify Design with Comprehensive Methods

SG 2 Analyze and Verify Technical Solution

SP 2.1 Analyze Technical Solution

SP 2.2 Analyze Interface Descriptions for Completeness

Specific Practices by Goal

SG 1

Develop Technical Constraints

Constraints for the technical solution are developed and satisfied by the supplier's design.

SP 1.1 Establish a Definition of Design Constraints

Determine the design constraints for a technical solution.

Design constraints express the qualities and performance points that are critical to the success of the product in the acquirer's operational environment. Design constraints may include standards and design rules governing development of products and their interfaces. The criteria for interfaces are often associated with safety, security, durability, and mission-critical characteristics.

To achieve high levels of reuse and interoperability, acquirers typically establish common design constraints for products or product families that can be deployed in one or more domain. Common design constraints (also reference architectures or product line architecture) provide a proven bundling of products, applications and configurations. They provide a base for creating technical solutions that use design constraints more reliably and cost effectively. 
Example tasks for identifying common design criteria may include the following:

- Establishing the structural relations of products and rules regarding interfaces between products

- Identifying external interfaces

- Identifying common products and common interfaces

- Developing reference architectures or frameworks

- Establishing design rules and authority for making decisions

- Defining criteria for physical deployment of software to hardware

- Identifying major reuse approaches and sources including legacy and COTS products

Design criteria can be a part of the organizational process assets.

Refer to the Organizational Process Definition process area for more information about establishing and maintaining organizational process assets.

\section{Typical Acquirer Work Products}

1. Design constraints including criteria for design and product reuse

2. Guidelines for choosing COTS products

3. Alternative solution screening criteria

4. Selection criteria for final selection

\section{Subpractices}

1. Define interface criteria between the supplier's product and the acquirer's operational environment.

2. Develop criteria for the reuse of products and other existing assets like design elements, code components, etc.

Analyze implications for maintenance when using off-the-shelf or nondevelopmental items (e.g., COTS, government off the shelf, and reuse).

Examples of implications for maintenance include the following:

- the compatibility with future releases of COTS products

- Configuration management of vendor changes

- Defects in a reused or off-the-shelf product and their resolution

- Unplanned obsolescence of off-the-shelf products.

3. Establish and maintain criteria against which the supplier's design and product can be evaluated. 
An acquirer typically specifies in the supplier agreement how the supplier has to document the design.

Examples of attributes, in addition to expected performance, for which design

criteria can be established, include the following:

- Modular

- Clear

- Simple

- Maintainable

- Verifiable

- Portable

- Reliable

- Accurate

- Secure

- Scalable

- Usable

4. Identify screening criteria to select a set of alternate solutions for considerations.

5. Develop the criteria for selecting the best alternative solution.

Criteria should be included that address design issues for the life of the product, such as provisions for more easily inserting new technologies or the ability to better exploit commercial products. Examples include criteria related to open design or open architecture concepts for the alternatives being evaluated.

6. Document the design constraints.

\section{SP 1.2 Verify Design with Comprehensive Methods}

Verify design to ensure the resulting product will perform as intended in the acquirer's environment.

Design verification (or technical review or architectural evaluation) is performed throughout the project life cycle to gain confidence that the requirements are capable of guiding a development that results in a satisfactory technical solution. This activity should be integrated with risk management activities. Mature organizations will typically perform design verification in a more sophisticated way using multiple techniques and will broaden the basis of the verification to include other stakeholder needs and expectations. 
- Analysis

- Simulations

- Architectural prototyping

- Demonstrations

\section{Typical Acquirer Work Products}

1. Record of analysis methods and results

Typical Supplier Deliverables

1. Alternative solutions

2. Product architecture

3. Product-component designs

4. Technical data package

5. Interface design specifications

6. Interface control documents

7. Interface specification criteria

8. Criteria for design and product-component reuse

9. Make-or-buy analyses

10. Documented solutions, evaluations, and rationale

11. Updated Requirements Traceability Matrix

\section{Subpractices}

1. Evaluate each alternative solution/set of solutions presented by suppliers against the selection criteria.

2. Based on the evaluation of alternatives, assess the adequacy of the selection criteria and update the criteria as necessary.

3. Select the best set of alternative solutions that satisfy the established criteria.

4. Ensure that the selected design adheres to applicable design standards and criteria.

5. Ensure that the design adheres to allocated requirements.

For example, putting required COTS products into the product architecture might modify the requirements and the requirements allocation. 
6. Analyze the supplier's design to determine the risk that the resulting product will not perform appropriately in its intended-use environment.

7. Explore the adequacy and completeness of the supplier's design by reviewing product representations (e.g., prototypes, simulations, models, scenarios, and storyboards) and by obtaining feedback about them from relevant stakeholders.

Refer to the Acquisition Verification process area for information about preparing for and performing verification on supplier deliverables.

8. Assess the design as it matures in the context of the requirements to identify issues and expose unstated needs and customer requirements.

\section{SG 2}

Analyze and Verify Technical Solution

Analyze and verify the development and implementation of the technical solution by supplier.

The supplier implements the design verified by acquirer under Verify Design with Comprehensive Methods practice. The implementation by supplier includes development of product components, integration of the components, unit and integration testing of the product and development of end-user documentation.

The acquirer verifies the implementation to ensure allocated requirements have been met by the implementation and the product is ready to be brought into acquirer environment for further integration and user acceptance testing.

\section{SP 2.1 Verify Technical Solution}

\section{Verify the technical solution implementation by supplier to ensure contractual requirements continue to be met.}

The acquirer examines a product to determine if it is ready for production and if the supplier has accomplished adequate production planning. The verification also examines risk; it determines if production or production preparations incur unacceptable risks that might breach objectives of schedule, performance, cost, or other established criteria. The acquirer evaluates the full, production-configured product to determine if it correctly and completely implements all contractual requirements. The acquirer also determines whether the traceability of final contractual requirements to the final production-configured product is maintained. 
A successful verification of the technical solution is predicated on the acquirer's determination that the requirements are fully met in the final production configuration, and that production capability forms a satisfactory basis for proceeding into pilots or full-rate production.

Examples of success criteria for the verification of the supplier's technical solution

include the following:

- Established and documented product baseline that enables hardware fabrication and software coding to proceed with proper configuration management

- Adequate production processes and measures are in place for the project to succeed

- Risks are managed effectively

- The detailed design is producible within the production budget

The acquirer convenes verifications of the technical solution with suppliers and subcontractors, as applicable. Verifications are conducted in an iterative fashion, concurrently with other technical reviews, such as design reviews.

Examples of considerations for follow-on verifications of technical solutions include the following:

- Changes during the production stage of the project, in either materials or manufacturing processes, occur

- Production start-up or re-start occurs after a significant shutdown period

- Production start-up with a new supplier

- Relocation of a manufacturing site

Typical Acquirer Work Products

1. Record of verification methods and results

Typical Supplier Deliverables

1. Product components

2. System Documentation

3. Supplier unit and integration test plans

4. Unit and Integration test results

5. Updated Requirements Traceability Matrix

\section{Subpractices}

1. Ensure that the implementation adheres to applicable standards and criteria.

2. Ensure that the implementation adheres to allocated requirements. 
3. Verify that the implementation has been sufficiently tested by the supplier.

4. Verify that the issues identified during testing have been resolved appropriately, with product revisions, if necessary.

5. Ensure sufficient end user documentation has been developed and is in alignment with the tested implementation.

SP 2.2 Analyze Interface Descriptions for Completeness

Analyze the product interface descriptions to ensure they are complete and in alignment with the intended environment.

Examples criteria for interfaces that typically are the focus of the acquirer's analyses

include the following:

- The interface spans organizational boundaries.

- The interface is mission critical.

- The interface is difficult or complex to manage.

- Capability, interoperability, or efficiency issues are associated with the interface.

- The interface impacts multiple acquisition project or programs.

Typical Acquirer Work Products

1. Record of analysis methods and results

Typical Supplier Deliverables

1. Interface description documents

\section{Subpractices}

1. Ensure that the interface description adheres to applicable standards, criteria, and required interface requirements between the supplier's product and acquirer's intended environment.

2. Ensure that the interface description adheres to allocated requirements.

3. Verify that the interfaces have been sufficiently tested by the supplier

4. Verify that the issues identified during testing have been resolved appropriately, with product revisions, if necessary. 
The purpose of Acquisition Validation (AVAL) is to demonstrate that an acquired product or service fulfills its intended use when placed in its intended environment.

Validation demonstrates that the acquired product or service, as provided, will fulfill its intended use. In other words, validation ensures that the acquired product or service meet the stakeholders' intensions and customer requirements.

Validation activities are performed early and incrementally throughout the project lifecycle. They can be applied to all aspects of the product in any of its intended environments, such as operation, training, manufacturing, maintenance, and support services. The methods employed to accomplish validation can be applied to acquirer work products such as customer requirements and supplier deliverables, for example, prototypes developed by the supplier as well as to the acquired product and service. The acquirer work products and supplier deliverables should be selected on the basis of which are the best predictors of how well the acquired product or service will satisfy stakeholder intentions.

Whenever possible, validation should be accomplished using the product operating in its intended environment. The entire environment can be used or only part of it. The validation environment therefore needs to represent the intended environment for the product or service as well as represent the intended environment suitable for validation activities with acquirer work products or supplier deliverables.

When validation issues are identified, they are referred to the processes associated with the Acquisition Requirements Development or Project Monitoring and Control process areas for resolution.

The specific practices of this process area build on each other in the following way:

- The Select Products for Validation specific practice enables the identification of the product or product component to be validated and the methods to be used to perform the validation. 
- The Establish the Validation Environment specific practice enables the determination of the environment that will be used to carry out the validation.

- The Establish Validation Procedures and Criteria specific practice enables the development of validation procedures and criteria that are aligned with the characteristics of selected products, customer constraints on validation, methods, and the validation environment.

- The Perform Validation specific practice enables the performance of validation according to the methods, procedures, and criteria.

Refer to the Acquisition Requirements Development process area for more information about requirements validation.

Specific Goal and Practice Summary

SG 1 Prepare for Validation

SP 1.1 Select Products for Validation

SP 1.2 Establish the Validation Environment

SP 1.3 Establish Validation Procedures and Criteria

SG 2 Validate Products or Services

SP 2.1 Perform Validation

SP 2.2 Analyze Validation Results

Specific Practices by Goal

SG 1

Prepare for Validation

Preparation for validation is conducted.

Preparation activities include selecting products and product components for validation and establishing and maintaining the validation environment, procedures, and criteria. The items selected for validation may include only the acquired product or it may include appropriate levels of the product components that are used by the supplier to build the product. Any product or product component may be subject to validation, including replacement, maintenance, and training products, to name a few.

The environment required to validate the product or product component is prepared. The environment may be purchased or may be specified, designed, and built. The environments used for verification may be considered in collaboration with the validation environment to reduce cost and improve efficiency or productivity. 


\section{SP 1.1 Select Products for Validation}

\section{Select products or services to be validated and the validation methods that will be used for each.}

Products or services are selected for validation on the basis of their relationship to stakeholder intensions and customer requirements. For each product or service, the scope of the validation (e.g., operational behavior, maintenance, training, and user interface) should be determined.

Examples of products and product components that can be validated include the following:

- Customer requirements and design constraints

- Acquired product and product components (e.g., system, hardware units, software, service documentation)

- User manuals

- Training materials

- Process documentation

Validation methods should be selected early in the life of the project so that they are clearly understood and agreed to by the relevant stakeholders.

The validation methods address the development, maintenance, support, and training for the product or product component as appropriate.

Examples of validation methods include the following:

- Discussions with the users, perhaps in the context of a formal review

- Prototype demonstrations

- Functional demonstrations (e.g., system, hardware units, software, service documentation, user interfaces)

- Pilots of training materials

- Acceptance test of products and product components by end users and other relevant stakeholders

- In the supplier agreement, expectations of suppliers for participation in validation of product and product components are captured.

Typical expectations built into the supplier agreement include the following:

- List of acquired products that need validation by the acquirer before formal acceptance 
- List of products that must be validated with customer, users, or other stakeholders by the supplier and applicable validation standards, procedures, methods, tools and criteria, if any.

- Measurements to be collected and provided by the supplier with regard to validation activities

\section{Typical Acquirer Work Products}

1. Lists of products or services selected for validation

2. Validation methods for each product or service

3. Requirements for performing validation for each product or service

4. Validation constraints for each product or service

\section{Subpractices}

1. Identify the key principles, features, and phases for product or service validation throughout the life of the project.

2. Determine which customer requirements are to be validated.

The product or product component must be maintainable and supportable in its intended environment. This specific practice also addresses the actual maintenance, training, and support services that may be delivered along with the product.

3. Select the product or service to be validated.

4. Select the evaluation methods for product or service validation.

5. Review the validation selection, constraints, and methods with relevant stakeholders.

\section{SP 1.2 Establish the Validation Environment}

\section{Establish and maintain the environment needed to support} validation.

The requirements for the validation environment are driven by the product or service selected, by the type of the work products (e.g., design, prototype, final version), and by the methods of validation. These may yield requirements for the purchase or development of equipment, software, or other resources. The validation environment may include the reuse of existing resources. In this case, arrangements for the use of these resources must be made. Examples of the type of elements in a validation environment include the following:

- Test tools interfaced with the product being validated (e.g., scope, electronic devices, probes)

- Temporary embedded test software

- Recording tools for dump or further analysis and replay 
- Simulated subsystems or components (by software, electronics, or mechanics)

- Simulated interfaced systems (e.g., a dummy warship for testing a naval radar)

- Real interfaced systems (e.g., aircraft for testing a radar with trajectory tracking facilities)

- Facilities and customer-supplied products

- The skilled people to operate or use all the preceding elements

- Dedicated computing or network test environment (e.g., pseudooperational telecommunications-network testbed or facility with actual trunks, switches, and systems established for realistic integration and validation trials)

Early selection of the products or service to be validated, the work products to be used in the validation, and the validation methods assure that the validation environment will be available when necessary.

The validation environment should be carefully controlled to provide for replication, analysis of results, and revalidation of problem areas.

Typical Acquirer Work Products

1. Validation environment

Typical Supplier Deliverable

1. Validation environment

\section{Subpractices}

1. Identify validation environment requirements.

2. Identify customer-supplied products.

3. Identify reuse items.

4. Identify validation equipment and tools.

5. Identify validation resources that are available for reuse and modification.

6. Plan the availability of resources in detail.

\section{SP 1.3 Establish Validation Procedures and Criteria}

\section{Establish and maintain procedures and criteria for validation.}

Validation procedures and criteria are defined to ensure that the product or product component will fulfill its intended use when placed in its intended environment. The validation procedures and criteria include validation of maintenance, training, and support services. 
They also address validation of requirements and the acquired product or service throughout the project life cycle. Typically, formal user acceptance testing procedures and criteria are established to ensure the delivered product or service meets stakeholder intentions before it is deployed in the intended environment.

The validation procedures and criteria applicable to the supplier are typically referenced in the solicitation package and supplier agreement.

Examples of sources for validation criteria include the following:

- Business process descriptions

- Customer requirements

- Acceptance criteria

- Standards

\section{Typical Acquirer Work Products}

1. Validation procedures

2. Validation criteria

3. Test and evaluation procedures for maintenance, training, and support

\section{Subpractices}

1. Review the customer requirements to ensure that issues affecting validation of the acquired product or service are identified and resolved.

2. Document the environment, operational scenario, procedures, inputs, outputs, and criteria for the validation of the acquired product or service.

3. Assess the product or service as it matures in the context of the validation environment to identify validation issues. use in their intended environment.

The validation methods, procedures, and criteria are used to validate the selected products and product components and any associated maintenance, training, and support services using the appropriate validation environment. Validation activities are performed throughout the project lifecycle.

SP 2.1 Perform Validation

Perform validation on the selected products or services. 
To be acceptable to stakeholders, a product or service must perform as expected in its intended environment.

Validation activities are performed and the resulting data are collected according to the established methods, procedures, and criteria.

The as-run validation procedures should be documented and the deviations occurring during the execution should be noted, as appropriate.

\section{Typical Acquirer Work Products}

1. Validation reports

2. Validation results

3. Validation cross-reference matrix

4. As-run procedures log

5. Operational demonstrations

\section{SP 2.2 Analyze Validation Results}

\section{Analyze the results of the validation activities.}

The data resulting from validation tests, inspections, demonstrations, or evaluations are analyzed against the defined validation criteria. Analysis reports indicate whether the stakeholders' intentions were met; in the case of deficiencies, these reports document the degree of success or failure and categorize probable cause of failure. The collected test, inspection, or review results are compared with established acceptance criteria to determine whether to proceed or to address requirements or design issues in the requirements development or technical solution processes.

Analysis reports or as-run validation documentation may also indicate that bad test results are due to a validation procedure problem or a validation environment problem.

\section{Typical Acquirer Work Products}

1. Validation deficiency reports

2. Validation issues

3. Procedure change request

\section{Subpractices}

1. Compare actual results to expected results. 
2. Based on the established validation criteria, identify products and product components that do not perform suitably in their intended operating environments, or identify problems with the methods, criteria, and/or environment.

3. Analyze the validation data for defects.

4. Record the results of the analysis and identify issues.

5. Use validation results to compare actual measurements and performance to intended use or operational need.

6. Identify, document, and track action items to closure for any work products that do not pass their validation procedures and criteria.

Refer to the Project Monitoring and Control process area for more information about tracking action items. 
The purpose of Acquisition Verification (AVER) is to ensure that selected work products meet their contractual requirements.

Acquisition verification addresses whether the acquired product, intermediate acquirer work products, and supplier deliverables properly reflects the contractual requirements.

The Acquisition Verification process area involves the following: verification preparation, verification performance, and identification of corrective action.

Verification is inherently an incremental process because it occurs throughout the acquisition of the product or service, beginning with verification of the requirements and plans, progressing through the verification of the evolving work products such as design and test results, and culminating in the verification of the completed product.

The specific practices of this process area build on each other in the following way:

- The Select Work Products for Verification specific practice enables the identification of the work products to be verified, the methods to be used to perform the verification, and the documented requirements to be satisfied by each selected work product.

- The Establish the Verification Environment specific practice enables the determination of the environment that will be used to carry out the verification.

- The Establish Verification Procedures and Criteria specific practice then enables the development of verification procedures and criteria that are aligned with the selected work products, requirements, methods, and characteristics of the verification environment.

- The Perform Verification specific practice conducts the verification according to the available methods, procedures, and criteria. 
Peer reviews are an important method for verification of work products and are a proven mechanism for effective defect removal. An important corollary is to develop a better understanding of the work products and the processes that produced them so that defects can be prevented and process improvement opportunities can be identified.

Peer reviews involve a methodical examination of work products by the producers' peers to identify defects and other changes that are needed.

Examples of peer review methods include the following:

- Inspections

- Structured walkthroughs

Refer to the Acquisition Validation process area for more information about confirming that a product or product component fulfills its intended use when placed in its intended environment.

Refer to the Acquisition Requirements Development process area for more information about the generation and development of customer and contractual requirements.

Refer to the Requirements Management process area for more information about managing requirements.

Specific Goal and Practice Summary

SG 1 Prepare for Verification

SP 1.1 Select Work Products for Verification

SP 1.2 Establish the Verification Environment

SP 1.3 Establish Verification Procedures and Criteria

SG 2 Verify Selected Work Products

SP 2.1 Perform Verification

SP 2.2 Analyze Verification Results and Identify Corrective

Action

Specific Practices by Goal

SG 1 Prepare for Verification Preparation for verification is conducted.

Up-front preparation is necessary to ensure that verification provisions are embedded in the contractual requirements, constraints, plans, and schedules. Verification includes selection, inspection, testing, analysis, and demonstration of acquirer work products and supplier deliverables. 
Methods of verification include, but are not limited to, inspections, peer reviews, audits, walkthroughs, analyses, simulations, testing, and demonstrations.

Preparation also entails the definition of support tools, test equipment and software, simulations, prototypes, and facilities.

SP 1.1 Select Work Products for Verification

Select the work products to be verified and the verification methods that will be used for each.

Acquirer work products are selected based on their contribution to meeting project objectives and requirements, and to addressing project risks.

The acquirer selects supplier deliverables for which the supplier must provide verification records. The required methods and criteria for these work products are described in the supplier agreement.

Verification can be performed by the project, as contrasted to Product and Process Quality Assurance, which is performed by an individual or group independent of the project.

Typical acquirer verification activities include review of the solicitation package, supplier agreements and plans, requirements documents, and design constraints developed by the acquirer.

Selection of the verification methods typically begins with involvement in the definition of contractual requirements to ensure that these requirements are verifiable. Re-verification should be addressed by the verification methods to ensure that rework performed on work products does not cause unintended defects. Suppliers should be involved in this selection to ensure that the project's methods are appropriate for the supplier's environment.

\section{Typical Acquirer Work Products}

1. Lists of work products selected for verification

2. Verification methods for each selected work product

Typical Supplier Deliverables

1. List of supplier deliverables

\section{Subpractices}

1. Identify acquirer work products for verification.

2. Identify the requirements to be satisfied by each selected work product. 
Refer to the Maintain Bidirectional Traceability of Requirements specific practice in the Requirements Management process area to help identify the requirements for each work product.

3. Identify the verification methods that are available for use.

4. Define the verification methods to be used for each selected work product.

5. Include verification activities and methods to be used in the project plan.

Refer to the Project Planning process area for information about coordinating with project planning.

6. Establish in the supplier agreement expectations of supplier for verification of supplier deliverables.

Typical expectations for verification addressed in or referenced by the supplier agreement include the following:

- List of deliverables and other work products that must be verified by the supplier

- Applicable standards, procedures, methods, tools

- Criteria for verification of supplier work products, if any

- Measurements to be collected and provided by the supplier with regard to verification activities

- Reviews of supplier verification results and corrective actions with the acquirer

SP 1.2 Establish the Verification Environment

\section{Establish and maintain the environment needed to support} verification.

An environment must be established to enable verification to take place. The type of environment required will depend on the work products selected for verification and the verification methods used. A peer review may require little more than a package of materials, reviewers, and a room. A product test may require simulators, emulators, scenario generators, data reduction tools, environmental controls, and interfaces with other systems.

The verification environment may be acquired, developed, reused, modified, or a combination of these, depending on the needs of the project.

\section{Typical Acquirer Work Products}

1. Verification environment

\section{Subpractices}

1. Identify verification environment requirements. 
2. Identify verification resources that are available for reuse and modification.

3. Identify verification equipment and tools.

4. Acquire verification support equipment and an environment, such as test equipment and software.

\section{SP 1.3 Establish Verification Procedures and Criteria}

\section{Establish and maintain verification procedures and criteria for the selected work products.}

Verification criteria are defined to ensure that the work products meet their requirements.

Examples of sources for verification criteria include the following:

- Product and product-component requirements

- Standards

- Organizational policies

- Test type

- Test parameters

- Parameters for tradeoff between quality and cost of testing

- Type of work products

- Suppliers

The verification procedures and criteria are typically included in the solicitation package and supplier agreement.

Typical Acquirer Work Products

1. Verification procedures

2. Verification criteria

Subpractices

1. Generate the set of comprehensive, integrated verification procedures for work products and any commercial off-the-shelf products, as necessary.

2. Develop and refine the verification criteria when necessary.

3. Identify the expected results, any tolerances allowed in observation, and other criteria for satisfying the requirements.

4. Identify any equipment and environmental components needed to support verification. 
5. Establish in the supplier agreement the verification methods such as acceptance criteria for supplier deliverables and other work products.

Refer to the Measurement and Analysis process area for more information about the use of measurements.

6. Analyze operational concepts and scenarios to refine the customer needs, constraints, and interfaces and to discover new requirements.

These criteria may be defined by the acquirer for critical supplier work products only, as identified under the Select Work Products For Verification practice.

The peer review is an important and effective engineering method implemented via inspections, structured walkthroughs, or a number of other collegial review methods.

SG 2 Verify Selected Work Products

Selected work products are verified against their contractual requirements.

The verification methods, procedures, and criteria are used to verify the selected work products and any associated maintenance, training, and support services using the appropriate verification environment. Verification activities should be performed throughout the project lifecycle.

SP 2.1 Perform Verification

\section{Perform verification on the selected work products.}

Verifying acquired products and work products incrementally promotes early detection of problems and can result in the early removal of defects. The results of verification save considerable cost of fault isolation and rework associated with troubleshooting problems.

Typical Acquirer Work Products

1. Verification results

2. Verification reports

3. Demonstrations

4. As-run procedures log

Typical Supplier Deliverables

1. Verification results

2. Verification reports 


\section{Subpractices}

1. Perform verification of selected work products against their requirements.

2. Record the results of verification activities.

3. Identify action items resulting from verification of work products.

4. Document the "as-run" verification method and the deviations from the available methods and procedures discovered during its performance.

5. Review critical verification results and data for verifications conducted by the supplier.

SP 2.2 Analyze Verification Results

\section{Analyze the results of all verification activities.}

Actual results must be compared to established verification criteria to determine acceptability.

The results of the analysis are recorded as evidence that verification was conducted.

For each work product, all available verification results are incrementally analyzed and corrective actions are initiated to ensure that the documented requirements have been met for both acquirer and supplier. Corrective actions are typically integrated into project monitoring activities. Since a peer review is one of several verification methods, peer review data should be included in this analysis activity to ensure that the verification results are analyzed sufficiently. Analysis reports or "as-run" method documentation may also indicate that bad verification results are due to method problems, criteria problems, or a verification environment problem.

Refer to the Project Monitoring and Control process area for information on corrective actions.

\section{Typical Acquirer Work Products}

1. Analysis report (e.g., statistics on performances, causal analysis of nonconformances, comparison of the behavior between the real product and models, and trends)

2. Trouble reports

3. Change requests for the verification methods, criteria, and environment

\section{Subpractices}

1. Compare actual results to expected results. 
2. Based on the established verification criteria, identify products that have not met their requirements or identify problems with the methods, procedures, criteria, and verification environment

3. Analyze the verification data on defects.

4. Record all results of the analysis in a report.

5. Use verification results to compare actual measurements and performance to technical performance parameters.

6. Provide information on how defects can be resolved (including verification methods, criteria, and verification environment) and formalize it in a plan. 
The purpose of Causal Analysis and Resolution (CAR) is to identify causes of defects and other problems and take action to prevent them from occurring in the future.

The Causal Analysis and Resolution process area involves the following:

- Identifying and analyzing causes of defects and other problems

- Taking specific actions to remove the causes and prevent the occurrence of those types of defects and problems in the future

Causal analysis and resolution improves quality and productivity by preventing the introduction of defects into a product. Reliance on detecting defects after they have been introduced is not cost effective. It is more effective to prevent defects from being introduced by integrating causal analysis and resolution activities into each phase of the project.

Since defects and problems may have been previously encountered on other projects or in earlier phases or tasks of the current project, causal analysis and resolution activities are a mechanism for communicating lessons learned among projects.

The types of defects and other problems encountered are analyzed to identify any trends. Based on an understanding of the defined process and how it is implemented, the root causes of the defects and the future implications of the defects are determined.

Causal analysis may also be performed on problems unrelated to defects. For example, causal analysis may be used to improve coordination and cycle time with one supplier or multiple suppliers. [ACQ]

Sometimes it may be impractical to perform causal analysis on all defects. In these cases, tradeoffs are made between estimated investments and estimated returns in quality, productivity, and cycle time, and defect targets are selected. 
A measurement process should already be in place. The defined measures can be used, though in some instances new measures may be needed to analyze the effects of the process change.

Refer to the Measurement and Analysis process area for more information about establishing objectives for measurement and analysis, specifying the measures and analyses to be performed, obtaining and analyzing measures, and reporting results.

Causal Analysis and Resolution activities provide a mechanism for projects to evaluate their processes at the local level and look for improvements that can be implemented.

Causal Analysis and Resolution activities also include the evaluation of supplier's processes that interface with the acquirer's processes, as appropriate. Root causes may cause the supplier to improve its processes to more effectively execute in the context of the project or it might cause the acquirer to improve its supplier interfaces. [AcQ]

When improvements are judged to be effective, the information is extended to the organizational level.

Refer to the Organizational Innovation and Deployment process area for more information about improving organizational level processes through proposed improvements and action proposals.

The informative material in this process area is written with the assumption that the specific practices are applied to a quantitatively managed process. The specific practices of this process area may be applicable, but with reduced value, if the assumption is not met.

See the definitions of "stable process" and "common cause of process variation" in the glossary.

Related Process Areas

Refer to the Quantitative Project Management process area for more information about the analysis of process performance and the creation of process capability measures for selected project processes.

Refer to the Organizational Innovation and Deployment process area for more information about the selection and deployment of improvements to organizational processes and technologies.

Refer to the Measurement and Analysis process area for more information about establishing objectives for measurement and analysis, specifying the measures and analyses to be performed, obtaining and analyzing measures, and reporting results. 


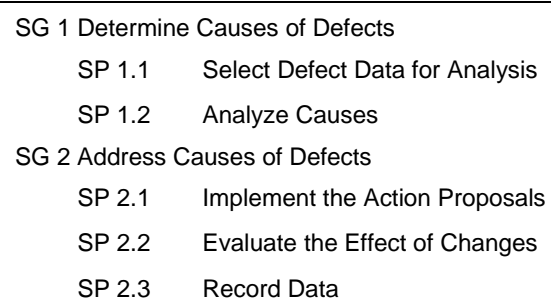

Specific Practices by Goal

A root cause is a source of a defect such that if it is removed, the defect is decreased or removed.

\section{SP 1.1 Select Defect Data for Analysis}

\section{Select the defects and other problems for analysis.}

Typical Acquirer Work Products

1. Defect and problem data selected for further analysis

\section{Subpractices}

1. Gather relevant defect or problem data.

Examples of relevant defect data may include the following: $\left.{ }^{A} \mathrm{ACQ}\right]$

- Defects reported by the customer

- Defects reported by end user

- Defects reported by the supplier

Examples of relevant problem data may include the following: [ACQ]

- Project-management problem reports requiring corrective action

- Process capability problems

- Process duration measurements

- Earned value measurements by process (e.g., cost performance index)

- Resource throughput, utilization, or response time measurements

Refer to the Quantitative Project Management process area for more information about statistical management.

2. Determine which defects and other problems will be analyzed further. 
When determining which defects to analyze further, consider the impact of the defects, the frequency of occurrence, the similarity between defects, the cost of analysis, the time and resources needed, the safety considerations, etc. [ACO]

Examples of methods for selecting defects and other problems include the

following: [ACQ]

- Pareto analysis

- Histograms

- Process capability analysis

\section{SP 1.2 Analyze Causes}

\section{Perform causal analysis of selected defects and other problems} and propose actions to address them.

The purpose of this analysis is to develop solutions to the identified problems by analyzing the relevant data and producing action proposals for implementation.

\section{Typical Acquirer Work Products}

1. Action proposal

2. Root cause analysis results [ACQ]

Typical Supplier Deliverables

1. Root cause analysis results [ACQ]

2. Recommended action proposals [AcQ]

\section{Subpractices}

1. Conduct causal analysis with the people who are responsible for performing the task.

Causal analysis is performed with those people who have an understanding of the selected defect or problem under study, typically in meetings. The people who have the best understanding of the selected defect are typically those responsible for performing the task.

Examples of when to perform causal analysis include the following: [AcQ]

- When a stable process does not meet its specified quality and processperformance objectives

- During the task, if and when problems warrant additional meetings

- When a work product exhibits an unexpected deviation from its requirements 
Refer to the Quantitative Project Management process area for more information about achieving the project's quality and processperformance objectives.

2. Analyze selected defects and other problems to determine their root causes.

Depending on the type and number of defects, it may make sense to first group the defects before identifying their root causes.

Examples of methods to determine root causes include the following: [ACQ]

- Cause-and-effect (fishbone) diagrams

- Check sheets

3. Group the selected defects and other problems based on their root causes.

Examples of cause groups, or categories, include the following: [ACQ]

- Inadequate training

- Breakdown of communications

- Not accounting for all details of the task

- Making mistakes in manual procedures (e.g., typing)

- Process deficiency

- Incomplete, ambiguous, or unclear contractual requirements

- Ineffective management of changes to the supplier agreement

4. Propose and document actions that need to be taken to prevent the future occurrence of similar defects or other problems.

Examples of proposed actions include changes to the following: [ACQ]

- The process in question

- Training

- Tools

- Methods

- Communications

- Work products 
Examples of specific actions include the following: $[\mathrm{ACQ}]$

- Providing training in common problems and techniques for preventing them

- Changing a process so that error-prone steps do not occur

- Automating all or part of a process

- Reordering process activities

- Adding process steps to prevent defects, such as task kickoff meetings to review common defects and actions to prevent them

An action proposal usually documents the following: $[A c Q]$

- Originator of the action proposal

- Description of the problem

- Description of the defect cause

- Defect cause category

- Phase when the problem was introduced

- Phase when the defect was identified

- Description of the action proposal

- Action proposal category

Root causes of defects and other problems are systematically addressed to prevent their future occurrence.

Projects operating according to a well-defined process will systematically analyze the operation where problems still occur and implement process changes to eliminate root causes of selected problems.

\section{SP 2.1 Implement the Action Proposals}

Implement the selected action proposals that were developed in causal analysis.

Action proposals describe the tasks necessary to remove the root causes of the analyzed defects or problems and avoid their reoccurrence.

Only changes that prove to be of value should be considered for broad implementation.

\section{Typical Acquirer Work Products}

1. Action proposals selected for implementation

2. Improvement proposals 


\section{Typical Supplier Deliverables}

1. Improvement proposals

\section{Subpractices}

1. Analyze the action proposals and determine their priorities.

Criteria for prioritizing action proposals include the following: $[A C Q]$

- Implications of not addressing the defects

- Cost to implement process improvements to prevent the defects

- Expected impact on quality

2. Select the action proposals that will be implemented.

3. Create action items for implementing the action proposals.

Examples of information provided in an action item include the following: [AcQ]

- Person responsible for implementing it

- Description of the areas affected by it

- People who are to be kept informed of its status

- Next date that status will be reviewed

- Rationale for key decisions

- Description of implementation actions

- Time and cost for identifying the defect and correcting it

- Estimated cost of not fixing the problem

To implement the action proposals, the following tasks must be done: [ACQ]

- Make assignments

- Coordinate the persons doing the work

- Review the results

- Track the action items to closure

Experiments may be conducted for particularly complex changes.

Examples of experiments include the following: [ACQ]

- Using a temporarily modified process

- Using a new tool

Action items may be assigned to members of the causal analysis team, members of the project team, or other members of the organization. [ACQ]

4. Identify and remove similar defects that may exist in other processes and work products. 
5. Identify and document improvement proposals for the organization's set of standard processes.

Refer to the Organizational Innovation and Deployment process area for more information about the selection and deployment of improvement proposals for the organization's set of standard processes.

\section{SP 2.2 Evaluate the Effect of Changes}

\section{Evaluate the effect of changes on process performance.}

Refer to the Quantitative Project Management process area for more information about analyzing process performance and creating process capability measures for selected processes.

Once the changed process is deployed across the project, the effect of the changes must be checked to gather evidence that the process change has corrected the problem and improved performance.

\section{Typical Acquirer Work Products}

1. Measures of performance and performance change

\section{Typical Supplier Deliverables}

1. Base and derived supplier measurement data sets [ACQ]

\section{Subpractices}

1. Measure the change in the performance of the project's defined process as appropriate.

This subpractice determines whether the selected change has positively influenced the process performance and by how much. [AcO]

2. Measure the capability of the project's defined process as appropriate.

This subpractice determines whether the selected change has positively influenced the ability of the process to meet its quality and process-performance objectives, as determined by relevant stakeholders. [AcO]

An example of a change in the capability of the project's defined change management process would be a change in the ability of the process to stay within its process-specification boundaries. This can be statistically measured by calculating the range of time taken for processing a change request before and after the improvement has been made. [Aco] 
Adapting CMMI for Acquisition Organizations: A Preliminary Report

\section{SP 2.3 Record Data}

Record causal analysis and resolution data for use across the project and organization.

Data are recorded so that other projects and organizations can make appropriate process changes and achieve similar results.

Record the following:

- Data on defects and other problems that were analyzed

- Rationale for decisions

- Action proposals from causal analysis meetings

- Action items resulting from action proposals

- Cost of the analysis and resolution activities

- Measures of changes to the performance of the defined process resulting from resolutions

Typical Acquirer Work Products

1. Causal analysis and resolution records 
The purpose of Configuration Management (CM) is to establish and maintain the integrity of work products using configuration identification, configuration control, configuration status accounting, and configuration audits.

The Configuration Management process area involves the following:

- Identifying the configuration of selected work products that compose the baselines at given points in time

- Controlling changes to configuration items

- Building or providing specifications to build work products from the configuration management system

- Maintaining the integrity of baselines

- Providing accurate status and current configuration data to developers, end users, and customers

The work products placed under configuration management include the products that are delivered to the customer, designated internal work products, acquired products, tools, and other items that are used in creating and describing these work products. (See the definition of "configuration management" in the glossary.)

Acquired products may need to be placed under configuration management by both the supplier and the project. Provisions for conducting configuration management should be established in supplier agreements. Methods to ensure that the data is complete and consistent should be established and maintained.

Planning for managing configuration items, including during transition to operations and support, is addressed as part of project planning to avoid unexpected costs to procure, reformat, and deliver configuration items from the supplier. Include plans for managing configuration items within the project teams and the infrastructure required to manage configuration items between the acquirer, supplier, operational users, and other relevant stakeholders. [ACQ] 
The approach for configuration management depends on acquisition specific factors such as acquisition approach, number of suppliers, design responsibility, support concept, and associated costs and risks. In any case, configuration management involves interaction between acquirer and supplier. With regard to the technical solution, the acquirer maintains configuration control of the contractual requirements and the supplier performs configuration management for the technical solution (e.g., establish and maintain product baseline). As such, the acquirer retains the authority and responsibility for approving any design changes that impact the product's ability to meet contractual requirements. The supplier manages other design changes. The acquirer maintains the right to access configuration data at any level required to implement planned or potential design changes and support options. Configuration management of legacy systems should be addressed on a case-by-case basis as design changes are contemplated. [ACQ]

Examples of work products that may be placed under configuration management

include the following: ${ }_{A C Q]}$

- Plans

- Process descriptions

- Requirements

- Acquisition strategy

- Solicitation package

- Supplier agreement

- Supplier deliverables

Configuration management of work products may be performed at several levels of granularity. Configuration items can be decomposed into configuration components and configuration units. Only the term "configuration item" is used in this process area. Therefore, in these practices, "configuration item" may be interpreted as "configuration component" or "configuration unit" as appropriate. (See the definition of "configuration item" in the glossary.)

Baselines provide a stable basis for continuing evolution of configuration items.

An example of an acquirer's baseline is a collection of acquirer work products such as contractual requirements and acceptance criteria that are related to the product baseline managed by the supplier. [ACQ] 
Baselines are added to the configuration management system as they are developed. Changes to baselines and the release of work products built from the configuration management system are systematically controlled and monitored via the configuration control, change management, and configuration auditing functions of configuration management.

This process area applies not only to configuration management on projects, but also to configuration management on organization work products such as standards, procedures, and reuse libraries.

Configuration management is focused on the rigorous control of the managerial and technical aspects of work products, including the delivered system.

This process area covers the practices for performing the configuration management function and is applicable to all work products that are placed under configuration management.

Refer to the Solicitation and Supplier Agreement Development process area for information on defining supplier configuration management responsibilities in the supplier agreement. [ACQ]

Refer to the Acquisition Management process area for information on formal acceptance of supplier deliverables. [AcQ]

Refer to the Project Planning process area for information on developing plans and work breakdown structures, which may be useful for determining configuration items.

Refer to the Project Monitoring and Control process area for more information about performance analyses and corrective actions. 


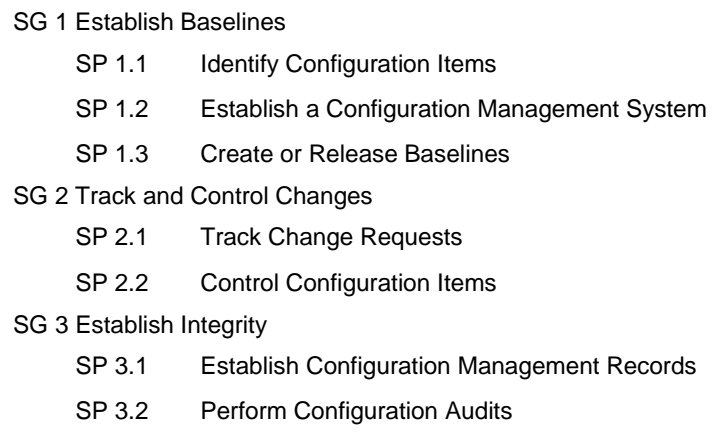

Specific Practices by Goal

SG 1 Establish Baselines

\section{Baselines of identified work products are established.}

Specific practices to establish baselines are covered by this specific goal. The specific practices under the Track and Control Changes specific goal serve to maintain the baselines. The specific practices of the Establish Integrity specific goal document and audit the integrity of the baselines.

\section{SP 1.1 Identify Configuration Items}

Identify the configuration items, components, and related work products that will be placed under configuration management.

Configuration identification is the selection, creation, and specification of the following:

- Products that are delivered to the customer

- Designated internal work products

- Acquired products

- Tools and other capital assets of the project's work environment

- Other items that are used in creating and describing these work products

Items under configuration management will include specifications and interface documents that define the requirements for the product. Other documents, such as test results, may also be included, depending on their criticality to defining the product.

A "configuration item" is an entity designated for configuration management, which may consist of multiple related work products that form a baseline. This logical grouping provides ease of identification and controlled access. The selection of work products for configuration management should be based on criteria established during planning. 
Configuration items may vary widely in complexity, size, and type, from an aircraft, commercial-of-the-shelf software to a test meter or project plan. Any item required for product support and designated for separate procurement is a configuration item. Acquirer work products provided to suppliers such as solicitation packages and technical standards are typically designated as configuration items. [ACQ]

\section{Typical Acquirer Work Products}

\section{Identified configuration items}

\section{Subpractices}

1. Select the configuration items and the work products that compose them based on documented criteria.

Example criteria for selecting configuration items at the appropriate work product

level include the following: [ACQ]

- Work products that may be used by two or more groups

- Work products that are expected to change over time either because of errors or change of requirements

- Work products that are dependent on each other in that a change in one mandates a change in the others

- Work products that are critical for the project

Examples of acquirer work products and supplier deliverables that may be part of a configuration item include the following: $[\mathrm{ACQ}]$

- Process descriptions

- Requirements

- Acceptance criteria

- Supplier performance measures

- Supplier test results

2. Assign unique identifiers to configuration items.

3. Specify the important characteristics of each configuration item.

4. Specify when each configuration item is placed under configuration management. 
Example criteria for determining when to place work products under configuration management include the following: $[\mathrm{ACQ}]$

- Stage of the project life cycle

- When the acquirer work product is ready for review and approval

- Degree of control desired on the work product

- Cost and schedule limitations

- Customer requirements

5. Identify the owner responsible for each configuration item.

\section{SP 1.2 Establish a Configuration Management System}

Establish and maintain a configuration management and change management system for controlling work products.

A configuration management system includes the storage media, the procedures, and the tools for accessing the configuration system.

A change management system includes the storage media, the procedures, and tools for recording and accessing change requests.

Consider how configuration items will be shared between acquirer and supplier as well as across relevant stakeholders. If the use of an acquirer's configuration management system is extended to a supplier, security and access control procedures must be exercised by the acquirer. In many cases, leaving acquired configuration items in the physical possession of the supplier and having access to supplier deliverables is an alternative solution. The supplier agreement specifies appropriate acquirer rights to the supplier deliverables, in addition to requirements for delivery or access. Supplier work products, whenever they are delivered to the acquirer, are formatted in accordance with accepted standards to ensure usability by the acquirer. [ACQ]

\section{Typical Acquirer Work Products}

1. Configuration management system with controlled work products

2. Configuration management system access control procedures

3. Change request database

\section{Subpractices}

1. Establish a mechanism to manage multiple control levels of configuration management. 
The level of control is typically selected based on project objectives, risk, and/or resources. Levels of control can range from informal control that simply tracks changes made when the configuration items are being developed by the acquirer or when supplier work products are delivered or made accessible to the acquirer to formal configuration control using baselines that can only be changed as part of a formal configuration management process. [ACQ]

2. Store and retrieve configuration items in configuration management system.

3. Share and transfer configuration items between control levels within the configuration management system.

4. Store and recover archived versions of configuration items.

5. Store, update, and retrieve configuration management records.

6. Create configuration management reports from the configuration management system.

7. Preserve the contents of the configuration management system.

Examples of preservation functions of the configuration management system include the following: $[A C O]$

- Backups and restoration of configuration management files

- Archiving of configuration management files

- Recovery from configuration management errors

8. Revise the configuration management structure as necessary.

\section{SP 1.3 Create or Release Baselines}

Create or release baselines for internal use and for delivery to the customer.

A baseline is a set of specifications or work products that has been formally reviewed and agreed on, that thereafter serves as the basis for further development or delivery, and that can be changed only through change control procedures. A baseline represents the assignment of an identifier to a configuration item or a collection of configuration items and associated entities.

The acquirer reviews and approves the release of the product baselines created by the supplier. The acquirer creates baselines for acquirer work products to mark the agreement on the description of the project, requirements, funding, schedule, and performance parameters and to make a commitment to manage the program to those baselines. [ACQ] 
Typical Acquirer Work Products

1. Baselines

2. Description of baselines

Typical Supplier Deliverables

1. Product baselines [ACQ]

2. Description of product baselines [AcQ]

Subpractices

1. Obtain authorization from the configuration control board (CCB) before creating or releasing baselines of configuration items.

2. Create or release baselines only from configuration items in the configuration management system.

3. Document the set of configuration items that are contained in a baseline.

4. Make the current set of baselines readily available.

\section{SG 2 Track and Control Changes}

\section{Changes to the work products under configuration management are} tracked and controlled.

The specific practices under this specific goal serve to maintain the baselines after they are established by the specific practices under the Establish Baselines specific goal.

\section{SP 2.1 Track Change Requests}

\section{Track change requests for the configuration items.}

Change requests address not only new or changed requirements, but also failures and defects in the work products.

Change requests can be initiated either by the acquirer or the supplier. Changes that impact the acquirer's work products and supplier deliverables as defined in the supplier agreement are handled through the acquirer's configuration management process. [ACQ]

Change requests are analyzed to determine the impact that the change will have on the work product, related work products, and schedule and cost.

Typical Acquirer Work Products

1. Change requests 


\section{Typical Supplier Deliverables}

1. Change requests $[\mathrm{ACQ}]$

\section{Subpractices}

1. Initiate and record change requests in the change request database.

2. Analyze the impact of changes and fixes proposed in the change requests.

The acquirer analyzes what impact submitted change requests have on the supplier agreements. [ACQ]

Refer to the Acquisition Management process area for information about changing the supplier agreement. [ACQ]

3. Review change requests that will be addressed in the next baseline with the relevant stakeholders and get their agreement.

Conduct the change request review with appropriate participants. Record the disposition of each change request and the rationale for the decision, including success criteria, a brief action plan if appropriate, and needs met or unmet by the change. Perform the actions required in the disposition, and report the results to relevant stakeholders. [Aco]

4. Track the status of change requests to closure.

\section{SP 2.2 Control Configuration Items}

\section{Control changes to the configuration items.}

Control is maintained over the configuration of the work product baseline. This control includes tracking the configuration of each of the configuration items, approving a new configuration if necessary, and updating the baseline.

Decide which configuration items require version control, or more stringent levels of configuration control, and establish mechanisms to ensure configuration items are controlled. Although the supplier may manage configuration items on the acquirer's behalf, the acquirer is responsible for approval and control of changes to such configuration items. [ACQ]

\section{Typical Acquirer Work Products}

1. Revision history of configuration items

2. Archives of the baselines

\section{Subpractices}

1. Control changes to configuration items throughout the life of the product. 
2. Obtain appropriate authorization before changed configuration items are entered into the configuration management system.

For example, authorization may come from the $\mathrm{CCB}$, the project manager, or the customer. [ACQ]

3. Check in and check out configuration items from the configuration management system for incorporation of changes in a manner that maintains the correctness and integrity of the configuration items.

4. Perform reviews to ensure that changes have not caused unintended effects on the baselines (e.g., ensure that the changes have not compromised the safety and/or security of the system).

5. Record changes to configuration items and the reasons for the changes as appropriate.

\section{SG 3 Establish Integrity}

\section{Integrity of baselines is established and maintained.}

The integrity of the baselines, established by processes associated with the Establish Baselines specific goal, and maintained by processes associated with the Track and Control Changes specific goal, is provided by the specific practices under this specific goal.

\section{SP 3.1 Establish Configuration Management Records}

\section{Establish and maintain records describing configuration items.}

Typical Acquirer Work Products

1. Revision history of configuration items

2. Change log

3. Status of configuration items

4. Differences between baselines [ACQ]

Typical Supplier Deliverables

1. Revision history of product and supplier deliverables defined in the supplier agreement [ACO]

2. Change log [ACQ]

3. Copy of the change requests [ACQ]

4. Status of product and supplier deliverables [ACQ]

5. Differences between baselines [ACQ] 


\section{Subpractices}

1. Record configuration management actions in sufficient detail so the content and status of each configuration item is known and previous versions can be recovered.

2. Ensure that relevant stakeholders have access to and knowledge of the configuration status of the configuration items.

3. Specify the latest version of the baselines.

4. Identify the version of configuration items that constitute a particular baseline.

5. Describe the differences between successive baselines.

6. Revise the status and history (i.e., changes and other actions) of each configuration item as necessary.

\section{SP 3.2 Perform Configuration Audits}

\section{Perform configuration audits to maintain integrity of the configuration baselines.}

Configuration audits confirm that the resulting baselines and documentation conform to a specified standard or requirement. Audit results should be recorded as appropriate. (See the glossary for a definition of "configuration audit.")

\section{Typical Acquirer Work Products}

1. Configuration audit results

2. Action items

\section{Typical Supplier Deliverables}

1. Supplier configuration audit results [ACQ]

\section{Subpractices}

1. Assess the integrity of the baselines.

2. Confirm that the configuration management records correctly identify the configuration items.

3. Review the structure and integrity of the items in the configuration management system.

4. Confirm the completeness and correctness of the items in the configuration management system.

Completeness and correctness of the content is based on the requirements as stated in the plan and the disposition of approved change requests. [ACQ] 
Adapting CMMI for Acquisition Organizations: A Preliminary Report

5. Confirm compliance with applicable configuration management standards and procedures.

6. Track action items from the audit to closure. 
The purpose of Decision Analysis and Resolution (DAR) is to analyze possible decisions using a formal evaluation process that evaluates identified alternatives against established criteria.

The Decision Analysis and Resolution process area involves establishing guidelines to determine which issues should be subjected to a formal evaluation process and then applying formal evaluation processes to these issues.

A formal evaluation process is a structured approach to evaluating alternative solutions against established criteria to determine a recommended solution to address an issue. A formal evaluation process involves the following actions:

- Establishing the criteria for evaluating alternatives

- Identifying alternative solutions

- Selecting methods for evaluating alternatives

- Evaluating the alternative solutions using the established criteria and methods

- Selecting recommended solutions from the alternatives based on the evaluation criteria

Rather than using the phrase "alternative solutions to address issues" each time it is needed, we will use one of two shorter phrases: "alternative solutions" or "alternatives."

A repeatable criteria-based decision-making process is especially important, both while making the critical decisions that define and guide the acquisition process and later when critical decisions are made with the selected supplier. The establishment of a formal process for decision-making provides the acquirer with documentation of the decision rationale. Such documentation allows the criteria for critical decisions to be revisited when changes or technology insertion decisions that impact requirements or other critical project parameters are considered. A formal process also supports the communication of decisions between acquirer and supplier. [ACQ] 
A formal evaluation process reduces the subjective nature of the decision and has a higher probability of selecting a solution that meets the multiple demands of the relevant stakeholders.

While the primary application of this process area is for selected technical concerns, formal evaluation processes can also be applied to many nontechnical issues, particularly when a project is being planned. Issues that have multiple alternative solutions and evaluation criteria lend themselves to a formal evaluation process.

Guidelines are created for deciding when to use formal evaluation processes to address unplanned issues. Guidelines often suggest using formal evaluation processes when issues are associated with medium to high risks or when issues affect the ability to achieve project objectives.

Formal evaluation processes can vary in formality, type of criteria, and methods employed. Less formal decisions can be analyzed in a few hours, use only a few criteria (e.g., effectiveness and cost to implement), and result in a one- or two-page report. More formal decisions may require separate plans, months of effort, meetings to develop and approve criteria, simulations, prototypes, piloting, and extensive documentation.

Both numeric and non-numeric criteria can be used in a formal evaluation process. Numeric criteria use weights to reflect the relative importance of the criteria. Non-numeric criteria use a more subjective ranking scale (e.g., high, medium, low). More formal decisions may require a full trade study.

A formal evaluation process identifies and evaluates alternative solutions. The eventual selection of a solution may involve iterative activities of identification and evaluation. Portions of identified alternatives may be combined, emerging technologies may change alternatives, and the business situation of vendors may change during the evaluation period.

A recommended alternative is accompanied by documentation of the selected methods, criteria, alternatives, and rationale for the recommendation. The documentation is distributed to the relevant stakeholders; it provides a record of the formal evaluation process and rationale that is useful to other projects that encounter a similar issue.

While some of the decisions made throughout the life of the project involve the use of a formal evaluation process, others do not. As mentioned earlier, guidelines should be established to determine which issues should be subjected to a formal evaluation process. 
Refer to the Project Planning process area for more information about general planning for projects.

Refer to the Integrated Project Management process area for more information about establishing the project's defined process. The project's defined process includes a formal evaluation process for each selected issue and incorporates the use of guidelines for applying a formal evaluation process to unforeseen issues.

Refer to the Risk Management process area for more information about identifying and mitigating risks. A formal evaluation process is often used to address issues with identified medium or high risks. Selected solutions typically affect risk mitigation plans.

Specific Goal and Practice Summary

SG 1 Evaluate Alternatives

$\begin{array}{ll}\text { SP 1.1 } & \text { Establish Guidelines for Decision Analysis } \\ \text { SP 1.2 } & \text { Establish Evaluation Criteria } \\ \text { SP 1.3 } & \text { Identify Alternative Solutions } \\ \text { SP 1.4 } & \text { Select Evaluation Methods } \\ \text { SP 1.5 } & \text { Evaluate Alternatives } \\ \text { SP 1.6 } & \text { Select Solutions }\end{array}$

Specific Practices by Goal

SG 1 Evaluate Alternatives

Decisions are based on an evaluation of alternatives using established criteria.

Issues requiring a formal evaluation process may be identified at any time. The objective should be to identify issues as early as possible to maximize the time available to resolve them

\section{SP 1.1 Establish Guidelines for Decision Analysis}

\section{Establish and maintain guidelines to determine which issues are subject to a formal evaluation process.}

Not every decision is significant enough to require a formal evaluation process. The choice between the trivial and the truly important will be unclear without explicit guidance. Whether a decision is significant or not is dependent on the project and circumstances, and is determined by the established guidelines.

Typical guidelines for determining when to require a formal evaluation process include the following: $[\mathrm{ACQ}]$ 
- When a decision is directly related to topics assessed as being of medium or high risk

- When a decision is related to changing work products under configuration management

- When a decision would cause schedule delays over a certain percentage or specific amount of time

- When a decision affects the ability to achieve project objectives

- When the costs of the formal evaluation process are reasonable when compared to the decision's impact

- When a legal obligation exists during a solicitation

- When there is a risk that the decision will have a significant adverse effect on cost, quality, resources, or schedule

- When legal or supplier agreement issues need to be resolved

Refer to the Risk Management process area for more information about determining which issues are medium or high risk.

Examples of when to use a formal evaluation process include the following: [ACQ]

- On decisions to trade off performance, cost, and schedule requirements during an acquisition

- On selecting, terminating, or renewing suppliers

Typical Acquirer Work Products

1. Guidelines for when to apply a formal evaluation process

Subpractices

1. Establish guidelines.

2. Incorporate the use of the guidelines into the defined process where appropriate.

Refer to the Integrated Project Management process area for more information about establishing the project's defined process.

\section{SP 1.2 Establish Evaluation Criteria}

Establish and maintain the criteria for evaluating alternatives, and the relative ranking of these criteria.

The evaluation criteria provide the basis for evaluating alternative solutions. The criteria are ranked so that the highest ranked criteria exert the most influence on the evaluation. 
This process area is referenced by many other process areas in the model, and there are many contexts in which a formal evaluation process can be used. Therefore, in some situations you may find that criteria have already been defined as part of another process. This specific practice does not suggest that a second development of criteria be conducted.

Document the evaluation criteria to minimize the possibility that decisions will be second-guessed, or that the reason for making the decision will be forgotten. Decisions based on criteria that are explicitly defined and established remove barriers to stakeholder buy-in.

\section{Typical Acquirer Work Products}

1. Documented evaluation criteria

2. Rankings of criteria importance

\section{Subpractices}

1. Define the criteria for evaluating alternative solutions.

Criteria should be traceable to requirements, scenarios, business case assumptions, business objectives, or other documented sources. Types of criteria to consider include the following: [ACQ]

- Technology limitations

- Environmental impact

- Risks

- Total ownership and life-cycle costs

2. Define the range and scale for ranking the evaluation criteria.

Scales of relative importance for evaluation criteria can be established with nonnumeric values or with formulas that relate the evaluation parameter to a numerical weight. $[\mathrm{ACQ}]$

3. Rank the criteria.

4. Assess the criteria and their relative importance.

5. Evolve the evaluation criteria to improve their validity.

6. Document the rationale for the selection and rejection of evaluation criteria.

SP 1.3 Identify Alternative Solutions

Identify alternative solutions to address issues. 
A wider range of alternatives can surface by soliciting as many stakeholders as practical for input. Input from stakeholders with diverse skills and backgrounds can help teams identify and address assumptions, constraints, and biases. Brainstorming sessions may stimulate innovative alternatives through rapid interaction and feedback. Sufficient candidate solutions may not be furnished for analysis. As the analysis proceeds, other alternatives should be added to the list of potential candidate solutions. The generation and consideration of multiple alternatives early in a decision analysis and resolution process increases the likelihood that an acceptable decision will be made, and that consequences of the decision will be understood.

\section{Typical Acquirer Work Products}

1. Identified alternatives

\section{Typical Supplier Deliverables}

1. Supplier identified alternatives, if any [ACQ]

\section{Subpractices}

1. Perform a literature search.

2. Identify alternatives for consideration in addition to those that may be provided with the issue.

3. Document the proposed alternatives.

\section{SP 1.4 Select Evaluation Methods}

\section{Select the evaluation methods.}

Methods for evaluating alternative solutions against established criteria can range from simulations to the use of probabilistic models and decision theory. These methods need to be carefully selected. The level of detail of a method should be commensurate with cost, schedule, performance, and risk impacts.

While many problems may need only one evaluation method, some problems may require multiple methods. For instance, simulations may augment a trade study to determine which design alternative best meets a given criterion.

Suppliers competing to develop a technical solution for the acquirer may be directly evaluated in a final competition that possibly involves performance or functional demonstration of proposed solutions. [ACQ]

\section{Typical Acquirer Work Products}

1. Selected evaluation methods 


\section{Subpractices}

1. Select the methods based on the purpose for analyzing a decision and on the availability of the information used to support the method.

Typical evaluation methods include the following: [ACQ]

- Benchmarking studies

- Cost studies

- Business opportunity studies

- Surveys

- Extrapolations based on field experience and prototypes

- User review and comment

- Judgment provided by an expert or group of experts (e.g., Delphi Method)

2. Select evaluation methods based on their ability to focus on the issues at hand without being overly influenced by side issues.

3. Determine the measures needed to support the evaluation method.

Refer to the Measurement and Analysis process area for information about specifying measures. [ACQ]

\section{SP 1.5 Evaluate Alternatives}

Evaluate alternative solutions using the established criteria and methods.

Evaluating alternative solutions involves analysis, discussion, and review. Iterative cycles of analysis are sometimes necessary. Supporting analyses, experimentation, prototyping, piloting, or simulations may be needed to substantiate scoring and conclusions.

Often, the relative importance of criteria is imprecise and the total effect on a solution is not apparent until after the analysis is performed. In cases where the resulting scores differ by relatively small amounts, the best selection among alternative solutions may not be clear cut. Challenges to criteria and assumptions should be encouraged.

\section{Typical Acquirer Work Products}

1. Evaluation results

\section{Subpractices}

1. Evaluate the proposed alternative solutions using the established evaluation criteria and selected methods.

2. Evaluate the assumptions related to the evaluation criteria and the evidence that supports the assumptions. 
3. Evaluate whether uncertainty in the values for alternative solutions affects the evaluation and address as appropriate.

4. Perform simulations, modeling, prototypes, and pilots as necessary to exercise the evaluation criteria, methods, and alternative solutions.

Untested criteria, their relative importance, and supporting data or functions may cause the validity of solutions to be questioned. Criteria and their relative priorities and scales can be tested with trial runs against a set of alternatives. These trial runs of a select set of criteria allow for the evaluation of the cumulative impact of the criteria on a solution. If the trials reveal problems, different criteria or alternatives might be considered to avoid biases. [ACQ]

5. Consider new alternative solutions, criteria, or methods if the proposed alternatives do not test well; repeat the evaluations until alternatives do test well.

Document the rationale for the addition of new alternatives or methods and changes to criteria, as well as the results of interim evaluations. Determine the score(s) for each alternative based upon the criteria evaluations and the scoring method(s) previously determined. [ACQ]

6. Document the results of the evaluation.

SP 1.6 Select Solutions

Select solutions from the alternatives based on the evaluation criteria.

Selecting solutions involves weighing the results from the evaluation of alternatives. Risks associated with implementation of the solutions must be assessed.

\section{Typical Acquirer Work Products}

1. Recommended solutions to address significant issues

\section{Subpractices}

1. Assess the risks associated with implementing the recommended solution.

Refer to the Risk Management process area for more information about identifying and managing risks.

2. Document the results and rationale for the recommended solution. 
The purpose of Integrated Project Management (IPM) is to establish and manage the project and the involvement of the relevant stakeholders according to an integrated and defined process that is tailored from the organization's set of standard processes.

Integrated Project Management involves the following:

- Establishing the project's defined process by tailoring the organization's set of standard processes

- Managing the project using the project's defined process

- Establishing the work environment for the project based on the organization's work environment standards

- Using and contributing to the organizational process assets

- Enabling relevant stakeholders' concerns to be identified, considered, and, when appropriate, addressed during the development of the product

- Ensuring that the relevant stakeholders perform their tasks in a coordinated and timely manner (1) to address product and productcomponent requirements, plans, objectives, issues, and risks; (2) to fulfill their commitments; and (3) to identify, track, and resolve issues

The integrated and defined process that is tailored from the organization's set of standard processes is called the project's defined process.

Integrated Project Management includes organizational acquisition guidance, regulations, instructions, and acquisition practices established to be used across various projects. [ACQ]

Managing the project's effort, cost, schedule, staffing, risks, and other factors is tied to the tasks of the project's defined process. The implementation and management of the project's defined process are typically described in the project plan. Certain activities may be covered in other plans that affect the project, such as the quality assurance plan, risk management strategy, and the configuration management plan. 
Since the defined process for each project is tailored from the organization's set of standard processes, variability among projects is typically reduced and projects can more easily share process assets, data, and lessons learned.

This process area also addresses the coordination of all activities associated with the project such as the following:

- Development activities (e.g., requirements development, design, and verification)

- Service activities (e.g., delivery, help desk, operations, and customer contact)

- Acquisition activities (e.g., solicitation, contract monitoring, and transition to operation)

- Support activities (e.g., configuration management, documentation, marketing, and training.

The working interfaces and interactions among relevant stakeholders internal and external to the project are planned and managed to ensure the quality and integrity of the entire product. Relevant stakeholders participate, as appropriate, in defining the project's defined process and the project plan. Reviews and exchanges are regularly conducted with the relevant stakeholders to ensure that coordination issues receive appropriate attention and everyone involved with the project is appropriately aware of the status, plans, and activities. (See the definition of "relevant stakeholder" in the glossary.) In defining the project's defined process, formal interfaces are created as necessary to ensure that appropriate coordination and collaboration occurs.

The acquirer needs to involve and integrate all relevant acquisition, technical, support, and operational stakeholders. Depending on the scope and risk of the project, the coordination efforts with the supplier can be significant. [ACQ]

Formal interfaces among relevant stakeholders take the form of memorandums of understanding (MOUs), memorandums of agreements (MOAs), contractual commitments, associated supplier agreements, and similar documents, depending on the nature of the interfaces and involved stakeholders. [ACQ]

This process area applies in any organizational structure, including projects that are structured as line organizations, matrix organizations, or integrated teams. The terminology should be appropriately interpreted for the organizational structure in place. 
Refer to the Project Planning process area for more information about planning the project.

Refer to the Project Monitoring and Control process area for more information about monitoring and controlling the project.

Refer to the Project Planning process area for more information about identifying relevant stakeholders and their appropriate involvement in the project.

Refer to the Organizational Process Definition process area for more information about organizational process assets and work environment standards.

Refer to the Measurement and Analysis process area for more information about defining a process for measuring and analyzing processes.

Refer to Acquisition Management process area for information about managing supplier agreements. [ACQ]

\section{Specific Goal and Practice Summary}

SG 1 Use the Project's Defined Process

SP 1.1 Establish the Project's Defined Process

SP 1.2 Use Organizational Process Assets for Planning

Project Activities

SP 1.3 Establish the Project's Work Environment

SP 1.4 Integrate Plans

SP 1.5 Manage the Project Using the Integrated Plans

SP 1.6 Contribute to the Organizational Process Assets

SG 2 Coordinate and Collaborate with Relevant Stakeholders

SP 2.1 Manage Stakeholder Involvement

SP 2.2 Manage Dependencies

SP 2.3 Resolve Coordination Issues

\section{Specific Practices by Goal}

SG 1 Use the Project's Defined Process

The project is conducted using a defined process that is tailored from the organization's set of standard processes.

The project's defined process must include those processes from the organization's set of standard processes that address all processes necessary to acquire or develop and maintain the product. The productrelated life-cycle processes, such as the manufacturing and support processes, are developed concurrently with the product. 


\section{Establish and maintain the project's defined process.}

Refer to the Organizational Process Definition process area for more information about the organizational process assets.

Refer to the Organizational Process Focus process area for more information about organizational process needs and objectives.

The project's defined process consists of defined processes that form an integrated, coherent life cycle for the project.

The project's defined process logically sequences acquirer activities and supplier deliverables (as identified in the supplier agreement) to deliver a product that meets the requirements. [ACQ]

The project's defined process should satisfy the project's contractual and operational needs, opportunities, and constraints. It is designed to provide a best fit for the project's needs. A project's defined process is based on the following factors:

- Customer requirements

- Product and product-component requirements

- Commitments

- Organizational process needs and objectives

- Operational environment

- Business environment

The project's defined process is driven by the acquisition strategy. For example, whether the acquisition strategy is to introduce new technology to the organization or focuses on consolidating acquired products or services in use by the acquirer impacts the project's defined process. [ACQ]

\section{Typical Acquirer Work Products}

1. The project's defined process

\section{Subpractices}

1. Select a life-cycle model from those available from the organizational process assets.

2. Select the standard processes from the organization's set of standard processes that best fit the needs of the project.

3. Tailor the organization's set of standard processes and other organizational process assets according to the tailoring guidelines to produce the project's defined process. 
Sometimes the available life-cycle models and standard processes are inadequate to meet a specific project's needs. Sometimes the project will be unable to produce required work products or measures. In such circumstances, the project will need to seek approval to deviate from what is required by the organization. Waivers are provided for this purpose. [ACO]

4. Use other artifacts from the organization's process asset library as appropriate.

Other artifacts may include the following: [ACQ]

- Lessons-learned documents

- Templates

- Example documents

- Estimating models

5. Document the project's defined process.

Examples of project activities include the following: [AcQ]

- Proposal evaluation

- Supplier selection

- Development of supplier agreements

- Management of supplier agreements

- Acceptance of supplier deliverables

6. Conduct peer reviews of the project's defined process.

7. Revise the project's defined process as necessary.

\section{SP 1.2 Use Organizational Process Assets for Planning Project} Activities

Use the organizational process assets and measurement repository for estimating and planning the project's activities.

Refer to the Organizational Process Definition process area for more information about organizational process assets and the organization's measurement repository.

When available, use the results of previous planning and execution activities as predictors of the relative scope and risk of the effort being estimated for the current acquisition. [ACQ]

\section{Typical Acquirer Work Products}

1. Project estimates

2. Project plans 


\section{Subpractices}

1. Base the activities for estimating and planning on the tasks and work products of the project's defined process.

An understanding of the relationships among the various tasks and work products of the project's defined process, and of the roles to be performed by the relevant stakeholders, is a basis for developing a realistic plan. [ACQ]

2. Use the organization's measurement repository in estimating the project's planning parameters.

This estimate typically includes the following: [ACQ]

- Using appropriate historical data from this project or similar projects

- Accounting for and recording similarities and differences between the current project and those projects whose historical data will be used

- Independently validating the historical data

- Recording the reasoning, assumptions, and rationale used to select the historical data

\section{SP 1.3 Establish the Project's Work Environment}

Establish and maintain the project's work environment based on the organization's work environment standards.

An appropriate work environment for a project comprises an infrastructure of facilities, tools, and equipment that people need to perform their jobs effectively in support of business and project objectives. The work environment and its components are maintained at a level of performance and reliability indicated by the organizational work environment standards. As required, the project's work environment or some of its components can be developed internally or acquired from external sources.

The project's work environment might encompass environments for product integration, verification, and validation or they might be separate environments.

Refer to the Establish Work Environment Standards specific practice in the Organizational Process Definition process area for more information on work environment standards.

\section{Typical Acquirer Work Products}

1. Equipment and tools for the project

2. Installation, operation, and maintenance manuals for the project work environment

3. User surveys and results

4. Usage, performance, and maintenance records 


\section{Support services for the project's work environment}

\section{Subpractices}

1. Plan, design, and install a work environment for the project.

The critical aspects of the project work environment are, like any other product, requirements driven. Work environment functionality and operations are explored with the same rigor as is done for any other product development. [ACQ]

It is necessary to make tradeoffs among performance improvements, costs, and risks. The following are examples of each: [aco]

- Performance improvements may include timely interoperable communications, safety, security, and maintainability.

- Costs may include capital outlays, training, support structure, disassembly and disposal of existing environments, and operation and maintenance of the environment.

- Risks may include workflow and project disruptions.

\section{Examples of equipment and tools include the following: [AcQ]}

- Office software

- Decision support software

- Project management tools

- Requirements management tools, design tools

- Configuration management tools

- Evaluation tools

- Test and/or evaluation equipment

2. Provide ongoing maintenance and operational support for the project's work environment.

Maintenance and support of the work environment can be accomplished either with capabilities found inside the organization or hired from outside the organization. [ACQ]

Examples of maintenance and support approaches include the following: [ACQ]

- Hiring people to perform the maintenance and support

- Training people to perform the maintenance and support

- Contracting the maintenance and support

- Developing expert users for selected tools

3. Maintain the qualification of the components of the project's work environment. 
Components include software, databases, hardware, tools, test equipment, and appropriate documentation. Qualification of software includes appropriate certifications. Hardware and test equipment qualification includes calibration and adjustment records and traceability to calibration standards. [ACQ]

4. Periodically review how well the work environment is meeting the project's needs and supporting collaboration, and take action as appropriate.

\section{SP 1.4 Integrate Plans}

Integrate the project plan and the other plans that affect the project to describe the project's defined process.

Refer to the Project Planning process area for more information about establishing and maintaining a project plan.

Refer to the Organizational Process Definition process area for more information about organizational process assets and, in particular, the organization's measurement repository.

Refer to the Measurement and Analysis process area for more information about defining measures and measurement activities and using analytic techniques.

Refer to the Risk Management process area for more information about identifying and analyzing risks.

Refer to the Organizational Process Focus process area for more information about organizational process needs and objectives.

This specific practice extends the specific practices for establishing and maintaining a project plan to address additional planning activities such as incorporating the project's defined process, coordinating with relevant stakeholders, using organizational process assets, incorporating plans for peer reviews, and establishing objective entry and exit criteria for tasks.

The development of the project plan should account for current and projected needs, objectives, and requirements of the organization, customer, suppliers, and end users, as appropriate.

\section{Typical Acquirer Work Products}

1. Integrated plans

Typical Supplier Deliverables

1. Supplier plans $[\mathrm{ACQ}]$

\section{Subpractices}

1. Integrate other plans that affect the project with the project plan. 
Other plans that affect the project may include the following: $[\mathrm{ACQ}]$

- Quality assurance plans

- Configuration management plans

- Risk management strategy

- Documentation plans

2. Incorporate into the project plan the definitions of measures and measurement activities for managing the project.

3. Identify and analyze product and project interface risks.

4. Schedule the tasks in a sequence that accounts for critical development factors and project risks.

Examples of factors considered in scheduling include the following: [AcQ]

- Size and complexity of the tasks

- Needs of the customer and end users

- Availability of critical resources

- Availability of key personnel

5. Incorporate the plans for performing peer reviews on the work products of the project's defined process.

6. Incorporate the training needed to perform the project's defined process in the project's training plans.

7. Establish objective entry and exit criteria to authorize the initiation and completion of the tasks described in the work breakdown structure (WBS).

Refer to the Project Planning process area for more information about the WBS.

8. Ensure that the project plan is appropriately compatible with the plans of relevant stakeholders.

9. Identify how conflicts will be resolved that arise among relevant stakeholders.

Refer to the Acquisition Management process area for more information about resolving issues related to supplier agreements. [ACQ]

SP 1.5 Manage the Project Using the Integrated Plans Manage the project using the project plan, the other plans that affect the project, and the project's defined process. 
Refer to the Organizational Process Definition process area for more information about the organizational process assets.

Refer to the Organizational Process Focus process area for more information about organizational process needs and objectives and coordinating process-improvement activities with the rest of the organization.

Refer to the Risk Management process area for more information about managing risks.

Refer to the Project Monitoring and Control process area for more information about monitoring and controlling the project.

\section{Typical Acquirer Work Products}

1. Work products created by performing the project's defined process

2. Collected measures ("actuals") and progress records or reports

3. Revised requirements, plans, and commitments

4. Integrated plans

\section{Typical Supplier Deliverables}

1. Supplier progress reports and performance measures [ACQ]

\section{Subpractices}

1. Implement the project's defined process using the organization's process asset library.

This task typically includes the following: $[\mathrm{ACQ}]$

- Incorporating artifacts from the organization's process asset library into the project as appropriate

- Using lessons learned from the organization's process asset library to manage the project

2. Monitor and control the project's activities and work products using the project's defined process, project plan, and other plans that affect the project.

This task typically includes the following: $[A \subset \mathrm{C}]$

- Using the defined entry and exit criteria to authorize the initiation and determine the completion of the tasks

- Monitoring the activities that could significantly affect the actual values of the project's planning parameters

- Tracking the project's planning parameters using measurable thresholds that will trigger investigation and appropriate actions

- Monitoring product and project interface risks 
- Managing external and internal commitments based on the plans for the tasks and work products of implementing the project's defined process

An understanding of the relationships among the various tasks and work products of the project's defined process, and of the roles to be performed by the relevant stakeholders, along with well-defined control mechanisms achieves better visibility into the project's performance and better control of the project. [ACO]

3. Obtain and analyze the selected measures to manage the project and support the organization's needs.

Refer to the Measurement and Analysis process area for more information about defining a process for obtaining and analyzing measures.

4. Periodically review and align the project's performance with the current and anticipated needs, objectives, and requirements of the organization, customer, and end users, as appropriate.

This review includes alignment with the organizational process needs and objectives. [AcQ]

Examples of actions that achieve alignment include the following: [ACQ]

- Accelerating the schedule, with appropriate adjustments to other planning parameters and the project risks

- Changing the requirements in response to a change in market opportunities or customer and end-user needs

- Terminating the project

SP 1.6 Contribute to the Organizational Process Assets

Contribute work products, measures, and documented experiences to the organizational process assets.

Refer to the Organizational Process Focus process area for more information about process improvement proposals.

Refer to the Organizational Process Definition process area for more information about the organizational process assets, the organization's measurement repository, and the organization's process asset library.

This specific practice addresses collecting information from processes in the project's defined process.

\section{Typical Acquirer Work Products}

1. Proposed improvements to the organizational process assets

2. Actual process and product measures collected from the project 
3. Documentation (e.g., exemplary process descriptions, plans, training modules, checklists, and lessons learned)

\section{Subpractices}

1. Propose improvements to the organizational process assets.

2. Store process and product measures in the organization's measurement repository.

Refer to the Project Planning process area for more information about recording planning and replanning data.

Refer to the Project Monitoring and Control process area for more information about recording measures.

3. Submit documentation for possible inclusion in the organization's process asset library.

4. Document lessons learned from the project for inclusion in the organization's process asset library.

SG 2 Coordinate and Collaborate with Relevant Stakeholders Coordination and collaboration of the project with relevant stakeholders is conducted.

SP 2.1 Manage Stakeholder Involvement

Manage the involvement of the relevant stakeholders in the project.

Stakeholder involvement is managed according to the project's integrated and defined process.

The acquirer encourages stakeholder involvement and ensures that stakeholder coordination and cooperation are maximized to the extent possible. The supplier agreement provides the basis for managing supplier involvement in the project. [ACQ]

Refer to the Project Planning process area for more information about identifying stakeholders and their appropriate involvement and about establishing and maintaining commitments.

Typical Acquirer Work Products

1. Agendas and schedules for collaborative activities

2. Documented issues [AcQ]

3. Recommendations for resolving relevant stakeholder issues 


\section{Typical Supplier Deliverables}

1. Documented issues (e.g., issues with customer requirements, product and product-component requirements, product architecture, and product design) [AcQ]

\section{Subpractices}

1. Coordinate with the relevant stakeholders who should participate in the project's activities.

2. Ensure that work products that are produced to satisfy commitments meet the requirements of the recipient projects.

3. Develop recommendations and coordinate the actions to resolve misunderstandings and problems with the product and productcomponent requirements, product and product-component architecture, and product and product-component design.

SP 2.2 Manage Dependencies

Participate with relevant stakeholders to identify, negotiate, and track critical dependencies.

Refer to the Project Planning process area for more information about identifying stakeholders and their appropriate involvement and about establishing and maintaining commitments.

\section{Typical Acquirer Work Products}

1. Defects, issues, and action items resulting from reviews with relevant stakeholders

2. Critical dependencies

3. Commitments to address critical dependencies

4. Status of critical dependencies

Typical Supplier Deliverables

1. Status of critical dependencies as documented in the supplier agreement $_{[\mathrm{ACQ}]}$

\section{Subpractices}

1. Conduct reviews with relevant stakeholders.

2. Identify each critical dependency.

3. Establish need dates and plan dates for each critical dependency based on the project schedule.

4. Review and get agreement on the commitments to address each critical dependency with the people responsible for providing the work product and the people receiving the work product. 
5. Document the critical dependencies and commitments.

The acquirer documents the supplier commitments to meet critical dependencies in the supplier agreement. [ACQ]

6. Track the critical dependencies and commitments and take corrective action as appropriate.

Refer to the Project Monitoring and Control process area for more information about tracking commitments.

Tracking the critical dependencies typically includes the following: [ACO]

- Evaluating the effects of late and early completion for impacts on future activities and milestones

- Resolving actual and potential problems with the responsible parties whenever possible

- Escalating to the appropriate party the actual and potential problems not resolvable by the responsible individual or group

\section{SP 2.3 Resolve Coordination Issues}

\section{Resolve issues with relevant stakeholders.}

Examples of coordination issues include the following: [ACQ]

- Late critical dependencies and commitments

- Product-level problems

- Unavailability of critical resources or personnel

- Incomplete customer requirements

- Unresolved defects

\section{Typical Acquirer Work Products}

1. Relevant stakeholder coordination issues

2. Status of relevant stakeholder coordination issues

\section{Subpractices}

1. Identify and document issues.

2. Communicate issues to the relevant stakeholders.

3. Resolve issues with the relevant stakeholders.

4. Escalate to the appropriate managers those issues not resolvable with the relevant stakeholders.

5. Track the issues to closure. 
Adapting CMMI for Acquisition Organizations: A Preliminary Report

6. Communicate with the relevant stakeholders on the status and resolution of the issues. 
The purpose of Measurement and Analysis (MA) is to develop and sustain a measurement capability that is used to support management information needs.

The Measurement and Analysis process area involves the following:

- Specifying the objectives of measurement and analysis such that they are aligned with identified information needs and objectives

- Specifying the measures, data collection and storage mechanisms, analysis techniques, and reporting and feedback mechanisms

- Implementing the collection, storage, analysis, and reporting of the data

- Providing objective results that can be used in making informed decisions, and taking appropriate corrective actions

The integration of measurement and analysis activities into the processes of the project supports the following:

- Objective planning and estimating

- Tracking actual performance against established plans and objectives

- Identifying and resolving process-related issues

- Providing a basis for incorporating measurement into additional processes in the future

The staff required to implement a measurement capability may or may not be employed in a separate organization-wide program.

Measurement capability may be integrated into individual projects or other organizational functions (e.g., quality assurance).

The initial focus for measurement activities is at the project level. However, a measurement capability may prove useful for addressing organization- and/or enterprise-wide information needs. To support this capability, the measurement activities should support information needs at multiple levels including the business, organizational unit, and project to minimize re-work as the organization matures. 
Projects may choose to store project-specific data and results in a project-specific repository. When data are shared more widely across projects, the data may reside in the organization's measurement repository.

Measurement and analysis of the product components provided by suppliers is essential for effective management of the quality and costs of the project. It is possible, with careful management of supplier agreements, to provide insight into the data that support supplierperformance analysis.

The measures specified by the acquirer are designed to enable the acquirer to determine the status of its progress and output, the supplier's progress and output per contractual requirements, and the status of the evolving products acquired. An acquirer establishes measurement objectives for acquirer activities, work products and for supplier deliverables. The measurement objectives are derived from information needs that come from project objectives, organizational objectives and business needs. The measurement objectives are used to define specific measures and collection, analysis, storage and usage procedures for the measures. These measures are specified in the project plan and for the supplier in the supplier agreement. [ACQ]

In projects where multiple products are acquired to deliver a capability to the end user, or where there are relationships with other projects to acquire joint capabilities, additional measures may be identified to track and achieve interoperability objectives in terms of programmatic, technical, and operational interfaces. [ACQ]

Refer to the Project Planning process area for more information about estimating project attributes and other planning information needs.

Refer to the Project Monitoring and Control process area for more information about monitoring project performance information needs.

Refer to the Configuration Management process area for more information about managing measurement work products.

Refer to the Acquisition Requirements Development process area for more information about meeting customer requirements and related information needs. [ACQ]

Refer to the Requirements Management process area for more information about maintaining requirements traceability and related information needs. 
Refer to Solicitation and Supplier Agreement Development including supplier measures in the solicitation package and in the supplier agreement. [ACQ]

Refer to the Organizational Process Definition process area for more information about establishing the organization's measurement repository.

Refer to the Quantitative Project Management process area for more information about understanding variation and the appropriate use of statistical analysis techniques.

Specific Goal and Practice Summary

\footnotetext{
SG 1 Align Measurement and Analysis Activities

SP 1.1 Establish Measurement Objectives

SP 1.2 Specify Measures

SP 1.3 Specify Data Collection and Storage Procedures

SP 1.4 Specify Analysis Procedures

SG 2 Provide Measurement Results

SP 2.1 Collect Measurement Data

SP 2.2 Analyze Measurement Data

SP 2.3 Store Data and Results

SP 2.4 Communicate Results
}

Specific Practices by Goal

SG 1 Align Measurement and Analysis Activities

Measurement objectives and activities are aligned with identified information needs and objectives.

The specific practices covered under this specific goal may be addressed concurrently or in any order:

- When establishing measurement objectives, experts often think ahead about necessary criteria for specifying measures and analysis procedures. They also think concurrently about the constraints imposed by data collection and storage procedures.

- It often is important to specify the essential analyses that will be conducted before attending to details of measurement specification, data collection, or storage.

\section{SP 1.1 Establish Measurement Objectives}

\section{Establish and maintain measurement objectives that are} derived from identified information needs and objectives.

Measurement objectives document the purposes for which measurement and analysis are done, and specify the kinds of actions that may be taken based on the results of data analyses. 
Measurement objectives focus on the acquirer's performance as well as the supplier's performance, and on understanding their impacts on customer operational and financial performance. Measurement objectives for the supplier enable defining and tracking service level expectations documented in the supplier agreement. [ACQ]

Identify what information is needed to [ACQ]

- maintain alignment to project objectives and provide results that keep a project on track to its successful conclusion

- $\quad$ support the organizational unit's ability to establish an infrastructure that reinforces and grows the acquirer's capabilities of processes, people, and technologies, as appropriate

- $\quad$ support the enterprise's ability to monitor and manage their financial results and their customer expectations, as appropriate

The sources for measurement objectives may be management, technical, project, product, or process implementation needs.

The measurement objectives may be constrained by existing processes, available resources, or other measurement considerations. Judgments may need to be made about whether the value of the results will be commensurate with the resources devoted to doing the work.

Modifications to identified information needs and objectives may, in turn, be indicated as a consequence of the process and results of measurement and analysis.

An acquirer needs to consider the impact of existing supplier agreements on measurement objectives. [ACQ]

Sources of information needs and objectives may include the following:

- Project plans

- Monitoring of project performance

- Interviews with managers and others who have information needs

- Established management objectives

- Strategic plans

- Business plans

- Formal requirements or contractual obligations

- Recurring or other troublesome management or technical problems

- Experiences of other projects or organizational entities

- External industry benchmarks

- Process-improvement plans 
- Supplier agreements and contractual requirements (e.g., service levels) [AcQ]

Example measurement objectives include the following:

- Reduce time to delivery

- Reduce total life cycle cost

- Deliver specified functionality completely

- Improve prior levels of quality

- Improve prior customer satisfaction ratings

- Maintain and improve the acquirer/supplier relationships

Refer to the Project Planning process area for more information about estimating project attributes and other planning information needs.

Refer to the Project Monitoring and Control process area for more information about project performance information needs.

Refer to the Acquisition Requirements Development process area for more information about meeting customer requirements and related information needs. [ACQ]

Refer to the Requirements Management process area for more information about maintaining requirements traceability and related information needs.

\section{Typical Acquirer Work Products}

1. Measurement objectives

\section{Subpractices}

1. Document information needs and objectives.

2. Prioritize information needs and objectives.

3. Document, review, and update measurement objectives.

It is important to carefully consider the purposes and intended uses of measurement and analysis. [ACQ]

The measurement objectives are documented, reviewed by management and other relevant stakeholders, and updated as necessary. Doing so enables traceability to subsequent measurement and analysis activities, and helps ensure that the analyses will properly address identified information needs and objectives. [AcQ]

4. Provide feedback for refining and clarifying information needs and objectives as necessary. 
Identified information needs and objectives may need to be refined and clarified as a result of setting measurement objectives. Initial descriptions of information needs may be unclear or ambiguous. Conflicts may arise between existing needs and objectives. Precise targets on an already existing measure may be unrealistic. [ACQ]

5. Review appropriate measurement objectives with potential suppliers throughout the solicitation, obtaining their feedback, and commitment. [ACQ]

6. Maintain traceability of the measurement objectives to the identified information needs and objectives.

Of course, the measurement objectives may also change to reflect evolving information needs and objectives. [AcQ]

\section{SP $1.2 \quad$ Specify Measures}

\section{Specify measures to address the measurement objectives.}

Measurement objectives are refined into precise, quantifiable measures.

Measurement of project and organizational work can typically be traced to one or more of measurement information categories. These categories include the following: schedule and progress, effort and cost, size and stability, and quality. [ACQ]

Measures may be either "base" or "derived." Data for base measures are obtained by direct measurement. Data for derived measures come from other data, typically by combining two or more base measures.

Derived measures typically are expressed as ratios, composite indices, or other aggregate summary measures. They are often more quantitatively reliable and meaningfully interpretable than the base measures used to generate them.

There is a direct relationship between measurement objectives, measurement categories, base measures, and derived measures. This direct relationship is depicted in Table 5.3: [AcQ]

Table 5.3: Measurement Relationships [ACQ]

\begin{tabular}{|l|l|l|l|}
\hline $\begin{array}{c}\text { Example } \\
\text { Measurement } \\
\text { Objectives }\end{array}$ & $\begin{array}{c}\text { Measurement } \\
\text { Information } \\
\text { Categories }\end{array}$ & Example Base Measures & Example Derived Measures \\
\hline $\begin{array}{l}\text { Shorter time to } \\
\text { delivery }\end{array}$ & $\begin{array}{c}\text { Schedule and } \\
\text { Progress }\end{array}$ & $\begin{array}{c}\text { Estimated and Actual Start } \\
\text { and End Dates by Task }\end{array}$ & Schedule Performance Index \\
\hline
\end{tabular}


Adapting CMMI for Acquisition Organizations: A Preliminary Report

\begin{tabular}{|c|c|c|c|}
\hline $\begin{array}{l}\text { Example } \\
\text { Measurement } \\
\text { Objectives }\end{array}$ & $\begin{array}{l}\text { Measurement } \\
\text { Information } \\
\text { Categories }\end{array}$ & Example Base Measures & Example Derived Measures \\
\hline & & $\begin{array}{c}\text { and End Dates of Acquisition } \\
\text { Tasks }\end{array}$ & Schedule Estimation Accuracy \\
\hline $\begin{array}{l}\text { Reduced total life } \\
\text { cycle cost }\end{array}$ & Effort and Cost & $\begin{array}{l}\text { Estimated and Actual Effort } \\
\text { Hours } \\
\text { Estimated and Actual Cost }\end{array}$ & $\begin{array}{l}\text { Return on Investment } \\
\text { Cost Performance Index }\end{array}$ \\
\hline $\begin{array}{l}\text { Deliver specified } \\
\text { functionality } \\
\text { completely }\end{array}$ & Size and Stability & $\begin{array}{l}\text { Function Points Count } \\
\text { Lines of Code Count } \\
\text { Requirements Count }\end{array}$ & $\begin{array}{l}\text { Requirements Volatility } \\
\text { Size Estimation Accuracy } \\
\text { Amount of New, Modified and } \\
\text { Reused Code } \\
\text { Percentage of Function Points } \\
\text { Completed }\end{array}$ \\
\hline $\begin{array}{l}\text { Improve levels of } \\
\text { quality }\end{array}$ & Quality & $\begin{array}{l}\text { Product Defects Count } \\
\text { Customer Satisfaction } \\
\text { Survey Scores } \\
\text { Supplier Performance and } \\
\text { Relationship Scores }\end{array}$ & $\begin{array}{c}\text { Defect Removal Efficiency } \\
\text { Number of Defects Per Phase } \\
\text { Total Unresolved Defects } \\
\text { Customer Satisfaction Trends } \\
\text { Supplier Performance and } \\
\text { Relationship Trends }\end{array}$ \\
\hline
\end{tabular}


To manage projects, an acquirer uses supplier data (base measures) and supplier reported derived measures in addition to measures of acquirer progress and output. The supplier measures required by the acquirer allow the acquirer to comprehensively address the measurement objectives and to comprehensively determine the progress of the project. In some cases, these supplier measures will augment the acquirer's measures (e.g., supplier's schedule performance index and size estimation accuracy). In most cases, the supplier measures will be the primary source of data, especially with regard to the development of the acquired product or service. For instance, measurement and analysis of the product or product components provided by a supplier through technical performance measures is essential for effective management of the quality, size, cost, and schedule of the project (e.g., amount of new, modified, reused code, percentage of function points complete, and defect removal efficiency). These supplier measures must be defined in the supplier agreement including a supplier's measurement collection requirements and the measurement reports to be provided to the acquirer. [AcQ]

\section{Typical Acquirer Work Products}

1. Specifications of base and derived measures

2. Acceptance criteria for supplier measures [ACQ]

\section{Subpractices}

1. Identify candidate measures based on documented measurement objectives.

The measurement objectives are refined into specific measures. The identified candidate measures are categorized and specified by name and unit of measure. [ACQ]

2. Identify existing measures that already address the measurement objectives.

Specifications for measures may already exist, perhaps established for other purposes earlier or elsewhere in the organization. [ACQ]

3. Specify operational definitions for the measures.

Operational definitions are stated in precise and unambiguous terms. They address two important criteria as follows: [AcO]

- Communication: What has been measured, how was it measured, what are the units of measure, and what has been included or excluded?

- Repeatability: Can the measurement be repeated, given the same definition, to get the same results?

4. Specify acceptance criteria based on operational definitions for the measures that will come from suppliers to the acquirer in a way that enables their intended use. [ACQ] 
Measures may be provided by the supplier as detailed measurement data or measurement reports. The measures that come from suppliers must be associated with the acquirer's acceptance criteria for supplier measures. The acceptance criteria may be captured in measurement specifications or by checklists, if appropriate. [ACQ]

The acceptance criteria should be defined in a way that enables the intended use of the supplier measures, such as potential aggregation and analysis. They need to include any criteria associated with the collection and transfer mechanisms and procedures that must be performed by the supplier. Consider all characteristics about the supplier measures that may impact their use such as differences in financial calendars used by different suppliers. [ACQ]

5. Prioritize, review, and update measures.

Proposed specifications of the measures are reviewed for their appropriateness with potential end users and other relevant stakeholders. Priorities are set or changed, and specifications of the measures are updated as necessary. [Aco]

\section{SP 1.3 Specify Data Collection and Storage Procedures}

\section{Specify how measurement data will be obtained and stored.}

Explicit specification of collection methods helps ensure that the right data are collected properly. It may also aid in further clarifying information needs and measurement objectives.

Proper attention to storage and retrieval procedures helps ensure that data are available and accessible for future use.

The supplier agreement specifies what measurement data the supplier has to provide to the acquirer, in what format it has to be provided to the acquirer, how the measurement data will be collected and stored by the supplier (e.g., retention period of data), how and how often it will be transferred to the acquirer and who has access to the data. Some supplier data may be considered proprietary by the supplier and may need to be protected as such by the acquirer. Also consider that some of the acquirer measurement data (e.g., total project cost data) may be proprietary and should not be shared with suppliers. An acquirer needs to plan for the collection, storage, and access control of this type of sensitive data. [ACQ]

The acquirer must ensure that appropriate mechanisms are in place to obtain the measurement data from the supplier in a consistent way. It is critical for the acquirer to insist in the supplier agreement on accurate data collection by the supplier for the acquirer's measurement and analysis. [ACQ]

\section{Typical Acquirer Work Products}

1. Data collection and storage procedures 


\section{Data collection tools}

\section{Typical Supplier Deliverables}

1. Recommendations for data collection and storage procedures [ACQ]

\section{Subpractices}

1. Identify existing sources of data that are generated from current work products, processes, or transactions.

2. Identify measures for which data are needed, but are not currently available.

3. Specify how to collect and store the data for each required measure.

Explicit specifications are made of how, where, and when the data will be collected. Procedures for collecting valid data are specified. The data are stored in an accessible manner for analysis, and it is determined whether they will be saved for possible reanalysis or documentation purposes. [AcQ]

Questions to be considered typically include the following: $[A C Q]$

- Have the frequency of collection and the points in the process where measurements will be made been determined?

- Has the time line that is required to move measurement results from the points of collection to repositories, other databases, or end users been established?

- Who is responsible for obtaining the data?

- Who is responsible for data storage, retrieval, and security?

- Have necessary supporting tools been developed or acquired?

- Have required data collection requirements and applicable procedures been specified in supplier agreement standards and related documents?

4. Create data collection mechanisms and process guidance.

Data collection and storage mechanisms are well integrated with other normal work processes. Data collection mechanisms may include manual or automated forms and templates. Clear, concise guidance on correct procedures is available to those responsible for doing the work. Training is provided as necessary to clarify the processes necessary for collection of complete and accurate data and to minimize the burden on those who must provide and record the data. [Aco]

Create mechanisms to transfer data from the supplier to the acquirer, along with process guidance, as appropriate. Data collection from a supplier may be integrated with periodic monitoring and review of supplier activities. Applicable standard report formats and/or tools to be used for reporting by the supplier must be specified in the supplier agreement. [ACQ]

5. Support automatic collection of the data where appropriate and feasible. 
6. Prioritize, review, and update data collection and storage procedures.

Proposed procedures are reviewed for their appropriateness and feasibility with those who are responsible for providing, collecting, and storing the data. They also may have useful insights about how to improve existing processes, or be able to suggest other useful measures or analyses. [ACQ]

Review data collection and storage procedures with potential suppliers throughout the solicitation. Update data collection and storage procedures as appropriate, and obtain supplier commitment to collect and store measurement data and reference the procedures in the supplier agreement. [AcQ]

7. Update measures and measurement objectives as necessary.

\section{SP 1.4 Specify Analysis Procedures}

\section{Specify how measurement data will be analyzed and reported.}

Specifying the analysis procedures in advance ensures that appropriate analyses will be conducted and reported to address the documented measurement objectives (and thereby the information needs and objectives on which they are based). This approach also provides a check that the necessary data will in fact be collected.

The supplier agreement defines the required data analysis and the definition and examples of the measures the supplier must provide to the acquirer. [ACQ]

\section{Typical Acquirer Work Products}

1. Analysis specification and procedures

2. Data analysis tools

Typical Supplier Deliverables

1. Recommendations for analysis specification and procedures [ACQ]

\section{Subpractices}

1. Specify and prioritize the analyses that will be conducted and the reports that will be prepared.

Early attention should be paid to the analyses that will be conducted and to the manner in which the results will be reported. These should meet the following criteria: [ACQ]

- The analyses explicitly address the documented measurement objectives

- Presentation of the results is clearly understandable by the audiences to whom the results are addressed

Priorities may have to be set within available resources. [Aco] 
Establish and maintain a description of the analysis approach for data element(s) and a description of the reports that must be provided by the supplier; provide a reference to the analysis specifications and procedures in the supplier agreement. [ACQ]

2. Select appropriate data analysis methods and tools.

Refer to the Select Measures and Analytic Techniques and Apply Statistical Methods to Understand Variation specific practices of the Quantitative Project Management process area for more information about the appropriate use of statistical analysis techniques and understanding variation, respectively.

Issues to be considered typically include the following: $[A C Q]$

- Choice of visual display and other presentation techniques (e.g., pie charts, bar charts, histograms, radar charts, line graphs, scatter plots, or tables)

- Choice of appropriate descriptive statistics (e.g., arithmetic mean, median, or mode)

- Decisions about statistical sampling criteria when it is impossible or unnecessary to examine every data element

- Decisions about how to handle analysis in the presence of missing data elements

- Selection of appropriate analysis tools

Descriptive statistics are typically used in data analysis to do the following: [ACQ]

- Examine distributions on the specified measures (e.g., central tendency, extent of variation, data points exhibiting unusual variation)

- Examine the interrelationships among the specified measures (e.g., comparisons of defects by phase of the product's life cycle or by product component)

- Display changes over time

3. Specify administrative procedures for analyzing the data and communicating the results.

Issues to be considered typically include the following: :Aco]

- Identifying the persons and groups responsible for analyzing the data and presenting the results

- Determining the time line to analyze the data and present the results

- Determining the venues for communicating the results (e.g., progress reports, transmittal memos, written reports, or staff meetings)

Data collected from a supplier is subjected to validity checks that can be achieved by means of periodic audits of the supplier's execution of the data collection and analysis procedures for acquirer required measures. The acquirer's option to perform validity checks of the measurement data collected by the supplier and the supplier's execution of their required analysis procedures must be defined in the supplier agreement. [ACQ] 
4. Review and update the proposed content and format of the specified analyses and reports.

All of the proposed content and format are subject to review and revision, including analytic methods and tools, administrative procedures, and priorities. The relevant stakeholders consulted should include intended end users, sponsors, data analysts, and data providers. [Aco]

Review the specified analyses and reports with suppliers and identify their commitment to support the analysis, and review any recommendations they may provide related to analysis of measurement data. [ACQ]

5. Update measures and measurement objectives as necessary.

Just as measurement needs drive data analysis, clarification of analysis criteria can affect measurement. Specifications for some measures may be refined further based on the specifications established for data analysis procedures. Other measures may prove to be unnecessary, or a need for additional measures may be recognized. [ACQ]

The exercise of specifying how measures will be analyzed and reported may also suggest the need for refining the measurement objectives themselves. [ACQ]

6. Specify criteria for evaluating the utility of the analysis results and the conduct of the measurement and analysis activities.

Criteria for evaluating the utility of the analysis might address the extent to which the following apply: [ACQ]

- The results are (1) provided on a timely basis, (2) understandable, and (3) used for decision making.

- The work does not cost more to perform than is justified by the benefits that it provides.

Criteria for evaluating the conduct of the measurement and analysis might include the extent to which the following apply: [ACO]

- The amount of missing data or the number of flagged inconsistencies is beyond specified thresholds.

- There is selection bias in sampling (e.g., only satisfied end users are surveyed to evaluate end-user satisfaction, or only unsuccessful projects are evaluated to determine overall productivity).

- The measurement data are repeatable (e.g., statistically reliable).

- Statistical assumptions have been satisfied (e.g., about the distribution of data or about appropriate measurement scales). 
The primary reason for doing measurement and analysis is to address identified information needs and objectives. Measurement results based on objective evidence can help to monitor performance, fulfill contractual obligations, make informed management and technical decisions, and enable corrective actions to be taken.

\section{SP 2.1 Collect Measurement Data}

\section{Obtain specified measurement data.}

The data necessary for analysis are obtained and checked for completeness and integrity.

The supplier's measurement data is collected according to the data collection and storage procedures as defined in the supplier agreements. The data necessary for analysis are obtained and checked for completeness and integrity. [ACQ]

\section{Typical Acquirer Work Products}

1. Base and derived measurement data sets

2. Results of data integrity tests

\section{Typical Supplier Deliverables}

1. Base and derived supplier measurement data sets [ACQ]

2. Results of data integrity tests of supplier measurement data [ACQ]

\section{Subpractices}

1. Obtain the data for base measures.

Data are collected as necessary for previously used as well as for newly specified base measures. Existing data are gathered from project records or from elsewhere in the organization. [ACQ]

Data is obtained from the supplier for base measures as defined in the supplier agreement. [ACQ]

2. Generate the data for derived measures.

Values are newly calculated for all derived measures. [ACQ]

Derived measures are obtained from the supplier as defined in the supplier agreement. [ACO]

3. Perform data integrity checks as close to the source of the data as possible. 
All measurements are subject to error in specifying or recording data. It is always better to identify such errors and to identify sources of missing data early in the measurement and analysis cycle. [AcQ]

Checks can include scans for missing data, out-of-bounds data values, and unusual patterns and correlation across measures. It is particularly important to do the following: $[A C Q]$

- Test and correct for inconsistency of classifications made by human judgment (i.e., to determine how frequently people make differing classification decisions based on the same information, otherwise known as "inter-coder reliability").

- Empirically examine the relationships among the measures that are used to calculate additional derived measures. Doing so can ensure that important distinctions are not overlooked and that the derived measures convey their intended meanings (otherwise known as "criterion validity").

Use acceptance criteria to verify the results of data integrity tests conducted by the supplier and of the integrity of supplier data. Follow up with suppliers if data is not available or data integrity checks indicate potential errors in data. [ACQ]

Refer to the Acquisition Management process area for information about resolving supplier agreement issues. [ACQ]

SP 2.2 Analyze Measurement Data

\section{Analyze and interpret measurement data.}

The measurement data are analyzed as planned, additional analyses are conducted as necessary, results are reviewed with relevant stakeholders, and necessary revisions for future analyses are noted.

\section{Typical Acquirer Work Products}

1. Analysis results and draft reports

\section{Typical Supplier Deliverables}

1. Response to analysis results and draft reports [ACQ]

\section{Subpractices}

1. Conduct initial analyses, interpret the results, and draw preliminary conclusions.

The results of data analyses are rarely self-evident. Criteria for interpreting the results and drawing conclusions should be stated explicitly. [ACO]

Discuss results and preliminary conclusions with suppliers, as appropriate. [ACQ]

2. Conduct additional measurement and analysis as necessary, and prepare results for presentation. 
The results of planned analyses may suggest (or require) additional, unanticipated analyses. In addition, they may identify needs to refine existing measures, to calculate additional derived measures, or even to collect data for additional base measures to properly complete the planned analysis. Similarly, preparing the initial results for presentation may identify the need for additional, unanticipated analyses. [ACO]

Coordinate additional analyses with suppliers, as appropriate. [ACO]

3. Review the initial results with relevant stakeholders.

It may be appropriate to review initial interpretations of the results and the way in which they are presented before disseminating and communicating them more widely. [AcQ]

Relevant stakeholders with whom reviews may be conducted include intended end users and sponsors, as well as data analysts and data providers. [Ace]

Review the initial results related to supplier progress or output also with suppliers and determine if revisions are appropriate based upon their response. [ACQ]

4. Refine criteria for future analyses.

Valuable lessons that can improve future efforts are often learned from conducting data analyses and preparing results. Similarly, ways to improve measurement specifications and data collection procedures may become apparent, as may ideas for refining identified information needs and objectives. [Aco]

Update data acceptance criteria for supplier measures, as appropriate. [Aco]

\section{SP 2.3 Store Data and Results}

\section{Manage and store measurement data, measurement specifications, and analysis results.}

Storing measurement-related information enables the timely and costeffective future use of historical data and results. The information also is needed to provide sufficient context for interpretation of the data, measurement criteria, and analysis results.

Information stored typically includes the following: [ACQ]

- Measurement plans

- Specifications of measures

- Sets of data that have been collected

- Analysis reports and presentations

- Retention period for data stored

- Data acceptance criteria for supplier data 
The stored information contains or references the information needed to understand and interpret the measures and to assess them for reasonableness and applicability (e.g., measurement specifications used on different projects when comparing across projects).

Data sets for derived measures typically can be recalculated and need not be stored. However, it may be appropriate to store summaries based on derived measures (e.g., charts, tables of results, or report prose).

Interim analysis results need not be stored separately if they can be efficiently reconstructed.

Projects may choose to store project-specific data and results in a project-specific repository. When data are shared more widely across projects, the data may reside in the organization's measurement repository.

Refer to the Establish the Organization's Measurement Repository specific practice of the Organizational Process Definition process area for more information about establishing the organization's measurement repository.

Refer to the Configuration Management process area for information about managing measurement work products.

\section{Typical Acquirer Work Products}

1. Stored data inventory

\section{Subpractices}

1. Review the data to ensure their completeness, integrity, accuracy, and currency.

2. Store the data according to the data storage procedures.

3. Make the stored contents available for use only by appropriate groups and personnel.

The acquirer also protects measurement data provided by the supplier according to the supplier agreement. The supplier agreement might specify that the acquirer must restrict access of a supplier's measurement data to employees of the acquirer only. [ACQ]

4. Prevent the stored information from being used inappropriately. 
Examples of inappropriate use include the following: [AcO]

- Disclosure of information that was provided in confidence

- Faulty interpretations based on incomplete, out-of-context, or otherwise misleading information

- Measures used to improperly evaluate the performance of people or to rank projects

- Impugning the integrity of specific individuals

SP 2.4 Communicate Results

Report results of measurement and analysis activities to all relevant stakeholders.

The results of the measurement and analysis process are communicated to relevant stakeholders in a timely and usable fashion to support decision making and assist in taking corrective action.

Relevant stakeholders include intended users, sponsors, data analysts, and data providers. Relevant stakeholders also include suppliers. [ACQ]

\section{Typical Acquirer Work Products}

1. Delivered reports and related analysis results

2. Contextual information or guidance to aid in the interpretation of analysis results

\section{Subpractices}

1. Keep relevant stakeholders apprised of measurement results on a timely basis.

To the extent possible and as part of the normal way they do business, users of measurement results are kept personally involved in setting objectives and deciding on plans of action for measurement and analysis. The users are regularly kept apprised of progress and interim results. [ACQ]

Refer to the Project Monitoring and Control process area for more information about the use of measurement results.

2. Assist relevant stakeholders in understanding the results.

Results are reported in a clear and concise manner appropriate to the methodological sophistication of the relevant stakeholders. They are understandable, easily interpretable, and clearly tied to identified information needs and objectives. [ACQ]

The acquirer establishes and maintains a standard format for communicating measurement data to suppliers. [AcQ] 
The data are often not self-evident to practitioners who are not measurement experts. Measurement choices should be explicitly clear about the following: $[A C Q]$

- How and why the base and derived measures were specified

- How the data were obtained

- How to interpret the results based on the data analysis methods that were used

- How the results address information needs Examples of actions to assist in understanding of results include the following: [ACQ]

- Discussing the results with the relevant stakeholders

- Providing a transmittal memo that provides background and explanation

- Briefing users on the results

- Providing training on the appropriate use and understanding of measurement results 
The purpose of Organizational Innovation and Deployment (OID) is to select and deploy incremental and innovative improvements that measurably improve the organization's processes and technologies. The improvements support the organization's quality and processperformance objectives as derived from the organization's business objectives.

The Organizational Innovation and Deployment process area enables the selection and deployment of improvements that can enhance the organization's ability to meet its quality and process-performance objectives. (See the definition of "quality and process-performance objectives" in the glossary.) The term "improvement," as used in this process area, refers to all of the ideas (proven and unproven) that would change the organization's processes and technologies to better meet the organization's quality and process-performance objectives.

Quality and process-performance objectives that this process area might address include the following:

- Improved product quality (e.g., functionality, performance)

- Increased productivity

- Decreased cycle time

- Greater customer and end-user satisfaction

- Shorter development or production time to change functionality or, add new features, or adapt to new technologies

- Reduce delivery time

- Reduce time to adapt to new technologies and business needs

Acquirer's improvement objectives may include the following: [ACQ]

- Improved performance of supply-chain involving multiple suppliers

- Improved inter-supplier performance

- Improved utilization of resources across the organization 
Achievement of these objectives depends on the successful establishment of an infrastructure that enables and encourages all people in the organization to propose potential improvements to the organization's processes and technologies. Achievement of these objectives also depends on being able to effectively evaluate and deploy proposed improvements to the organization's processes and technologies. All members of the organization can participate in the organization's process- and technology-improvement activities. Their proposals are systematically gathered and addressed.

Improvements may be identified and executed by the acquirer or the supplier. The acquirer encourages all suppliers to participate in the acquirer's process and technology improvement activities. Some of the selected improvements may be deployed across acquirer and supplier organizations. [ACQ]

The acquirer and suppliers may share the costs and benefits of improvements. Acquirers may increase the incentive for suppliers to participate in improvement efforts across the supply chain by allowing suppliers to appropriate all the value derived from a contributed improvement in the short term (e.g., 6 to 18 months). Over time the supplier may be expected to share a proportion of those savings with the acquirer (e.g., through cost reductions to the acquirer). [ACQ]

Pilots are conducted to evaluate significant changes involving untried, high-risk, or innovative improvements before they are broadly deployed.

Process and technology improvements that will be deployed across the organization are selected from process- and technology-improvement proposals based on the following criteria:

- A quantitative understanding of the organization's current quality and process performance

- The organization's quality and process-performance objectives

- Estimates of the improvement in quality and process performance resulting from deploying the process and technology improvements

- Estimated costs of deploying process and technology improvements, and the resources and funding available for such deployment

The expected benefits added by the process and technology improvements are weighed against the cost and impact to the organization. Change and stability must be balanced carefully. Change that is too great or too rapid can overwhelm the organization, destroying its investment in organizational learning represented by organizational process assets. Rigid stability can result in stagnation, allowing the changing business environment to erode the organization's business position. 
Improvements are deployed, as appropriate, to new and ongoing projects.

In this process area, the term "process and technology improvements" refers to incremental and innovative improvements to processes and also to process or product technologies (including project work environments).

The informative material in this process area is written with the assumption that the specific practices are applied to a quantitatively managed process. The specific practices of this process area may be applicable, but with reduced value, if the assumption is not met.

The specific practices in this process area complement and extend those found in the Organizational Process Focus process area. The focus of this process area is process improvement that is based on a quantitative knowledge of the organization's set of standard processes and technologies and their expected quality and performance in predictable situations. In the Organizational Process Focus process area, no assumptions are made about the quantitative basis of improvement.

Refer to the Organizational Process Definition process area for more information about incorporating the deployed process improvements into organizational process assets.

Refer to the Organizational Process Focus process area for more information about soliciting, collecting, and handling process improvement proposals and coordinating the deployment of process improvement into the project's defined processes.

Refer to the Organizational Training process area for more information about providing updated training to support deployment of process and technology improvements.

Refer to the Organizational Process Performance process area for more information about quality and process-performance objectives and process performance models. Quality and process-performance objectives are used to analyze and select process- and technologyimprovement proposals for deployment. Process performance models are used to quantify the impact and benefits of innovations.

Refer to the Measurement and Analysis process area for more information about establishing objectives for measurement and analysis, specifying the measures and analyses to be performed, obtaining and analyzing measures, and reporting results. 
Refer to the Integrated Project Management process area for more information about coordinating the deployment of process and technology improvements into the project's defined process and project work environment.

Refer to the Decision Analysis and Resolution process area for more information about formal evaluations related to improvement proposals and innovations.

\section{Specific Goal and Practice Summary}

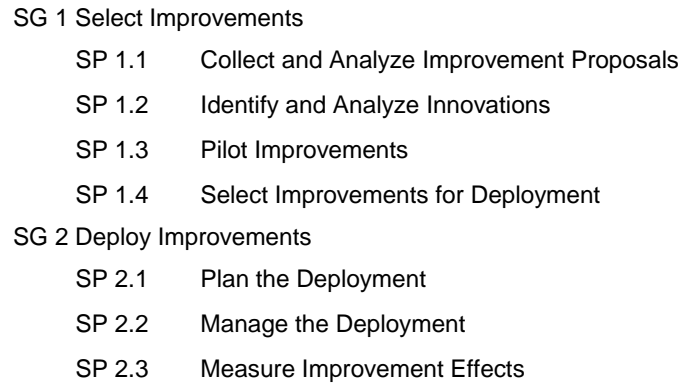

Specific Practices by Goal

SG 1 Select Improvements

Process and technology improvements that contribute to meeting quality and process-performance objectives are selected.

SP 1.1 Collect and Analyze Improvement Proposals

Collect and analyze process- and technology-improvement proposals.

Each process- and technology-improvement proposal must be analyzed.

The acquirer must continuously improve its processes and its alignment with its suppliers. The acquirer may look for opportunities to maximize throughput based on the identification of the most limiting resource and, as a result, create a more agile supply chain (e.g., improvement proposals that promote a supply chain that responds both quickly and cost effectively). [ACQ]

Simple process and technology improvements, with well-understood benefits and effects, will not usually undergo detailed evaluations.

Examples of simple process and technology improvements include the following: [ACQ]

- Combine the technical review and management review for suppliers into a single technical/management review.

- Establish guidelines for multi-supplier interactions 


\section{Typical Acquirer Work Products}

\section{Analyzed process- and technology-improvement proposals}

\section{Typical Supplier Deliverables}

1. Process- and technology-improvement proposals [ACQ]

\section{Subpractices}

1. Collect process- and technology-improvement proposals.

A process- and technology-improvement proposal documents proposed incremental and innovative improvements to specific processes and technologies. Managers and staff in the organization, as well as customers, end users, and suppliers can submit process- and technology-improvement proposals. Process and technology improvements may be implemented at the local level before being proposed for the organization. [ACQ]

Examples of sources for process- and technology-improvement proposals include the following: $\left.{ }^{A C Q}\right]$

- Findings and recommendations from process appraisals

- The organization's quality and process-performance objectives

- Analysis of data about customer and end-user problems as well as customer and end-user satisfaction

- Analysis of data about project performance compared to quality and productivity objectives

- Analysis of technical performance measures

- Results of process and product benchmarking efforts

- Analysis of data on defect causes

- Measured effectiveness of process activities

- Measured effectiveness of the project's work environment

- Examples of process- and technology-improvement proposals that were successfully adopted elsewhere

- Feedback on previously submitted process- and technology-improvement proposals

- Spontaneous ideas from managers and staff

- Findings and recommendations from joint acquirer and supplier study groups

Refer to the Organizational Process Focus process area for more information about process- and technology-improvement proposals.

2. Analyze the costs and benefits of process- and technologyimprovement proposals as appropriate. 
Process- and technology-improvement proposals that have a large cost-to-benefit ratio are rejected. [ACQ]

Criteria for evaluating costs and benefits include the following: [ACO]

- Contribution toward meeting the organization's quality and process-performance objectives

- Effect on mitigating identified project and organizational risks

- Ability to respond quickly to changes in project requirements, market situations, and the business environment

- Effect on related processes and associated assets

- Cost of defining and collecting data that supports the measurement and analysis of the process- and technology-improvement proposal

- Expected life span of the proposal

Process- and technology-improvement proposals that would not improve the organization's processes are rejected. [ACQ]

Process performance models provide insight into the effect of process changes on process capability and performance. [ACQ]

Refer to the Organizational Process Performance process area for more information about process performance models.

3. Identify the process- and technology-improvement proposals that are innovative.

Innovative improvements are also identified and analyzed in the Identify and Analyze Innovations specific practice. [ACO]

Whereas this specific practice analyzes proposals that have been passively collected, the purpose of the Identify and Analyze Innovations specific practice is to actively search for and locate innovative improvements. The search primarily involves looking outside the organization. [ACQ]

Innovative improvements are typically identified by reviewing process- and technology-improvement proposals or by actively investigating and monitoring innovations that are in use in other organizations or are documented in research literature. Innovation may be inspired by internal improvement objectives or by the external business environment. [ACQ]

Innovative improvements are typically major changes to the process that represent a break from the old way of doing things (e.g., changing the life-cycle model). Innovative improvements may also include changes in the products that support, enhance, or automate the process (e.g., using off-the-shelf products to support the process). [ACQ] 
Examples of innovative improvements include the following: [ACQ]

- New support tools

- New techniques, methodologies, processes, or life-cycle models

- New interface standards

- New reusable components

- New management techniques

- New quality-improvement techniques

- New process-development and deployment-support tools

4. Identify potential barriers and risks to deploying each process- and technology-improvement proposal.

Examples of barriers to deploying process and technology improvements include the following: $[\mathrm{ACQ}]$

- Turf guarding and parochial perspectives

- Unclear or weak business rationale

- Lack of short-term benefits and visible successes

- Unclear picture of what is expected from everyone

- Too many changes at the same time

- Lack of involvement and support of relevant stakeholders

Examples of risk factors that affect the deployment of process and technology improvements include the following: $[A C O]$

- Compatibility of the improvement with existing processes, values, and skills of potential end users

- Complexity of the improvement

- Difficulty implementing the improvement

- Ability to demonstrate the value of the improvement before widespread deployment

- Justification for large, up-front investments in areas such as tools and training

- Inability to overcome "technology drag" where the current implementation is used successfully by a large and mature installed base of end users

- Additional cost to the supplier

- Misalignment of acquirer and supplier improvement priorities

5. Estimate the cost, effort, and schedule required for deploying each process- and technology-improvement proposal.

6. Select the process- and technology-improvement proposals to be piloted before broadscale deployment. 
Since innovations, by definition, usually represent a major change, most innovative improvements will be piloted. [ACQ]

7. Document the results of the evaluation of each process- and technology-improvement proposal.

8. Monitor the status of each process- and technology-improvement proposal.

SP 1.2 Identify and Analyze Innovations

Identify and analyze innovative improvements that could increase the organization's quality and process performance.

The specific practice, Collect and Analyze Improvement Proposals, analyzes proposals that are passively collected. The purpose of this specific practice is to actively search for, locate, and analyze innovative improvements. This search primarily involves looking outside the organization.

An acquirer's customers and suppliers are vital sources of innovative ideas. Inter-organizational and organizational learning are therefore critical to actively identifying and analyzing innovations. [ACQ]

\section{Typical Acquirer Work Products}

1. Candidate innovative improvements

2. Analysis of proposed innovative improvements

\section{Typical Supplier Deliverables}

1. Candidate innovative improvements [ACQ]

\section{Subpractices}

1. Analyze the organization's set of standard processes to determine areas where innovative improvements would be most helpful.

These analyses are performed to determine which subprocesses are critical to achieving the organization's quality and process-performance objectives and which ones are good candidates to be improved. [ACQ]

2. Investigate innovative improvements that may improve the organization's set of standard processes.

Investigating innovative improvements involves the following: [ACO]

- Systematically maintaining awareness of leading relevant technical work and technology trends

- Periodically searching for commercially available innovative improvements

- Collecting proposals for innovative improvements from the projects and the organization 
- Systematically reviewing processes and technologies used externally and comparing them to those used within the organization

- Identifying areas where innovative improvements have been used successfully, and reviewing data and documentation of experience using these improvements

- Identifying improvements that integrate new technology into products and the project's work environment

- Determining where suppliers' products stand in terms of technology cycles and product life cycles

- Monitoring economies all over the world to spot new supply bases and markets

3. Analyze potential innovative improvements to understand their effects on process elements and predict their influence on the process.

The acquirer together with its suppliers may establish an innovation review program. This program may create time-boxed innovation solicitation, which is a well-communicated formal process for analysis and guaranteed response to innovative ideas proposed by customers, employees, and suppliers. [Ace]

Process performance models can provide a basis for analyzing possible effects of changes to process elements. [ACQ]

Refer to the Organizational Process Performance process area for more information about process performance models.

4. Analyze the costs and benefits of potential innovative improvements.

Innovative improvements that have a very large cost-to-benefit ratio are rejected. [ACQ]

5. Create process- and technology-improvement proposals for those innovative improvements that would result in improving the organization's processes or technologies.

6. Select the innovative improvements to be piloted before broadscale deployment.

Since innovations, by definition, usually represent a major change, most innovative improvements will be piloted. [ACQ]

7. Document the results of the evaluations of innovative improvements.

SP 1.3 Pilot Improvements

Pilot process and technology improvements to select which ones to implement.

Pilots are performed to assess new and unproven major changes before they are broadly deployed, as appropriate. 
The implementation of this specific practice may overlap with the implementation of the Implement the Action Proposals specific practice in the Causal Analysis and Resolution process area (e.g., when causal analysis and resolution is implemented organizationally or across multiple projects).

\section{Typical Acquirer Work Products}

1. Pilot evaluation reports

2. Documented lessons learned from pilots

\section{Typical Supplier Deliverables}

1. Pilot evaluation reports for pilots executed in supplier environment [ACQ]

2. Documented lessons learned from pilots executed in supplier environment [ACQ]

\section{Subpractices}

1. Plan the pilots.

When planning pilots, it is critical to define quantitative criteria to be used for evaluating pilot results. [ACQ]

2. Review and get relevant stakeholder agreement on the plans for the pilots.

3. Consult with and assist the people performing the pilots.

4. Perform each pilot in an environment that is characteristic of the environment present in a broadscale deployment.

5. Track the pilots against their plans.

6. Review and document the results of pilots.

Pilot results are evaluated using the quantitative criteria defined during pilot planning. Reviewing and documenting the results of pilots usually involves the following: $[\mathrm{ACQ}]$

- Deciding whether to terminate the pilot, replan and continue the pilot, or proceed with deploying the process and technology improvement

- Updating the disposition of process- and technology-improvement proposals associated with the pilot

- Identifying and documenting new process- and technology-improvement proposals as appropriate

- Identifying and documenting lessons learned and problems encountered during the pilot 
Select process and technology improvements for deployment across the organization.

Selection of process and technology improvements for deployment across the organization is based on quantifiable criteria derived from the organization's quality and process-performance objectives.

\section{Typical Acquirer Work Products}

1. Process and technology improvements selected for deployment

\section{Subpractices}

1. Prioritize the candidate process and technology improvements for deployment.

Priority is based on an evaluation of the estimated cost-to-benefit ratio with regard to the quality and process-performance objectives. [ACQ]

Refer to the Organizational Process Performance process area for more information about quality and process-performance objectives.

2. Select the process and technology improvements to be deployed.

The selection of the process improvements is based on their priorities and the available resources. [ACQ]

3. Determine how each process and technology improvement will be deployed.

Examples of how the process and technology improvements may be deployed include incorporating these improvements into the following: [ACQ]

- Organizational process assets

- Project-specific or common work environments

- All or a subset of the organization's product families

- All or a subset of the organization's projects

- All or a subset of the organizational groups

4. Document the results of the selection process.

The results of the selection process usually include the following: [ACQ]

- The selection criteria for candidate improvements

- The disposition of each improvement proposal

- The rationale for the disposition of each improvement proposal

- The assets to be changed for each selected improvement 
SP 2.1 Plan the Deployment

\section{Establish and maintain the plans for deploying the selected process and technology improvements.}

The plans for deploying each process and technology improvement may be included in the organization's plan for organizational innovation and deployment or they may be documented separately.

An acquirer's plan for deploying improvements may include openly sharing most process know-how with its suppliers. Any process related knowledge that the acquirer or one of its suppliers possesses is viewed as accessible to virtually any other supplier in the acquirer's supply chain (perhaps with the exception of a direct competitor). In this case, the acquirer needs to establish rules and norms that prevent suppliers from accessing the acquirer's knowledge unless they first explicitly agree to openly share knowledge with other suppliers of the acquirer. For example, the acquirer has the ability to impose economic sanctions (e.g., withdrawal of business) on the supplier that violates the rule. [ACQ]

The implementation of this specific practice complements the Deploy Organizational Process Assets specific practice in the Organizational Process Focus process area, and adds the use of quantitative data to guide the deployment and to determine the value of the improvements with respect to quality and process performance objectives.

Refer to the Organizational Process Focus process area for more information about planning the deployment of organizational process assets.

This specific practice plans the deployment of individual process and technology improvements. The Plan the Process generic practice addresses comprehensive planning that covers the specific practices in this process area.

Typical Acquirer Work Products

1. Deployment plan for selected process and technology improvements

\section{Subpractices}

1. Determine how each process and technology improvement must be adjusted for organization-wide deployment.

Process and technology improvements proposed within a limited context (e.g., for a single project) might have to be modified to work across the organization. [ACQ] 
2. Determine the changes necessary to deploy each process and technology improvement.

Examples of changes needed to deploy a process and technology improvement

include the following: $[\mathrm{ACO}]$

- Process descriptions, standards, and procedures

- Work environments

- Education and training

- Skills

- Existing commitments

- Existing activities

- Continuing support to end users

- Organizational culture and characteristics

- Supplier agreements

3. Identify strategies to address potential barriers to deploying each process and technology improvement.

4. Establish measures and objectives for determining the value of each process and technology improvement with respect to the organization's quality and process-performance objectives.

Examples of measures for determining the value of a process and technology

improvement include the following: [ACQ]

- Return on investment

- Time to recover the cost of the process or technology improvement

- Measured improvement in the project's or organization's process performance

- Number and types of project and organizational risks mitigated by the process or technology improvement

- Ability to respond quickly to changes in project requirements, market situations, and the business environment

Refer to the Measurement and Analysis process area for more information about establishing objectives for measurement and analysis, specifying the measures and analyses to be performed, obtaining and analyzing measures, and reporting results.

5. Document the plan for deploying each process and technology improvement.

6. Review and get agreement with relevant stakeholders on the plan for deploying each process and technology improvement. 
7. Revise the plan for deploying each process and technology improvement as necessary.

\section{SP 2.2 Manage the Deployment}

\section{Manage the deployment of the selected process and technology improvements.}

The implementation of this specific practice may overlap with the implementation of the Implement the Action Proposals specific practice in the Causal Analysis and Resolution process area (e.g., when causal analysis and resolution is implemented organizationally or across multiple projects). The primary difference is that in the Causal Analysis and Resolution process area, planning is done to manage the removal of the root causes of defects or problems from the project's defined processes. In the Organizational Innovation and Deployment process area, planning is done to manage the deployment of improvements to the organization's processes and technologies that can be quantified against the organization's business objectives.

\section{Typical Acquirer Work Products}

1. Updated training materials (to reflect deployed process and technology improvements)

2. Documented results of process- and technology-improvement deployment activities

3. Revised process- and technology-improvement measures, objectives, priorities, and deployment plans

\section{Subpractices}

1. Monitor the deployment of the process and technology improvements using the deployment plan.

2. Coordinate the deployment of process and technology improvements across the organization.

Coordinating deployment includes the following activities: [AcQ]

- Coordinating the activities of projects, support groups, and organizational groups for each process and technology improvement

- Coordinating the activities for deploying related process and technology improvements

3. Quickly deploy process and technology improvements in a controlled and disciplined manner, as appropriate. 
Examples of methods for quickly deploying process and technology improvements include the following: $[\mathrm{ACQ}]$

- Using red-lines, process change notices, or other controlled process documentation as interim process descriptions

- Deploying process and technology improvements incrementally, rather than as a single deployment

- Providing comprehensive consulting to early adopters of the process and technology improvement in lieu of revised formal training

4. Incorporate the process and technology improvements into organizational process assets, as appropriate.

Refer to the Organizational Process Definition process area for more information about organizational process assets.

5. Coordinate the deployment of the process and technology improvements into the projects' defined processes as appropriate.

Refer to the Organizational Process Focus process area for more information about deploying organizational process assets.

6. Provide consulting, as appropriate, to support deployment of the process and technology improvements.

7. Provide updated training materials to reflect the improvements to the organizational process assets.

Refer to the Organizational Training process area for more information about training materials.

8. Confirm that the deployment of all process and technology improvements is completed.

9. Determine whether the ability of the defined process to meet quality and process-performance objectives is adversely affected by the process and technology improvement, and take corrective action as necessary.

Refer to the Quantitative Project Management process area for more information about quantitatively managing the project's defined process to achieve the project's established quality and process-performance objectives.

10. Document and review the results of process- and technologyimprovement deployment.

Documenting and reviewing the results includes the following: $[\mathrm{ACQ}]$

- Identifying and documenting lessons learned 
- Identifying and documenting new process- and technology-improvement proposals

- Revising process- and technology-improvement measures, objectives, priorities, and deployment plans

\section{SP 2.3 Measure Improvement Effects}

Measure the effects of the deployed process and technology improvements.

Refer to the Measurement and Analysis process area for more information about establishing objectives for measurement and analysis, specifying the measures and analyses to be performed, obtaining and analyzing measures, and reporting results.

The implementation of this specific practice may overlap with the implementation of the Evaluate the Effect of Changes specific practice in the Causal Analysis and Resolution process area (e.g., when causal analysis and resolution is implemented organizationally or across multiple projects).

\section{Typical Acquirer Work Products}

1. Documented measures of the effects resulting from the deployed process and technology improvements

\section{Subpractices}

1. Measure the actual cost, effort, and schedule for deploying each process and technology improvement.

2. Measure the value of each process and technology improvement.

3. Measure the progress toward achieving the organization's quality and process-performance objectives.

4. Analyze the progress toward achieving the organization's quality and process-performance objectives and take corrective action as needed.

Refer to the Organizational Process Performance process area for more information about process performance analyses.

5. Store the measures in the organization's measurement repository. 
The purpose of Organizational Process Definition (OPD) is to establish and maintain a usable set of organizational process assets and work environment standards.

Organizational process assets enable consistent process performance across the organization and provide a basis for cumulative, long-term benefits to the organization. (See the definition of "organizational process assets" in the glossary.)

The organization's process asset library is a collection of items maintained by the organization for use by the people and projects of the organization. This collection of items includes descriptions of processes and process elements, descriptions of life-cycle models, process tailoring guidelines, process-related documentation, and data. The organization's process asset library supports organizational learning and process improvement by allowing the sharing of best practices and lessons learned across the organization.

The acquirer's set of standard processes also describes standard interactions with suppliers. Supplier interactions are typically identified in terms of deliverables expected from suppliers, acceptance criteria applicable to those deliverables, standards (e.g., architecture and technology standards), and standard milestone and progress reviews. [ACQ]

The organization's set of standard processes is tailored by projects to create their defined processes. The other organizational process assets are used to support tailoring as well as the implementation of the defined processes. The work environment standards are used to create the project work environment.

A standard process is composed of other processes or process elements. A process element is the fundamental (e.g., atomic) unit of process definition and describes the activities and tasks to consistently perform work. Process architecture provides rules for connecting the process elements of a standard process. The organization's set of standard processes may include multiple process architectures. 
(See the definitions of "standard process," "process architecture," and "process element" in the glossary.)

The organizational process assets may be organized in many ways, depending on the implementation of the Organizational Process Definition process area. Examples

include the following:

- Descriptions of life-cycle models may be documented as part of the organization's set of standard processes, or they may be documented separately.

- The organization's set of standard processes may be stored in the organization's process asset library, or they may be stored separately.

- A single repository may contain both the measurements and the process-related documentation, or they may be stored separately.

Refer to the Organizational Process Focus process area for more information about organizational process-related matters.

Specific Goal and Practice Summary

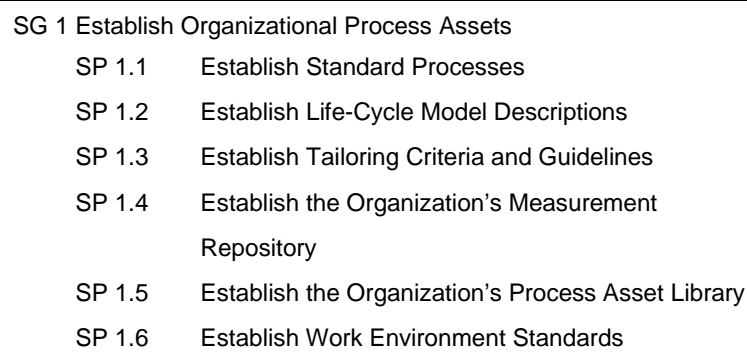

SP 1.6 Establish Work Environment Standards 
Standard processes may be defined at multiple levels in an enterprise and they may be related in a hierarchical manner. For example, an enterprise may have a set of standard processes that is tailored by individual organizations (e.g., a division or site) in the enterprise to establish their set of standard processes. The set of standard processes may also be tailored for each of the organization's business areas or product lines. Thus "the organization's set of standard processes" can refer to the standard processes established at the organization level and standard processes that may be established at lower levels, although some organizations may only have a single level of standard processes. (See the definitions of "standard process" and "organization's set of standard processes" in the glossary.)

Multiple standard processes may be needed to address the needs of different application domains, life-cycle models, methodologies, and tools. The organization's set of standard processes contains process elements (e.g., a work product size-estimating element) that may be interconnected according to one or more process architectures that describe the relationships among these process elements. Processes may be composed of other processes or process elements. [AcQ]

The organization's set of standard processes typically includes technical, management, administrative, support, and organizational processes.

Basing standard processes on industry standards and widely accepted models, with common terminology and lexicon, enables seamless interactions between acquirer and supplier. In a multi-supplier environment, this is most important for the standard processes of the acquirer that directly interface with the supplier processes. Also, there may be cost and coordination benefits from having suppliers work together to develop or reconcile common support processes that are aligned with the acquirer's processes. [AcQ]

The level of detail required for standard processes depends on the flexibility needed by an enterprise, for instance, based on differences in business context, project types, and application domains. [AcQ]

The organization's set of standard processes should collectively cover all processes needed by the organization and projects, including those processes addressed by the process areas at Maturity Level 2.

\section{Typical Acquirer Work Products}

1. Organization's set of standard processes

\section{Typical Supplier Deliverables}

1. Standard supplier processes that interface with acquirer's processes [ACQ] 


\section{Subpractices}

1. Decompose each standard process into constituent process elements to the detail needed to understand and describe the process.

Each process element covers a bounded and closely related set of activities. The descriptions of the process elements may be templates to be filled in, fragments to be completed, abstractions to be refined, or complete descriptions to be tailored or used unmodified. These elements are described in sufficient detail such that the process, when fully defined, can be consistently performed by appropriately trained and skilled people.

Examples of process elements include the following: [ACQ]

- Template for conduct of management reviews

- Templates for supplier deliverables

- Common lexicon for directly interfacing acquirer and supplier processes

- Templates for standard supplier agreements

- Description of method for verifying supplier estimates

- Description of standard acquisition approaches

- Description of standard acceptance criteria

2. Specify the critical attributes of each process element.

Examples of critical attributes include the following: $[\mathrm{ACO}]$

- Process roles

- Applicable standards

- Applicable procedures, methods, tools, and resources

- Process performance objectives

- Entry criteria

- Inputs

- Product and process measures to be collected and used

- Verification points

- Outputs

- Interfaces

- Exit criteria

3. Specify the relationships of the process elements. 
Examples of relationships include the following:

- Ordering of the process elements

- Interfaces among the process elements

- Interfaces with external processes

- Interdependencies among the process elements

The rules for describing the relationships among process elements are referred to as "process architecture." The process architecture covers the essential requirements and guidelines. The detailed specifications of these relationships are covered in the descriptions of the defined processes that are tailored from the organization's set of standard processes.

4. Ensure that the organization's set of standard processes adheres to applicable policies, standards and models.

Adherence to applicable process standards and models is typically demonstrated by developing a mapping from the organization's set of standard processes to the relevant process standards and models. In addition, this mapping will be a useful input to future appraisals.

5. Ensure that the organization's set of standard processes satisfies the process needs and objectives of the organization.

Refer to the Organizational Process Focus process area for more information about establishing and maintaining the organization's process needs and objectives.

6. Ensure that there is appropriate integration among the processes that are included in the organization's set of standard processes.

7. Document the organization's set of standard processes.

8. Conduct peer reviews on the organization's set of standard processes.

The acquirer's review of its standard processes can include the participation of suppliers for those processes and process elements that define standard interactions with suppliers. [ACQ]

9. Revise the organization's set of standard processes as necessary.

SP 1.2 Establish Life-Cycle Model Descriptions

Establish and maintain descriptions of the life-cycle models approved for use in the organization. 
Life-cycle models may be developed for a variety of customers or in a variety of situations, since one life-cycle model may not be appropriate for all situations. The organization may identify more than one life-cycle model for use. Typically, the organization needs life-cycle models for the types of products and services that it delivers and to define the phases of the project.

The lifecycle models describe acquisition lifecycles, depending on the specific acquisition strategy chosen. The acquisition life-cycle typically begins with the pre-award phase of a supplier agreement, continues through the phases of awarding and managing the supplier agreement, and ends when the supplier agreement period of performance ends, usually with the acceptance and completion of the warranty for the acquired product and the transition of the product to the support organization. [ACQ]

\section{Typical Acquirer Work Products}

1. Descriptions of life-cycle models

\section{Subpractices}

1. Select life-cycle models based on the needs of projects and the organization.

Examples of project characteristics that could affect life-cycle models include the following: [ACQ]

- Size of the project

- Experience and familiarity of project staff in implementing the process

- Constraints such as schedule and acceptable defect levels

2. Document the descriptions of the life-cycle models.

The life-cycle models may be documented as part of the organization's standard process descriptions or they may be documented separately.

3. Conduct peer reviews on the life-cycle models.

The acquirer's review of life cycle models should include the participation of suppliers for those processes and process elements that define expectations and constraints for suppliers. [ACQ]

4. Revise the descriptions of the life-cycle models as necessary.

\section{SP 1.3 Establish Tailoring Criteria and Guidelines}

Establish and maintain the tailoring criteria and guidelines for the organization's set of standard processes. 
The tailoring criteria and guidelines describe the following:

- How the organization's set of standard processes and organizational process assets are used to create the defined processes

- Mandatory requirements that must be satisfied by the defined processes (e.g., the subset of the organizational process assets that are essential for any defined process)

- Options that can be exercised and criteria for selecting among the options

- Procedures that must be followed in performing and documenting process tailoring

Examples of reasons for tailoring include the following: $[\mathrm{ACO}]$

- Adapting the process for a new supplier

- Customizing the process for a specific application or class of applications (e.g., initial development, maintenance, or creation of prototypes)

- Elaborating the process description so that the resulting defined process can be performed

- Supplier characteristics like number of projects executed for the acquirer, supplier's process maturity

- Acquisition strategy

Flexibility in tailoring and defining processes is balanced with ensuring appropriate consistency in the processes across the organization. Flexibility is needed to address contextual variables such as the domain; nature of the customer; cost, schedule, and quality tradeoffs; technical difficulty of the work; and experience of the people implementing the process. Consistency across the organization is needed so that organizational standards, objectives, and strategies are appropriately addressed, and process data and lessons learned can be shared.

Tailoring is a critical activity to allow for controlled changes to the processes due to specific needs of a project or a part of the organization. Processes and process elements that are more directly related to critical business goals and objectives should usually be defined as mandatory (allowing less variation), but processes and process elements that are less critical or only indirectly affect business objectives may allow for more tailoring (and therefore more variation). It could also depend on the life-cycle model of the project, the supplier, or the acquirer-supplier relationship. [ACQ]

Tailoring criteria and guidelines may allow for using a standard process "as is," with no tailoring. 


\section{Typical Acquirer Work Products}

1. Tailoring guidelines for the organization's set of standard processes

\section{Subpractices}

1. Specify the selection criteria and procedures for tailoring the organization's set of standard processes.

To fully leverage the supplier's process capability, the acquirer may choose to minimize the tailoring of the supplier's standard processes due to the acquirer's processes. Depending on the interfaces of the acquirer's processes with the supplier's processes, the acquirer's standard processes may need to be tailored to allow the supplier to execute their standard processes. [ACO]

Examples of criteria and procedures include the following: $[\mathrm{ACO}]$

- Criteria for selecting life-cycle models from those approved by the organization

- Criteria for selecting process elements from the organization's set of standard processes

- Procedures for tailoring the selected life-cycle models and process elements to accommodate specific process characteristics and needs

- Criteria for selecting acquisition strategy and suppliers

- Criteria for selecting acquirer processes based on supplier process tailoring like adding or combining testing cycles

Examples of tailoring actions include the following: [ACQ]

- Modifying a life-cycle model

- Combining elements of different life-cycle models

- Modifying process elements

- Replacing process elements

- Reordering process elements

2. Specify the standards for documenting the defined processes.

3. Specify the procedures for submitting and obtaining approval of waivers from the requirements of the organization's set of standard processes.

4. Document the tailoring guidelines for the organization's set of standard processes.

5. Conduct peer reviews on the tailoring guidelines.

6. Revise the tailoring guidelines as necessary. 


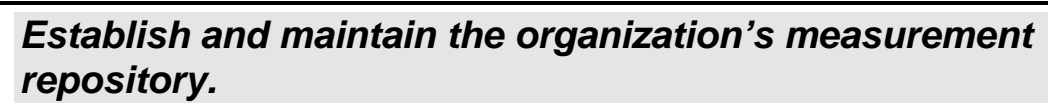

Refer to the Use Organizational Process Assets for Planning Project Activities specific practice of the Integrated Project Management process area for more information about the use of the organization's measurement repository in planning project activities.

The repository contains both product and process measures that are related to the organization's set of standard processes. It also contains or refers to the information needed to understand and interpret the measures and assess them for reasonableness and applicability. For example, the definitions of the measures are used to compare similar measures from different processes.

Standard measures that need to be collected from the supplier are included as requirements in the standard supplier agreements. [ACQ]

\section{Typical Acquirer Work Products}

1. Definition of the common set of product and process measures for the organization's set of standard processes

2. Design of the organization's measurement repository

3. Organization's measurement repository (that is, the repository structure and support environment)

4. Organization's measurement data

\section{Subpractices}

1. Determine the organization's needs for storing, retrieving, and analyzing measurements.

2. Define a common set of process and product measures for the organization's set of standard processes.

The measures in the common set are selected based on the organization's set of standard processes. They are selected for their ability to provide visibility into process performance to support expected business objectives. The common set of measures may vary for different standard processes.

The standard measures are selected for their ability to provide visibility into processes critical to support expected business objectives and help focus on elements significantly impacting the performance within a project and across the organization. [ACQ]

The measures defined include measures related to acquisition management, some of which may need to be collected from the suppliers. [ACQ] 
Operational definitions for the measures specify the procedures for collecting valid data and the point in the process where the data will be collected.

Examples of classes of commonly used acquirer measures include the following: [ACQ]

- Requirements Volatility

- Return on Investment

- Cost Performance Index

- Number of Defects Per Phase and/or by severity of defects

- Schedule Performance Index

- Customer Satisfaction Trends

- Supplier Performance and Relationship Trends

Refer to the Measurement and Analysis process area for more information about defining measures.

3. Design and implement the measurement repository.

4. Specify the procedures for storing, updating, and retrieving measures.

5. Conduct peer reviews on the definitions of the common set of measures and the procedures for storing and retrieving measures.

6. Enter the specified measures into the repository.

Refer to the Measurement and Analysis process area for more information about collecting and analyzing data.

7. Make the contents of the measurement repository available for use by the organization and projects as appropriate.

8. Revise the measurement repository, common set of measures, and procedures as the organization's needs change.

Examples of when the common set of measures may need to be revised include the following:

- New processes are added

- Processes are revised and new measures are needed

- Finer granularity of data is required

- Greater visibility into the process is required

- Measures are retired

SP 1.5 Establish the Organization's Process Asset Library

Establish and maintain the organization's process asset library. 
Examples of items to be stored in the organization's process asset library include the following:

- Organizational policies

- Defined process descriptions

- Procedures (e.g., estimating procedure)

- Development plans

- Acquisition plans

- Quality assurance plans

- Training materials

- Process aids (e.g., checklists)

- Lessons-learned reports

Typical Acquirer Work Products

1. Design of the organization's process asset library

2. Organization's process asset library

3. Selected items to be included in the organization's process asset library

4. Catalog of items in the organization's process asset library

\section{Subpractices}

1. Design and implement the organization's process asset library, including the library structure and support environment.

2. Specify the criteria for including items in the library.

The items are selected based primarily on their relationship to the organization's set of standard processes.

3. Specify the procedures for storing and retrieving items.

4. Enter the selected items into the library and catalog them for easy reference and retrieval.

5. Make the items available for use by the projects.

6. Periodically review the use of each item and use the results to maintain the library contents.

7. Revise the organization's process asset library as necessary.

Examples of when the library may need to be revised include the following:

- New items are added

- Items are retired 
- Current versions of items are changed

SP 1.6 Establish Work Environment Standards

Establish and maintain work environment standards.

Work environment standards allow the organization and projects to benefit from common tools, training, and maintenance, as well as cost savings from volume purchases. Work environment standards address the needs of all stakeholders and consider productivity, cost, availability, security, and workplace health, safety, and ergonomic factors. Work environment standards can include guidelines for tailoring and/or the use of waivers that allow adaptation of the project's work environment to meet specific needs.

Examples of work environment standards include the following:

- Procedures for operation, safety, and security of the work environment

- Standard workstation hardware and software

- Standard application software and tailoring guidelines for it

- Standard production and calibration equipment

- Process for requesting and approving tailoring or waivers

Typical Acquirer Work Products

1. Work environment standards

\section{Subpractices}

1. Evaluate commercially-available work environment standards appropriate for the organization.

2. Adopt existing work environment standards and develop new ones to fill gaps based on the organization's process needs and objectives. 
The purpose of Organizational Process Focus (OPF) is to plan and implement organizational process improvement based on a thorough understanding of the current strengths and weaknesses of the organization's processes and process assets.

The organization's processes include all the processes used by the organization and its projects. Candidate improvements to the organization's processes are obtained from various sources, including measurement of the processes, lessons learned in implementing the processes, results of process appraisals, results of product evaluation activities, results of benchmarking against other organizations' processes, and recommendations from other improvement initiatives in the organization.

Process improvement occurs within the context of the organization's needs and is used to address the organization's objectives. The organization encourages participation in process improvement activities by those who will perform the process. The responsibility for facilitating and managing the organization's process improvement activities, including coordinating the participation of others, is typically assigned to a process group. The organization provides the long-term commitment and resources required to sponsor this group.

The acquirer encourages participation of suppliers in process improvement activities. [ACQ] 
Careful planning is required to ensure that process improvement efforts across the organization are adequately managed and implemented. The organization's planning for process improvement results in a process improvement plan. The organization's process improvement plan will address appraisal planning, process action planning, pilot planning, and deployment planning. Appraisal plans describe the appraisal time line and schedule, the scope of the appraisal, the resources required to perform the appraisal, the reference model against which the appraisal will be performed, and the logistics for the appraisal. Process action plans usually result from appraisals and document how specific improvements targeting the weaknesses uncovered by an appraisal will be implemented. In cases in which it is determined that the improvement described in the process action plan should be tested on a small group before deploying it across the organization, a pilot plan is generated. Finally, when the improvement is to be deployed, a deployment plan is used. This plan describes when and how the improvement will be deployed across the organization.

Organizational process assets are used to describe, implement, and improve the organization's processes (see the definition of "organizational process assets" in the glossary).

Related Process Areas

Refer to the Organizational Process Definition process area for more information about the organizational process assets.

Refer to the Organizational Training process area for more information about coordination of training. [ACQ]

Refer to the Measurement and Analysis process area for more information about analyzing measures. [ACQ] 


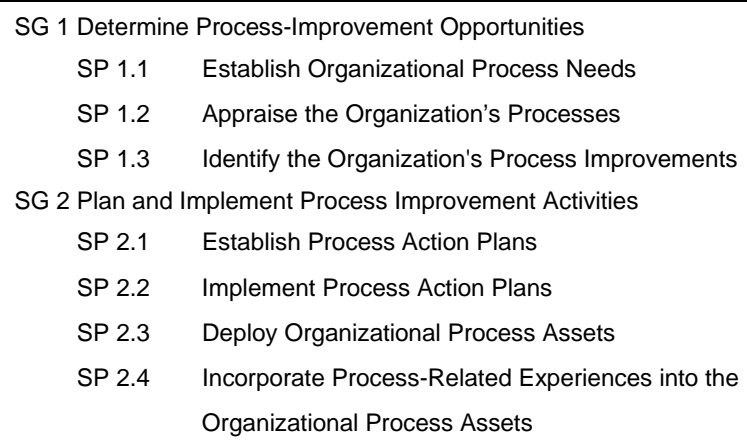

Specific Practices by Goal organization's processes are identified periodically and as needed.

Strengths, weaknesses, and improvement opportunities may be determined relative to a process standard or model such as a CMMI model or International Organization for Standardization (ISO) standard. The process improvements should be selected specifically to address the organization's needs.

Changing business objectives, legal and regulatory requirements, and results of benchmarking studies may be a source of process improvement opportunities. [ACQ]

SP 1.1 Establish Organizational Process Needs

Establish and maintain the description of the process needs and objectives for the organization.

The organization's processes operate in a business context that must be understood. The organization's business objectives, needs, and constraints determine the needs and objectives for the organization's processes. Typically, the issues related to financial, technological, quality, human resource, and marketing are important process considerations.

The organization's process needs and objectives cover aspects that include the following:

- Characteristics of the processes

- Process-performance objectives, such as time-to-market and delivered quality

- Process effectiveness 
The issues related to the organization's acquisition management needs are important process considerations. [ACQ]

\section{Typical Acquirer Work Products}

1. Organization's process needs and objectives

\section{Subpractices}

1. Identify the policies, standards, and business objectives that are applicable to the organization's processes.

2. Examine relevant process standards and models for best practices.

3. Determine the organization's process-performance objectives.

Process-performance objectives may be expressed in quantitative or qualitative terms. [ACQ]

Refer to the Measurement and Analysis process area for more information about establishing measurement objectives. [ACQ]

Examples of process-performance objectives include the following: [ACQ]

- Cycle time

- Defect removal rates

- Productivity

4. Define the essential characteristics of the organization's processes.

The essential characteristics of the organization's processes are determined based on the following: [ACQ]

- Processes currently being used in the organization

- Process and product standards imposed by the organization

- Process and product standards commonly imposed by customers of the organization

Examples of process characteristics include the following: [ACQ]

- Level of detail used to describe the processes

- Process notation used

- Granularity of the processes

5. Document the organization's process needs and objectives.

6. Revise the organization's process needs and objectives as needed. 

needed to maintain an understanding of their strengths and weaknesses.

Process appraisals may be performed for the following reasons:

- To identify processes that should be improved

- To confirm progress and make the benefits of process improvement visible

- To satisfy the needs of a customer-supplier relationship

- To motivate and facilitate buy-in

The buy-in gained during a process appraisal can be eroded significantly if it is not followed by an appraisal-based action plan.

\section{Typical Acquirer Work Products}

1. Plans for the organization's process appraisals

2. Appraisal findings that address strengths and weaknesses of the organization's processes

3. Improvement recommendations for the organization's processes

\section{Subpractices}

1. Obtain sponsorship of the process appraisal from senior management.

Senior management sponsorship includes the commitment to have the organization's managers and staff participate in the process appraisal and to provide the resources and funding to analyze and communicate the findings of the appraisal. [ACQ]

2. Define the scope of the process appraisal.

Process appraisals may be performed on the entire organization or may be performed on a smaller part of an organization such as a single project or business area. [ACQ]

The scope of the process appraisal addresses the following: $[\mathrm{ACQ}]$

- Definition of the organization (e.g., sites or business areas) that will be covered by the appraisal

- Identification of the project and support functions that will represent the organization in the appraisal

- Processes that will be appraised

3. Determine the method and criteria for process appraisal. 
Process appraisals can occur in many forms. Process appraisals should address the needs and objectives of the organization, which may change over time. For example, the appraisal may be based on a process model, such as a CMMI model, or on a national or international standard, such as ISO 9001 [ISO 2000]. The appraisals may also be based on a benchmark comparison with other organizations. The appraisal method may assume a variety of characteristics in terms of time and effort expended, makeup of the appraisal team, and the method and depth of investigation. [ACQ]

4. Plan, schedule, and prepare for the process appraisal.

5. Conduct the process appraisal.

6. Document and deliver the appraisal's activities and findings.

\section{SP 1.3 Identify the Organization's Process Improvements}

\section{Identify improvements to the organization's processes and process assets.}

\section{Typical Acquirer Work Products}

1. Analysis of candidate process improvements

2. Identification of improvements for the organization's processes

\section{Subpractices}

1. Determine candidate process improvements.

Candidate process improvements are typically determined by doing the following: [ACQ]

- Measure the processes and analyze the measurement results

- Review the processes for effectiveness and suitability

- Review the lessons learned from tailoring the organization's set of standard processes

- Review the lessons learned from implementing the processes

- Review process improvement proposals submitted by the organization's managers and staff, and other relevant stakeholders

- Solicit inputs on process improvements from senior management and leaders in the organization

- Examine the results of process appraisals and other process-related reviews

- Review results of other organization improvement initiatives

Candidate process improvements are also determined by doing the following: [ACQ]

- Review process-improvement proposals submitted by the organization's suppliers

- Obtain feedback from suppliers on acquirer processes and supplier-acquirer interface points

2. Prioritize the candidate process improvements. 
Criteria for prioritization are as follows: [ACQ]

- Consider the estimated cost and effort to implement the process improvements

- Appraise the expected improvement against the organization's improvement objectives and priorities

- Determine the potential barriers to the process improvements and develop strategies for overcoming these barriers

Examples of techniques to help determine and prioritize the possible

improvements to be implemented include the following: $\left.{ }^{A c Q}\right]$

- A gap analysis that compares current conditions in the organization with optimal conditions

- Force-field analysis of potential improvements to identify potential barriers and strategies for overcoming those barriers

- Cause-and-effect analyses to provide information on the potential effects of different improvements that can then be compared

3. Identify and document the process improvements that will be implemented.

4. Revise the list of planned process improvements to keep it current.

SG 2 Plan and Implement Process Improvement Activities

Improvements are planned and implemented, organizational process assets are deployed, and process-related experiences are incorporated into the organizational process assets.

Successful implementation of improvements requires participation in the process definition and improvement activities by process owners, those performing the process, and support organizations.

\section{SP 2.1 Establish Process Action Plans}

\section{Establish and maintain process action plans to address improvements to the organization's processes and process assets.}

Establishing and maintaining process action plans typically involves the following roles:

- Management steering committees to set strategies and oversee process improvement activities

- $\quad$ Process group staff to facilitate and manage the process improvement activities

- Process action teams to define and implement the improvement

- Process owners to manage the deployment

- Practitioners to perform the process 
This involvement helps to obtain buy-in on the process improvements and increases the likelihood of effective deployment.

Process action plans are detailed implementation plans. These plans differ from the organization's process improvement plan in that they are plans targeting specific improvements that have been defined to address weaknesses usually uncovered by appraisals.

Suppliers may be involved in developing the process action plans if the processes that define interfaces between acquirer and supplier are targeted for improvement. [ACQ]

\section{Typical Acquirer Work Products}

1. Organization's approved process action plans

\section{Subpractices}

1. Identify strategies, approaches, and actions to address the identified process improvements.

New, unproven, and major changes are piloted before they are incorporated into normal use. [ACQ]

2. Establish process action teams to implement the actions.

The teams and people performing the process improvement actions are called "process action teams." Process action teams typically include process owners and those who perform the process. [ACQ]

Process action teams may include supplier representatives when suppliers interact with the acquirer process to be improved or provide supplemental resources to the acquirer to perform an acquirer process. [AcQ]

3. Document process action plans.

Process action plans typically cover the following: [ACQ]

- Process improvement infrastructure

- Process-improvement objectives

- Process improvements that will be addressed

- Procedures for planning and tracking process actions

- Strategies for piloting and implementing the process actions

- Responsibility and authority for implementing the process actions

- Resources, schedules, and assignments for implementing the process actions

- Methods for determining the effectiveness of the process actions

- Risks associated with process action plans

4. Review and negotiate process action plans with relevant stakeholders. 
5. Review process action plans as necessary.

SP 2.2 Implement Process Action Plans

\section{Implement process action plans across the organization.}

Typical Acquirer Work Products

1. Commitments among the various process action teams

2. Status and results of implementing process action plans

3. Plans for pilots

\section{Subpractices}

1. Make process action plans readily available to relevant stakeholders.

2. Negotiate and document commitments among the process action teams and revise their process action plans as necessary.

3. Track progress and commitments against process action plans.

4. Conduct joint reviews with the process action teams and relevant stakeholders to monitor the progress and results of the process actions.

5. Plan pilots needed to test selected process improvements.

6. Review the activities and work products of process action teams.

7. Identify, document, and track to closure issues in implementing process action plans.

8. Ensure that the results of implementing process action plans satisfy the organization's process-improvement objectives.

\section{SP 2.3 Deploy Organizational Process Assets}

\section{Deploy organizational process assets across the organization.}

Deployment of organizational process assets or of changes to organizational process assets should be performed in an orderly manner. Some organizational process assets or changes to organizational process assets may not be appropriate for implementation in some parts of the organization (because of customer requirements or the current life-cycle phase being implemented, for example). It is therefore important that those that are or will be executing the process, as well as other organization functions (such as training and quality assurance) be involved in the deployment as necessary. 
Refer to the Organizational Process Definition process area for more information about how the deployment of organizational process assets is supported and enabled by the organization's process asset library.

The acquirer defines in the supplier agreement how changes to organizational process assets that impact the supplier (e.g., standard supplier deliverables, acceptance criteria) have to be deployed. [AcQ]

\section{Typical Acquirer Work Products}

1. Plans for deploying the organizational process assets and changes to organizational process assets

2. Training materials for deploying the organizational process assets and changes to organizational process assets

3. Documentation of changes to the organizational process assets

4. Support materials for deploying the organizational process assets and changes to organizational process assets

\section{Subpractices}

1. Deploy organizational process assets and associated methods and tools.

Typical activities performed as a part of this deployment include the following: [ACQ]

- Planning the deployment

- Identifying the organizational process assets that should be adopted by those who will be performing the process

- Ensuring that training is available for the organizational process assets that are being deployed

- Identifying the support resources (e.g., tools) needed to transition the deployed organizational process assets

- Determining the schedule for deploying the organizational process assets

Refer to the Organizational Training process area for more information about coordination of training.

2. Deploy the changes that were made to the organizational process assets.

Typical activities performed as a part of this deployment include the following: [ACQ]

- Planning the deployment

- Determining which changes are appropriate for those that are or will be performing the process

- Determining the time frame for deploying the changes

- Arranging for the associated support needed to successfully transition the changes 
3. Document the changes to the organizational process assets.

The documentation of changes is used to understand the relationship of the changes to resulting changes in process performance and results. [AcO]

4. Provide guidance and consultation on the use of the organizational process assets.

SP 2.4 Incorporate Process-Related Experiences into the Organizational Process Assets

Incorporate process-related work products, measures, and improvement information derived from planning and performing the process into the organizational process assets.

Typical Acquirer Work Products

1. Process improvement proposals

2. Process lessons learned

3. Measurements on the organizational process assets

4. Improvement recommendations for the organizational process assets

5. Records of the organization's process-improvement activities

6. Information on the organizational process assets and improvements to them

\section{Subpractices}

1. Conduct periodic reviews of the effectiveness and suitability of the organization's set of standard processes and related organizational process assets relative to the organization's business objectives.

2. Obtain feedback about the use of the organizational process assets.

3. Derive lessons learned from defining, piloting, implementing, and deploying the organizational process assets.

4. Make lessons learned available to the people in the organization as appropriate.

Actions may have to be taken to ensure that lessons learned are used appropriately. [ACQ]

Examples of inappropriate use of lessons learned include the following: [ACQ]

- Evaluating the performance of people

- Judging process performance or results 
Examples of ways to prevent inappropriate use of lessons learned include the following: $[\mathrm{ACO}]$

- Controlling access to the lessons learned

- Educating people about the appropriate use of lessons learned

5. Analyze the organization's common set of measures.

Refer to the Measurement and Analysis process area for more information about analyzing measures.

Refer to the Organizational Process Definition process area for more information about establishing an organizational measurement repository, including common measures.

6. Appraise the processes, methods, and tools in use in the organization and develop recommendations for improving the organizational process assets.

This appraisal typically includes the following: [Ace]

- Determining which of the processes, methods, and tools are of potential use to other parts of the organization

- Appraising the quality and effectiveness of the organizational process assets

- Identifying candidate improvements to the organizational process assets

- Determining compliance with the organization's set of standard processes and tailoring guidelines

7. Make the best use of the organization's processes, methods, and tools available to the people in the organization as appropriate.

8. Manage process improvement proposals.

Process improvement proposals can address both process and technology improvements. [ACQ]

The activities for managing process improvement proposals typically include the following: $[\mathrm{ACO}]$

- Soliciting process improvement proposals

- Collecting process improvement proposals

- Reviewing the process improvement proposals

- Selecting the process improvement proposals that will be implemented

- Tracking the implementation of the process improvement proposals

Process improvement proposals are documented as process change requests or problem reports, as appropriate. [ACQ] 
Some process improvement proposals may be incorporated into the organization's process action plans. [ACO]

9. Establish and maintain records of the organization's process improvement activities. 
The purpose of Organizational Process Performance (OPP) is to establish and maintain a quantitative understanding of the performance of the organization's set of standard processes in support of quality and process-performance objectives, and to provide the process performance data, baselines, and models to quantitatively manage the organization's projects.

Process performance is a measure of the actual results achieved by following a process. Process performance is characterized by process measures (e.g., effort, cycle time, and defect removal effectiveness) and product measures (e.g., reliability, defect density, capacity, response time, and cost).

The common measures for the organization are composed of process and product measures that can be used to summarize the actual performance of processes in individual projects in the organization. The organizational data for these measures are analyzed to establish a distribution and range of results, which characterize the expected performance of the process when used on any individual project in the organization.

In this process area, the phrase "quality and process-performance objectives" covers objectives and requirements for product quality, service quality, and process performance. As indicated above, the term "process performance" includes quality; however, to emphasize the importance of quality, the phrase "quality and process-performance objectives" is used rather than just "process-performance objectives."

Measuring quality and process-performance objectives may involve combining existing measures into additional derived measures to provide more insight into the overall efficiencies and effectiveness at a project, program, and organization level. The analysis at the organization level may be used to study productivity, improve efficiencies, and increase throughput across projects within the organization. [ACQ] 
The expected process performance can be used in establishing the project's quality and process-performance objectives and can be used as a baseline against which actual project performance can be compared. This information is used to quantitatively manage the project. Each quantitatively managed project, in turn, provides actual performance results that become a part of the baseline data for the organizational process assets.

The acquirer may use some of the process performance objectives to define expected performance and service level expectations for the suppliers. [ACQ]

The associated process performance models are used to represent past and current process performance and to predict future results of the process. For example, the latent defects in the delivered product can be predicted using measurements of defects identified during product-verification activities.

The same measures of latent defects, analyzed using a supplier's past projects data, can be used to predict the quality of products delivered by that supplier. The acquirer can incorporate performance models of the supplier(s) to predict the overall solution delivery capability of the acquirer. [ACQ]

When the organization has measures, data, and analytical techniques for critical process, product, and service characteristics, it is able to do the following:

- Determine whether processes are behaving consistently or have stable trends (i.e., are predictable)

- Identify processes where the performance is within natural bounds that are consistent across process implementation teams

- Establish criteria for identifying whether a process or subprocess should be statistically managed, and determine pertinent measures and analytical techniques to be used in such management

- Identify processes that show unusual (e.g., sporadic or unpredictable) behavior

- Identify any aspects of the processes that can be improved in the organization's set of standard processes

- Identify the implementation of a process which performs best

- Identify aspects of the processes that could be improved across acquirer-supplier interfaces [ACQ] 
Refer to the Quantitative Project Management process area for more information about the use of process performance baselines and models.

Refer to the Measurement and Analysis process area for more information about specifying measures and collecting and analyzing data.

Specific Goal and Practice Summary

SG 1 Establish Performance Baselines and Models

SP 1.1 Select Processes

SP 1.2 Establish Process Performance Measures

SP 1.3 Establish Quality and Process-Performance

Objectives

SP 1.4 Establish Process Performance Baselines

SP 1.5 Establish Process Performance Models

Specific Practices by Goal

SG 1

Establish Performance Baselines and Models

Baselines and models that characterize the expected process performance of the organization's set of standard processes are established and maintained.

Prior to establishing process performance baselines and models, it is necessary to determine which processes are suitable to be measured (the Select Processes specific practice), which measures are useful for determining process performance (the Establish Process Performance Measures specific practice), and the quality and process-performance objectives for those processes (the Establish Quality and ProcessPerformance Objectives specific practice). These specific practices are often interrelated and may need to be performed concurrently to select the appropriate processes, measures, and quality and processperformance objectives. Often, the selection of one process, measure, or objective will constrain the selection of the others. For example, if a certain process is selected, the measures and objectives for that process may be constrained by the process itself.

SP 1.1 Select Processes

Select the processes or subprocesses in the organization's set of standard processes that are to be included in the organization's process performance analyses.

Refer to the Organizational Process Definition process area for more information about the structure of the organizational process assets. 
The organization's set of standard processes consists of a set of standard processes that, in turn, are composed of subprocesses.

Typically, it will not be possible, useful, or economically justifiable to apply statistical management techniques to all processes or subprocesses of the organization's set of standard processes. Selection of the processes and/or subprocesses is based on the needs and objectives of both the organization and projects.

The selection of subprocesses for analysis, the determination of process-performance objectives, and the selection of appropriate measures are often concurrent and iterative processes of both projects and the organization.

When selecting the processes or subprocesses for analyses, it is critical to understand the relationships between different processes and subprocesses and their impact on the acquirer's and supplier's performance of delivering the product specified by the customer. Such an approach will help ensure that quantitative and statistical management is applied to where it will have the most overall value to the organization. [ACQ]

Examples of criteria which may be used for the selection of a subprocess for organizational analysis include the following:

- The relationship of the subprocess to key business objectives

- Current availability of valid historical data relevant to the subprocess

- The current degree of variability of this data

- Subprocess stability (e.g. stable performance in comparable instances)

- The availability of corporate or commercial information that can be used to build predictive models

The existence of project data that indicates the subprocess has been or can be stabilized is a useful criterion for subprocess selection.

Typical Acquirer Work Products

1. List of processes or subprocesses identified for process performance analyses

SP 1.2 Establish Process Performance Measures

Establish and maintain definitions of the measures that are to be included in the organization's process performance analyses.

Refer to the Measurement and Analysis process area for more information about selecting measures. 


\section{Typical Acquirer Work Products}

1. List of processes or subprocesses identified for process performance analyses [ACQ]

2. Definitions for the selected measures of process performance

\section{Typical Supplier Deliverables}

1. List of processes or subprocesses identified for process performance analyses, if any [ACQ]

\section{Subpractices}

1. Determine which of the organization's business objectives for quality and process performance need to be addressed by the measures.

2. Select measures that provide appropriate insight into the organization's quality and process performance.

The measurement repository provides a list of common measures for this purpose. [ACQ]

For those business objectives that are met through acquisition, performance measures typically lead to measures and related service level expectations for suppliers. [ACQ]

Examples of criteria used to select measures include the following: [ACQ]

- Relationship of the measures to the organization's business objectives

- Coverage that the measures provide over the entire life of the product or service

- Visibility that the measures provide into the process performance

- Availability of the measures

- Extent to which the measures are objective

- Frequency at which the observations of the measure can be collected

- Extent to which the measures are controllable by changes to the process

- Extent to which the measures represent the users' view of effective process performance

- Measures selected must also include those that provide insights into supplier performance with respect to service levels and effectiveness of acquisition management by acquirer.

3. Incorporate the selected measures into the organization's set of common measures.

Measures expected to be collected and reported by suppliers are incorporated into standard supplier agreement templates and standard service level agreements, as appropriate. [ACQ] 
Refer to the Organizational Process Definition process area for more information about establishing organizational process assets.

4. Revise the set of measures as necessary.

Measures are periodically evaluated for their continued usefulness and ability to indicate process effectiveness. [ACQ]

SP 1.3 Establish Quality and Process-Performance Objectives

Establish and maintain quantitative objectives for quality and process performance for the organization.

The organization's quality and process-performance objectives should have the following attributes:

- Based on the organization's business objectives

- Based on the past performance of projects

- Defined to gauge process performance in areas such as product quality, productivity, cycle time, or response time

- Constrained by the inherent variability or natural bounds of the process

Typical Acquirer Work Products

1. Organization's quality and process-performance objectives

2. Supplier service levels based on quality and process-performance objectives [ACQ]

\section{Subpractices}

1. Review the organization's business objectives related to quality and process performance.

Examples of business objectives include the following: $[\mathrm{ACQ}]$

- Delivery of functionality within a target percentage of estimated cost

- Achieve a development cycle of a specified duration for a specified release of a product

- Decrease the cost of maintenance of the products by a specified percent

2. Define the organization's quantitative objectives for quality and process performance.

Objectives may be established for process measurements (e.g., effort, cycle time, and defect removal effectiveness) as well as for product measurements (e.g., reliability and defect density) and service measurements (e.g., capacity and response times) where appropriate. [ACO] 
Examples of quality and process-performance objectives include the following: [ACQ]

- Achieve a specified productivity

- Deliver work products with no more than a specified number of latent defects

- Shorter time to delivery within $+/-5$ percent of the process performance baseline

- Reduced total life cycle cost of new and existing products by 15 percent

- Delivery 100 percent of specified functionality of the product

- Improve supplier performance and relationship scores to 4.8 (out of 5)

3. Define the priorities of the organization's objectives for quality and process performance.

4. Review, negotiate, and obtain commitment for the organization's quality and process-performance objectives and their priorities from the relevant stakeholders.

5. Revise the organization's quantitative objectives for quality and process performance as necessary.

Examples of when the organization's quantitative objectives for quality and process performance may need to be revised include the following: [AcQ]

- When the organization's business objectives change

- When the organization's processes change

- When actual quality and process performance differs significantly from the objectives

\section{SP 1.4 Establish Process Performance Baselines}

Establish and maintain the organization's process performance baselines.

The organization's process performance baselines are a measurement of performance for the organization's set of standard processes at various levels of detail, as appropriate. The processes include the following:

- Sequence of connected processes

- Processes that cover the entire life of the project

- Processes for developing individual work products

There may be several process performance baselines to characterize performance for subgroups of the organization. 
Examples of criteria used to categorize subgroups include the following: [ACQ]

- Product line

- Line of business

- Application domain

- Complexity

- Team size

- Work product size

- Process elements from the organization's set of standard processes

- Process performance may be categorized additionally based on specific supplier, acquisition approach, and contract type (e.g., fixed price and time and effort)

Allowable tailoring of the organization's set of standard processes may significantly affect the comparability of the data for inclusion in process performance baselines. The effects of tailoring should be considered in establishing baselines. Depending on the tailoring allowed, separate performance baselines may exist for each type of tailoring.

Refer to the Quantitative Project Management process area for more information about the use of process performance baselines.

\section{Typical Acquirer Work Products}

1. Baseline data on the organization's process performance

\section{Typical Supplier Deliverables}

1. Supplier's process performance data for performance objectives and expected service levels [ACQ]

\section{Subpractices}

1. Collect measurements from the organization's projects.

The process in use when the measurement was taken is recorded to enable appropriate use later. [ACQ]

Refer to the Measurement and Analysis process area for information about collecting and analyzing data.

2. Establish and maintain the organization's process performance baselines from the collected measurements and analyses.

Refer to the Measurement and Analysis process area for information about establishing objectives for measurement and analysis, specifying the measures and analyses to be performed, obtaining and analyzing measures, and reporting results. 
Process performance baselines are derived by analyzing the collected measures to establish a distribution and range of results that characterize the expected performance for selected processes when used on any individual project in the organization. [ACQ]

The measurements from stable processes from projects should be used; other data may not be reliable. [ACQ]

3. Review and get agreement with relevant stakeholders about the organization's process performance baselines.

4. Make the organization's process performance information available across the organization in the organization's measurement repository.

The organization's process performance baselines are used by the projects to estimate the natural bounds for process performance. [ACQ]

Refer to the Organizational Process Definition process area for more information about establishing the organization's measurement repository.

5. Compare the organization's process performance baselines to the associated objectives.

6. Revise the organization's process performance baselines as necessary.

Examples of when the organization's process performance baselines may need to be revised include the following: $[\mathrm{ACO}]$

- When the processes change

- When the organization's results change

- When the organization's needs change

- When suppliers processes change

When suppliers change

SP 1.5 Establish Process Performance Models

Establish and maintain the process performance models for the organization's set of standard processes.

Process performance models are used to estimate or predict the value of a process performance measure from the values of other process, product, and service measurements. These process performance models typically use process and product measurements collected throughout the life of the project to estimate progress toward achieving objectives that cannot be measured until later in the project's life. 
Process performance models are used to estimate or predict when to fund, hold, cancel, migrate, re-engineer, or retire a project or programs. Process performance models allow the acquirer to synchronize processes with the customer's needs. The organization's process performance baselines provide quantitative data on those aspects of the projects and organization that can approximate the throughput potential of its processes. Focusing on these critical constraints, process performance models allow the acquirer to predict how to best maximize the flow of work through the projects and the organization. [ACQ]

The process performance models are used as follows:

- The organization uses them for estimating, analyzing, and predicting the process performance associated with the processes in the organization's set of standard processes.

- The organization uses them to assess the (potential) return on investment for process improvement activities.

- Projects use them for estimating, analyzing, and predicting the process performance for their defined processes.

- Projects use them for selecting processes for use.

Performance models are also used to set performance objectives for the suppliers and to provide data that can help suppliers achieve these objectives. [ACQ]

These measures and models are defined to provide insight into and to provide the ability to predict critical process and product characteristics that are relevant to business value.

The results of the acquirer's process performance models are shared with the suppliers so that they can ensure synchronized delivery of products and services. [ACQ]

Examples of areas of concern to projects in which models may be useful include the following:

- Schedule and cost

- Reliability

- Defect identification and removal rates

- Defect removal effectiveness

- Latent defect estimation

- Response time

- Project progress

- Combinations of these areas 
- System dynamics models

- Reliability growth models

- Complexity models

- Supply chain models

Refer to the Quantitative Project Management process area for more information about the use of process performance models.

Typical Acquirer Work Products

1. Process performance models

Typical Supplier Deliverables

1. Supplier's process performance models [AcQ]

\section{Subpractices}

1. Establish the process performance models based on the organization's set of standard processes and the organization's process performance baselines.

2. Calibrate the process performance models based on the organization's past results and current needs.

3. Review the process performance models and get agreement with relevant stakeholders.

4. Support the projects' use of the process performance models.

5. Revise the process performance models as necessary.

Examples of when the process performance models may need to be revised include the following: [ACQ]

- When the processes change

- When the organization's results change

- When the organization's needs change

- When supplier's processes that directly interface with acquirer's processes change

- When suppliers change 
The purpose of Organizational Training (OT) is to develop the skills and knowledge of people so they can perform their roles effectively and efficiently.

Organizational Training includes training to support the organization's strategic business objectives and to meet the tactical training needs that are common across projects and support groups. Specific training needs identified by individual projects and support groups are handled at the project and support group level and are outside the scope of Organizational Training. Project and support groups are responsible for identifying and addressing their specific training needs.

Refer to the Project Planning process area for more information about the specific training needs identified by projects.

An organizational training program involves the following:

- Identifying the training needed by the organization

- Obtaining and providing training to address those needs

- Establishing and maintaining training capability

- Establishing and maintaining training records

- Assessing training effectiveness

Effective training requires assessment of needs, planning, instructional design, and appropriate training media (e.g., workbooks, computer software), as well as a repository of training process data. As an organizational process, the main components of training include a managed training development program, documented plans, personnel with appropriate mastery of specific disciplines and other areas of knowledge, and mechanisms for measuring the effectiveness of the training program.

The identification of process training needs is primarily based on the skills that are required to perform the organization's set of standard processes. 
Identification of training needs may also address some training needs of suppliers, especially in those process elements which define interfaces with and expectations for suppliers. [ACQ]

Refer to the Organizational Process Definition process area for more information about the organization's set of standard processes.

Certain skills may be effectively and efficiently imparted through vehicles other than in-class training experiences (e.g., informal mentoring). Other skills require more formalized training vehicles, such as in a classroom, by Web-based training, through guided self-study, or via a formalized on-the-job training program. The formal or informal training vehicles employed for each situation should be based on an assessment of the need for training and the performance gap to be addressed. The term "training" used throughout this process area is used broadly to include all of these learning options.

Success in training can be measured in terms of the availability of opportunities to acquire the skills and knowledge needed to perform new and ongoing enterprise activities.

Skills and knowledge may be technical, organizational, or contextual. Technical skills pertain to the ability to use the equipment, tools, materials, data, and processes required by a project or a process. Organizational skills pertain to behavior within and according to the employee's organization structure, role and responsibilities, and general operating principles and methods. Contextual skills are the selfmanagement, communication, and interpersonal abilities needed to successfully perform in the organizational and social context of the project and support groups.

The phrase "project and support groups" is used frequently in the text of the process area description to indicate an organization-level perspective.

Refer to the Organizational Process Definition process area for more information about the organization's process assets.

Refer to the Project Planning process area for more information about the specific training needs identified by projects.

Refer to the Decision Analysis and Resolution process area for how to apply decision-making criteria when determining training approaches. 


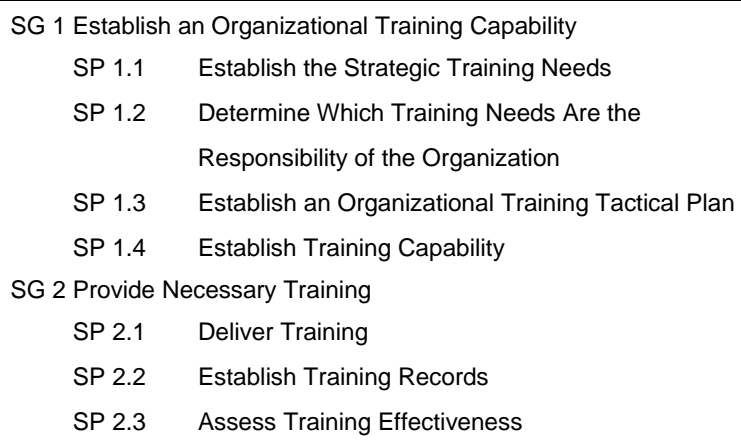

Specific Practices by Goal

SG 1 Establish an Organizational Training Capability

A training capability that supports the organization's management and technical roles is established and maintained.

The organization identifies the training required to develop the skills and the knowledge necessary to perform enterprise activities. Once the needs are identified, a training program addressing those needs is developed.

SP 1.1 Establish the Strategic Training Needs

\section{Establish and maintain the strategic training needs of the organization.}

Strategic training needs address long-term objectives to build a capability by filling significant knowledge gaps, introducing new technologies, or implementing major changes in behavior. Strategic planning typically looks two to five years into the future.

Examples of sources of strategic training needs include the following: [ACQ]

- Organization's standard processes

- Organization's strategic business plan

- Organization's process improvement plan

- Enterprise-level initiatives

- Skill assessments

- Risk analyses

- Acquisition and supplier management

\section{Typical Acquirer Work Products}

1. Training needs 


\section{Assessment analysis}

\section{Subpractices}

1. Analyze the organization's strategic business objectives and process improvement plan to identify potential future training needs.

2. Document the strategic training needs of the organization.

Examples of categories of training needs include (but are not limited to) the following: [ACQ]

- Process analysis and documentation

- Engineering (e.g., requirements analysis, design, testing, configuration management, and quality assurance)

- Selection and management of suppliers

- Management (e.g., estimating, tracking, and risk management)

- Disaster recovery and continuity of operations

- Acquisition management (e.g., solicitation, supplier selection, supplier management)

- Communication and negotiation skills

3. Determine the roles and skills needed to perform the organization's set of standard processes.

Roles may include project/program manager, architects, business process analysts and suppliers, especially in process elements that identify interfaces with and expectations from suppliers. [ACO]

4. Document the training needed to perform the roles in the organization's set of standard processes.

5. Document the training needed to maintain the safe, secure and continued operation of the business.

6. Revise the organization's strategic needs and required training as necessary.

SP 1.2 Determine Which Training Needs Are the Responsibility of the Organization

Determine which training needs are the responsibility of the organization and which will be left to the individual project or support group.

Refer to the Project Planning process area for more information about project- and support-group-specific plans for training. 
In addition to strategic training needs, organizational training addresses training requirements that are common across projects and support groups. Projects and support groups have the primary responsibility for identifying and addressing their specific training needs. The organization's training staff is only responsible for addressing common cross-project and support group training needs, e.g., training in work environments common to multiple projects. In some cases, however, the organization's training staff may address additional training needs of projects and support groups, as negotiated with them, within the context of the training resources available and the organization's training priorities.

\section{Typical Acquirer Work Products}

1. Common project and support group training needs

\section{Training commitments}

\section{Subpractices}

1. Analyze the training needs identified by the various projects and support groups.

Analysis of project and support group needs is intended to identify common training needs that can be most efficiently addressed organization-wide. These needs-analysis activities are used to anticipate future training needs that are first visible at the project and support group level. [ACQ]

2. Negotiate with the various projects and support groups on how their specific training needs will be satisfied.

The support provided by the organization's training staff depends on the training resources available and the organization's training priorities. [ACQ]

Examples of training appropriately performed by the project or support group

include the following: [ACQ]

- Training in the application or service domain of the project

- Training in the unique tools and methods used by the project or support group

- Training in safety, security, and human factors

3. Document the commitments for providing training support to the projects and support groups. 
The organizational training tactical plan is the plan to deliver the training that is the responsibility of the organization and is necessary for individuals to perform their roles effectively. This plan addresses the near-term execution of training and is adjusted periodically in response to changes (e.g., in needs or resources) and to evaluations of effectiveness.

Typical Acquirer Work Products

1. Organizational training tactical plan

\section{Subpractices}

1. Establish plan content.

Organizational training tactical plans typically contain the following: [AcQ]

- Training needs

- Training topics

- Schedules based on training activities and their dependencies

- Methods used for training

- Requirements and quality standards for training materials

- Training tasks, roles, and responsibilities

- Required resources including tools, facilities, environments, staffing, and skills and knowledge

2. Establish commitments to the plan.

Documented commitments by those responsible for implementing and supporting the plan are essential for the plan to be effective. [ACQ]

3. Revise plan and commitments as necessary.

SP 1.4 Establish Training Capability

\section{Establish and maintain training capability to address} organizational training needs.

Refer to the Decision Analysis and Resolution process area for how to apply decision-making criteria when selecting training approaches and developing training materials.

\section{Typical Acquirer Work Products}

1. Training materials and supporting artifacts

\section{Subpractices}

1. Select the appropriate approaches to satisfy specific organizational training needs. 
Many factors may affect the selection of training approaches, including audiencespecific knowledge, costs and schedule, work environment, and so on. Selection of an approach requires consideration of the means to provide skills and knowledge in the most effective way possible given the constraints. [ACQ]

Examples of training approaches include the following: [ACQ]

- Classroom training

- Computer-aided instruction

- Guided self-study

- Formal apprenticeship and mentoring programs

- Facilitated videos

- Chalk talks

- Brown-bag lunch seminars

- Structured on-the-job training

2. Determine whether to develop training materials internally or acquire them externally.

Determine the costs and benefits of internal training development or of obtaining training externally. [ACQ]

Example criteria that can be used to determine the most effective mode of knowledge or skill acquisition include the following: $\left.{ }_{[A C O}\right]$

- Performance objectives

- Time available to prepare for project execution

- Business objectives

- Availability of in-house expertise

- Availability of training from external sources

Examples of external sources of training include the following: [ACQ]

- Customer-provided training

- Commercially available training courses

- Academic programs

- Professional conferences

- Seminars

3. Develop or obtain training materials.

Training may be provided by the project, by support groups, by the organization, or by an external organization. The organization's training staff coordinates the acquisition and delivery of training regardless of its source. [ACQ] 
Examples of training materials include the following: [ACQ]

- Courses

- Computer-aided instruction

- Videos

4. Develop or obtain qualified instructors.

To ensure that internally provided training instructors have the necessary knowledge and training skills, criteria can be defined to identify, develop, and qualify them. In the case of externally provided training, the organization's training staff can investigate how the training provider determines which instructors will deliver the training. This can also be a factor in selecting or continuing to use a specific training provider. [ACQ]

5. Describe the training in the organization's training curriculum.

Examples of the information provided in the training descriptions for each course include the following: ${ }_{[A C Q]}$

- Topics covered in the training

- Intended audience

- Prerequisites and preparation for participating

- Training objectives

- Length of the training

- Lesson plans

- Completion criteria for the course

- Criteria for granting training waivers

6. Revise the training materials and supporting artifacts as necessary.

Examples of situations in which the training materials and supporting artifacts may need to be revised include the following: [ACO]

- Training needs change (e.g., when new technology associated with the training topic is available)

- An evaluation of the training identifies the need for change (e.g., evaluations of training effectiveness surveys, training program performance assessments, or instructor evaluation forms)

SG 2 Provide Necessary Training

Training necessary for individuals to perform their roles effectively is provided.

In selecting people to be trained, the following should be taken into consideration: $[\mathrm{ACQ}]$ 
- Background of the target population of training participants

- Prerequisite background to receive training

- Skills and abilities needed by people to perform their roles

- Need for cross-discipline technical management training for all disciplines, including project management

- Need for managers to have training in appropriate organizational processes

- Need for training in the basic principles of discipline-specific engineering or services to support personnel in quality management, configuration management, and other related support functions

- Need to provide competency development for critical functional areas

- Need to maintain the competencies and qualifications of personnel to operate and maintain work environments common to multiple projects

SP 2.1 Deliver Training

Deliver the training following the organizational training tactical plan.

Typical Acquirer Work Products

1. Delivered training course

\section{Subpractices}

1. Select the people who will receive the training necessary to perform their roles effectively.

The acquirer must include supplier representatives, as appropriate, to ensure selected suppliers can effectively interface with the acquirer's processes. [Aco]

Training is intended to impart knowledge and skills to people performing various roles within the organization. Some people already possess the knowledge and skills required to perform well in their designated roles. Training can be waived for these people, but care should be taken that training waivers are not abused. [ACQ]

2. Schedule the training, including any resources, as necessary (e.g., facilities and instructors).

Training should be planned and scheduled. Training is provided that has a direct bearing on the expectations of work performance. Therefore, optimal training occurs in a timely manner with regard to imminent job-performance expectations. These expectations often include the following: $[\mathrm{ACQ}]$

- Training in the use of specialized tools

- Training in procedures that are new to the individual who will perform them 
3. Conduct the training.

Experienced instructors should perform training. When possible, training is conducted in settings that closely resemble actual performance conditions and includes activities to simulate actual work situations. This approach includes integration of tools, methods, and procedures for competency development. Training is tied to work responsibilities so that on-the-job activities or other outside experiences will reinforce the training within a reasonable time after the training. [ACQ]

4. Track the delivery of training against the plan.

\section{SP 2.2 Establish Training Records}

\section{Establish and maintain records of the organizational training.}

Refer to the Project Monitoring and Control process area for information about how project or support group training records are maintained.

The scope of this practice is for the training performed at the organizational level. Establishment and maintenance of training records for project- or support-group-sponsored training is the responsibility of each individual project or support group.

\section{Typical Acquirer Work Products}

1. Training records

2. Training updates to the organizational repository

\section{Typical Supplier Deliverables}

1. Training records, if appropriate ${ }_{\text {[ACQ] }}$

\section{Subpractices}

1. Keep records of all students who successfully complete each training course or other approved training activity as well as those who are unsuccessful.

2. Keep records of all staff who have been waived from specific training.

The rationale for granting a waiver should be documented, and both the manager responsible and the manager of the excepted individual should approve the waiver for organizational training. [ACQ]

3. Keep records of all students who successfully complete their designated required training.

4. Make training records available to the appropriate people for consideration in assignments. 
Training records may be part of a skills matrix developed by the training organization to provide a summary of the experience and education of people, as well as training sponsored by the organization. [ACQ]

\section{SP 2.3 Assess Training Effectiveness}

\section{Assess the effectiveness of the organization's training} program.

A process should exist to determine the effectiveness of training (i.e., how well the training is meeting the organization's needs).

Examples of methods used to assess training effectiveness include the following:

- Testing in the training context

- Post-training surveys of training participants

- Surveys of managers' satisfaction with post-training effects

- Assessment mechanisms embedded in courseware

Measures may be taken to assess the benefit of the training against both the project's and organization's objectives. Particular attention should be paid to the need for various training methods, such as training teams as integral work units. When used, performance objectives should be shared with course participants, and should be unambiguous, observable, and verifiable. The results of the trainingeffectiveness assessment should be used to revise training materials as described in the Establish Training Capability specific practice.

\section{Typical Acquirer Work Products}

1. Training-effectiveness surveys

2. Training program performance assessments

3. Instructor evaluation forms

4. Training examinations

\section{Subpractices}

1. Assess in-progress or completed projects to determine whether staff knowledge is adequate for performing project tasks.

2. Provide a mechanism for assessing the effectiveness of each training course with respect to established organizational, project, or individual learning (or performance) objectives.

3. Obtain student evaluations of how well training activities met their needs. 
The purpose of Project Monitoring and Control (PMC) is to provide an understanding of the project's progress so that appropriate corrective actions can be taken when the project's performance deviates significantly from the plan.

A project's documented plan is the basis for monitoring activities, communicating status, and taking corrective action. Progress is primarily determined by comparing actual work product and task attributes, effort, cost, and schedule to the plan at prescribed milestones or control levels within the project schedule or work breakdown structure (WBS). Appropriate visibility enables timely corrective action to be taken when performance deviates significantly from the plan. A deviation is significant if, when left unresolved, it precludes the project from meeting its objectives.

The term "project plan" is used throughout these practices to refer to the overall plan for controlling the project.

Monitoring and control functions are directed within the project early in the process as the project's planning is performed and the acquisition strategy is defined. As the acquisition of technology solutions unfolds, monitoring and controlling are essential to ensuring that appropriate resources are being applied and that the acquirer's activities are progressing according to plan. [ACQ]

When actual status deviates significantly from the expected values, corrective actions are taken as appropriate. These actions may require replanning, which may include revising the original plan, establishing new agreements, or including additional mitigation activities within the current plan.

If a corrective action is required to resolve variances from project plans, these actions should be defined and tracked to closure. [ACQ] 
After a supplier is selected and a supplier agreement is established, the role of monitoring and control becomes twofold, concerned with continuing to monitor and control acquirer activities and work products while also monitoring and controlling the progress and performance of the supplier's execution under the supplier agreement and the supplier's project plans. [ACQ]

Related Process Areas

Refer to the Project Planning process area for more information about the project plan, including how it specifies the appropriate level of project monitoring, the measures used to monitor progress, and known risks.

Refer to the Measurement and Analysis process area for information about the process of measuring, analyzing, and recording information.

Refer to the Acquisition Management process area for information about the process resolving issues or making changes to the supplier agreement. [ACQ] 


\begin{aligned} & \hline SG 1 Monitor Project Against Plan \\ & SP 1.1 Monitor Project Planning Parameters \\ & SP 1.2 Monitor Commitments \\ & SP 1.3 Monitor Project Risks \\ & SP 1.4 Monitor Data Management \\ & SP 1.5 Monitor Stakeholder Involvement \\ & SP 1.6 Conduct Progress Reviews \\ & SP 1.7 Conduct Milestone Reviews \\ & SP 1.8 Monitor Transition to Operations and Support \\ & SG 2 Manage Corrective Action to Closure \\ & SP 2.1 Analyze Issues \\ & SP 2.2 Take Corrective Action \\ & SP 2.3 Manage Corrective Action \end{aligned}

Specific Practices by Goal

SG 1 Monitor Project Against Plan

Actual performance and progress of the project are monitored against the project plan.

Monitoring of the acquirer's progress and performance begins as soon as a plan is established. The acquirer is responsible for monitoring the progress and output of the project. After a supplier is selected and a supplier agreement put in place, the acquirer's monitoring and control activities extend to the supplier and its activities. The acquirer monitors the progress of the supplier, including achievement of service levels established in the supplier agreement, using the supplier's measurement data about the progress and output produced by the supplier. [ACQ]

SP 1.1 Monitor Project Planning Parameters

Monitor the actual values of the project planning parameters against the project plan.

Project planning parameters constitute typical indicators of project progress and performance and include attributes of work products and tasks, cost, effort, and schedule. Attributes of the work products and tasks include such items as size, complexity, weight, form, fit, or function.

Monitoring typically involves measuring the actual values of project planning parameters, comparing actual values to the estimates in the plan, and identifying significant deviations. Recording actual values of the project planning parameters includes recording associated contextual information to help understand the measures. An analysis of the impact that significant deviations have on determining what corrective actions to take is handled in the second specific goal and its specific practices in this process area. 


\section{Typical Acquirer Work Products}

1. Records of project performance

2. Records of significant deviations

\section{Typical Supplier Deliverables}

1. Supplier progress reports and performance measures [ACQ]

2. Records of significant deviations [ACQ]

\section{Subpractices}

1. Monitor progress against the schedule.

Progress monitoring typically includes the following: [ACQ]

- Periodically measuring the actual completion of activities and milestones

- Comparing actual completion of activities and milestones against the schedule documented in the project plan

- Identifying significant deviations from the schedule estimates in the project plan

2. Monitor the project's cost and expended effort.

Effort and cost monitoring typically includes the following: [ACQ]

- Periodically measuring the actual effort and cost expended and staff assigned

- Comparing actual effort, costs, staffing, and training to the estimates and budgets documented in the project plan

- Identifying significant deviations from the budgets in the project plan

3. Monitor the attributes of the work products and tasks.

Refer to the Project Planning process area for information about the attributes of work products and tasks.

Monitoring the attributes of the work products and tasks typically includes the following: [ACQ]

- Periodically measuring the actual attributes of the work products and tasks, such as size or complexity (and the changes to the attributes)

- Comparing the actual attributes of the work products and tasks (and the changes to the attributes) to the estimates documented in the project plan

- Identifying significant deviations from the estimates in the project plan

In addition to monitoring the attributes of its work products, the acquirer monitors the attributes of supplier deliverables through acceptance criteria and through analyzing the supplier's peer review results. [ACQ]

4. Monitor resources provided and used.

Refer to the Project Planning process area for information about planned resources. 
This includes monitoring the availability of resources provided by the supplier for the project. [aco]

5. Monitor the knowledge and skills of project personnel.

Refer to the Project Planning process area for information about planning for knowledge and skills needed to perform the project.

Monitoring the knowledge and skills of the project personnel typically includes the following: [ACO]

- Periodically measuring the acquisition of knowledge and skills by project personnel

- Comparing actual training obtained to that documented in the project plan

- Identifying significant deviations from estimates in the project plan

This includes monitoring the skills and knowledge of the supplier personnel provided for the project. [AcQ]

6. Document the significant deviations in the project planning parameters.

Document the significant deviations that apply either to the acquirer's project execution or to the supplier's deviations from the project plan. [ACQ]

SP 1.2 Monitor Commitments

Monitor commitments against those identified in the project plan.

Commitments for resources that will result in expenditures (e.g., issued purchase orders and completed supplier deliverables that have been accepted) are tracked when incurred, even prior to formal payment, to ensure that future financial and legal obligations are accounted for as soon as they are incurred. [ACQ]

Supplier commitments for the project are also monitored by the acquirer through these practices. [ACQ]

\section{Typical Acquirer Work Products}

1. Records of commitment reviews

\section{Subpractices}

1. Regularly review commitments (both external and internal).

2. Identify commitments that have not been satisfied or that are at significant risk of not being satisfied.

3. Document the results of the commitment reviews. 


\section{Monitor risks against those identified in the project plan.}

Refer to the Project Planning process area for more information about identifying project risks.

Refer to the Risk Management process area for more information about risk management activities.

The acquirer monitors overall project risk. Many risks are the sole responsibility of the acquirer and may include sensitive information that should not be shared with the supplier (e.g., source selection sensitive, re-competition, internal staffing, or other risks). [ACQ]

There can also be risks that require careful coordination with suppliers and establishing appropriate escalation of risks and risk status (e.g., feasibility of the technology to meet end user performance requirements). Shared risks may affect the mitigation approaches and result in jointly-planned mitigations. [ACQ]

\section{Typical Acquirer Work Products}

1. Records of project risk monitoring

\section{Typical Supplier Deliverables}

1. Records of supplier risk monitoring [ACQ]

\section{Subpractices}

1. Periodically review the documentation of the risks in the context of the project's current status and circumstances.

2. Revise the documentation of the risks, as additional information becomes available, to incorporate changes.

3. Communicate risk status to relevant stakeholders.

Examples of risk status include the following: [ACO]

- A change in the probability that the risk occurs

- A change in risk priority

SP 1.4 Monitor Data Management

Monitor the management of project data against the project plan.

Refer to the Plan for Data Management specific practice in the Project Planning process area for more information about identifying the types of data that should be managed and how to plan for their management. 
Once the plans for the management of project data are made, the management of that data must be monitored to ensure that those plans are accomplished.

Typical Acquirer Work Products

1. Records of data management

Typical Supplier Deliverables

1. Records of supplier data management $[\mathrm{ACQ}]$

\section{Subpractices}

1. Periodically review data management activities against their description in the project plan.

2. Identify and document significant issues and their impacts.

3. Document the results of data management activity reviews.

SP 1.5 Monitor Stakeholder Involvement

Monitor stakeholder involvement against the project plan.

Refer to the Plan Stakeholder Involvement specific practice in the Project Planning process area for more information about identifying relevant stakeholders and planning the appropriate involvement with them.

Once the stakeholders are identified and the extent of their involvement within the project is specified in project planning, that involvement must be monitored to ensure that the appropriate interactions are occurring.

The supplier's role as a stakeholder is specified in the supplier agreement. [ACQ]

\section{Typical Acquirer Work Products}

1. Records of stakeholder involvement

Typical Supplier Deliverables

1. Records of supplier involvement [ACQ]

\section{Subpractices}

1. Periodically review the status of stakeholder involvement.

2. Identify and document significant issues and their impacts.

3. Document the results of the stakeholder involvement status reviews. 
Periodically review the project's progress, performance, and issues.

Progress reviews are reviews on the project to keep stakeholders informed. These project reviews can be informal reviews and may not be specified explicitly in the project plans.

Examples of these reviews include the following: [AcQ]

- Reviews with staff

- Reviews with project engineers and support

- Reviews with management

- Reviews with suppliers

Typical Acquirer Work Products

1. Documented project review results

\section{Typical Supplier Deliverables}

1. Supplier progress reports and performance measures [ACQ]

2. Supplier review materials and reports [ACQ]

3. Documentation of product and document deliveries [ACQ]

\section{Subpractices}

1. Regularly communicate status on assigned activities and work products to relevant stakeholders.

Managers, staff members, customers, end users, suppliers, and other relevant stakeholders within the organization are included in the reviews as appropriate. [ACQ]

2. Review the results of collecting and analyzing measures for controlling the project. 
Examples of classes of commonly used acquirer measures include the following: [ACQ]

- Requirements Volatility

- Return on Investment

- Cost Performance Index

- Number of Defects Per Phase and/or by severity of defects

- Schedule Performance Index

- Customer Satisfaction Trends

- Supplier Performance and Relationship Trends

Refer to the Measurement and Analysis process area for more information about the process for measuring and analyzing project performance data.

3. Monitor supplier progress and performance (schedule, effort, cost, and technical performance) as defined in the supplier agreement. [ACQ]

4. Conduct progress reviews with the supplier as specified in the supplier agreement. [ACQ]

Technical and management progress reviews may be coordinated and held jointly. Management reviews typically include acquirer and supplier measures, critical dependencies, and project risks and issues. Technical reviews are an important oversight tool that the acquirer can use to review and evaluate the state of the product and of the project, re-directing activity after the review if found necessary. [ACQ]

Technical reviews typically include the following: [Aco]

- Reviewing the supplier's technical activities and verifying that the supplier's interpretation and implementation of the requirements are consistent with the customer's interpretation

- Ensuring that technical commitments are being met and that technical issues are communicated and resolved in a timely manner

- Obtaining technical information about the supplier's products

- Providing appropriate technical information (e.g., design constraints) and support to the supplier

5. Identify and document significant issues and deviations from the plan.

This includes identifying and documenting both acquirer and supplier issues and deviations. [ACQ]

6. Document change requests and problems identified in any of the work products and processes. 
Refer to the Configuration Management process area for more information about how changes are managed.

7. Document the results of the reviews.

Use the results of reviews to improve the supplier's performance and to establish and nurture long-term relationships with preferred suppliers. [ACQ]

8. Track change requests and problem reports to closure.

SP 1.7 Conduct Milestone Reviews

Review the accomplishments and results of the project at selected project milestones.

Refer to the Project Planning process area for more information about milestone planning.

Refer to the Measurement and Analysis process area for information about the process of measuring, analyzing, and recording project performance data. [AcQ]

Milestone reviews are planned during project planning and are typically formal reviews.

\section{Typical Acquirer Work Products}

1. Documented milestone review results

\section{Typical Supplier Deliverables}

1. Documented measurement results [ACQ]

2. Measurement analysis reports [ACQ]

\section{Subpractices}

1. Conduct reviews at meaningful points in the project's schedule, such as the completion of selected stages, with relevant stakeholders.

Managers, staff members, customers, end users, suppliers, and other relevant stakeholders within the organization are included in the milestone reviews as appropriate. [ACQ]

Conduct milestone reviews with the supplier as specified in the supplier agreement. [ACQ]

2. Review the commitments, plan, status, and risks of the project.

3. Identify and document significant issues and their impacts.

4. Document the results of the review, action items, and decisions.

5. Track action items to closure. 


\section{Monitor the transition to operations and support [ACQ]}

Refer to the Acquisition Management process area for more information on escalation of agreement related issues. [AcQ]

\section{Typical Acquirer Work Products}

1. Records of transition to support reviews [ACQ]

2. Transition Analysis Report $[\mathrm{ACO}]$

\section{Typical Supplier Deliverables}

1. Training materials and supporting artifacts [ACQ]

2. Site Readiness Report ${ }_{[\mathrm{ACQ}]}$

3. Verification Reports [ACQ]

4. Training records [ACQ]

5. Operational readiness reports [ACQ]

6. Test results $[\mathrm{ACQ}]$

7. Pilot results $[\mathrm{ACQ}]$

\section{Subpractices}

1. Monitor the organization's capability and facilities designated to receive, store, use, and maintain the acquired products [ACQ]

The acquirer makes adequate provisions through the supplier agreement or inhouse operations and support organizations to operate the acquired product. Typically, the acquirer uses the verification practices to confirm that the organization, the physical environment, and the operations and support resources are equipped to execute the operations and support activities. [Aco]

The acquirer also reviews operations and support organizations designated to take responsibility for operation of the product and to ensure that the resources identified, and budgeted are available when needed. The designated operations and support organizations demonstrate their readiness (capability and capacity) to accept responsibility for the product and to ensure uninterrupted support. Typically a demonstration involves execution of all the activities of operations (e.g., a pilot). [ACQ]

2. Monitor delivery of training for those involved in receiving, storing, using, and maintaining the acquired products. [ACQ] 
Typically the supplier develops training resources for the product. The training materials and resources are specified in the supplier agreement to meet the needs of various audiences (e.g., operations staff, support staff, end users). The acquirer verifies that the training is provided at the appropriate time to the appropriate audience and determines whether the training capability provided is adequate. [ACQ]

3. Review pilot results, if any, and operational readiness reports for the acquired product [ACQ]

Determine readiness of the product and the involved stakeholders such as the operations and support organizations for the transition of responsibility. The acquirer typically uses transition readiness criteria and the verification and validation practices to determine if the supplier's delivered products meet specified requirements. The criteria also address the readiness of the product for maintenance over the intended product life cycle. [Ace]

4. Review and analyze the results of transition activities. [ACQ]

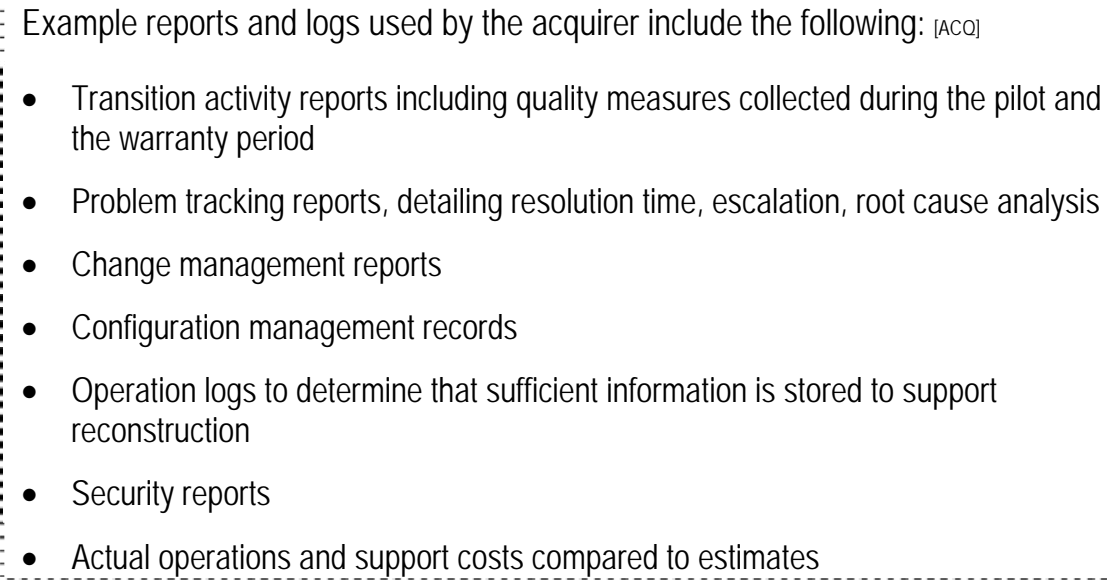
the warranty period

- Problem tracking reports, detailing resolution time, escalation, root cause analysis

- Change management reports

- Configuration management records

- Operation logs to determine that sufficient information is stored to support reconstruction

- Security reports

- Actual operations and support costs compared to estimates

SG 2 Manage Corrective Action to Closure

Corrective actions are managed to closure when the project's performance or results deviate significantly from the plan.

When the acquirer identifies, for example, through its monitoring of measurement data that supplier progress does not appear to be sufficient to meet a service level defined in the supplier agreement, then the acquirer initiates and manages corrective action through the supplier. [ACQ]

If the supplier does not comply appropriately with the acquirer's initiation of corrective action, the acquirer escalates and handles this as a supplier agreement issue or dispute. [ACQ]

Refer to the Acquisition Management process area for more information on escalation of agreement related issues. [ACQ] 
Collect and analyze the issues and determine the corrective actions necessary to address the issues.

Many issues and corrective actions are the sole responsibility of the acquirer and may include sensitive information that should not be shared with the supplier (e.g., source selection sensitive, recompetition, and internal staffing). [ACQ]

\section{Typical Acquirer Work Products}

1. List of issues needing corrective actions

\section{Typical Supplier Deliverables}

1. List of supplier issues needing corrective action by the acquirer [ACQ]

\section{Subpractices}

1. Gather issues for analysis.

Issues are collected from reviews and the execution of other processes. [Ace] Examples of issues to be gathered include: [ACQ]

- Issues discovered through performing verification and validation activities

- Significant deviations in the project planning parameters from the estimates in the project plan

- Commitments (either internal or external) that have not been satisfied

- Significant changes in risk status

- Data access, collection, privacy, or security issues

- Stakeholder representation or involvement issues

2. Analyze issues to determine need for corrective action.

Refer to the Project Planning process area for information about corrective action criteria.

Corrective action is required when the issue, if left unresolved, may prevent the project from meeting its objectives. [Aco]

\section{SP 2.2 Take Corrective Action}

\section{Take corrective action on identified issues.}

Corrective action is taken for both acquirer deviations and when supplier execution does not align with project planning (e.g., milestones and work product date slippages). Some corrective actions may be assigned to a supplier. Significant supplier issues and disputes can be escalated and addressed through the Acquisition Management practices. [ACQ] 
The acquirer oversees corrective actions for the supplier as appropriate. [ACQ]

Refer to the Acquisition Management process area for more information about how supplier issues may be escalated and addressed. [ACQ]

Typical Acquirer Work Products

1. Corrective action plan

Typical Supplier Deliverables

1. Corrective action plans for supplier issues [ACQ]

\section{Subpractices}

1. Determine and document the appropriate actions needed to address the identified issues.

Refer to the Project Planning process area for more information about the project plan when replanning is needed.

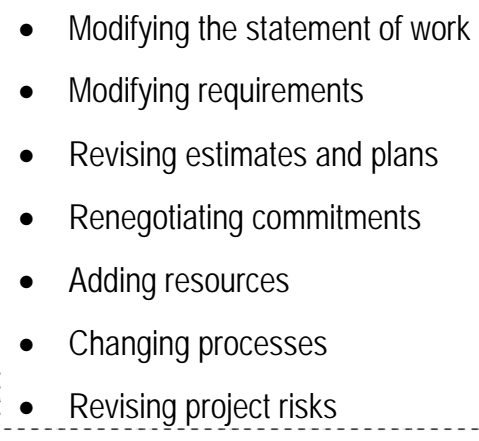

2. Review and get agreement with relevant stakeholders on the actions to be taken.

3. Negotiate changes to internal and external commitments.

SP 2.3 Manage Corrective Action

\section{Manage corrective actions to closure.}

Typical Acquirer Work Products

1. Corrective action results

Typical Supplier Deliverables

1. Corrective action plans for supplier issues [ACQ]

\section{Subpractices}

1. Monitor corrective actions for completion. 
Adapting CMMI for Acquisition Organizations: A Preliminary Report

2. Analyze results of corrective actions to determine the effectiveness of the corrective actions.

3. Determine and document appropriate actions to correct deviations from planned results for corrective actions.

Lessons learned as a result of taking corrective action can be inputs to planning and risk management processes. [ACQ] 
The purpose of Project Planning (PP) is to establish and maintain plans that define project activities.

The Project Planning process area involves the following:

- Developing the project plan

- Interacting with stakeholders appropriately

- Getting commitment to the plan

- Maintaining the plan

Planning begins with requirements that define the product and project.

Project planning is based on the acquisition strategy developed by the Solicitation and Supplier Agreement Development process area. The acquisition strategy outlines the objectives for the acquisition, constraints, availability of assets and technologies, consideration of acquisition methods, potential supplier agreement types and terms, accommodation of end user considerations, considerations of risk, and support for the project over the project life cycle. [ACQ]

Planning includes estimating the attributes of the work products and tasks, determining the resources needed, negotiating commitments, producing a schedule, and identifying and analyzing project risks. Iterating through these activities may be necessary to establish the project plan. The project plan provides the basis for performing and controlling the project's activities that address the commitments with the project's customer.

Project Planning involves development and maintenance of plans for all acquirer processes including those processes required for an effective acquirer-supplier interaction. Once the supplier agreement is signed, and schedule, cost, and resources from the supplier are established, the acquirer's project plan takes the supplier estimations for the project into account at an appropriate level of detail. [ACQ] 
Project planning includes establishing and maintaining a plan for the orderly, smooth transition of the acquired product from a supplier to its use by the acquirer or its customers. In addition, if an existing product is to be replaced as part of the acquisition, the acquirer may be required to consider the disposal of the existing product as part of the planning for acquiring the new product. Any such transition activities are included in the project plan, and provisions for accommodating such specialized requirements are also included. [ACQ]

The project plan will usually need to be revised as the project progresses to address changes in requirements and commitments, inaccurate estimates, corrective actions, and process changes. Specific practices describing both planning and replanning are contained in this process area.

Changes to the supplier agreement can also affect the project's planning estimates, budget, schedules, risks, project work tasks, commitments, and resources. [ACQ]

The term "project plan" is used throughout the generic and specific practices in this process area to refer to the overall plan for controlling the project.

Refer to the Acquisition Requirements Development process area for more information about developing requirements. [ACQ]

Refer to the Requirements Management process area for more information about managing requirements needed for planning and replanning.

Refer to the Risk Management process area for more information about identifying and managing risks.

Refer to the Acquisition Technical Solution process area for more information about transforming requirements into solutions. [AcQ]

Refer to the Solicitation and Supplier Agreement Development process area for more information about developing an acquisition strategy and establishing supplier agreements. [ACQ]

Refer to the Measurement and Analysis process area for more information about specifying project measurement data requirements. 


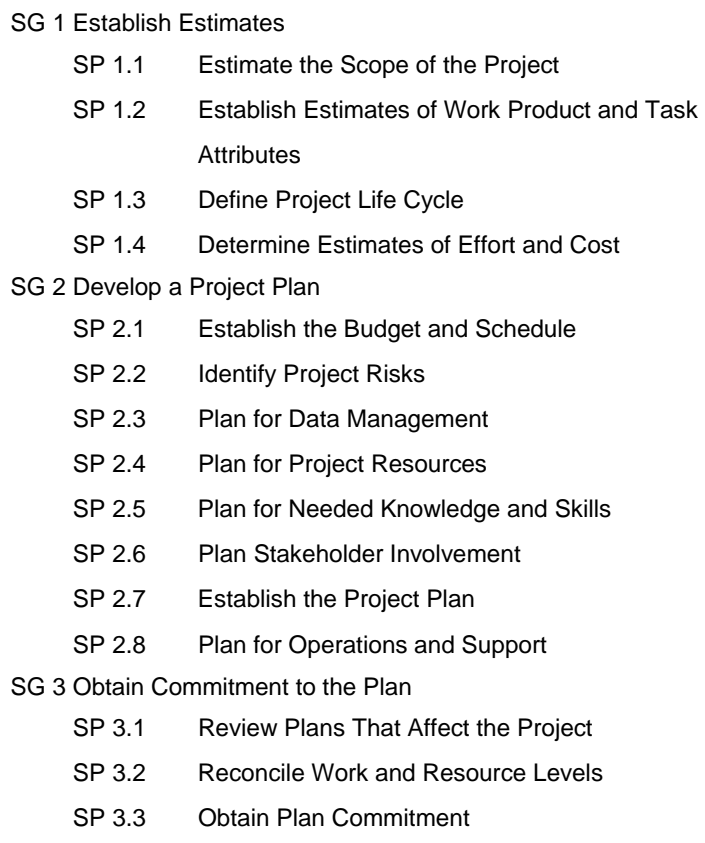

Specific Practices by Goal

\section{SG 1 Establish Estimates}

Estimates of project planning parameters are established and maintained.

Project planning parameters include all information needed by the project to perform the necessary planning, organizing, staffing, directing, coordinating, reporting, and budgeting.

The acquirer develops estimates for the project work, including high level estimates for the work to be done by suppliers. Initial estimates may be revised based upon the suppliers' estimates in responses to the solicitation package. [ACQ]

Estimates of planning parameters should have a sound basis to instill confidence that any plans based on these estimates are capable of supporting project objectives.

Factors that are typically considered when estimating these parameters include the following:

- Project requirements, including the product requirements, the requirements imposed by the organization, the requirements imposed by the customer, and other requirements that impact the project

- Scope of the project

- Identified tasks and work products 
- Technical approach

- Selected project life-cycle model (e.g., waterfall, incremental, or spiral)

- Attributes of the work products and tasks (e.g., size or complexity)

- Schedule

- Models or historical data for converting the attributes of the work products and tasks into labor hours and cost

- Methodology (e.g., models, data, algorithms) used to determine needed material, skills, labor hours, and cost

The acquisition strategy is a key factor when estimating the project. [ACO]

Documentation of the estimating rationale and supporting data is needed for stakeholders' review and commitment to the plan and for maintenance of the plan as the project progresses.

SP 1.1 Estimate the Scope of the Project

\section{Establish a top-level work breakdown structure (WBS) to estimate the scope of the project.}

The acquirer establishes the objectives of the project. Together with an initial set of requirements the project objectives are the basis for establishing the WBS or for selecting a standard WBS from the organization's process assets. The WBS includes activities performed by the acquirer as well as milestones and deliverables for the suppliers. [ACQ]

The acquisition strategy drives a key decision in this practice, specifically how much work, and what work, to give to a supplier. The acquirer develops a WBS that clearly identifies what project work is performed by the acquirer and what project work is performed by the supplier. The supplier work identified in the WBS becomes the foundation for the statement of work defined in the Solicitation and Supplier Agreement Development process area. The WBS identifies the deliverables from the supplier and the work products developed by the acquirer. [ACQ]

The WBS evolves with the project. Initially a top-level WBS can serve to structure the initial estimating. The development of a WBS divides the overall project into an interconnected set of manageable components. Typically, the WBS is a product oriented structure that provides a scheme for identifying and organizing the logical units of work to be managed, which are called "work packages." The WBS provides a reference and organizational mechanism for assigning effort, schedule, and responsibility and is used as the underlying framework to plan, organize, and control the work done on the project. 


\section{Typical Acquirer Work Products}

1. Task descriptions

2. Work package descriptions

3. WBS

\section{Subpractices}

1. Develop a WBS based on the product architecture.

The WBS should permit the identification of the following items: [ACQ]

- Identified risks and their mitigation tasks

- Tasks for deliverables and supporting activities

- Tasks for skill and knowledge acquisition

- Tasks for development of needed support plans, such as configuration management, quality assurance, and verification plans

- Tasks for integration and management of nondevelopmental items

2. Identify the work packages in sufficient detail to specify estimates of project tasks, responsibilities, and schedule.

The top-level WBS is intended to help in gauging the project work effort in terms of tasks and organizational roles and responsibilities. The amount of detail in the WBS at this more detailed level helps in developing realistic schedules, thereby minimizing the need for management reserve. [AcQ]

3. Identify work products (or components of work products) that will be externally acquired.

4. Identify work products that will be reused.

SP 1.2 Establish Estimates of Work Product and Task Attributes Establish and maintain estimates of the attributes of the work products and tasks.

Size is the primary input to many models used to estimate effort, cost, and schedule. The models can also be based on inputs such as connectivity, complexity, and structure.

Examples of types of work products for which size estimates are made include the following:

- Deliverable and nondeliverable work products

- Documents and files

- Operational and support hardware, firmware, and software 
Estimation models can be built based on the historical data as part of organizational process performance and estimates for any project to be validated using these models. [ACQ]

Refer Organizational Process Performance process area for details on how to build process performance models. [AcQ]

Examples of size measures for acquired products include the following: [Ace]

- Source lines of code

- Number of function points

- Number of interfaces within product architecture.

Examples of size measures include the following: [ACO]

- Number of functions

- Function points

- Source lines of code

- Number of classes and objects

- Number of requirements

- Number and complexity of interfaces

- Number of pages

- Number of inputs and outputs

- Number of technical risk items

- Volume of data

- Number of logic gates for integrated circuits

- Number of parts (e.g., printed circuit boards, components, and mechanical parts)

- Physical constraints (e.g., weight and volume)

Methods for estimation include using historical acquirer and supplier data and standard estimating models to compare projects of similar complexity. Where historical size data are not available, develop an estimate based on the understanding of the design of similar products. [ACQ]

The estimates should be consistent with project requirements to determine the project's effort, cost, and schedule. A relative level of difficulty or complexity should be assigned for each size attribute.

\section{Typical Acquirer Work Products}

1. Technical approach

2. Size and complexity of tasks and work products 
3. Estimating models

4. Attribute estimates

\section{Subpractices}

1. Determine the technical approach for the project.

The technical approach defines a top-level strategy for development of the products. It includes decisions on architectural features, such as distributed or client/server; state-of-the-art or established technologies to be applied, such as robotics, composite materials, or artificial intelligence; and breadth of the functionality expected in the final products, such as safety, security, and ergonomics. [ACO]

The technical approach provides a basis for interoperability and supportability of the technical solution developed by the supplier. [Ace]

Refer to the Acquisition Technical Solution process area for more information about defining design constraints. [ACQ]

2. Use appropriate methods to determine the attributes of the work products and tasks that will be used to estimate the resource requirements. [ACQ]

Methods for determining size and complexity should be based on validated models or historical data. [ACQ]

Examples of attributes include the following: [ace]

- Maturity of the technology specified in the technical solution

- Amount and complexity of the work potentially assigned to suppliers.

- Number of locations where the product is to be installed

The methods for determining attributes evolve as our understanding of the relationship of product characteristics to attributes increases. [ACQ]

Examples of current methods include the following: [Aco]

- Number of logic gates for integrated circuit design

- Lines of code or function points for software

- Number/complexity of requirements for systems engineering

- Number of square feet for standard-specified residential homes

3. Estimate the attributes of the work products and tasks.

SP 1.3 Define Project Life Cycle

Define the project life-cycle phases on which to scope the planning effort. 
The determination of a project's life-cycle phases provides for planned periods of evaluation and decision making. These are normally defined to support logical decision points at which significant commitments are made concerning resources and technical approach. Such points provide planned events at which project course corrections and determinations of future scope and cost can be made.

The project life cycle phases need to be defined depending on the scope of requirements, the estimates for project resources, and the nature of the project. [ACQ]

The acquirer refines the acquisition strategy when determining the project life cycle phases. Include in the planning the entire known life cycle from user needs through initial and subsequent upgrades. The acquirer considers all supplier agreements within the context of the acquisition so that an integrated approach results, rather than dealing with activities individually. A complex project can involve managing multiple supplier agreements simultaneously or in sequence. In such cases, any acquisition life cycle can end during any phase of the project life cycle. Depending on the acquisition strategy, there may be intermediate phases for the creation of prototypes, increments of capability, or spiral model cycles. [AcQ]

An acquirer's understanding of suppliers' life-cycle models and processes, especially those that interact directly with the acquirer's processes, enables seamless interactions between supplier and acquirer, resulting in a successful acquirer-supplier relationship. [ACQ]

Understanding the project life cycle is crucial in determining the scope of the planning effort and the timing of the initial planning, as well as the timing and criteria (critical milestones) for replanning.

\section{Typical Acquirer Work Products}

1. Project life-cycle phases

Refer to the Organization Process Definition process area for more information about choosing the life-cycle approach. [ACQ]

SP 1.4 Determine Estimates of Effort and Cost

Estimate the project effort and cost for the work products and tasks based on estimation rationale. 
Estimates of effort and cost are generally based on the results of analysis using models or historical data applied to size, activities, and other planning parameters. Confidence in these estimates is based on the rationale for the selected model and the nature of the data. There may be occasions when the available historical data does not apply, such as where efforts are unprecedented or where the type of task does not fit available models. An effort is unprecedented (to some degree) if a similar product or component has never been built.

Unprecedented efforts are more risky, require more research to develop reasonable bases of estimate, and require more management reserve. The uniqueness of the project must be documented when using these models to ensure a common understanding of any assumptions made in the initial planning stages.

Estimates address all processes and activities performed by the project for the project life cycle, including an estimate of effort and cost for the supplier's work. The project estimate includes detailed estimates for activities performed by the acquirer and its stakeholders. As the project evolves, these estimates may be revised based upon changed conditions (e.g., new circumstances during execution of the supplier agreement). [ACQ]

In addition to creating an estimation of the project work products, the acquirer is encouraged to have its estimate independently reviewed by individuals external to the project to ensure that the project estimation can be validated. Be sure to include the effort and cost supporting execution of the acquirer's processes as well as developing the product. [ACQ]

\section{Typical Acquirer Work Products}

1. Estimation rationale

2. Project effort estimates

3. Project cost estimates

\section{Subpractices}

1. Collect the models or historical data that will be used to transform the attributes of the work products and tasks into estimates of the labor hours and cost.

Effort estimation at the work product and task level needs to be done for the acquirer work. Estimation at a higher level should be sufficient for supplier deliverables and processes. [ACQ] 
Many parametric models have been developed to aid in estimating cost and schedule. The use of these models as the sole source of estimation is not recommended because these models are based on historical project data that may or may not be pertinent to your project. Multiple models and/or methods can be used to ensure a high level of confidence in the estimate. [ACO]

Historical data include the cost, effort, and schedule data from previously executed projects, plus appropriate scaling data to account for differing sizes and complexity. [ACQ]

2. Include supporting infrastructure needs when estimating effort and cost.

Examples of supporting infrastructure typically provided by the supplier include the following: $[\mathrm{ACQ}]$

- Critical computing resources in the host and testing environment (e.g., memory, disk and network capability)

- Test equipment

3. Estimate effort and cost using models and/or historical data.

Effort and cost inputs used for estimating typically include the following: [ACQ]

- Judgmental estimates provided by an expert or group of experts (e.g., Delphi Method)

- Estimates for development of requirements

- Risks, including the extent to which the effort is unprecedented

- Critical competencies and roles needed to perform the work

- WBS

- Cost of acquired work products

- Selected project life-cycle model and processes

- Life-cycle cost estimates

- Skill levels of managers and staff needed to perform the work

- Knowledge, skill, and training needs

- Facilities needed (e.g., office and meeting space and workstations)

- Travel

- Level of security required for tasks, work products, hardware, software, personnel, and work environment

- Service level agreements for call centers and warranty work

- Direct labor and overhead 
The amount of supplier work for a project largely determines the amount of acquirer work to manage the project and the supplier. Estimate supplier work at a high level; acquirer work at a more detailed level. Effort for the acquirer include (1) effort associated with defining the scope of the project, (2) effort associated with the development and deployment of the technical solution, (3) operating and maintenance effort associated with the sustainment of the solution, and (4) disposal effort. [ACQ]

A project plan is established and maintained as the basis for managing the project.

A project plan is a formal, approved document used to manage and control the execution of the project. It is based on the project requirements and the established estimates.

The project plan should consider all phases of the project life cycle. Project planning should ensure that all plans affecting the project are consistent with the overall project plan.

SP 2.1 Establish the Budget and Schedule

\section{Establish and maintain the project's budget and schedule.}

The project's budget and schedule are based on the developed estimates and ensure that budget allocation, task complexity, and task dependencies are appropriately addressed.

The project's budget and schedule, including the life-cycle-related activities of the acquirer, the supplier's efforts, and those of the supporting organizations and other stakeholders, including any contractors to support the acquirer, are created and maintained for the duration of the project. [ACQ]

Event-driven, resource-limited schedules have proven to be effective in dealing with project risk. Identifying accomplishments to be demonstrated before initiation of the event provides some flexibility in the timing of the event, a common understanding of what is expected, a better vision of the state of the project, and a more accurate status of the project's tasks.

\section{Typical Acquirer Work Products}

1. Project schedules

2. Schedule dependencies

3. Project budget

\section{Subpractices}

1. Identify major milestones. 
Milestones are often imposed to ensure completion of certain deliverables by the milestone. Milestones can be event based or calendar based. If calendar based, once milestone dates have been agreed on, it is often very difficult to change them. [ACQ]

2. Identify schedule assumptions.

When schedules are initially developed, it is common to make assumptions about the duration of certain activities. These assumptions are frequently made on items for which little if any estimation data is available. Identifying these assumptions provides insight into the level of confidence (uncertainties) in the overall schedule. [ACQ]

\section{Identify constraints.}

Factors that limit the flexibility of management options need to be identified as early as possible. The examination of the attributes of the work products and tasks often will bring these issues to the surface. Such attributes can include task duration, resources, inputs, and outputs. [ACQ]

Since the characteristics of pre-qualified or other potential suppliers including technical and financial capability, management and delivery processes, production capacity, business type and size are a key element of project success, the acquirer considers these characteristics in identifying constraints for the project. [AcQ]

4. Identify task dependencies.

Typically, the tasks for a project can be accomplished in some ordered sequence that will minimize the duration of the project. This involves the identification of predecessor and successor tasks to determine the optimal ordering. [ACQ]

Examples of tools that can help determine an optimal ordering of task activities include the following: [ACQ]

- Critical Path Method (CPM)

- Program Evaluation and Review Technique (PERT)

- Resource-limited scheduling

- Critical chain method

5. Define the budget and schedule.

Establishing and maintaining the project's budget and schedule typically includes the following: [ACQ]

- Defining the committed or expected availability of resources and facilities

- Determining time phasing of activities

- Determining a breakout of subordinate schedules 
- Defining the dependencies between the activities (predecessor or successor relationships)

- Defining the schedule activities and milestones to support accuracy in progress measurement

- Identifying milestones for delivery of products to the customer

- Defining activities of appropriate duration

- Defining milestones of appropriate time separation

- Defining a management reserve based on the confidence level in meeting the schedule and budget

- Using appropriate historical data to verify the schedule

- Defining incremental funding requirements

- Documenting project assumptions and rationale

- Determining the approach for incorporation of supplier schedules at an appropriate level of detail

6. Establish corrective action criteria.

Criteria are established for determining what constitutes a significant deviation from the project plan. A basis for gauging issues and problems is necessary to determine when a corrective action should be taken. The corrective actions may require replanning, which may include revising the original plan, establishing new agreements, or including mitigation activities within the current plan. [Aco]

\section{SP 2.2 Identify Project Risks}

\section{Identify and analyze project risks.}

Refer to the Risk Management process area for more information about risk management activities.

Refer to the Monitor Project Risks specific practice in the Project Monitoring and Control process area for more information about risk monitoring activities.

Risks are identified or discovered and analyzed to support project planning. This specific practice should be extended to all the plans that affect the project to ensure that the appropriate interfacing is taking place between all relevant stakeholders on identified risks. Project planning risk identification and analysis typically include the following:

- Identifying risks

- Analyzing the risks to determine the impact, probability of occurrence, and time frame in which problems are likely to occur

- Prioritizing risks 
Risks are identified from multiple perspectives (e.g., acquisition, technical, management, operational, supplier agreement, industry, support, and user) to ensure all project risks are considered comprehensively in planning activities. Applicable regulatory and statutory requirements with respect to safety and security must be considered while identifying risks. [ACQ]

Together with the acquisition strategy, the risks identified in project planning form the basis for some of the criteria used in the evaluation practices in Solicitation and Supplier Agreement Development. As the project evolves, risks may be revised based upon changed conditions (e.g., new circumstances during execution of the supplier agreement). [ACQ]

\section{Typical Acquirer Work Products}

1. Identified risks

2. Risk impacts and probability of occurrence

3. Risk priorities

\section{Subpractices}

1. Identify risks.

The identification of risks involves the identification of potential issues, hazards, threats, vulnerabilities, and so on that could negatively affect work efforts and plans. Risks must be identified and described in an understandable way before they can be analyzed. When identifying risks, it is good to use a standard method for defining risks. Risk identification and analysis tools can be used to help identify possible problems. [ACQ]
Examples of risk iden
- Risk taxonomies
- Risk assessments
- Checklists
- Structured interviews
- Brainstorming
- Performance models
- Cost models
- Network analysis
- Quality factor analysis

2. Identify risks associated with the acquisition. [ACQ] 
There are numerous risks that are associated with acquiring products through suppliers (e.g., the stability of the supplier, the ability to maintain sufficient insight into the progress of their work, the supplier's capability to meet the product requirements, and the skills and availability of supplier resources to meet commitments). [ACQ]

3. Document the risks.

4. Review and obtain agreement with relevant stakeholders on the completeness and correctness of the documented risks.

5. Revise the risks as appropriate.

Examples of when identified risks may need to be revised include the following:
[ACQ]
- When new risk is identified
- When risks become problems
- When risks are retired

SP 2.3 Plan for Data Management

\section{Plan for the management of project data.}

Data are the various forms of documentation required to support a program in all of its areas (e.g., administration, engineering, configuration management, financial, logistics, quality, safety, manufacturing, and procurement). The data can take any form (e.g., reports, manuals, notebooks, charts, drawings, specifications, files, or correspondence). The data may exist in any medium (e.g., printed or drawn on various materials, photographs, electronic, or multimedia). Data may be deliverable (e.g., items identified by a program's contract data requirements) or data may be nondeliverable (e.g., informal data, trade studies and analyses, internal meeting minutes, internal design review documentation, lessons learned, and action items). Distribution can take many forms, including electronic transmission.

The data requirements for the project should be established for both the data items to be created and their content and form, based on a common or standard set of data requirements. Uniform content and format requirements for data items facilitate understanding of data content and help with consistent management of the data resources.

The reason for collecting each document should be clear. This task includes the analysis and verification of project deliverables and nondeliverables, contract and noncontract data requirements, and customer-supplied data. Often, data is collected with no clear understanding of how it will be used. Data is costly and should be collected only when needed. 
This includes both acquirer and supplier created data. The acquirer identifies the minimal data required to cost-effectively operate, maintain, and improve the acquired product and to foster source of support competition throughout the product's life cycle in the acquirer's intended environment. Data should be available in a format that is compatible with the intended user's environment and a quality assurance program should be implemented to guarantee the accuracy and completeness of the data. [ACQ]

Consider how data will be shared between acquirer and supplier as well as across relevant stakeholders. In many cases, leaving acquirer data in the physical possession of the supplier and having access to the supplier's data is the preferred solution. In addition to data access, the requirement for acquirer use, reproduction, manipulation, altering or transfer of possession of data should be part of the data management plan. The supplier agreement specifies appropriate acquirer rights to the data acquired, in addition to requirements for delivery or access. Data, whenever it is delivered to the acquirer, is formatted in accordance with accepted data standards to ensure usability by the acquirer. Planning for managing data, including during transition to operations and support, is addressed as part of project planning to avoid unexpected costs to procure, reformat, and deliver data. Include plans for managing data within the project teams and the infrastructure required to manage data between the supplier, operational users, and other relevant stakeholders. Decide which project data and plans require version control, or more stringent levels of configuration control, and establish mechanisms to ensure project data is controlled. Consider the implications of controlling access to classified and sensitive data (e.g., proprietary, export controlled, source selection sensitive) and other access controlled data. [AcQ]

\section{Typical Acquirer Work Products}

1. Data management plan

2. Master list of managed data

3. Data content and format description

4. Data requirements lists for acquirers and for suppliers

5. Privacy requirements

6. Security requirements

7. Security procedures

8. Mechanism for data retrieval, reproduction, and distribution

9. Schedule for collection of project data

10. Listing of project data to be collected 


\section{Subpractices}

1. Establish requirements and procedures to ensure privacy and security of the data.

Not everyone will have the need or clearance necessary to access the project data. Procedures must be established to identify who has access to what data as well as when they have access to the data. [ACQ]

Security and access control are critical when the acquirer provides data access to the supplier. This includes access lists of authorized supplier personnel and nondisclosure agreements between acquirer and supplier. For example, when the supplier performs work for the acquirer off-site (e.g., off-shore development center) then the acquirer needs to consider additional security measures like firewall between the acquirer's and the supplier's network and restricted access to the acquirer's work place. [Aco]

2. Establish a mechanism to archive data and to access archived data.

Accessed information should be in an understandable form (e.g., electronic or computer output from a database) or represented as originally generated. [ACQ]

The data management plan is ideally supported by an integrated data system that meets the needs of both initial acquisition and the support community. Integrating acquisition and sustainment data systems into a total life cycle integrated data environment provides the capability needed to plan effectively for sustainment and to facilitate technology insertion for affordability improvements during reprocurement and post-production support, while also insuring that acquisition planners have accurate information about total life cycle costs. [Aco]

3. Determine the project data to be identified, collected, and distributed.

\section{SP 2.4 Plan for Project Resources}

\section{Plan for necessary resources to perform the project.}

Defining project resources (labor, machinery/equipment, materials, and methods) and quantities needed to perform project activities builds on the initial estimates and provides additional information that can be applied to expand the WBS used to manage the project. 
The top-level WBS developed earlier as an estimation mechanism is typically expanded by decomposing these top levels into work packages that represent singular work units that can be separately assigned, performed, and tracked. This subdivision is done to distribute management responsibility and provide better management control. Each work package or work product in the WBS should be assigned a unique identifier (e.g., number) to permit tracking. A WBS can be based on requirements, activities, work products, or a combination of these items. A dictionary that describes the work for each work package in the WBS should accompany the work breakdown structure.

The resource plan needs to include planning for staff with appropriate training and experience to evaluate supplier proposals and to participate in negotiations with suppliers. It also identifies the project resources expected from the supplier. This includes any critical facilities or equipment needed to support the work packages and determines which will be provided by the supplier. The resource plan may be revised based upon the supplier agreement or changed conditions during execution of the project. [ACQ]

\section{Typical Acquirer Work Products}

1. WBS work packages

2. WBS task dictionary

3. Staffing requirements based on project size and scope

4. Critical facilities/equipment list

5. Process/workflow definitions and diagrams

6. Program administration requirements list

\section{Subpractices}

1. Determine process requirements.

The processes used to manage a project must be identified, defined, and coordinated with all the relevant stakeholders to ensure efficient operations during project execution. [ACQ]

The acquirer must also determine how the acquirer's processes interact with the supplier's processes to enable a seamless execution of the project and a successful acquirer-supplier relationship. [Aco]

2. Determine staffing requirements.

The staffing of a project depends on the decomposition of the project requirements into tasks, roles, and responsibilities for accomplishing the project requirements as laid out within the work packages of the WBS. [ACQ] 
Staffing requirements must consider the knowledge and skills required for each of the identified positions, as defined in the Plan for Needed Knowledge and Skills specific practice. [ACQ]

The acquirer determines its staffing requirements, including staffing for solicitation and supplier agreement management, and the staffing expected by the supplier to complete their portion of the work as defined in the WBS. [ACQ]

3. Determine facilities, equipment, and component requirements.

Most projects are unique in some sense and require some set of unique assets to accomplish the objectives of the project. The determination and acquisition of these assets in a timely manner are crucial to project success. [ACO]

Lead-time items need to be identified early to determine how they will be addressed. Even when the required assets are not unique, compiling a list of all of the facilities, equipment, and parts (e.g., number of computers for the personnel working on the project, software applications, and office space) provides insight into aspects of the scope of an effort that are often overlooked. [ACQ]

The acquirer considers what facilities and equipment must be provided by the supplier, as well as what the acquirer may need to provide for acceptance of the supplier deliverables, transition and support of the acquired product. The acquirer must include any facility or equipment requirements for the supplier in the supplier agreement. [ACQ]

The acquirer must also identify and ensure that any facilities or equipment to be provided to the supplier for their project work are accounted for in the project plan. [ACQ]

\section{SP 2.5 Plan for Needed Knowledge and Skills}

\section{Plan for knowledge and skills needed to perform the project.}

Refer to the Organizational Training process area for more information about knowledge and skills information to be incorporated into the project plan.

Knowledge delivery to projects involves both training of project personnel and acquisition of knowledge from outside sources.

Staffing requirements are dependent on the knowledge and skills available to support the execution of the project. 
Plan for knowledge and skills required by the project team to perform their tasks. Knowledge and skill requirements can be derived from project risk. For example, if the acquirer is purchasing a softwareintensive product, ensure the personnel from the acquirer that is assigned to the project has expertise in systems and software engineering, or provide training for the acquirer's project team in these areas. Include orientation and training for acquirer in Solicitation and Supplier Agreement Development and the domain knowledge required to execute the project. The acquirer also plans for the knowledge and skills needed from the supplier. For example, the acquirer can provide specific role descriptions and skill profiles to the supplier as part of the solicitation package. [ACQ]

Training includes ensuring appropriate training is planned for personnel involved in receiving, storing, using, and supporting the transitioned product and that costs and funding sources to pay for training and lead times to obtain the funding are identified. [ACQ]

\section{Typical Acquirer Work Products}

1. Inventory of skill needs

2. Staffing and new hire plans

3. Databases (e.g., skills and training)

4. Training Plans $[\mathrm{ACQ}]$

\section{Subpractices}

1. Identify the knowledge and skills needed to perform the project.

2. Assess the knowledge and skills available.

3. Select mechanisms for providing needed knowledge and skills.

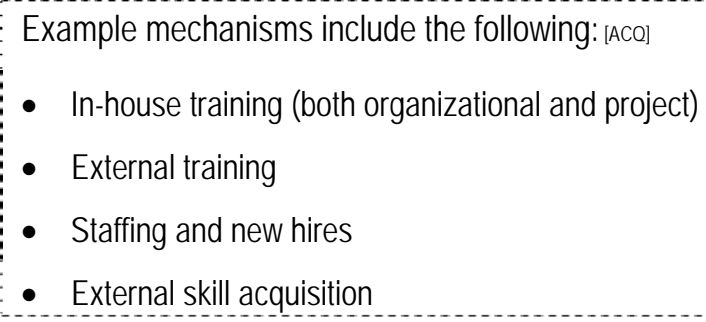

The choice of in-house training or outsourced training for the needed knowledge and skills is determined by the availability of training expertise, the project's schedule, and the business objectives. [Aco]

4. Incorporate selected mechanisms into the project plan.

\section{SP 2.6 Plan Stakeholder Involvement}

\section{Plan the involvement of identified stakeholders.}


Stakeholders are identified from all phases of the project life cycle by identifying the type of people and functions needing representation in the project and describing their relevance and the degree of interaction for specific project activities. A two-dimensional matrix with stakeholders along one axis and project activities along the other axis is a convenient format for accomplishing this identification. Relevance of the stakeholder to the activity in a particular project phase and the amount of interaction expected would be shown at the intersection of the project phase activity axis and the stakeholder axis.

Stakeholders can include operational users and project participants as well as potential suppliers. When acquiring products that need to interoperate with other products, plan for involvement of stakeholders from other projects or communities to ensure the delivered product can perform as required in its intended environment. [ACQ]

For the inputs of stakeholders to be useful, careful selection of relevant stakeholders is necessary. For each major activity, identify the stakeholders who are affected by the activity and those who have expertise that is needed to conduct the activity. This list of relevant stakeholders will probably change as the project moves through the phases of the project life cycle. It is important, however, to ensure that relevant stakeholders in the latter phases of the life cycle have early input to requirements and design decisions that affect them.

Examples of the type of material that should be included in a plan for stakeholder interaction include the following:

- List of all relevant stakeholders

- Rationale for stakeholder involvement

- Roles and responsibilities of the relevant stakeholders with respect to the project, by project life-cycle phase

- Relationships between stakeholders

- Relative importance of the stakeholder to success of the project, by project lifecycle phase

- Resources (e.g., training, materials, time, funding) needed to ensure stakeholder interaction

- Schedule for phasing of stakeholder interaction

Conduct of this specific practice relies on shared or exchanged information with the previous Plan for Needed Knowledge and Skills specific practice.

\section{Typical Acquirer Work Products}

1. Stakeholder involvement plan 


\section{Establish and maintain the overall project plan content.}

A documented plan that addresses all relevant planning items is necessary to achieve the mutual understanding, commitment, and performance of individuals, groups, and organizations that must execute or support the plans. The plan generated for the project defines all aspects of the effort, tying together in a logical manner: project lifecycle considerations; technical and management tasks; budgets and schedules; milestones; data management, risk identification, resource and skill requirements; and stakeholder identification and interaction. Infrastructure descriptions include responsibility and authority relationships for project staff, management, and support organizations.

The project plan may include multiple plans such as staffing plans, stakeholder involvement plans, risk mitigation plans, transition plans, quality assurance plans, and configuration management plans. Regardless of form, the plan or plans should address the acquisition strategy as well as the cradle-to-grave considerations for the project and product to be acquired. [ACQ]

Examples of plans that have been used in the U.S. Department of Defense community include the following:

- Integrated Master Plan-an event-driven plan that documents significant accomplishments with pass/fail criteria for both business and technical elements of the project and that ties each accomplishment to a key program event.

- Integrated Master Schedule-an integrated and networked multi-layered schedule of program tasks required to complete the work effort documented in a related Integrated Master Plan.

- Systems Engineering Management Plan—a plan that details the integrated technical effort across the project.

- Systems Engineering Master Schedule-an event-based schedule that contains a compilation of key technical accomplishments, each with measurable criteria, requiring successful completion to pass identified events.

- Systems Engineering Detailed Schedule-a detailed, time-dependent, task oriented schedule that associates specific dates and milestones with the Systems Engineering Master Schedule. 
A documented plan that addresses all relevant planning items is necessary to achieve the mutual understanding, commitment, and performance of individuals, groups, and organizations that must execute or support the plans. The plan generated for the project defines all aspects of the effort, tying together in a logical manner: project lifecycle considerations; technical and management tasks; budgets and schedules; milestones; data management, risk identification, resource and skill requirements; and stakeholder identification and interaction. Infrastructure descriptions include responsibility and authority relationships for project staff, management, and support organizations.

\section{Typical Acquirer Work Products}

1. Overall project plan

SP 2.8 Plan for Operations and Support [ACQ]

Plan for transition and life cycle operations and support for the product. [ACQ]

Refer to the Solicitation and Supplier Agreement Development process area for more information about incorporating requirements and plans for transitioning the product to operations and support in the solicitation package. [AcQ]

Planning for transition must be considered as part of the initial planning for the project. [ACQ]

The transition and support plans include the approach for introducing and maintaining the readiness, sustainment, and operational capability of the product(s) delivered by the supplier. Plans for transitioning to operations and support include assignment of responsibility for transition to operations and for support of the product, as well as all activities needed to manage the transition and support of the product in the intended environment, for example, definition of transition readiness criteria agreed to by relevant stakeholders. These plans include reasonable accommodations for potential risks and for the evolution of acquired products and their eventual removal from operational use. [AcQ]

The transition to operations and support plans typically include the following: $[\mathrm{ACQ}]$

- Standard processes and procedures for the transition to operations and support

- Verification methods and acceptance criteria for transitioning the product to operations and support

- Readiness criteria for the product

- Readiness criteria for the operations organization

- Readiness criteria for the product support organization 
- Expectations for supplier's execution of the transition

- Warranty expectations for the acquired product

- Resolution of any problems encountered

Typically, the acquirer develops initial transition and support plans, and then reviews and approves more detailed transition and support plans developed and executed by the supplier as defined in the supplier agreement. [ACQ]

Typical Acquirer Work Products

1. Transition to Operations and Support Plans [ACQ]

\section{Commitments to the project plan are established and maintained.}

Refer to the Solicitation and Supplier Agreement Development process area for more information about supplier agreements and finalizing supplier plans. [ACQ]

To be effective, plans require commitment by those responsible for implementing and supporting the plan.

\section{SP 3.1 Review Plans That Affect the Project}

\section{Review all plans that affect the project to understand project commitments.}

Plans developed within other process areas will typically contain information similar to that called for in the overall project plan. These plans may provide additional detailed guidance and should be compatible with and support the overall project plan to indicate who has the authority, responsibility, accountability, and control. All plans that affect the project should be reviewed to ensure a common understanding of the scope, objectives, roles, and relationships that are required for the project to be successful. Many of these plans are described by the Plan the Process generic practice in each of the process areas.

The project may have a hierarchy of plans (e.g., risk mitigation plans, transition plans, quality assurance plans, and configuration management plans). In addition, stakeholder plans (e.g., operational, test, support, and supplier plans) must be reviewed to ensure consistency among all project participants. This includes reviewing cross supplier dependencies. [ACQ]

\section{Typical Acquirer Work Products}

1. Record of the reviews of plans that affect the project 
Reconcile the project plan to reflect available and estimated resources.

To establish a project that is feasible, obtain commitment from relevant stakeholders and reconcile any differences between the estimates and the available resources. Reconciliation is typically accomplished by lowering or deferring technical performance requirements, negotiating more resources, finding ways to increase productivity, outsourcing, adjusting the staff skill mix, or revising all plans that affect the project or schedules.

During supplier selection and negotiation of the supplier agreement, the acquirer reconciles overall project work and resource levels based on the proposals from the supplier. Following completion of the supplier agreement, the acquirer incorporates supplier plans at an appropriate level of detail into the project plan to support alignment of the plans. For example, an acquirer may incorporate major supplier milestones, deliverables, and reviews. [AcQ]

\section{Typical Acquirer Work Products}

1. Revised methods and corresponding estimating parameters (e.g., better tools, use of off-the-shelf components)

2. Renegotiated budgets

3. Revised schedules

4. Revised requirements list

5. Renegotiated stakeholder agreements

SP 3.3 Obtain Plan Commitment

Obtain commitment from relevant stakeholders responsible for performing and supporting plan execution.

Obtaining commitment involves interaction among all relevant stakeholders both internal and external to the project. The individual or group making a commitment should have confidence that the work can be performed within cost, schedule, and performance constraints. Often, a provisional commitment is adequate to allow the effort to begin and to permit research to be performed to increase confidence to the appropriate level needed to obtain a full commitment.

\section{Typical Acquirer Work Products}

1. Documented requests for commitments

2. Documented commitments 


\section{Subpractices}

1. Identify needed support and negotiate commitments with relevant stakeholders.

The WBS can be used as a checklist for ensuring that commitments are obtained for all tasks. [ACQ]

The plan for stakeholder interaction should identify all parties from whom commitment should be obtained. [ACQ]

2. Document all organizational commitments, both full and provisional, ensuring appropriate level of signatories.

Commitments must be documented to ensure a consistent mutual understanding as well as for tracking and maintenance. Provisional commitments should be accompanied by a description of the risks associated with the relationship. [AcQ]

3. Review internal commitments with senior management as appropriate.

4. Review external commitments with senior management as appropriate.

Management may have the necessary insight and authority to reduce risks associated with external commitments. [ACQ]

5. Identify commitments on interfaces between elements in the project, and with other projects and organizational units so that they can be monitored.

Well-defined interface specifications form the basis for commitments. [ACQ] 
The purpose of Process and Product Quality Assurance (PPQA) is to provide staff and management with objective insight into processes and associated work products.

The Process and Product Quality Assurance process area involves the following:

- Objectively evaluating performed processes, work products, and services against the applicable process descriptions, standards, and procedures

- Identifying and documenting noncompliance issues

- Providing feedback to project staff and managers on the results of quality assurance activities

- Ensuring that noncompliance issues are addressed

The Process and Product Quality Assurance process area supports the delivery of high-quality products and services by providing the project staff and managers at all levels with appropriate visibility into, and feedback on, processes and associated work products throughout the life of the project.

The acquirer evaluates critical acquirer work products, acquirer processes, results of supplier's process quality assurance and supplier deliverables. For example, process and product quality assurance ensures that the solicitation package was developed per the standard processes agreed to by the organization and that it conforms to all applicable policies. The acquirer may review the results of the supplier's quality assurance activities for selected supplier processes to ensure that the supplier is following its own processes. Typically, selected supplier processes would be critical processes, such as engineering or verification processes, where the supplier is required through the supplier agreement to follow project-specified standards. In exceptional cases, the acquirer may directly perform product and process quality assurance for selected supplier processes. The acquirer and supplier periodically share quality assurance issues and findings that are of mutual interest. [ACQ] 
The practices in the Process and Product Quality Assurance process area ensure that planned processes are implemented, while the practices in the Acquisition Verification process area ensure that the specified requirements are satisfied. These two process areas may on occasion address the same work product but from different perspectives. Projects should take advantage of the overlap in order to minimize duplication of effort while taking care to maintain the separate perspectives. [ACQ]

Objectivity in process and product quality assurance evaluations is critical to the success of the project. (See the definition of "objectively evaluate" in the glossary.) Objectivity is achieved by both independence and the use of criteria. A combination of methods providing evaluations against criteria by those not producing the work product is often used. Less formal methods can be used to provide broad day-to-day coverage. More formal methods can be used periodically to assure objectivity.

Examples of ways to perform objective evaluations include the following:

- Formal audits by organizationally separate quality assurance organizations

- Peer reviews which may be performed at various levels of formality

- In-depth review of work at the place it is performed (i.e., desk audits)

- Distributed review and comment of work products

Traditionally, a quality assurance group that is independent of the project provides this objectivity. It may be appropriate in some organizations, however, to implement the process and product quality assurance role without that kind of independence. For example, in an organization with an open, quality-oriented culture, the process and product quality assurance role may be performed, partially or completely, by peers; and the quality assurance function may be embedded in the process. For small organizations, this might be the most feasible approach.

If quality assurance is embedded in the process, several issues must be addressed to ensure objectivity. Everyone performing quality assurance activities should be trained in quality assurance. Those performing quality assurance activities for a work product should be separate from those directly involved in developing or maintaining the work product. An independent reporting channel to the appropriate level of organizational management must be available so that noncompliance issues can be escalated as necessary. 
For example, in implementing peer reviews as an objective evaluation method

- Members are trained and roles are assigned for people attending the peer reviews.

- Either (1) a member from outside the project is asked to attend the peer review and perform the role of QA, or (2) checklists are available to support the QA activity, and

- Defects are recorded as part of the peer review report and are tracked and escalated outside the project when necessary.

Quality assurance should begin in the early phases of a project to establish plans, processes, standards, and procedures that will add value to the project and satisfy the requirements of the project and the organizational policies. Those performing quality assurance participate in establishing the plans, processes, standards, and procedures to ensure that they fit the project's needs and that they will be useable for performing quality assurance evaluations. In addition, the specific processes and associated work products that will be evaluated during the project are designated. This designation may be based on sampling or on objective criteria that are consistent with organizational policies and project requirements and needs.

When noncompliance issues are identified, they are first addressed within the project and resolved there if possible. Any noncompliance issues that cannot be resolved within the project are escalated to an appropriate level of management for resolution.

This process area primarily applies to evaluations of products and services, but it also applies to evaluations of nonproject activities and work products such as training activities. For these activities and work products, the term "project" should be appropriately interpreted.

It also applies to the reviews of supplier process quality results as defined in the supplier agreement. For example, the supplier agreement can require the supplier to provide detailed appraisal results of mandatory, acquirer-scoped CMMI for Development appraisals of supplier processes. [ACQ]

Refer to the Project Planning process area for more information about identifying processes and associated work products that will be objectively evaluated.

Refer to Solicitation and Supplier Agreement Development process area for information about specifying evaluation of selected supplier processes and work products. [AcQ] 
Refer to Acquisition Management process area for information about managing conformance to supplier agreements. [AcQ]

Refer to Acquisition Verification process area for information about verification of acquirer work product and supplier deliverables such as the technical solution. [ACQ]

Specific Goal and Practice Summary

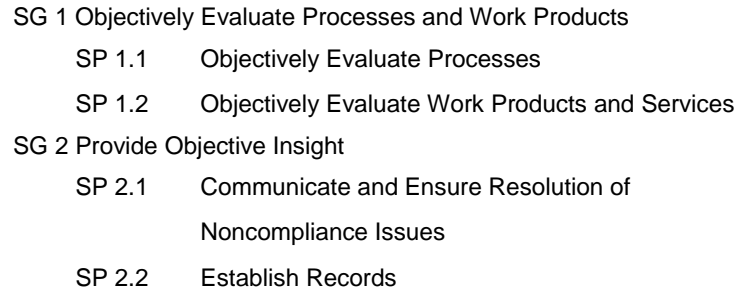

SP 2.2 Establish Records services to applicable process descriptions, standards, and procedures is objectively evaluated.

\section{SP 1.1 Objectively Evaluate Processes}

Objectively evaluate the designated performed processes against the applicable process descriptions, standards, and procedures.

Objectivity in quality assurance evaluations is critical to the success of the project. A description of the quality assurance reporting chain and how it ensures objectivity should be defined.

The description of the quality assurance reporting chain is extended to include the relationship of the acquirer and suppliers. It is important to ensure that acquirer, and supplier processes comply with applicable statutory and regulatory requirements. [ACQ]

The acquirer evaluates the project's execution of acquirer processes including interactions with suppliers and reviews the evaluation reports provided by suppliers to determine if they follow their processes. There should be sufficient process quality assurance to detect noncompliance issues as early as possible that may affect the acquirer's or supplier's ability to successfully deliver the products to the customer. [ACQ]

Through the supplier agreement, the acquirer should retain the right to audit supplier processes if there is an indication that suppliers are not following acceptable processes. [AcQ] 
Typical Acquirer Work Products

1. Evaluation reports

2. Noncompliance reports

3. Corrective actions

Typical Supplier Deliverables

1. Reports for evaluations carried out by supplier [ACQ]

2. Noncompliance reports [ACQ]

3. Corrective actions [ACQ]

\section{Subpractices}

1. Promote an environment (created as part of project management) that encourages employee participation in identifying and reporting quality issues.

2. Establish and maintain clearly stated criteria for the evaluations.

3. Use the stated criteria to evaluate performed processes for adherence to process descriptions, standards, and procedures.

The supplier regularly provides process evaluation reports as defined in the supplier agreement. [ACQ]

4. Identify each noncompliance found during the evaluation.

Analyze the results of monitoring the selected acquirer processes to detect issues as early as possible that may affect the supplier's ability to satisfy the requirements of their agreement. [ACQ]

5. Identify lessons learned that could improve processes for future products and services.

SP 1.2 Objectively Evaluate Work Products and Services

Objectively evaluate the designated work products and services against the applicable process descriptions, standards, and procedures.

In addition to objectively evaluating critical acquirer work products, the acquirer uses objective acceptance criteria to evaluate supplier deliverables throughout the project life cycle. For that, the acquirer's acceptance criteria for supplier deliverables are consistent with the project objectives and sufficient to allow the supplier to satisfactorily demonstrate that the product conforms to contractual requirements. [ACQ]

Refer to the Acquisition Verification process area for information about verifying selected work products. [ACQ] 
Typical Acquirer Work Products

1. Evaluation reports

2. Noncompliance reports

3. Corrective actions

Subpractices

1. Select work products to be evaluated, based on documented sampling criteria if sampling is used.

2. Establish and maintain clearly stated criteria for the evaluation of work products.

3. Use the stated criteria during the evaluations of work products.

4. Evaluate work products before they are delivered to the customer.

5. Evaluate work products at selected milestones in their development.

6. Perform in-progress or incremental evaluations of work products and services against process descriptions, standards, and procedures.

7. Identify each case of noncompliance found during the evaluations.

8. Identify lessons learned that could improve processes for future products and services.

SG 2 Provide Objective Insight

Noncompliance issues are objectively tracked and communicated, and resolution is ensured.

SP 2.1 Communicate and Ensure Resolution of Noncompliance Issues

Communicate quality issues and ensure resolution of noncompliance issues with the staff and managers.

Noncompliance issues are problems identified in evaluations that reflect a lack of adherence to applicable standards, process descriptions, or procedures. The status of noncompliance issues provides an indication of quality trends. Quality issues include noncompliance issues and results of trend analysis.

When local resolution of noncompliance issues cannot be obtained, use established escalation mechanisms to ensure that the appropriate level of management can resolve the issue. Track noncompliance issues to resolution.

Noncompliance issues of both acquirer and supplier are tracked and resolved. [ACQ] 


\section{Typical Acquirer Work Products}

1. Corrective action reports

2. Evaluation reports

3. Quality trends

4. Acquirer feedback to suppliers [AcQ]

\section{Typical Supplier Deliverables}

1. Corrective actions [ACQ]

\section{Subpractices}

1. Resolve each noncompliance with the appropriate members of the staff where possible.

The acquirer involves suppliers when resolving noncompliance issues, as appropriate. [ACQ]

2. Document noncompliance issues when they cannot be resolved within the project.

Examples of ways to resolve noncompliance within the project include the following: $[A C Q]$

- Fixing the noncompliance

- Changing the process descriptions, standards, or procedures that were violated

- Obtaining a waiver to cover the noncompliance issue

3. Escalate noncompliance issues that cannot be resolved within the project to the appropriate level of management designated to receive and act on noncompliance issues.

4. Analyze the noncompliance issues to see if there are any quality trends that can be identified and addressed.

5. Ensure that relevant stakeholders are aware of the results of evaluations and the quality trends in a timely manner.

6. Periodically review open noncompliance issues and trends with the manager designated to receive and act on noncompliance issues.

7. Track noncompliance issues to resolution.

SP 2.2 Establish Records

Establish and maintain records of the quality assurance activities.

Typical Acquirer Work Products

1. Evaluation logs 
Adapting CMMI for Acquisition Organizations: A Preliminary Report

2. Quality assurance reports

3. Status reports of corrective actions

4. Reports of quality trends

Subpractices

1. Record process and product quality assurance activities in sufficient detail such that status and results are known.

2. Revise the status and history of the quality assurance activities as necessary. 
The purpose of the Quantitative Project Management (QPM) process area is to quantitatively manage the project's defined process to achieve the project's established quality and process-performance objectives.

The Quantitative Project Management process area involves the following:

- Establishing and maintaining the project's quality and processperformance objectives

- Identifying suitable subprocesses that compose the project's defined process based on historical stability and capability data found in process performance baselines or models

- Selecting the subprocesses of the project's defined process to be statistically managed

- Monitoring the project to determine whether the project's objectives for quality and process performance are being satisfied, and identifying appropriate corrective action

- Selecting the measures and analytic techniques to be used in statistically managing the selected subprocesses

- Establishing and maintaining an understanding of the variation of the selected subprocesses using the selected measures and analytic techniques

- Monitoring the performance of the selected subprocesses to determine whether they are capable of satisfying their quality and process-performance objectives, and identifying corrective action

- Recording statistical and quality management data in the organization's measurement repository 
The quality and process-performance objectives, measures, and baselines identified here are developed as described in the Organizational Process Performance process area. Subsequently, the results of performing the processes associated with the Quantitative Project Management process area (e.g., measurement definitions and measurement data) become part of the organizational process assets referred to in the Organizational Process Performance process area.

To effectively address the specific practices in this process area, the organization should have already established a set of standard processes and related organizational process assets, such as the organization's measurement repository and the organization's process asset library for use by each project in establishing its defined process. The project's defined process is a set of subprocesses that form an integrated and coherent life cycle for the project. It is established, in part, through selecting and tailoring processes from the organization's set of standard processes. (See the definition of "defined process" in the glossary.)

The project should also ensure that the measurements and progress of the supplier's efforts are made available. Establishment of effective relationships with suppliers is necessary for the successful implementation of this process area's specific practices.

The acquirer uses quantitative methods to manage the work of the acquirer and to gain insight into the work and products of the supplier. In addition to its own quantitative data, the acquirer uses quantitative data provided by the supplier as specified in the supplier agreement to address the specific practices in this process area. [ACO]

Process performance is a measure of the actual process results achieved. Process performance is characterized by both process measures (e.g., effort, cycle time, and defect removal efficiency) and product measures (e.g., reliability, defect density, and response time).

Subprocesses are defined components of a larger defined process. The subprocesses themselves may be further decomposed as necessary into other subprocesses and process elements.

One essential element of quantitative management is having confidence in estimates (i.e., being able to predict the extent to which the project can fulfill its quality and process-performance objectives). The subprocesses that will be statistically managed are chosen based on identified needs for predictable performance. (See the definitions of "statistically managed process," "quality and process-performance objective," and "quantitatively managed process" in the glossary.) 
Another essential element of quantitative management is understanding the nature and extent of the variation experienced in process performance, and recognizing when the project's actual performance may not be adequate to achieve the project's quality and processperformance objectives.

Statistical management involves statistical thinking and the correct use of a variety of statistical techniques, such as run charts, control charts, confidence intervals, prediction intervals, and tests of hypotheses. Quantitative management uses data from statistical management to help the project predict whether it will be able to achieve its quality and process-performance objectives and identify what corrective action should be taken.

This process area applies to managing a project, but the concepts found here also apply to managing other groups and functions. Applying these concepts to managing other groups and functions may not necessarily contribute to achieving the organization's business objectives, but may help these groups and functions control their own processes.

Examples of other groups and functions include the following:

- Quality assurance

- $\quad$ Process definition and improvement

- $\quad$ Effort reporting

- Customer complaint handling

- $\quad$ Problem tracking and reporting

Refer to the Project Monitoring and Control process area for more information about monitoring and controlling the project and taking corrective action.

Refer to the Measurement and Analysis process area for more information about establishing measurable objectives, specifying the measures and analyses to be performed, obtaining and analyzing measures, and providing results.

Refer to the Organizational Process Performance process area for more information about the organization's quality and processperformance objectives, process performance analyses, process performance baselines, and process performance models. 
Refer to the Organizational Process Definition process area for more information about the organizational process assets, including the organization's measurement repository.

Refer to the Integrated Project Management process area for more information about establishing and maintaining the project's defined process.

Refer to the Causal Analysis and Resolution process area for more information about how to identify the causes of defects and other problems, and taking action to prevent them from occurring in the future.

Refer to the Organizational Innovation and Deployment process area for more information about selecting and deploying improvements that support the organization's quality and process-performance objectives.

Refer to the Solicitation and Supplier Agreement Development process area for more information about establishing the requirements for supplier measurements and service levels in the supplier agreement. [ACQ]

Refer to the Acquisition Management process area for more information about managing the service level requirements specified in the supplier agreement. [ACQ]

Specific Goal and Practice Summary

SG 1 Quantitatively Manage the Project

SP 1.1 Establish the Project's Objectives

SP 1.2 Compose the Defined Process

SP 1.3 Select the Subprocesses that Will Be Statistically

Managed

SP 1.4 Manage Project Performance

SG 2 Statistically Manage Subprocess Performance

SP 2.1 Select Measures and Analytic Techniques

SP 2.2 Apply Statistical Methods to Understand Variation

SP 2.3 Monitor Performance of the Selected Subprocesses

SP 2.4 Record Statistical Management Data

SG 1 Quantitatively Manage the Project

The project is quantitatively managed using quality and processperformance objectives.

SP 1.1 Establish the Project's Objectives

Establish and maintain the project's quality and processperformance objectives. 
When establishing the project's quality and process-performance objectives, it is often useful to think ahead about which processes from the organization's set of standard processes will be included in the project's defined process, and what the historical data indicates regarding their process performance. These considerations will help in establishing realistic objectives for the project. Later, as the project's actual performance becomes known and more predictable, the objectives may need to be revised.

The acquirer establishes the project's quality and process performance objectives based on the objectives of the organization and the project's objectives. The acquirer may require the supplier to provide process performance measurements for their participation in project processes or subprocesses (e.g., the estimating subprocess). The acquirer may also establish quality performance objectives for supplier deliverables. These quantitative quality and process performance objectives for the supplier are documented in the supplier agreement. The acquirer typically expects the supplier to execute its processes and apply its performance models to meet the acquirer's quality performance objectives. [ACQ]

\section{Typical Acquirer Work Products}

1. The project's quality and process-performance objectives

\section{Subpractices}

1. Review the organization's objectives for quality and process performance.

The intent of this review is to ensure that the project understands the broader business context in which the project will need to operate. The project's objectives for quality and process performance are developed in the context of these overarching organizational objectives. [ACQ]

Refer to the Organizational Process Performance process area for more information about the organization's quality and processperformance objectives.

2. Identify the quality and process performance needs and priorities of the customer, suppliers, end users, and other relevant stakeholders. 
Examples of quality and process performance attributes for which needs and

priorities might be identified include the following: [ACQ]

- Functionality

- Reliability

- Maintainability

- Usability

- Duration

- Predictability

- Timeliness

- Accuracy

3. Identify how process performance is to be measured.

Consider whether the measures established by the organization are adequate for assessing progress in fulfilling customer, end-user, and other stakeholder needs and priorities. It may be necessary to supplement these with additional measures. [ACQ]

Refer to the Measurement and Analysis process area for more information about defining measures.

4. Define and document measurable quality and processperformance objectives for the project.

Defining and documenting objectives for the project involve the following: [ACQ]

- Incorporating the organization's quality and process-performance objectives

- Writing objectives that reflect the quality and process performance needs and priorities of the customer, end users, and other stakeholders, and the way these objectives should be measured

Examples of quality attributes for which objectives might be written include the following: [ACQ]

- Mean time between failures

- Critical resource utilization

- Number and severity of defects in the released product

- Number and severity of customer complaints concerning the provided service 
Examples of process performance attributes for which objectives might be written

include the following: $[\mathrm{ACQ}]$

- Percentage of defects removed by product verification activities (perhaps by type of verification, such as peer reviews and testing)

- Defect escape rates

- Number and density of defects (by severity) found during the first year following product delivery (or start of service)

- Cycle time

- Percentage of rework time

5. Derive interim objectives for each life-cycle phase, as appropriate, to monitor progress toward achieving the project's objectives.

An example of a method to predict future results of a process is the use of process performance models to predict the latent defects in the delivered product using interim measures of defects identified during product verification activities (e.g., peer reviews and testing). [ACO]

6. Resolve conflicts among the project's quality and processperformance objectives (e.g., if one objective cannot be achieved without compromising another objective).

Resolving conflicts involves the following: [ACQ]

- Setting relative priorities for the objectives

- Considering alternative objectives in light of long-term business strategies as well as short-term needs

- Involving the customer, end users, senior management, project management, and other relevant stakeholders in the tradeoff decisions

- Revising the objectives as necessary to reflect the results of the conflict resolution

7. Establish traceability to the project's quality and processperformance objectives from their sources.

Examples of sources for objectives include the following: $\left.{ }^{A C Q}\right]$

- Requirements

- Organization's quality and process-performance objectives

- Customer's quality and process-performance objectives

- Business objectives

- Discussions with customers and potential customers

- Market surveys 
An example of a method to identify and trace these needs and priorities is Quality Function Deployment (QFD). [AcQ]

8. Define and negotiate quality and process-performance objectives for suppliers.

Refer to the Solicitation and Supplier Agreement Development process area for more information about incorporating project quality and process performance objectives into solicitation packages and into supplier agreements. [ACQ]

9. Revise the project's quality and process-performance objectives as necessary.

\section{SP 1.2 Compose the Defined Process}

Select the subprocesses that compose the project's defined process based on historical stability and capability data.

Refer to the Integrated Project Management process area for more information about establishing and maintaining the project's defined process.

Refer to the Organizational Process Definition process area for more information about the organization's process asset library, which might include a process element of known and needed capability.

Refer to the Organizational Process Performance process area for more information about the organization's process performance baselines and process performance models.

Subprocesses are identified from the process elements in the organization's set of standard processes and the process artifacts in the organization's process asset library.

These subprocesses may include subprocesses for interacting with a supplier (e.g., negotiating a supplier agreement and conducting supplier reviews). [ACQ]

\section{Typical Acquirer Work Products}

1. Criteria used in identifying which subprocesses are valid candidates for inclusion in the project's defined process

2. Candidate subprocesses for inclusion in the project's defined process

3. Subprocesses to be included in the project's defined process

4. Identified risks when selected subprocesses lack a process performance history 


\section{Subpractices}

1. Establish the criteria to use in identifying which subprocesses are valid candidates for use.

Identification may be based on the following: [ACQ]

- Quality and process-performance objectives

- Existence of process performance data

- Product line standards

- Project life-cycle models

- Customer requirements

- Laws and regulations

2. Determine whether the subprocesses that are to be statistically managed, and that were obtained from the organizational process assets, are suitable for statistical management.

A subprocess may be more suitable for statistical management if it has a history of the following: [ACQ]

- Stable performance in previous comparable instances

- Process performance data that satisfies the project's quality and processperformance objectives

Historical data are primarily obtained from the organization's process performance baselines. However, these data may not be available for all subprocesses. [Aco]

3. Analyze the interaction of subprocesses to understand the relationships among the subprocesses and the measured attributes of the subprocesses.

Examples of analysis techniques include system dynamics models and simulations. [ACQ]

4. Identify the risk when no subprocess is available that is known to be capable of satisfying the quality and process-performance objectives (i.e., no capable subprocess is available or the capability of the subprocess is not known).

Even when a subprocess has not been selected to be statistically managed, historical data and process performance models may indicate that the subprocess is not capable of satisfying the quality and process-performance objectives. [Ace]

Refer to the Risk Management process area for more information about risk identification and analysis. 
Select the subprocesses of the project's defined process that will be statistically managed.

Selecting the subprocesses to be statistically managed is often a concurrent and iterative process of identifying applicable project and organization quality and process-performance objectives, selecting the subprocesses, and identifying the process and product attributes to measure and control. Often the selection of a process, quality and process-performance objective, or measurable attribute will constrain the selection of the other two. For example, if a particular process is selected, the measurable attributes and quality and processperformance objectives may be constrained by that process.

\section{Typical Acquirer Work Products}

1. Quality and process-performance objectives that will be addressed by statistical management

2. Criteria used in selecting which subprocesses will be statistically managed

3. Subprocesses that will be statistically managed

4. Identified process and product attributes of the selected subprocesses that should be measured and controlled

\section{Subpractices}

1. Identify which of the quality and process-performance objectives of the project will be statistically managed.

2. Identify the criteria to be used in selecting the subprocesses that are the main contributors to achieving the identified quality and process-performance objectives and for which predictable performance is important.

Examples of sources for criteria used in selecting subprocesses include the following: $[A C Q]$

- Customer requirements related to quality and process performance

- Quality and process-performance objectives established by the customer

- Quality and process-performance objectives established by the organization

- Organization's performance baselines and models

- Stable performance of the subprocess on other projects

Laws and regulations

3. Select the subprocesses that will be statistically managed using the selection criteria. 
It may not be possible to statistically manage some subprocesses (e.g., where new subprocesses and technologies are being piloted). In other cases, it may not be economically justifiable to apply statistical techniques to certain subprocesses. [ACQ]

4. Identify the product and process attributes of the selected subprocesses that will be measured and controlled.

Examples of product and process attributes include the following: [AcQ]

- Defect density

- Cycle time

- Test coverage

Refer to the Solicitation and Supplier Agreement Development process area for more information about establishing requirements for statistical management and reporting of supplier subprocesses in the supplier agreement. [ACQ]

\section{SP 1.4 Manage Project Performance}

\section{Monitor the project to determine whether the project's objectives for quality and process performance will be satisfied, and identify corrective action as appropriate.}

Refer to the Measurement and Analysis process area for more information about analyzing and using measures.

A prerequisite for such a comparison is that the selected subprocesses of the project's defined process are being statistically managed and their process capability is understood. The specific practices of specific goal 2 provide detail on statistically managing the selected subprocesses.

The acquirer monitors the performance of selected subprocesses, including those that involve interaction with a supplier, as well as the quality and performance of the supplier deliverables, for adherence to the quality and performance objectives. This selective monitoring provides the acquirer with insight into project and supplier performance in order to predict the likelihood of achieving the project's objectives for quality and process performance. The acquirer uses this information to manage the risks of the project and to initiate corrective actions in time to meet the project objectives. [AcQ]

\section{Typical Acquirer Work Products}

1. Estimates (predictions) of the achievement of the project's quality and process-performance objectives

2. Documentation of the risks in achieving the project's quality and process-performance objectives 
3. Documentation of actions needed to address the deficiencies in achieving the project's objectives

\section{Typical Supplier Deliverables}

1. Supplier estimates (predictions) of the achievement of the project's quality and process-performance objectives [ACQ]

2. Documentation of the supplier risks in achieving the project's quality and process-performance objectives [ACQ]

3. Documentation of actions needed to address the deficiencies in achieving the project's objectives [ACQ]

\section{Subpractices}

1. Periodically review the performance of each subprocess and the capability of each subprocess selected to be statistically managed to appraise progress toward achieving the project's quality and process-performance objectives.

The process capability of each selected subprocess is determined with respect to that subprocess' established quality and process-performance objectives. These objectives are derived from the project's quality and process-performance objectives, which are for the project as a whole. [Aco]

2. Periodically review the actual results achieved against established interim objectives for each phase of the project life cycle to appraise progress toward achieving the project's quality and process-performance objectives.

3. Track suppliers' results for achieving their quality and processperformance objectives.

4. Use process performance models calibrated with obtained measures of critical attributes to estimate progress toward achieving the project's quality and process-performance objectives.

Process performance models are used to estimate progress toward achieving objectives that cannot be measured until a future phase in the project life cycle. An example is the use of process performance models to predict the latent defects in the delivered product using interim measures of defects identified during peer reviews. [AcQ]

Refer to the Organizational Process Performance process area for more information about process performance models.

The calibration is based on the results obtained from performing the previous subpractices. [ACQ]

5. Identify and manage the risks associated with achieving the project's quality and process-performance objectives. 
Refer to the Risk Management process area for more information about identifying and managing risks.

Example sources of the risks include the following: [AcQ]

- Inadequate stability and capability data in the organization's measurement repository

- Subprocesses having inadequate performance or capability

- Suppliers not achieving their quality and process-performance objectives

- Lack of visibility into supplier capability

- Inaccuracies in the organization's process performance models for predicting future performance

- Deficiencies in predicted process performance (estimated progress)

- Other identified risks associated with identified deficiencies

6. Determine and document actions needed to address the deficiencies in achieving the project's quality and processperformance objectives.

The intent of these actions is to plan and deploy the right set of activities, resources, and schedule to place the project back on track as much as possible to meet its objectives. [Aco]

Examples of actions that can be taken to address deficiencies in achieving the project's objectives include the following: [AcQ]

- Changing quality or process-performance objectives so that they are within the expected range of the project's defined process

- Improving the implementation of the project's defined process so as to reduce its normal variability (reducing variability may bring the project's performance within the objectives without having to move the mean)

- Adopting new subprocesses and technologies that have the potential for satisfying the objectives and managing the associated risks

- Identifying the risk and risk mitigation strategies for the deficiencies

- Terminating the project

Refer to the Project Monitoring and Control process area for more information about taking corrective action. 
This specific goal describes an activity critical to achieving the Quantitatively Manage the Project specific goal of this process area. The specific practices under this specific goal describe how to statistically manage the subprocesses whose selection was described in the specific practices under the first specific goal. When the selected subprocesses are statistically managed, their capability to achieve their objectives can be determined. By these means, it will be possible to predict whether the project will be able to achieve its objectives, which is key to quantitatively managing the project.

SP 2.1 Select Measures and Analytic Techniques

Select the measures and analytic techniques to be used in statistically managing the selected subprocesses.

Refer to the Measurement and Analysis process area for more information about establishing measurable objectives; on defining, collecting, and analyzing measures; and on revising measures and statistical analysis techniques.

Typical Acquirer Work Products

1. Definitions of the measures and analytic techniques to be used in (or proposed for) statistically managing the subprocesses

2. Operational definitions of the measures, their collection points in the subprocesses, and how the integrity of the measures will be determined

3. Traceability of measures back to the project's quality and processperformance objectives

4. Instrumented organizational support environment to support automatic data collection

\section{Subpractices}

1. Identify common measures from the organizational process assets that support statistical management.

Refer to the Organizational Process Definition process area for more information about common measures.

Product lines or other stratification criteria may categorize common measures. [ACO]

2. Identify additional measures that may be needed for this instance to cover critical product and process attributes of the selected subprocesses. 
In some cases, measures may be research oriented. Such measures should be explicitly identified. [AcQ]

3. Identify the measures that are appropriate for statistical management.

Critical criteria for selecting statistical management measures include the following: $[\mathrm{ACQ}]$

- Controllable (e.g., can a measure's values be changed by changing how the subprocess is implemented?)

- Adequate performance indicator (e.g., is the measure a good indicator of how well the subprocess is performing relative to the objectives of interest?)

Examples of subprocess measures include the following: [ACQ]

- Requirements volatility

- Ratios of estimated to measured values of the planning parameters (e.g., size, cost, and schedule)

- Coverage and efficiency of peer reviews

- Test coverage and efficiency

- Effectiveness of training (e.g., percent of planned training completed and test scores)

- Reliability

- Percentage of the total defects inserted or found in the different phases of the project life cycle

- Percentage of the total effort expended in the different phases of the project life cycle

4. Specify the operational definitions of the measures, their collection points in the subprocesses, and how the integrity of the measures will be determined.

Operational definitions are stated in precise and unambiguous terms. They address two important criteria as follows: [ACQ]

- Communication: What has been measured, how it was measured, what the units of measure are, and what has been included or excluded

- Repeatability: Whether the measurement can be repeated, given the same definition, to get the same results

5. Analyze the relationship of the identified measures to the organization's and project's objectives, and derive objectives that state specific target measures or ranges to be met for each measured attribute of each selected subprocess.

6. Instrument the organizational support environment to support collection, derivation, and analysis of statistical measures. 
The instrumentation is based on the following: [ACQ]

- Description of the organization's set of standard processes

- Description of the project's defined process

- Capabilities of the organizational support environment

7. Identify the appropriate statistical analysis techniques that are expected to be useful in statistically managing the selected subprocesses.

The concept of "one size does not fit all" applies to statistical analysis techniques. What makes a particular technique appropriate is not just the type of measures, but more important, how the measures will be used and whether the situation warrants applying that technique. The appropriateness of the selection may need to be investigated from time to time. [Ace]

Examples of statistical analysis techniques are given in the next specific practice. [ACQ]

8. Revise the measures and statistical analysis techniques as necessary.

SP 2.2 Apply Statistical Methods to Understand Variation

Establish and maintain an understanding of the variation of the selected subprocesses using the selected measures and analytic techniques.

Refer to the Measurement and Analysis process area for more information about collecting, analyzing, and using measurement results.

Understanding variation is achieved, in part, by collecting and analyzing process and product measures so that special causes of variation can be identified and addressed to achieve predictable performance.

A special cause of process variation is characterized by an unexpected change in process performance. Special causes are also known as "assignable causes" because they can be identified, analyzed, and addressed to prevent recurrence.

The identification of special causes of variation is based on departures from the system of common causes of variation. These departures can be identified by the presence of extreme values, or other identifiable patterns in the data collected from the subprocess or associated work products. Knowledge of variation and insight about potential sources of anomalous patterns are typically needed to detect special causes of variation. 
Sources of anomalous patterns of variation may include the following:

- Lack of process compliance

- Undistinguished influences of multiple underlying subprocesses on the data

- Ordering or timing of activities within the subprocess

- Uncontrolled inputs to the subprocess

- Environmental changes during subprocess execution

- Schedule pressure

- Inappropriate sampling or grouping of data

\section{Typical Acquirer Work Products}

1. Collected measures

2. Natural bounds of process performance for each measured attribute of each selected subprocess

3. Process performance compared to the natural bounds of process performance for each measured attribute of each selected subprocess

\section{Typical Supplier Deliverables}

1. Collected supplier measures [ACQ]

2. Natural bounds of supplier process performance for each measured attribute of each selected subprocess [ACQ]

3. Supplier process performance compared to the natural bounds of process performance for each measured attribute of each selected subprocess [ACQ]

\section{Subpractices}

1. Establish trial natural bounds for subprocesses having suitable historical performance data.

Refer to the Organizational Process Performance process area for more information about organizational process performance baselines.

Natural bounds of an attribute are the range within which variation normally occurs. All processes will show some variation in process and product measures each time they are executed. The issue is whether this variation is due to common causes of variation in the normal performance of the process or to some special cause that can and should be identified and removed. 
When a subprocess is initially executed, suitable data for establishing trial natural bounds are sometimes available from prior instances of the subprocess or comparable subprocesses, process performance baselines, or process performance models. These data are typically contained in the organization's measurement repository. As the subprocess is executed, data specific to that instance are collected and used to update and replace the trial natural bounds. However, if the subprocess in question has been materially tailored, or if the conditions are materially different from those in previous instantiations, the data in the repository may not be relevant and should not be used.

In some cases, there may be no historical comparable data (e.g., when introducing a new subprocess, when entering a new application domain, or when significant changes have been made to the subprocess). In such cases, trial natural bounds will have to be made from early process data of this subprocess. These trial natural bounds must then be refined and updated as subprocess execution continues.

Examples of criteria for determining whether data are comparable include the following: $[\mathrm{ACO}]$

- Product lines

- Application domain

- Work product and task attributes (e.g., size of product)

- Size of project

2. Collect data, as defined by the selected measures, on the subprocesses as they execute.

3. Calculate the natural bounds of process performance for each measured attribute.

Examples of where the natural bounds are calculated include the following: [ACQ]

- Control charts

- Confidence intervals (for parameters of distributions)

- Prediction intervals (for future outcomes)

4. Identify special causes of variation.

An example of a criterion for detecting a special cause of process variation in a control chart is a data point that falls outside of the 3-sigma control limits. [ACO]

The criteria for detecting special causes of variation are based on statistical theory and experience and depend on economic justification. As criteria are added, special causes are more likely to be identified if present, but the likelihood of false alarms also increases. [AcQ] 
5. Analyze the special cause of process variation to determine the reasons the anomaly occurred.

Examples of techniques for analyzing the reasons for special causes of variation

include the following: [ACQ]

- Cause-and-effect (fishbone) diagrams

- Designed experiments

- Control charts (applied to subprocess inputs or to lower level subprocesses)

- Subgrouping (analyzing the same data segregated into smaller groups based on an understanding of how the subprocess was implemented facilitates isolation of special causes)

Some anomalies may simply be extremes of the underlying distribution rather than problems. The people implementing a subprocess are usually the ones best able to analyze and understand special causes of variation. [ACQ]

6. Determine what corrective action should be taken when special causes of variation are identified.

Removing a special cause of process variation does not change the underlying subprocess. It addresses an error in the way the subprocess is being executed. [ACQ]

Refer to the Project Monitoring and Control process area for more information about taking corrective action.

7. Recalculate the natural bounds for each measured attribute of the selected subprocesses as necessary.

Recalculating the (statistically estimated) natural bounds is based on measured values that signify that the subprocess has changed, not on expectations or arbitrary decisions. [ACQ]

Examples of when the natural bounds may need to be recalculated include the following: [ACQ]

- There are incremental improvements to the subprocess

- New tools are deployed for the subprocess

- A new subprocess is deployed

- The collected measures suggest that the subprocess mean has permanently shifted or the subprocess variation has permanently changed

SP 2.3 Monitor Performance of the Selected Subprocesses

Monitor the performance of the selected subprocesses to determine their capability to satisfy their quality and processperformance objectives, and identify corrective action as necessary. 
The intent of this specific practice is to do the following:

- Determine statistically the process behavior expected from the subprocess

- Appraise the probability that the process will meet its quality and process-performance objectives

- Identify the corrective action to be taken, based on a statistical analysis of the process performance data

Corrective action may include renegotiating the affected project objectives, identifying and implementing alternative subprocesses, or identifying and measuring lower level subprocesses to achieve greater detail in the performance data. Any or all of these actions are intended to help the project use a more capable process. (See the definition of "capable process" in the glossary.)

A prerequisite for comparing the capability of a selected subprocess against its quality and process-performance objectives is that the performance of the subprocess is stable and predictable with respect to its measured attributes.

Process capability is analyzed for those subprocesses and those measured attributes for which (derived) objectives have been established. Not all subprocesses or measured attributes that are statistically managed are analyzed regarding process capability.

The historical data may be inadequate for initially determining whether the subprocess is capable. It also is possible that the estimated natural bounds for subprocess performance may shift away from the quality and process-performance objectives. In either case, statistical control implies monitoring capability as well as stability.

\section{Typical Acquirer Work Products}

1. Natural bounds of process performance for each selected subprocess compared to its established (derived) objectives

2. For each subprocess, its process capability

3. For each subprocess, the actions needed to address deficiencies in its process capability

\section{Typical Supplier Deliverables}

1. Actions needed to address deficiencies in supplier process performance measures or quality measures for deliverables [AcQ]

\section{Subpractices}

1. Compare the quality and process-performance objectives to the natural bounds of the measured attribute. 
This comparison provides an appraisal of the process capability for each measured attribute of a subprocess. These comparisons can be displayed graphically, in ways that relate the estimated natural bounds to the objectives or as process capability indices, which summarize the relationship of the objectives to the natural bounds. [ACQ]

2. Monitor changes in quality and process-performance objectives and selected subprocess' process capability.

3. Identify and document subprocess capability deficiencies.

4. Determine and document actions needed to address subprocess capability deficiencies.

Examples of actions that can be taken when a selected subprocess's

performance does not satisfy its objectives include the following: [ACQ]

- Changing quality and process-performance objectives so that they are within the subprocess' process capability

- Improving the implementation of the existing subprocess so as to reduce its normal variability (reducing variability may bring the natural bounds within the objectives without having to move the mean)

- Adopting new process elements and subprocesses and technologies that have the potential for satisfying the objectives and managing the associated risks

- Identifying risks and risk mitigation strategies for each subprocess's process capability deficiency

Refer to the Project Monitoring and Control process area for more information about taking corrective action.

SP 2.4 Record Statistical Management Data

\section{Record statistical and quality management data in the organization's measurement repository.}

Refer to the Measurement and Analysis process area for more information about managing and storing data, measurement definitions, and results.

Refer to the Organizational Process Definition process area for more information about the organization's measurement repository.

\section{Typical Acquirer Work Products}

1. Statistical and quality management data recorded in the organization's measurement repository 
The purpose of Requirements Management (REQM) is to manage the requirements of the project's products and product components and to identify inconsistencies between those requirements and the project's plans and work products.

Requirements management processes manage all requirements received or generated by the project, including both technical and nontechnical requirements as well as those requirements levied on the project by the organization. In particular, if the Acquisition Requirements Development process area is implemented, its processes will generate customer and contractual requirements that will also be managed by the requirements management processes. Throughout the process areas, where we use the terms product and product component, they are intended to include service and service component and should be interpreted in that way. When the Requirements Management, Acquisition Requirements Development, and Acquisition Technical Solution process areas are all implemented, their associated processes may be closely tied and be performed concurrently. [ACQ]

The project takes appropriate steps to ensure that the agreed-on set of requirements is managed to support the planning and execution needs of the project. When a project receives requirements from an approved requirements provider, the requirements are reviewed with the requirements provider to resolve issues and prevent misunderstanding before the requirements are incorporated into the project's plans. Once the requirements provider and the requirements receiver reach an agreement, commitment to the requirements is obtained from the project participants. The project manages changes to the requirements as they evolve and identifies any inconsistencies that occur among the plans, work products, and requirements.

Part of the management of requirements is to document requirements changes and rationale and to maintain bidirectional traceability between source requirements and all product and product-component requirements. (See the definition of "bidirectional traceability" in the glossary.). 
All projects have requirements. In the case of a project that is focused on maintenance activities, the changes to the product or product components are based on changes to the existing requirements, design, or implementation. The requirements changes, if any, might be documented in change requests from the customer or users, or they might take the form of new requirements received from the requirements development process. Regardless of their source or form, the maintenance activities that are driven by changes to requirements are managed accordingly.

Related Process Areas

Refer to the Acquisition Requirements Development process area for more information about transforming stakeholder intentions into customer requirements and deciding how to allocate or distribute requirements among the suppliers and their deliverables. [ACQ]

Refer to the Acquisition Technical Solution process area for more information about design constraints. [ACQ]

Refer to the Project Planning process area for more information about how project plans reflect requirements and need to be revised as requirements change.

Refer to the Configuration Management process area for more information about baselines and controlling changes to configuration documentation for requirements.

Refer to the Project Monitoring and Control process area for more information about tracking and controlling the activities and work products that are based on the requirements and taking appropriate corrective action.

Refer to the Risk Management process area for more information about identifying and handling risks associated with requirements. 
SG 1 Manage Requirements

SP 1.1 Obtain an Understanding of Requirements

SP 1.2 Obtain Commitment to Requirements

SP 1.3 Manage Requirements Changes

SP 1.4 Maintain Bidirectional Traceability of Requirements

SP 1.5 Identify Inconsistencies between Project Work and

Requirements

Specific Practices by Goal

SG 1 Manage Requirements

Requirements are managed and inconsistencies with project plans and work products are identified.

The project maintains a current and approved set of requirements over the life of the project by doing the following:

- Managing all changes to the requirements

- Maintaining the relationships among the requirements, the project plans, and the work products

- Identifying inconsistencies among the requirements, the project plans, and the work products

- Taking corrective action

This typically includes directly managing changes to customer and contractual requirements developed by acquirer and oversight of the supplier's requirements management process. Requirements changes may result in changes to the supplier agreement. [ACQ]

Refer to the Project Monitoring and Control process area for more information about taking corrective action.

SP 1.1 Obtain an Understanding of Requirements

Develop an understanding with the requirements providers on the meaning of the requirements.

As the project matures and requirements are derived, all activities or disciplines will receive requirements. To avoid requirements creep, criteria are established to designate appropriate channels, or official sources, from which to receive requirements. The receiving activities conduct analyses of the requirements with the requirements provider to ensure that a compatible, shared understanding is reached on the meaning of the requirements. The result of this analysis and dialog is an agreed-to set of requirements. 


\section{Typical Acquirer Work Products}

1. Lists of criteria for distinguishing appropriate requirements providers

2. Criteria for evaluation and acceptance of requirements

3. Results of analyses against criteria

4. An agreed-to set of requirements

\section{Subpractices}

1. Establish criteria for distinguishing appropriate requirements providers.

2. Establish objective criteria for the evaluation and acceptance of requirements.

Lack of evaluation and acceptance criteria often results in inadequate verification, costly rework, or customer rejection. [ACQ]

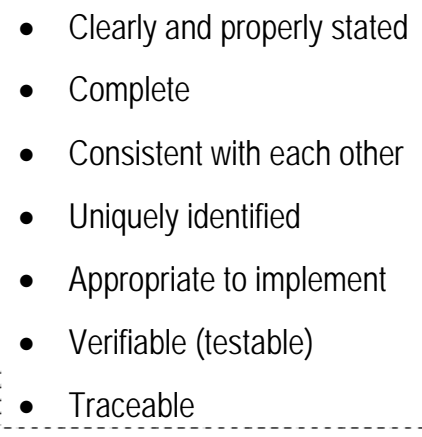

3. Analyze requirements to ensure that the established criteria are met.

4. Reach an understanding of the requirements with the requirements provider so that the project participants can commit to them.

SP 1.2 Obtain Commitment to Requirements

\section{Obtain commitment to the requirements from the project} participants.

Refer to the Project Monitoring and Control process area for more information about monitoring the commitments made. 
Whereas the previous specific practice dealt with reaching an understanding with the requirements providers, this specific practice deals with agreements and commitments among those who have to carry out the activities necessary to implement the requirements. Requirements evolve throughout the project, especially as described by the specific practices of the Acquisition Requirements Development process area and the Acquisition Technical Solution process area. As the requirements evolve, this specific practice ensures that project participants commit to the current, approved requirements and the resulting changes in project plans, activities, and work products. [ACQ]

Changes to requirements may lead to changes in supplier agreements; these changes need to be agreed upon between the project and the supplier after appropriate negotiations. [ACQ]

\section{Typical Acquirer Work Products}

1. Requirements impact assessments

2. Documented commitments to requirements and requirements changes

Typical Supplier Deliverables

1. Supplier's requirements impact assessments [ACQ]

\section{Subpractices}

1. Assess the impact of requirements on existing commitments.

2. Negotiate and record commitments.

Changes to existing commitments should be negotiated before project participants commit to the requirement or requirement change. [ACO]

The acquirer negotiates commitments with the customer and supplier before committing to the requirement changes. [ACQ]

SP 1.3 Manage Requirements Changes

Manage changes to the requirements as they evolve during the project.

Refer to the Configuration Management process area for more information about maintaining and controlling the requirements baseline and on making the requirements and change data available to the project. 
During the project, requirements change for a variety of reasons. As needs change and as work proceeds, additional requirements are derived and changes may have to be made to the existing requirements. It is essential to manage these additions and changes efficiently and effectively. To effectively analyze the impact of the changes, it is necessary that the source of each requirement is known and the rationale for any change is documented. The project manager may, however, want to track appropriate measures of requirements volatility to judge whether new or revised controls are necessary.

If the contractual requirements defined in supplier agreement are impacted due to the changes, the supplier agreements also need to be aligned with the changed requirements. [ACQ]

\section{Typical Acquirer Work Products}

1. Requirements change requests [ACQ]

2. Requirements change impact reports [ACQ]

3. Requirements status

4. Requirements database

5. Requirements decision database

Typical Supplier Deliverables

1. Requirements change requests [ACQ]

2. Requirements change impact reports [ACQ]

\section{Subpractices}

1. Document all requirements and requirements changes that are given to or generated by the project.

2. Maintain the requirements change history with the rationale for the changes.

Maintaining the change history helps track requirements volatility. [ACO]

3. Evaluate the impact of requirement changes from the standpoint of relevant stakeholders.

4. Make the requirements and change data available to the project.

SP 1.4 Maintain Bidirectional Traceability of Requirements

Maintain bidirectional traceability among the requirements and work products. 
The intent of this specific practice is to maintain the bidirectional traceability of requirements for each level of product decomposition. (See the definition of "bidirectional traceability" in the glossary.) When the requirements are managed well, traceability can be established from the source requirement to its lower level requirements and from the lower level requirements back to their source. Such bidirectional traceability helps determine that all source requirements have been completely addressed and that all lower level requirements can be traced to a valid source.

Requirements traceability can also cover the relationships to other entities such as intermediate and final work products, changes in design documentation, and test plans. The traceability can cover horizontal relationships, such as across interfaces, as well as vertical relationships. Traceability is particularly needed in conducting the impact assessment of requirements changes on the project's activities and work products.

The supplier maintains comprehensive bidirectional traceability to the requirements defined in the supplier agreement by the acquirer, and the acquirer verifies that traceability. The acquirer traces the contractual requirements to the customer requirements. [ACQ]

\section{Typical Acquirer Work Products}

1. Requirements traceability matrix

2. Requirements tracking system

\section{Typical Supplier Deliverables}

1. Comprehensive requirements traceability matrix managed by the supplier as required by the supplier agreement [ACQ]

\section{Subpractices}

1. Maintain requirements traceability to ensure that the source of lower level (derived) requirements is documented.

The traceability from contractual requirements to derived or additional requirements is maintained by the supplier. [ACQ]

2. Maintain requirements traceability from a requirement to its derived requirements and allocation to functions, interfaces, objects, people, processes, and work products.

3. Generate the requirements traceability matrix.

The comprehensive traceability matrix, tracing from contractual requirements to lower level requirements is maintained by the supplier. [ACQ] 
Identify inconsistencies between the project plans and work products and the requirements.

Refer to the Project Monitoring and Control process area for more information about monitoring and controlling the project plans and work products for consistency with requirements and taking corrective actions when necessary.

This specific practice finds the inconsistencies between the requirements and the project plans and work products and initiates the corrective action to fix them.

Corrective actions taken by the project to fix inconsistencies may also result in changes to project plans and supplier agreements. [ACQ]

\section{Typical Acquirer Work Products}

1. Documentation of inconsistencies including sources, conditions, and rationale $[\mathrm{ACQ}]$

2. Corrective actions [ACQ]

\section{Subpractices}

1. Review the project's plans, activities, and work products for consistency with the requirements and the changes made to them.

2. Identify the source of the inconsistency and the rationale.

3. Identify changes that need to be made to the plans and work products resulting from changes to the requirements baseline.

4. Initiate corrective actions. 
The purpose of Risk Management (RSKM) is to identify potential problems before they occur so that risk-handling activities can be planned and invoked as needed across the life of the product or project to mitigate adverse impacts on achieving objectives.

Risk management is a continuous, forward-looking process that is an important part of management. Risk management should address issues that could endanger achievement of critical objectives. A continuous risk management approach is applied to effectively anticipate and mitigate the risks that may have a critical impact on the project.

Effective risk management includes early and aggressive risk identification through the collaboration and involvement of relevant stakeholders, as described in the stakeholder involvement plan addressed in the Project Planning process area. Strong leadership across all relevant stakeholders is needed to establish an environment for the free and open disclosure and discussion of risk.

Risk management must consider both internal and external sources for cost, schedule, and performance risk as well as other risks. Early and aggressive detection of risk is important because it is typically easier, less costly, and less disruptive to make changes and correct work efforts during the earlier, rather than the later, phases of the project.

Risk Management has two contexts. The first context is the identification and assessment of project risks during the project planning process and managing these risks throughout the project. This includes identifying risks associated with the acquisition process and the use of a supplier to perform project work. The acquisition strategy initially identifies the risks associated with an acquisition. The approach to the acquisition is planned based upon those risks. As the project progresses to the selection of a supplier, the risks specific to the supplier's technical and management approach become important to the success of the acquisition. These risks particularly lie in the capability of the supplier to meet contractual requirements, including schedules and cost targets. [ACQ] 
The second context for Risk Management is following the selection of a supplier and award of the supplier agreement. In this context, the acquirer continues to manage project risks, including those risks related to the supplier meeting contractual requirements. Typically the acquirer does not manage risks being addressed or managed by the supplier.

[ACQ]

Risk management can be divided into three parts: defining a risk management strategy; identifying and analyzing risks; and handling identified risks, including the implementation of risk mitigation plans when needed.

Both the acquirer and the supplier must understand the project risks and how to modify the risk management strategy and plans as a project progresses through its life cycle. Managing a project's risks requires a close partnership between the acquirer and the supplier. Both the acquirer and the supplier need to share appropriate risk management documentation, understand the risks, and develop and execute risk management efforts. [ACQ]

Due to the acquirer-supplier relationship, the need for an early and aggressive detection of risk is compounded by the complexity of projects acquiring products and services. For example, the acquirer's capabilities, the supplier's experience of working with the acquirer, financial stability of the supplier, or availability of well-defined dispute resolution processes influence the risk of a project. [ACQ]

As represented in the Project Planning and Project Monitoring and Control process areas, organizations may initially focus simply on risk identification for awareness, and react to the realization of these risks as they occur. The Risk Management process area describes an evolution of these specific practices to systematically plan, anticipate, and mitigate risks to proactively minimize their impact on the project.

Although the primary emphasis of the Risk Management process area is on the project, the concepts can also be applied to manage organizational risks.

Refer to the Project Planning process area for more information about identification of project risks and planning for involvement of relevant stakeholders.

Refer to the Project Monitoring and Control process area for more information about monitoring project risks. 
Refer to the Decision Analysis and Resolution process area for more information about using a formal evaluation process to evaluate alternatives for selection and mitigation of identified risks.

Refer to the Solicitation and Supplier Agreement Development process area for more information about establishing supplier agreements. [ACQ]

Specific Goal and Practice Summary

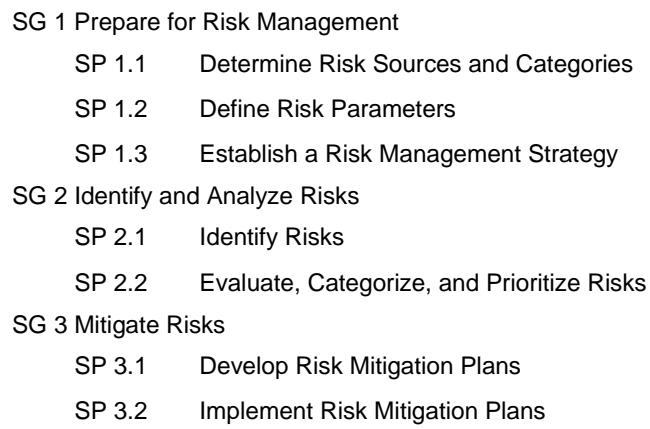

Preparation is conducted by establishing and maintaining a strategy for identifying, analyzing, and mitigating risks. This is typically documented in a risk management plan. The risk management strategy addresses the specific actions and management approach used to apply and control the risk management program. This includes identifying the sources of risk; the scheme used to categorize risks; and the parameters used to evaluate, bound, and control risks for effective handling.

\section{SP 1.1 Determine Risk Sources and Categories}

\section{Determine risk sources and categories.}

Identification of risk sources provides a basis for systematically examining changing situations over time to uncover circumstances that impact the ability of the project to meet its objectives. Risk sources are both internal and external to the project. As the project progresses, additional sources of risk may be identified. Establishing categories for risks provides a mechanism for collecting and organizing risks as well as ensuring appropriate scrutiny and management attention for those risks that can have more serious consequences on meeting project objectives. 
Acquirers identify and categorize risk sources and categories for the project initially and refine those sources and categories over time (e.g., schedule, cost, sourcing, contract management, supplier execution, technology readiness, human safety, reliability related risks and other issues outside the control of the acquirer). The supplier is also a source of risk (e.g., financial stability of the suppler and possibility of acquisition by another supplier). [ACQ]

\section{Typical Acquirer Work Products}

1. Risk source lists (external and internal)

2. Risk categories list

\section{Subpractices}

1. Determine risk sources.

Risk sources are the fundamental drivers that cause risks within a project or organization. There are many sources of risks, both internal and external, to a project. Risk sources identify common areas where risks may originate. Typical internal and external risk sources include the following: [ACQ]

- Uncertain requirements

- Unprecedented efforts-estimates unavailable

- Infeasible design

- Unavailable technology

- Unrealistic schedule estimates or allocation

- Inadequate staffing and skills

- Cost or funding issues

- Uncertain or inadequate subcontractor capability

- Uncertain or inadequate vendor capability

- Disruptions to continuity of operations

Many of these sources of risk are often accepted without adequate planning. Early identification of both internal and external sources of risk can lead to early identification of risks. Risk mitigation plans can then be implemented early in the project to preclude occurrence of the risks or reduce the consequences of their occurrence. [ACQ]

2. Determine risk categories.

Risk categories reflect the "bins" for collecting and organizing risks. A reason for identifying risk categories is to help in the future consolidation of the activities in the risk mitigation plans. [ACO] 
The following factors may be considered when determining risk categories: [ACQ]

- The phases of the project's life-cycle model (e.g., requirements, design, manufacturing, test and evaluation, delivery, disposal)

- The types of processes used

- The types of products used

- Program management risks (e.g., contract risks, budget/cost risks, schedule risks, resources risks, performance risks, supportability risks)

- Supplier specific risks (e.g., financial viability of the supplier, geographic location of supplier resources).

- Safety, security and reliability of the product

A risk taxonomy can be used to provide a framework for determining risk sources and categories. [ACQ]

SP $1.2 \quad$ Define Risk Parameters

Define the parameters used to analyze and categorize risks, and the parameters used to control the risk management effort.

Parameters for evaluating, categorizing, and prioritizing risks include the following:

- Risk likelihood (i.e., probability of risk occurrence)

- Risk consequence (i.e., impact and severity of risk occurrence)

- Thresholds to trigger management activities

Risk parameters are used to provide common and consistent criteria for comparing the various risks to be managed. Without these parameters, it would be very difficult to gauge the severity of the unwanted change caused by the risk and to prioritize the necessary actions required for risk mitigation planning.

Acquirers should record the parameters used to analyze and categorize risk so that they are available throughout the project period for reference when circumstances change over time. In this way, risks can easily be re-categorized and analyzed relative to the original information when changes occur. [ACQ]

The acquirer may use tools such as Failure Mode and Effects Analysis for examining risks such as potential failures in products or processes. It may be used to evaluate risk management priorities for mitigating known threat-vulnerabilities. [ACQ]

\section{Typical Acquirer Work Products}

1. Risk evaluation, categorization, and prioritization criteria 
2. Risk management requirements (e.g., control and approval levels, reassessment intervals)

\section{Subpractices}

1. Define consistent criteria for evaluating and quantifying risk likelihood and severity levels.

Consistently used criteria (e.g., the bounds on the likelihood and severity levels) allow the impacts of different risks to be commonly understood, to receive the appropriate level of scrutiny, and to obtain the management attention warranted. In managing dissimilar risks (e.g., personnel safety versus environmental pollution), it is important to ensure consistency in end result (e.g., a high risk of environmental pollution is as important as a high risk to personnel safety). [ACQ]

2. Define thresholds for each risk category.

For each risk category, thresholds can be established to determine acceptability or unacceptability of risks, prioritization of risks, or triggers for management action. [ACQ]

Examples of thresholds include the following: [ACQ]

- Project-wide thresholds could be established to involve senior management when product costs exceed 10 percent of the target cost or when Cost Performance Indexes (CPIs) fall below 0.95 .

- Schedule thresholds could be established to involve senior management when Schedule Performance Indexes (SPIs) fall below 0.95 .

- Performance thresholds could be set to involve senior management when specified key design items (e.g., processor utilization) exceed 125 percent of the intended design.

These may be refined later, for each identified risk, to establish points at which more aggressive risk monitoring is employed or to signal the implementation of risk mitigation plans. [ACQ]

3. Define bounds on the extent to which thresholds are applied against or within a category.

There are few limits to which risks can be assessed in either a quantitative or qualitative fashion. Definition of bounds (or boundary conditions) can be used to help scope the extent of the risk management effort and avoid excessive resource expenditures. Bounds may include exclusion of a risk source from a category. These bounds can also exclude any condition that occurs less than a given frequency. [AcQ]

SP 1.3 Establish a Risk Management Strategy 
A comprehensive risk management strategy addresses items such as the following:

- The scope of the risk management effort

- Methods and tools to be used for risk identification, risk analysis, risk mitigation, risk monitoring, and communication

- Project-specific sources of risks

- How these risks are to be organized, categorized, compared, and consolidated

- Parameters, including likelihood, consequence, and thresholds, for taking action on identified risks

- Risk mitigation techniques to be used, such as prototyping, piloting, simulation, alternative designs, or evolutionary development

- Definition of risk measures to monitor the status of the risks

- Time intervals for risk monitoring or reassessment

The risk management strategy should be guided by a common vision of success that describes the desired future project outcomes in terms of the product that is delivered, its cost, and its fitness for the task. The risk management strategy is often documented in an organizational or a project risk management plan. The risk management strategy is reviewed with relevant stakeholders to promote commitment and understanding.

A risk management strategy must be developed early in the project, so that relevant risks are identified and managed aggressively. The acquisition strategy evolves based on risk identification and analysis. The early identification and assessment of critical risks allows the acquirer to formulate risk handling approaches and to streamline the project definition and the solicitation around critical product and process risks. [ACQ]

Typical Acquirer Work Products

1. Project risk management strategy

SG 2 Identify and Analyze Risks

Risks are identified and analyzed to determine their relative importance.

The degree of risk impacts the resources assigned to handle an identified risk and the determination of when appropriate management attention is required. 
Analyzing risks entails identifying risks from the internal and external sources identified and then evaluating each identified risk to determine its likelihood and consequences. Categorization of the risk, based on an evaluation against the established risk categories and criteria developed for the risk management strategy, provides the information needed for risk handling. Related risks may be grouped for efficient handling and effective use of risk management resources.

SP 2.1 Identify Risks

\section{Identify and document the risks.}

The identification of potential issues, hazards, threats, and vulnerabilities that could negatively affect work efforts or plans is the basis for sound and successful risk management. Risks must be identified and described in an understandable way before they can be analyzed and managed properly. Risks are documented in a concise statement that includes the context, conditions, and consequences of risk occurrence.

Risk identification should be an organized, thorough approach to seek out probable or realistic risks in achieving objectives. To be effective, risk identification should not be an attempt to address every possible event regardless of how highly improbable it may be. Use of the categories and parameters developed in the risk management strategy, along with the identified sources of risk, can provide the discipline and streamlining appropriate to risk identification. The identified risks form a baseline to initiate risk management activities. The list of risks should be reviewed periodically to reexamine possible sources of risk and changing conditions to uncover sources and risks previously overlooked or nonexistent when the risk management strategy was last updated.

Risk identification activities focus on the identification of risks, not placement of blame. The results of risk identification activities are not used by management to evaluate the performance of individuals.

There are many methods for identifying risks. Typical identification methods include the following:

- Examine each element of the project work breakdown structure to uncover risks.

- Conduct a risk assessment using a risk taxonomy.

- Interview subject matter experts.

- Review risk management efforts from similar products.

- Examine lessons-learned documents or databases.

- Examine design specifications and agreement requirements. 
Some risks are identified by examining the supplier's WBS, product and processes using the categories and parameters developed in the risk management strategy. Risks can be identified in many areas, e.g., requirements, technology, design, testing, vulnerability to threats, life cycle costs. An examination of the project in these areas can help to develop or refine the acquisition strategy and the risk-sharing structure between the acquirer and supplier. [ACQ]

The acquirer considers the risks associated with a supplier's capability (e.g., meeting schedule and cost requirements for the project) including the potential risks to the acquirer's intellectual capital or security vulnerabilities introduced by using a supplier. [AcQ]

\section{Typical Acquirer Work Products}

1. List of identified risks, including the context, conditions, and consequences of risk occurrence

\section{Typical Supplier Deliverables}

1. List of identified risks, including the context, conditions, and consequences of risk occurrence $\left.{ }_{[\mathrm{ACQ}}\right]$

\section{Subpractices}

1. Identify the risks associated with cost, schedule, and performance.

Cost, schedule, and performance risks should be examined during all phases of the product life cycle in the acquirer's intended environment to the extent that they impact project objectives. There may be potential risks discovered that are outside the scope of the project's objectives but vital to customer interests. For example, the risks in development costs, product acquisition costs, cost of spare (or replacement) products, and product disposition (or disposal) costs have design implications. The customer may not have provided requirements for the cost of supporting the fielded product. The customer should be informed of such risks, but actively managing those risks may not be necessary. The mechanisms for making such decisions should be examined at project and organization levels and put in place if deemed appropriate, especially for risks that impact the ability to verify and validate the product. [ACO]

In addition to the cost risks identified above, other cost risks may include those associated with funding levels, funding estimates, and distributed budgets. [ACO]

Schedule risks may include risks associated with planned activities, key events, and milestones. [ACQ]

Performance risks may include risks associated with the following: [ACQ]

- Requirements

- Analysis and design

- Application of new technology 
- Physical size

- Shape

- Weight

- Manufacturing and fabrication

- Functional performance and operation

- Verification

- Validation

- Performance maintenance attributes

Performance maintenance attributes are those characteristics that enable an inuse product or service to provide originally required performance, such as maintaining safety and security performance. [ACQ]

There are other risks that do not fall into cost, schedule, or performance categories. [ACQ]

Examples of these other risks include the following: [ACQ]

- Risks associated with strikes

- Diminishing sources of supply

- Technology cycle time

- Competition

2. Review environmental elements that may impact the project.

Risks to a project that frequently are missed include those supposedly outside the scope of the project (i.e., the project does not control whether they occur but can mitigate their impact), such as weather, natural or manmade disasters that affect continuity of operations, political changes, and telecommunications failures. [ACQ]

3. Review all elements of the work breakdown structure as part of identifying risks to help ensure that all aspects of the work effort have been considered.

4. Review all elements of the project plan as part of identifying risks to help ensure that all aspects of the project have been considered.

Refer to the Project Planning process area for more information about identifying project risks.

5. Document the context, conditions, and potential consequences of the risk. 
Risks statements are typically documented in a standard format that contains the risk context, conditions, and consequences of occurrence. The risk context provides additional information such that the intent of the risk can be easily understood. In documenting the context of the risk, consider the relative time frame of the risk, the circumstances or conditions surrounding the risk that has brought about the concern, and any doubt or uncertainty. [ACO]

6. Identify the relevant stakeholders associated with each risk.

\section{SP 2.2 Evaluate, Categorize, and Prioritize Risks}

Evaluate and categorize each identified risk using the defined risk categories and parameters, and determine its relative priority.

The evaluation of risks is needed to assign relative importance to each identified risk, and is used in determining when appropriate management attention is required. Often it is useful to aggregate risks based on their interrelationships, and develop options at an aggregate level. When an aggregate risk is formed by a roll up of lower level risks, care must be taken to ensure that important lower level risks are not ignored.

Collectively, the activities of risk evaluation, categorization, and prioritization are sometimes called "risk assessment" or "risk analysis."

The acquirer should conduct a risk assessment prior to solicitation to evaluate if the project can achieve its technical, schedule, and budget constraints. Technical, schedule, and cost risks should be discussed with potential suppliers before the solicitation is released. In this way, critical risks inherent in the project can be identified and addressed in the solicitation. [ACQ]

\section{Typical Acquirer Work Products}

1. List of risks, with a priority assigned to each risk

\section{Typical Supplier Deliverables}

1. List of risks, with a priority assigned to each risk [ACQ]

\section{Subpractices}

1. Evaluate the identified risks using the defined risk parameters.

Each risk is evaluated and assigned values in accordance with the defined risk parameters, which may include likelihood, consequence (severity, or impact), and thresholds. The assigned risk parameter values can be integrated to produce additional measures, such as risk exposure, which can be used to prioritize risks for handling. $[\mathrm{ACQ}]$ 
Often, a scale with three to five values is used to evaluate both likelihood and consequence. Likelihood, for example, can be categorized as remote, unlikely, likely, highly likely, or a near certainty. [ACQ]

\footnotetext{
- Low

- Medium

- High

- Negligible

- Marginal

- Significant

- Critical

- Catastrophic
}

Examples for consequences include the following: [ACQ]

Probability values are frequently used to quantify likelihood. Consequences are generally related to cost, schedule, environmental impact, or human measures (e.g., labor hours lost, severity of injury). [ACQ]

This evaluation is often a difficult and time-consuming task. Specific expertise or group techniques may be needed to assess the risks and gain confidence in the prioritization. In addition, priorities may require reevaluation as time progresses. [ACQ]

2. Categorize and group risks according to the defined risk categories.

Risks are categorized into the defined risk categories, providing a means to look at risks according to their source, taxonomy, or project component. Related or equivalent risks may be grouped for efficient handling. The cause-and-effect relationships between related risks are documented. [ACQ]

An acquirer's risk categories may include sourcing, contract management, supplier execution, in addition to project management, technology, and requirements. [ACQ]

\section{Prioritize risks for mitigation.}

A relative priority is determined for each risk based on the assigned risk parameters. Clear criteria should be used to determine the risk priority. The intent of prioritization is to determine the most effective areas to which resources for mitigation of risks can be applied with the greatest positive impact to the project. [ACQ] 

impacts on achieving objectives.

The steps in handling risks include developing risk-handling options, monitoring risks, and performing risk-handling activities when defined thresholds are exceeded. Risk mitigation plans are developed and implemented for selected risks to proactively reduce the potential impact of risk occurrence. This can also include contingency plans to deal with the impact of selected risks that may occur despite attempts to mitigate them. The risk parameters used to trigger risk-handling activities are defined by the risk management strategy.

SP 3.1 Develop Risk Mitigation Plans

Develop a risk mitigation plan for the most important risks to the project, as defined by the risk management strategy.

A critical component of a risk mitigation plan is to develop alternative courses of action, workarounds, and fallback positions, with a recommended course of action for each critical risk. The risk mitigation plan for a given risk includes techniques and methods used to avoid, reduce, and control the probability of occurrence of the risk, the extent of damage incurred should the risk occur (sometimes called a "contingency plan"), or both. Risks are monitored and when they exceed the established thresholds, the risk mitigation plans are deployed to return the impacted effort to an acceptable risk level. If the risk cannot be mitigated, a contingency plan can be invoked. Both risk mitigation and contingency plans are often generated only for selected risks where the consequences of the risks are determined to be high or unacceptable; other risks may be accepted and simply monitored.

Options for handling risks typically include alternatives such as the following:

- Risk avoidance: Changing or lowering requirements while still meeting the user's needs

- Risk control: Taking active steps to minimize risks

- Risk transfer: Reallocating requirements to lower the risks

- Risk monitoring: Watching and periodically reevaluating the risk for changes to the assigned risk parameters

- Risk acceptance: Acknowledgment of risk but not taking any action

Often, especially for high risks, more than one approach to handling a risk should be generated. 
For example, in the case of an event that disrupts continuity of operations, approaches

to risk management can include;

- Resource reserves to respond to disruptive events

- Lists of appropriate back-up equipment to be available

- Back-up personnel for key personnel

- Plans and results of/for testing emergency response systems

- Posted procedures for emergencies

- Disseminated lists of key contacts and information resources for emergencies

In many cases, risks will be accepted or watched. Risk acceptance is usually done when the risk is judged too low for formal mitigation, or when there appears to be no viable way to reduce the risk. If a risk is accepted, the rationale for this decision should be documented. Risks are watched when there is an objectively defined, verifiable, and documented threshold of performance, time, or risk exposure (the combination of likelihood and consequence) that will trigger risk mitigation planning or invoke a contingency plan if it is needed.

Thresholds for supplier risks that affect the project (e.g., schedule, quality or risk exposure due to supplier risks) are specified in the supplier agreement along with escalation actions if the thresholds are exceeded. [ACQ]

Adequate consideration should be given early to technology demonstrations, models, simulations, pilots, and prototypes as part of risk mitigation planning.

\section{Typical Acquirer Work Products}

1. Documented handling options for each identified risk

2. Risk mitigation plans

3. Contingency plans

4. Disaster recovery or continuity plans [ACQ]

5. List of those responsible for tracking and addressing each risk

\section{Typical Supplier Deliverables}

1. Documented handling options for each identified risk [ACQ]

2. Risk mitigation plans [ACQ]

3. Contingency plans [ACQ]

4. Disaster recovery or continuity plans [ACQ]

5. List of those responsible for tracking and addressing each risk [ACQ] 


\section{Subpractices}

1. Determine the levels and thresholds that define when a risk becomes unacceptable and triggers the execution of a risk mitigation plan or a contingency plan.

Risk level (derived using a risk model) is a measure combining the uncertainty of reaching an objective with the consequences of failing to reach the objective. [ACO]

Risk levels and thresholds that bound planned or acceptable performance must be clearly understood and defined to provide a means with which risk can be understood. Proper categorization of risk is essential for ensuring appropriate priority based on severity and the associated management response. There may be multiple thresholds employed to initiate varying levels of management response. Typically, thresholds for the execution of risk mitigation plans are set to engage before the execution of contingency plans. [ACQ]

2. Identify the person or group responsible for addressing each risk.

3. Determine the cost-to-benefit ratio of implementing the risk mitigation plan for each risk.

Risk mitigation activities should be examined for the benefits they provide versus the resources they will expend. Just like any other design activity, alternative plans may need to be developed and the costs and benefits of each alternative assessed. The most appropriate plan is then selected for implementation. At times the risk may be significant and the benefits small, but the risk must be mitigated to reduce the probability of incurring unacceptable consequences. [ACQ]

4. Develop an overall risk mitigation plan for the project to orchestrate the implementation of the individual risk mitigation and contingency plans.

The complete set of risk mitigation plans may not be affordable. A tradeoff analysis should be performed to prioritize the risk mitigation plans for implementation. [ACQ]

5. Develop contingency plans for selected critical risks in the event their impacts are realized.

Risk mitigation plans are developed and implemented as needed to proactively reduce risks before they become problems. Despite best efforts, some risks may be unavoidable and will become problems that impact the project. Contingency plans can be developed for critical risks to describe the actions a project may take to deal with the occurrence of this impact. The intent is to define a proactive plan for handling the risk, either to reduce the risk (mitigation) or respond to the risk (contingency), but in either event to manage the risk. [ACQ]

Some risk management literature may consider contingency plans a synonym or subset of risk mitigation plans. These plans also may be addressed together as risk-handling or risk action plans. [ACQ] 
Monitor the status of each risk periodically and implement the risk mitigation plan as appropriate.

To effectively control and manage risks during the work effort, follow a proactive program to regularly monitor risks and the status and results of risk-handling actions. The risk management strategy defines the intervals at which the risk status should be revisited. This activity may result in the discovery of new risks or new risk-handling options that can require replanning and reassessment. In either event, the acceptability thresholds associated with the risk should be compared against the status to determine the need for implementing a risk mitigation plan.

The acquirer shares selected risks with the supplier. Risks associated specifically with the acquisition process are tracked and resolved or controlled until mitigated. This monitoring includes risks that may be escalated by the supplier. [ACQ]

\section{Typical Acquirer Work Products}

1. Updated lists of risk status

2. Updated assessments of risk likelihood, consequence, and thresholds

3. Updated lists of risk-handling options

4. Updated list of actions taken to handle risks

5. Risk mitigation plans

Typical Supplier Deliverables

1. Updated lists of risk status [ACQ]

2. Updated assessments of risk likelihood, consequence, and thresholds [ACQ]

3. Updated lists of risk-handling options [ACQ]

4. Updated list of actions taken to handle risks [ACQ]

5. Risk mitigation plans [ACQ]

\section{Subpractices}

1. Monitor risk status.

After a risk mitigation plan is initiated, the risk is still monitored. Thresholds are assessed to check for the potential execution of a contingency plan. [Aco]

A periodic mechanism for monitoring should be employed. [ACQ]

2. Provide a method for tracking open risk-handling action items to closure. 
Refer to the Project Monitoring and Control process area for more information about tracking action items.

3. Invoke selected risk-handling options when monitored risks exceed the defined thresholds.

Quite often, risk handling is only performed for those risks judged to be "high" and "medium." The risk-handling strategy for a given risk may include techniques and methods to avoid, reduce, and control the likelihood of the risk or the extent of damage incurred should the risk (anticipated event or situation) occur or both. In this context, risk handling includes both risk mitigation plans and contingency plans. [ACQ]

Risk-handling techniques are developed to avoid, reduce, and control adverse impact to project objectives and to bring about acceptable outcomes in light of probable impacts. Actions generated to handle a risk require proper resource loading and scheduling within plans and baseline schedules. This replanning effort needs to closely consider the effects on adjacent or dependent work initiatives or activities. [ACQ]

Refer to the Project Monitoring and Control process area for more information about revising the project plan.

4. Establish a schedule or period of performance for each riskhandling activity that includes the start date and anticipated completion date.

5. Provide continued commitment of resources for each plan to allow successful execution of the risk-handling activities.

6. Collect performance measures on the risk-handling activities. 
The purpose of Solicitation and Supplier Agreement Development (SSAD) is to prepare a solicitation package and to select one or more suppliers for delivering the product or service.

The Solicitation and Supplier agreement development process area includes developing the acquisition strategy. The acquisition strategy is a guide to direct and control the project and a framework to integrate the activities essential to acquiring an operational product.

The Solicitation and Supplier Agreement Development process area provides a set of practices that enable the acquirer to initialize and formalize a relationship with the supplier for the successful execution of the project. A formal agreement is any legal agreement between the organization (representing the project) and the supplier. This agreement may be a contract, a license, or a memorandum of agreement. The acquired product is delivered to the project from the supplier according to this formal agreement (also known as the "supplier agreement").

The supplier agreement created using these practices enables the acquirer to execute its monitoring and control of supplier activities using other process areas, such as Project Monitoring and Control and Acquisition Management.

The practices of this process area apply equally to initial supplier agreements and to subsequent change orders, task orders, or amendments related to those agreements.

The acquirer is responsible for establishing and maintaining the ground rules for supplier communication, documenting decisions, and conflict resolution through the life of the agreement. The acquirer facilitates these activities with relevant project stakeholders. Specific roles and responsibilities of relevant project stakeholders for interaction with or direction of the suppliers are defined, coordinated, and adhered to. 
The specific goals and specific practices of this process area build on each other in the following way. The Prepare for Solicitation and Supplier Agreement Development specific goal and associated practices identify potential suppliers and develop the evaluation criteria and the solicitation package. The solicitation package is developed using work products from other process areas, e.g., requirements from Acquisition Requirements Development and design constraints from Acquisition Technical Solution. The Select Suppliers specific goal and associated specific practices use the work products from the preparation for solicitation to solicit responses from potential suppliers, evaluate these responses, negotiate and select a supplier who can best deliver to the solicitation package. Subsequently, the "Establish Supplier Agreement" specific goal and associated practices are used to document the approved supplier agreement. In turn, the data provided by the supplier and documented in the supplier agreement (e.g., cost, schedule, risks) is used by Project Planning practices to update the project plan.

Although this process area describes acquisition practices for a project, an acquirer would use the same practices in establishing a supplier agreement for multiple projects. The requirements included in the solicitation package and the supplier agreement would reflect the broader scope, and the evaluation and selection process would require an appropriate level of review before a selection is made.

Refer to the Project Planning process area for information on planning for solicitation, including developing and documenting the project plan for the acquisition, estimating the supplier's work, and for information about revising the project plan.

Refer to the Acquisition Requirements Development process area for more information about defining customer and contractual requirements.

Refer to Acquisition Verification and Acquisition Validation process areas for more information about evaluating requirements.

Refer to the Requirements Management process area for more information about managing requirements, including the traceability of requirements for products acquired from suppliers and for managing changes to requirements.

Refer to the Acquisition Technical Solution process area for more information about determining the design constraints, including standards that are included in the solicitation package. 
Refer to the Acquisition Management process area for more information about managing selected suppliers' activities based upon the supplier agreement.

Refer to Decision Analysis and Resolution process area for more information about formal evaluation approaches that can be used to select suppliers.

\section{Specific Goal and Practice Summary}

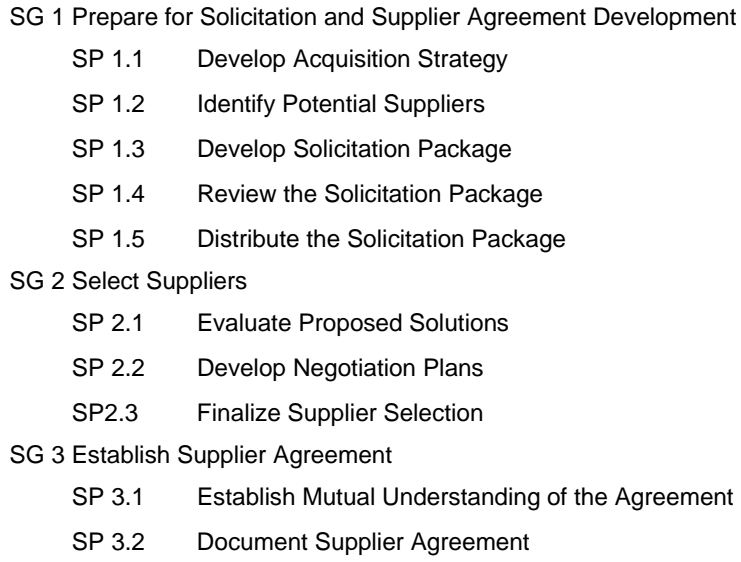

Specific Practices by Goal

SG 1 Prepare for Solicitation and Supplier Agreement Development Develop the acquisition strategy, qualify potential suppliers and develop a solicitation package that includes the requirements and proposal evaluation criteria.

SP 1.1 Develop the Acquisition Strategy

\section{Develop and maintain the overall acquisition strategy content.}

The acquisition strategy is the business and technical management framework for planning, directing, contracting for, and managing a project or program. The acquisition strategy relates to the objectives for the acquisition, the constraints, availability of resources and technologies, consideration of acquisition methods, potential supplier agreement types, terms and conditions, accommodation of business considerations, considerations of risk, and support for the acquired product over its life cycle. 
The acquisition strategy results from a thorough understanding of both the specific acquisition project or program and the general acquisition environment. The acquirer accounts for the potential value or benefit of the acquisition in the light of the potential risks, considers constraints, and takes into account experiences with different types of suppliers, agreements and terms. A well-developed strategy minimizes the time and cost required to satisfy approved capability needs, and maximizes affordability throughout the project life cycle.

The acquisition strategy for a project typically tailors a program or organizational level acquisition strategy.

Refer to the Organizational Process Definition process area for information about tailoring criteria and guidelines.

The acquisition strategy is the basis for formulating solicitation packages, supplier agreements, and project plans. The strategy evolves over time and should continuously reflect the current status and desired end point of the project.

\section{Typical Acquirer Work Products}

1. Acquisition strategy

\section{Subpractices}

1. Identify the capabilities and objectives the acquisition is intended to satisfy or provide

The capabilities describe what the organization intends to acquire. Typically the capability included in the acquisition strategy summary highlights product characteristics driven by interoperability and/or and families of products. It also identifies any dependency on planned or existing capabilities of other projects or products.

Refer to Acquisition Requirements Development for information about determining capabilities and customer requirements.

At a minimum, the acquirer identifies the cost, schedule, and key performance objectives for the acquisition. Each objective consists of an objective value representing customer expectations and a threshold value representing acceptable limits that, in the customer's judgment, still provide the needed capability. While the number and specificity of performance parameters may change over the duration of an acquisition, the acquirer typically focuses on the minimum number of parameters that, if thresholds are not met, will require a reevaluation of the project. 
The acquisition strategy establishes the milestone decision points and acquisition phases planned for the project. It prescribes the accomplishments for each phase, and identifies the critical events affecting project management. Schedule parameters include, at a minimum, the projected dates for the project initiation, other major decision points, and initial operational capability.

\section{Examples of cost parameters include the following:}

- Research, development, test, and evaluation costs

- Procurement costs

- Acquisition related operations, support, and disposal costs

- Total product quantity (to include both fully configured development and production units)

2. Identify the acquisition approach

The acquirer defines the approach the project will use to achieve full capability: either evolutionary or single step; it should include a brief rationale to justify the choice. When a project uses an evolutionary acquisition approach, the acquisition strategy describes the initial capability, and how it will be funded, developed, tested, produced, and supported. The acquisition strategy previews similar planning for subsequent increments, and identifies the approach to integrate and/or retrofit earlier increments with later increments.

Examples of additional considerations for the acquisition approach include the following:

- Actions a project team can take on their own, if the acquiring organization or unit has a procurement, contracting, or purchasing department

- Who will prepare independent estimates and if they are need as evaluation criteria

- Managing multiple suppliers

- Anticipated lead times from potential suppliers to acquire items

\section{Document business considerations}

Examples of business considerations for an acquisition strategy include the following:

- Competition planned for all phases of acquisition, or explains why competition is not practicable or not in the best interests of the acquirer. This includes considerations for establishing or maintaining access to competitive suppliers for critical areas at the product or product components.

- Product and technology areas critical to satisfy or provide the desired capabilities.

- Availability and suitability of commercial items and the extent to which the interfaces for these items have broad market acceptance, standards-organization support, and stability. This includes considerations for both international and domestic sources that can meet the required need, as the primary sources of supply consistent with organizational policies and regulations.

4. Identify major risks and risk sharing with the supplier 
All acquisition risks, whether primarily managed by the acquirer or by the supplier, must be assessed and managed by the acquirer. The acquisition strategy describes how risk is to be handled and identifies major risks and which risks are to be shared with the supplier and which are to be retained by acquirer.

\section{Refer to Risk Management for information about determining capabilities and customer requirements.}

5. Identify the supplier agreement type

The acquirer identifies standardized procurement documents (e.g., standard supplier agreements), if any. The acquirer also determines the type of supplier agreement planned (e.g., firm fixed-price; fixed-price incentive, firm target; cost plus incentive fee; or cost plus award fee) and the reasons it is suitable, including considerations of risk assessment and reasonable risk-sharing by the acquirer and the supplier.

The acquisition strategy explains the planned incentive structure for the acquisition, and how it incentivizes the supplier to provide the product or services at or below the established cost objectives and satisfy the schedule and key performance objectives. If more than one incentive is planned for a supplier agreement, the acquisition strategy explains how the incentives complement each other and do not interfere with one another. The acquisition strategy identifies any unusual terms and conditions of the planned supplier agreement and all existing or contemplated deviations to an organization's terms and conditions, if any.

6. Identify the product support strategy

The acquirer develops a product support strategy for life cycle sustainment and continuous improvement of product affordability, reliability, and supportability, while sustaining readiness. The support strategy addresses how the acquirer will maintain oversight of the fielded product.

The acquirer's sustainment organization or supplier typically participates in product support strategy development.

7. Review and obtain agreement with senior management on the acquisition strategy

The development of the acquisition strategy for a project typically requires senior management sponsorship. The appropriate senior management needs to approve the acquisition strategy before initiating a project.

\section{SP 1.2 Identify Potential Suppliers}

\section{Identify and qualify potential suppliers.}


Consistent with the acquisition strategy and along with the scope and requirements for the project or program, the acquirer identifies potential suppliers to receive the solicitation. The acquirer can identify suppliers from a variety of sources (e.g., employees, international seminars, market analysis reports).

Acquirers need to limit the number of suppliers they solicit proposals from in order to reduce their cost and efforts for the solicitation, while at the same time making sure they have included suppliers who are capable of meeting the requirements and that enough suppliers are included to provide a competitive environment. This competition enhances the leverage of the acquirer in achieving its objectives (e.g., providing different approaches to meeting the requirements).

Depending upon the applicable regulations or characteristics of the project, the acquirer may determine to sole source the project rather than place it for competitive bid.

\section{Typical Acquirer Work Products}

1. List of potential suppliers prepared to respond to the solicitation

\section{Subpractices}

1. Develop a list of potential suppliers.

In developing the list of potential suppliers, the acquirer considers which suppliers have had experience with similar systems or projects, what kind of performance the acquirer has experienced with suppliers on previous projects, what suppliers are likely to provide the specific capabilities needed for the project, and what is the availability of critical resources to staff and support the project. In addition to assessing the supplier's capabilities, a risk assessment is prepared on the supplier's financial capabilities (e.g., credit worthiness, financial stability and access to capital and the impact to the supplier of a successful bid).

2. Communicate with potential suppliers concerning the forthcoming solicitation.

The acquirer contacts the suppliers to outline the plans for the solicitation, including the projected schedule for releasing the solicitation package and the expected dates for responses from suppliers. If the supplier indicates their interest in responding to the solicitation, the appropriate confidentiality agreements are put in place.

Typical information included in communication to candidate suppliers:

- Anticipated scope of the solicitation

- Schedule for release of the solicitation package

- Overall project schedule

- Approach/procedures that will be used throughout the solicitation process 
- High level criteria for evaluating proposal responses

- Required supplier qualifications, e.g., appraisal at a specific CMMI level

- Schedule for return of proposal

- Date for supplier to indicate if it will or will not participate in the solicitation

3. Verify the participants who will evaluate supplier proposals.

4. Verify the participants in supplier negotiations.

\section{SP 1.3 Develop Solicitation Package}

\section{Establish and maintain a solicitation package that includes the requirements and proposal evaluation criteria.}

Solicitation packages are used to seek proposals from potential suppliers. The acquirer structures the solicitation package to facilitate an accurate and complete response from each potential supplier and to allow for an effective comparison and evaluation of proposals.

The solicitation package includes a description of the desired form of the response, the relevant statement of work for the supplier, and any required contractual provisions (e.g., a copy of the standard supplier agreement, non-disclosure provisions). With government agreements, some or all of the content and structure of the solicitation package can be defined by regulation.

The solicitation package typically contains the following:

- The statement of work for the supplier, including supplier measures and service levels

- Guidance on how potential suppliers are to respond to the solicitation package

- Criteria that will be used to evaluate the proposals

- Documentation requirements to submit with the response (e.g., project plans)

- Schedule for completing the solicitation process

- Procedures for addressing questions and contacts

The solicitation package is rigorous enough to ensure consistent, comparable responses, but flexible enough to allow consideration of supplier suggestions for better ways to satisfy the requirements. Inviting the suppliers to submit a proposal that is wholly responsive to the request for proposal and to provide a proposed alternative solution in a separate proposal can do this. 
The complexity and level of detail of the solicitation package should be consistent with the value of, and risk associated with the planned acquisition. In some cases, the solicitation may not include detailed requirements (e.g., it may be a solicitation for development of detailed requirements or it may include a statement of objectives to provide the supplier greater flexibility in addressing the scope of the project).

Proposal and supplier evaluation criteria are identified and documented.

\section{Typical Acquirer Work Products}

\section{Solicitation package}

2. Supplier and proposal evaluation criteria

\section{Subpractices}

1. Develop the statement of work for the supplier

The statement of work for the supplier defines, for those items being acquired, just the portion of the project scope that is included within the related supplier agreement. The statement of work for a supplier is developed from the project scope, the work breakdown structure and task dictionary.

The statement of work for the supplier is written to be clear, complete, and concise. It describes the acquired product or service in sufficient detail to allow prospective suppliers to determine if they are capable of providing the product or service. 
Example content of the statement of work for the supplier includes the following:

- Project or program objectives

- Requirements (incl. period of performance, work location, legal, statutory and regulatory requirements)

- Design constraints

- Deliverables and rights (e.g., work breakdown structure of the supplier's work, detailed design, test results)

- Expectations for supplier transition of product to operations

- Measurements, service levels, and reports that provide the acquirer visibility into the supplier's process and results

- Collateral services required (e.g. study reports, development of training materials, delivering training to end users)

- Acquirer specified standard processes for the project (e.g., configuration management, escalation, corrective action for non-conformances, conflict resolution, and change management)

- The type of reviews that will be conducted with the supplier and other communication processes and procedures

- Product acceptance criteria

- Post-project support

The statement of work for the supplier can be revised and refined as required as it moves through the solicitation and supplier agreement development process until incorporated into a signed supplier agreement. For example, a prospective supplier can suggest a more efficient approach or a less costly product than that originally specified.

2. Specify the measures, acceptance criteria, and the associated service levels for the supplier.

Service levels are designed to support the acquisition strategy. Typically the service levels are a limited set with a precise definition, including the assessment and calculation of incentives and penalties. 
Examples of considerations for service levels include the following:

- Specific methodology to be followed in measuring supplier performance, including goals, objectives, credits, earnbacks, and measurement calculations.

- On-going level of performance of the service acquired, the minimum allowed performance level, and the amount of credit allocated to each performance measurement

- One-time deliverables with monthly credits to the acquirer for non-performance by the supplier

A service level for a project, for example, may refer to an output from the supplier, such as providing a specific deliverable at an agreed upon time, and to the quality of that output. Service levels also (directly or indirectly) refer to progress measures, e.g., \% of completion of that deliverable according to schedule, to initiate corrective action based on their associated performance target or thresholds, for instance, if the supplier doesn't appear to be on schedule to meet the service level agreement, in this example on time completion of a deliverable.

\section{Refer to the Project Monitoring and Control practices for more information on the use of supplier measurement data to monitor a project.}

4. Develop supplier evaluation and proposal evaluation criteria.

Evaluation criteria are developed and used to rate or score proposals. Evaluation criteria are included as apart of the solicitation package. Evaluation criteria can be limited to purchase price if the procurement item is readily available from a number of acceptable suppliers. Purchase price in this context includes both the cost of the item and ancillary expenses such as delivery. Other selection criteria can be identified and documented to support an assessment for a more complex product or service (e.g., the individuals identified in the Project Planning resource plan, develop, and document the criteria for evaluating potential suppliers and for evaluating their proposals). 
Examples of areas to evaluate the potential suppliers' ability and proposals include the following:

- compliance to stated requirements contained in the solicitation package

- experience with similar products or services (e.g., familiarity with the acquirer's processes, technical environment and the core business)

- total ownership and life-cycle cost

- technical capability (e.g., expected functional and performance compliance to the requirements and criteria, given the architecture and technical solution proposed)

- management and delivery processes and procedures

- proposed technical methodologies, techniques, solutions, and services

- financial capability

- production capacity and interest (e.g., staff available to perform the effort, available facilities and resources)

- business size and type

- intellectual property and proprietary rights

5. Document the proposal content that the suppliers must submit with their response. 
The following are examples of proposal content for suppliers to submit:

- Compliance with the requirements

- References, company overview, case studies

- Evidence of the supplier's organizational processes upon which the supplier's processes for the project will be based and the commitment to execute those processes from project inception

- Plan describing how the potential supplier will carry out the scope and content of the solicitation package, including any improvement of execution capability over the duration of the supplier agreement

- Understanding of the size and complexity of the requested work based on the requirements

- Pricing and compensation which typically include:

- Pricing and compensation methodology that provides for calculation of the charges with respect to the services being provided to the acquirer pursuant to the supplier agreement and terms \& conditions, including taxes, credits, foreign currency translation, licenses, pass-through costs, and travel reimbursements.

- Pricing and compensation schedules that provide for the charges for the products and services provided, including frequency, term, and pricing type (e.g., fixed price lump sum, time and materials) as well as rate cards, and skills matrix.

- Acquirer's Travel Reimbursement policies

- References and experience validating the capability of the potential supplier's proposed approach to meet the proposed funding, schedule, and quality targets

- Risk management plan describing how the potential supplier will identify and manage risks associated with the risks called out in the solicitation package

- Methods for early defect identification and the prevention of defects in the products delivered

- Supplier's approach to quality assurance of the product

- Approach to escalation and resolution of issues

- Description of the potential supplier's proposed use of COTS and the rationale for the supplier's confidence that the use of COTS can achieve the requirements.

- Description of the potential supplier's proposed re-use of previously developed hardware and software, and the rationale for the supplier's confidence that the reuse can be achieved.

- Approach to provide visibility for development progress and costs at a level appropriate for the type of contract and commensurate with the degree of risk

- Retention of critical staff during the project

- Identification of any work to be performed by subcontractors

6. Incorporate acquirer's (standard) supplier agreement, terms and conditions, and additional information into the solicitation package.

Contract terms and conditions, typically include the following:

- Recitals 
Adapting CMMI for Acquisition Organizations: A Preliminary Report

- Deliverables and Rights

- Compensation and payments

- Confidentiality

- Privacy statements

- Continuous improvement and best practices

- Exclusive services, Key Employees, Supplier's Personnel at Acquirer's sites

- Information Gathering Practices and Ethical Representation

- Force Majeure

- Term

- Termination for Insolvency, Breach or Non-performance

- Termination for Convenience

- Termination Assistance

- Indemnification

- Insurance

- Right to Audit

- Notices

Typical considerations for additional instructions and general Information for the supplier when responding to the solicitation package include the following:

- Submission of intent to submit proposal

- Submission due date, time, and destination

- Number of proposal copies that must be submitted

- Proposal format

- Non-complying proposals

- Proposal ownership

- Bidder inquiries

- Key dates and activities

- Discretionary selection and potential modifications of solicitation process

- No implied offer

- Response constitutes an offer to do business

- Confidentiality of information

- Publicity

- Use of subcontractors

- Due diligence

- Incurred costs

- Language and statutory units 
- Warranty provisions

- Licensing provisions

SP 1.4 Review the Solicitation Package

Review the solicitation package with stakeholders to make sure the approach is realistic and can reasonably lead to a usable product.

The solicitation package is reviewed with end users and other stakeholders, to make sure the requirements have been accurately and sufficiently stated so that the solicitation can lead to a manageable agreement. The acquirer establishes traceability between the requirements and the solicitation package. Suppliers may be included as stakeholders in the review of the solicitation package. The acquirer wants the solicitation package to attract a variety of responses and encourage competition. The acquirer also wants to ensure that the package is legally inclusive of all qualified suppliers.

The acquirer may use standard templates and checklists to verify the necessary components (e.g., skills, standards, verification and validation methods, measures and acceptance criteria are covered in the solicitation package).

Refer to the Organizational Process Definition process area for more information about organizational process assets.

The independent cost and schedule estimates for the supplier's project work developed in the practice above are also reviewed.

Typical Acquirer Work Products

1. Record of the reviews of the solicitation package

SP 1.5 Distribute and Maintain Solicitation Package

Distribute the Solicitation Package to potential suppliers for their response and maintain its content throughout the solicitation.

The solicitation package is distributed to the potential suppliers identified above.

The acquirer uses the Project Planning practices and the Project Monitoring and Control practices to monitor, control, and replan acquirer activities during the solicitation process as necessary.

Typical Acquirer Work Products

1. Potential suppliers

2. Responses to supplier questions 
3. Amendments to the solicitation package

Typical Supplier Deliverables

1. Supplier proposals

2. Supplier questions, requests for clarification

\section{Subpractices}

1. Finalize list of potential suppliers.

2. Distribute solicitation package to potential suppliers.

3. Document and respond to supplier questions according to the instructions in the solicitation package.

Verify that all potential suppliers have equal access and opportunity to provide feedback on the solicitation package. Provide the opportunity for the selected potential suppliers and stakeholders to clarify points of ambiguity in the requirements as well as any disconnects or concerns with the requirements.

4. Acknowledge the receipt of supplier proposals according to the schedule identified in the solicitation package.

5. Verify the conformance to requirements and completeness of the supplier response. Contact suppliers if the response is nonconforming or incomplete for corrective action.

6. Issue amendments to the solicitation package when changes are made to the solicitation.

SG 2 Select Suppliers

Select suppliers based on an evaluation of their ability to meet the specified requirements and established criteria.

\section{SP 2.1 Evaluate Proposed Solutions}

Evaluate proposed solutions according to the documented proposal evaluation plans and criteria.

Refer to Decision Analysis and Resolution process area for more information about formal evaluation approaches that can be used to select suppliers.

Proposals, submitted in response to solicitation packages, are evaluated in accordance with an overall established timeline, and preliminary project plans and proposal evaluation criteria. The proposal evaluation criteria are used to evaluate the potential suppliers' responses to the solicitation. Evaluation results and decision making notes (e.g., advantages and disadvantages of potential suppliers and scoring against criteria) should be documented and maintained. 
The acquirer refines the negotiation strategy based upon the evaluation of the suppliers' proposals and the evaluation of the suppliers. The proposal evaluation and the negotiations with the suppliers provide the basis for selecting a supplier best able to meet the requirements of the solicitation.

For task orders or contractual changes against an existing supplier agreement, the acquirer uses documented evaluation criteria against which to evaluate the task order responses or proposed contractual changes. In a sole source or change order environment, this practice is critical for relevant stakeholders to understand the intent of the effort or changes before placing the additional work against the supplier agreement.

\section{Typical Acquirer Work Products}

1. Clarification correspondence between the acquirer and potential suppliers

2. Evaluation results and rationale

3. Candidate suppliers

\section{Typical Supplier Deliverables}

1. Proposal revisions based upon clarifications

2. Supplier documentation of their approach to the project work, capabilities, preliminary technical solution

\section{Subpractices}

1. Distribute supplier proposals to the individuals identified by the acquirer to perform the evaluation.

2. Schedule acquirer evaluation review of supplier proposals to consolidate questions, concerns and issues.

3. Schedule supplier presentations.

4. Verify the mutual understanding of the statement of work.

A good practice is to compare the supplier's estimates to those developed in the project planning practices; this comparison provides a means to determine if there is a mutual understanding of the requirements and the associated work to fulfill them.

5. Evaluate supplier proposals and document findings.

6. Execute due diligence. 
Due diligence provides an opportunity for the acquirer to further clarify requirements, particularly those related to the acquirer's existing environment and products in use. The potential suppliers ask questions and gain understanding, which enables them to make their proposals more realistic. It also enables the acquirer to gain insight into the capability of the potential suppliers' proposed solutions to meet requirements.

Due diligence helps to eliminate assumptions and replace them with facts, to identify and document risks and their mitigation plans or effect on the agreement, and to list issues and dependencies between the acquirer and supplier to include in the agreement.

The following are typical examples of due diligence activities:

- Reviews of requirements with current supplier or acquirer resources maintaining the products or providing services

- Reviews of interfaces of a system with other systems maintained by the acquirer

- Review and validation of supplier references

- Reviews of operating environment's facilities and capabilities

- Reviews of regulatory and security requirements

- Reviews of supplier capabilities

7. Document candidate supplier recommendations based upon proposal evaluation

\section{SP 2.2 Develop Negotiation Plans}

\section{Develop negotiation plans to use in completing a supplier agreement.}

Develop a negotiation plan for each of the candidate suppliers based upon evaluation of the suppliers and their proposals.

The size of a negotiation team depends upon the size and complexity of the project. Typically the team is led by supplier management and also includes individuals who have detailed knowledge of the statement of work documented in the solicitation package. The negotiation team is typically supported by legal staff, a financial analyst, purchasing and the project manager for the project. 
Example of items included in a negotiation strategy include the following:

- Roles and responsibilities of negotiation team members

- Key issues to be negotiated from the supplier responses

- Negotiation "levers," and where and when they should be used

- Sequence of events to negotiate the issues

- Fall-back or compromise positions as necessary on given issues (possible concessions and trades)

- List of items that are non-negotiable

- External factors that could influence the negotiations; (e.g., other pending deals, strategic plans, etc.)

- Prior supplier contracting experiences to discover previous positions and issues (and negotiating styles)

- Schedule and sequence for supplier negotiations meetings

- Specific objectives for each negotiating session

- $\quad$ Risks, consequences and mitigation alternatives

Typical Acquirer Work Products

1. Negotiation Strategy for candidate suppliers

SP 2.3 Finalize Supplier Selection

Select suppliers based on an evaluation of their ability to meet the specified requirements and established criteria.

Proposal evaluation results are used to finalize a supplier selection based on the outcome of negotiations. The negotiations enable the acquirer to select the best supplier for the project. In some cases the acquirer may take the top two proposals and use negotiations to make the final selection decision.

The evaluation results, along with the negotiation results, support the selection decision or cause the acquirer to take other action as appropriate. If the return on investment is not sufficient the acquirer may decide to defer or cancel the project.

\section{Typical Acquirer Work Products}

1. Revisions due to negotiations

2. Supplier sourcing decision

\section{Subpractices}

1. Negotiate with supplier(s) to determine best fit for the project. 
Negotiate with the selected supplier or candidate suppliers to resolve any issues identified during due diligence and to address any remaining issues with requirements and revise the requirements to be fulfilled by the supplier.

2. Select a supplier to be awarded the supplier agreement.

3. Document sourcing decision

SG 3 Establish Supplier Agreements

Establish and maintain formal agreements with selected suppliers.

A formal agreement is established based on the supplier sourcing decision.

SP 3.1 Establish Mutual Understanding of the Agreement

Establish and maintain a mutual understanding of the contract with selected suppliers and end users based on the acquisition needs and the suppliers' proposed approaches.

As points of clarification and ambiguities continue to arise after contract award, ensure the mutual understanding is revised and maintained through the life of the project. Ensure that the supplier makes a contractual commitment to execute its proposed processes.

Typical Acquirer Work Products

1. Correspondence clarifying elements of the agreement

2. Frequently asked questions (for use with end users, other suppliers)

SP 3.2 Document Supplier Agreement

\section{Document approved supplier agreement}

The agreement may be either a stand-alone agreement or part of a master agreement. When part of a master agreement, the project may be, for instance, an addendum, work order, or service request to the master agreement.

Typical Acquirer Work Products

1. Supplier agreement (including terms \& conditions)

\section{Subpractices}

1. Document the supplier agreement for the project.

The supplier agreement provisions typically include the following:

- The statement of work, specification, terms and conditions, list of deliverables, schedule, budget, and acceptance process

- Product acceptance criteria to be satisfied by the supplier 
- Statement of work for the supplier

- Measurements and reports that provide the acquirer visibility into the supplier's process and results

- Mechanisms and deliverables that provide the acquirer sufficient data to allow evaluation and analysis of acquired products

- Who from the project and supplier are responsible and authorized to make changes to the supplier agreement

- Supplier's responsibility for supporting business acceptance working with the acquirer

- How requirements changes and changes to the supplier agreement are determined, communicated, and addressed

- Standards and procedures that will be followed (e.g., configuration management, escalation, non-conformances, conflicts, issues, etc.)

- Requirements for the supplier to establish a corrective action system that includes a change control process for rework and reevaluation

- Critical dependencies between the acquirer and the supplier

- Documentation of what the acquirer will provide to the supplier such as facilities, tools, software, documentation and services

- Verification methods and acceptance criteria for designated supplier deliverables.

- The type and depth of project oversight of the supplier procedures and evaluation criteria to be used in monitoring supplier performance

- The types of reviews that will be conducted with the supplier

- The supplier's responsibilities to execute corrective actions when initiated by the Project Monitoring and Control practices

- Non-hire and non-compete clauses

- Confidentiality, non-disclosure, intellectual capital clauses pertaining to PPQA, Measurement Data, personnel who would perform audits or are authorized to validate measurement data.

- The supplier's responsibilities for preparation of the site and training of the support and operations organizations according to acquirer specified standards, tools and methods.

- The supplier's responsibilities for ongoing maintenance and support of the acquired products

- Requirements for the supplier to be involved in the deployment of process assets as necessary

- Warranty, ownership, and usage rights for the acquired products

- Security and legal penalty recoveries

3. Verify that all parties to the agreement understand and agree to all requirements by signing the supplier agreement.

4. Notify those suppliers not selected for the award. 
Adapting CMMI for Acquisition Organizations: A Preliminary Report

Refer to Organizational Process Definition for organizational guidelines on communication to suppliers not selected for the agreement.

5. Communicate the supplier agreement within the organization as required. 


\section{PART THREE \\ The Appendices and Glossary}




\section{Appendix A: References}

Publicly Available Sources

Ahern 2005

Curtis 2002

Deming 1986

EIA 1994

EIA 1998

Humphrey 1989

IEEE 1990

ISO 1987

ISO 1995
Ahern, Dennis M.; Armstrong Jim; Clouse, Aaron; Ferguson, Jack; Hayes, Will; and Nidiffer, Kenneth. CMMI SCAMPI Distilled: Appraisals for Process Improvement. Boston: Addison Wesley, 2005.

Curtis, Bill; Hefley, William E.; and Miller, Sally A. The People Capability Maturity Model Guidelines for Improving the Workforce. Boston: Addison-Wesley, 2002.

Deming, W. Edwards. Out of the Crisis. Cambridge, MA: MIT Center for Advanced Engineering, 1986.

Electronic Industries Alliance. EIA Interim Standard: Systems Engineering (EIA/IS-632). Washington, DC, 1994.

Electronic Industries Alliance. Systems Engineering Capability Model (EIA/IS-731). Washington, DC, 1998. <http://geia.org/sstc/G47/731dwnld.htm>

Humphrey, Watts S. Managing the Software Process. Reading, MA: Addison-Wesley, 1989.

Institute of Electrical and Electronics Engineers. IEEE Standard Computer Dictionary: A Compilation of IEEE Standard Computer Glossaries. New York: IEEE, 1990.

International Organization for Standardization. ISO 9000:

International Standard. New York, 1987.

$<$ http://www.iso.ch/>

International Organization for Standardization and International Electrotechnical Commission. ISO/IEC TR 12207 Information Technology-Software Life Cycle Processes, 1995.

< www.jtc1-sc7.org > 
ISO 2000

ISO 2002

ISO 2006

Juran 1988

SEI 1995

SEI 1997

SEI 2002

\section{Shewhart 1931}

International Organization for Standardization. ISO 9001, Quality Management Systems-Requirements, 2000. $<$ http://www.iso.ch/>

International Organization for Standardization and International Electrotechnical Commission. ISO/IEC 15288 Systems Engineering-System Life Cycle Processes, 2002. $<$ http://www.jtc1-sc7.org/>

International Organization for Standardization and International Electrotechnical Commission. ISO/IEC TR 15504 Information Technology-Software Process Assessment Part 1: Concepts and vocabulary, Part 2: Performing an Assessment, Part 3: Guidance on Performing an Assessment, Part 4: Guidance on use for process improvement and process capability determination, Part 5: An exemplar Process Assessment Model, 2003-2006. $<$ http://www.jtc1-sc7.org/>

Juran, J. M. Juran on Planning for Quality. New York: Macmillan, 1988.

Software Engineering Institute. The Capability Maturity Model: Guidelines for Improving the Software Process. Reading, MA: Addison-Wesley, 1995.

Integrated Product Development Capability Maturity Model, Draft Version 0.98. Pittsburgh, PA: Enterprise Process Improvement Collaboration and Software Engineering Institute, Carnegie Mellon University, July 1997.

<ftp://ftp.sei.cmu.edu/pub/CMMl/ipd-cmm-draft/>

Software Engineering Institute. Software Acquisition Capability Maturity Model (SA-CMM) Version 1.03 (CMU/SEI-2002-TR-010, ESC-TR-2002-010). Pittsburgh, PA: Software Engineering Institute, Carnegie Mellon University, March 2002.

<http://www.sei.cmu.edu/publications/documents/02.reports/ 02tr010.html>

Shewhart, Walter A. Economic Control of Quality of Manufactured Product. New York: Van Nostrand, 1931. 
Adapting CMMI for Acquisition Organizations: A Preliminary Report

\section{Regularly Updated Sources}

SEI 1

SEI 2

SEI 3
Software Engineering Institute. Transitioning Your Organization from Software CMM Version 1.1 to CMMI-SW Version 1.0.

$<$ http://www.sei.cmu.edu/cmmi/publications/whitepaper.html>

Software Engineering Institute. The IDEAL Model. $<$ http://www.sei.cmu.edu/ideal/ideal.html>

Software Engineering Institute. Advice for Change Agents. $<$ http://www.sei.cmu.edu/asta/advice.html> 


\section{Appendix B: Acronyms}

\begin{tabular}{|c|c|}
\hline AM & Acquisition Management (process area) \\
\hline ARC & Appraisal requirements for CMMI \\
\hline ARD & Acquisition Requirements Development (process area) \\
\hline ATS & Acquisition Technical Solution (process area) \\
\hline AVAL & Acquisition Validation (process area) \\
\hline AVER & Acquisition Verification (process area) \\
\hline CAD & computer-aided design \\
\hline CAR & Causal Analysis and Resolution (process area) \\
\hline CCB & configuration control board \\
\hline CL & capability level \\
\hline CM & Configuration Management (process area) \\
\hline CMM & Capability Maturity Model \\
\hline CMMI & Capability Maturity Model Integration \\
\hline CMMI-DEV & CMMI for Development \\
\hline CMMI-DEV+IPPD & CMMI for Development with IPPD \\
\hline COTS & commercial off the shelf \\
\hline CPI & cost performance index \\
\hline CPM & critical path method \\
\hline $\mathrm{CSCl}$ & computer software configuration item \\
\hline DAR & Decision Analysis and Resolution (process area) \\
\hline DoD & Department of Defense \\
\hline
\end{tabular}


Adapting CMMI for Acquisition Organizations: A Preliminary Report

EIA

EIA/IS

EPG

FCA

GG

GP

IBM

IDEAL

IEEE

INCOSE

IPD-CMM

IPM

IPM+IPPD

IPPD

IPT

ISO

ISO/IEC

MA

MDD

MOA

ML

NDI

NDIA

OID

OPD
Electronic Industries Alliance

Electronic Industries Alliance Interim Standard

engineering process group

functional configuration audit

generic goal

generic practice

International Business Machines

Initiating, Diagnosing, Establishing, Acting, Learning

Institute of Electrical and Electronics Engineers

International Council on Systems Engineering

Integrated Product Development Capability Maturity Model

Integrated Project Management (process area)

Integrated Project Management with IPPD (process area)

integrated product and process development

integrated product team

International Organization for Standardization

International Organization for Standardization and International Electrotechnical Commission

Measurement and Analysis (process area)

method definition document

memorandum of agreement

maturity level

nondevelopmental item

National Defense Industrial Association

Organizational Innovation and Deployment (process area)

Organizational Process Definition (process area) 


\begin{tabular}{|c|c|}
\hline OPD+IPPD & $\begin{array}{l}\text { Organizational Process Definition with IPPD (process } \\
\text { area) }\end{array}$ \\
\hline OPF & Organizational Process Focus (process area) \\
\hline OPP & Organizational Process Performance (process area) \\
\hline OT & Organizational Training (process area) \\
\hline OUSD (AT\&L) & $\begin{array}{l}\text { Office of the Under Secretary of Defense (Acquisition, } \\
\text { Technology, and Logistics) }\end{array}$ \\
\hline P-CMM & People Capability Maturity Model \\
\hline PA & process area \\
\hline PCA & physical configuration audit \\
\hline PERT & Program Evaluation and Review Technique \\
\hline PI & Product Integration (process area) \\
\hline PMC & Project Monitoring and Control (process area) \\
\hline PP & Project Planning (process area) \\
\hline PPQA & Process and Product Quality Assurance (process area) \\
\hline QA & quality assurance \\
\hline QFD & Quality Function Deployment \\
\hline QPM & Quantitative Project Management (process area) \\
\hline RD & Requirements Development (process area) \\
\hline REQM & Requirements Management (process area) \\
\hline ROI & return on investment \\
\hline RSKM & Risk Management (process area) \\
\hline SA-CMM & Software Acquisition Capability Maturity Model \\
\hline SAM & Supplier Agreement Management (process area) \\
\hline SCAMPI & $\begin{array}{l}\text { Standard CMMI Appraisal Method for Process } \\
\text { Improvement }\end{array}$ \\
\hline SECM & Systems Engineering Capability Model \\
\hline
\end{tabular}

$\begin{array}{ll}\text { Acronyms } & 363\end{array}$ 
Adapting CMMI for Acquisition Organizations: A Preliminary Report

SEI

SG

SP

SPI

SSAD

SW-CMM

TS

URL

VAL

VER

WBS
Software Engineering Institute

specific goal

specific practice

schedule performance index

Solicitation and Supplier Agreement Development (process area)

Capability Maturity Model for Software or Software Capability Maturity Model

Technical Solution (process area)

Uniform Resource Locator

Validation (process area)

Verification (process area)

work breakdown structure 


\section{Appendix C: Adapting CMMI for Acquisition Organizations Project Participants}

Many talented people were part of the product team that created the initial draft CMMI-ACQ. The three primary groups involved in this development have been the primary development team, the review participants, and the CMMI Steering Group.

Primary Development Team

The primary development team wrote and revised the structure and technical content of this document. Development activities were based on an A-Specification and CMMI Framework, provided by the Steering Group, two source models, one source module, and comments from reviewers, stakeholders, and Steering Group members.

\section{Development Team}

Kathryn M. Dodson, EDS

Dr. Hubert F. Hofmann, General Motors

Gowri S. Ramani, Hewlett Packard

Deborah K. Yedlin, General Motors

\section{Accenture Ltd.}

Heston, Keith

Vautier, Andrew

Best Practice Implementations, LLC

Singh, Roz

\section{Cap Gemini}

MacDonald, Doug

Pentescu, David 
Adapting CMMI for Acquisition Organizations: A Preliminary Report

\section{Carnegie Mellon University}

Bate, Roger

Ferguson, Jack

Fisher, Matt

Gallagher, Brian

Konrad, Mike

Deutsche Bank

Kerl, Berhold

Moths, Arne

EDS

Adler, Stu

Bialk, Kelly

Bilger, Mark

Niles, Gail

Phifer, Bill

Sawyer, Jodie

\section{General Motors Corporation}

Brown, Michele

Chen, Helen

Chodnicki, Darin

Gonzalvo, Zahira

Khan, Assif

King, Carla

Konda, Damodar

Long, Earl Jr.

MacDonald, Karen

Mahlebashian, Daniel

Mecklenburg, Karsten

Murthy, Bala

Oswald, Thomas

Page, Dennis

Slykhouse, Roger

Steele, Christopher

Wright, Craig

Wu, Addons

Zabinski, Bradley 
Hewlett-Packard Company

Channaveer, Patil

Gurumurthy, Ashok

Henrichs, Debra

Kaliappan, Marappa

Mohan, Mythili

Murthy, Gangadhar

Naumann, Karl

Pais, Eric-A

Sundar, Gayatri

Swaminathan, Murli

IBM

McLachlan, Tim

Yu, Chung

Infosys

Kumars, Aman

\section{Lucent Technologies}

Chellappa, Mallika

Moksha Technologies

Vijayan, Ajita

NASA

Niles, Charles

Northrop Grumman Corporation

Wilson, Hal

Onstar

Ottoson, Robert

Satyam

Khendry, Anu

Science Applications International Corporation

Pyster, Arthur

Support Systems Associates, Inc.

Jones, James 
Adapting CMMI for Acquisition Organizations: A Preliminary Report

\section{Tata Consultancy Services Limited}

Keeni, Gangi

TPI

Creamer, Frank

Stout, Bill

US Army

D'Agosto, Tony

\section{US Defense Department}

Baldwin, Kristen

Richter, Karen

US Navy

Zettervall, Brenda

Wipro Technologies

Banavar, Thara

The Steering Group has guided and approved the plans of the Product Team, provided consultation on significant CMMI project issues, and ensured involvement from a variety of interested communities.

\section{Steering Group Members}

Baldwin, Kristen (OUSD [AT\&L] DS/SE)

Chittister, Clyde (Software Engineering Institute)

D'Agosto, Tony (US Army RDECOM-ARDEC)

Gill, Jim (Boeing Integrated Defense Systems)

Kelly, John (NASA HQ)

Lundeen, Kathy (Defense Contract Management Agency)

McCarthy, Larry (Motorola, Inc.)

Nicol, Mike (US Air Force ASC/EN)

Peterson, Bill (Software Engineering Institute)

Rassa, Bob (Raytheon Space \& Airborne Systems)

Sumpter, Beth (National Security Agency)

Weszka, Joan (Lockheed Martin)

Wilson, Hal (Northrop Grumman Mission Systems)

Zettervall, Brenda (US Navy, ASN/RDA CHENG) 


\section{Ex Officio Steering Group Members}

Anderson, Lloyd (Department of Homeland Security)

Bate, Roger, chief architect (Software Engineering Institute)

Drake, Thomas (National Security Agency)

Phillips, Mike, CMMI project manager (Software Engineering Institute)

Yedlin, Debbie (General Motors)

Steering Group Support: Acquisition

Gallagher, Brian (Software Engineering Institute)

Steering Group Support: CCB

Konrad, Mike (Software Engineering Institute) 


\section{Appendix D: Glossary}

The glossary defines the basic terms used in CMMI models. Glossary entries are typically multiple-word terms consisting of a noun and one or more restrictive modifiers. (There are some exceptions to this rule that account for one-word terms in the glossary.)

To formulate definitions appropriate for CMMI models, we consult multiple sources. We first consult Webster's Online dictionary (www.mw.com) and the source models (i.e., CMMI v1.2, EIA 731, SW-CMM v2, draft C, and IPD-CMM v0.98). We also consult other standards as needed, including the following:

- ISO 9000 [ISO 1987]

- ISO/IEC 12207 [ISO 1995]

- ISO/IEC 15504 [ISO 2006]

- ISO/IEC 15288 [ISO 2002]

- IEEE [IEEE 1990]

- $\quad$ SW-CMM v1.1

- EIA 632 [EIA 1994]

- SA-CMM [SEI 2002]

- P-CMM [Curtis 2002]

We developed the glossary recognizing the importance of using terminology that all model users can understand. We also recognized that words and terms can have different meanings in different contexts and environments. The glossary in CMMI models is designed to document the meanings of words and terms that should have the widest use and understanding by users of CMMI products.

acceptance criteria

acceptance testing
The criteria that a product or product component must satisfy to be accepted by a user, customer, or other authorized entity.

Formal testing conducted to enable a user, customer, or other authorized entity to determine whether to accept a product or product component. (See also "unit testing.") 
achievement profile

acquisition

acquisition strategy

adequate

agreement/contract requirements

allocated requirement

alternative practice

appraisal

appraisal findings
In the continuous representation, a list of process areas and their corresponding capability levels that represent the organization's progress for each process area while advancing through the capability levels. (See also "capability level profile," "target profile," and "target staging.")

The process of obtaining products (goods and services) through contract.

The specific approach to acquiring products and services that is based on considerations of supply sources, acquisition methods, requirements specification types, contract or agreement types, and the related acquisition risk.

This word is used so that you can interpret goals and practices in light of your organization's business objectives. When using any CMMI model, you must interpret the practices so that they work for your organization. This term is used in goals and practices where certain activities may not be done all of the time. (See also "appropriate" and "as needed.")

All technical and nontechnical requirements related to an acquisition.

Requirement that levies all or part of the performance and functionality of a higher level requirement on a lower level architectural element or design component.

A practice that is a substitute for one or more generic or specific practices contained in CMMI models that achieves an equivalent effect toward satisfying the generic or specific goal associated with model practices. Alternative practices are not necessarily one-for-one replacements for the generic or specific practices.

In the CMMI Product Suite, an examination of one or more processes by a trained team of professionals using an appraisal reference model as the basis for determining strengths and weaknesses. (See also "assessment" and "capability evaluation.")

The conclusions of an appraisal that identify the most important issues, problems, or opportunities within the appraisal scope. Findings include, at a minimum, strengths and weaknesses based on valid observations. 
appraisal participants

appraisal rating

appraisal reference model

appraisal scope

appraisal tailoring

appraisal team leader

appropriate

\section{as needed}

Members of the organizational unit who participate in providing information during the appraisal.

As used in CMMI appraisal materials, the value assigned by an appraisal team to (1) a CMMI goal or process area, (2) the capability level of a process area, or (3) the maturity level of an organizational unit. The rating is determined by enacting the defined rating process for the appraisal method being employed.

As used in CMMI appraisal materials, the CMMI model to which an appraisal team correlates implemented process activities.

The definition of the boundaries of the appraisal encompassing the organizational limits and the CMMI model limits.

Selection of options within the appraisal method for use in a specific instance.

The intent of appraisal tailoring is to assist an organization in aligning application of the method with its business objectives.

A person who leads the activities of an appraisal and has satisfied the qualification criteria for experience, knowledge, and skills defined by the appraisal method.

This word is used so that you can interpret goals and practices in light of your organization's business objectives. When using any CMMI model, you must interpret the practices so that they work for your organization. This term is used in goals and practices where certain activities may not be done all of the time. (See also "adequate" and "as needed.")

This phrase is used so that you can interpret goals and practices in light of your organization's business objectives. When using any CMMI model, you must interpret the practices so that they work for your organization. This term is used in goals and practices where certain activities may not be done all the time. (See also "adequate" and "appropriate.") 
assessment

assignable cause of process variation

audit

base measure

baseline

\section{bidirectional traceability}

business objectives

capability evaluation

capability level
In the CMMI Product Suite, an appraisal that an organization does internally for the purposes of process improvement. The word assessment is also used in the CMMI Product Suite in an everyday English sense (e.g., risk assessment). (See also "appraisal" and "capability evaluation.")

In CMMI, the term special cause of process variation is used in place of assignable cause of process variation to ensure consistency. The two terms are defined identically. (See "special cause of process variation.")

In CMMI process improvement work, an objective examination of a work product or set of work products against specific criteria (e.g., requirements).

A distinct property or characteristic of an entity and the method for quantifying it. (See also "derived measures.")

A set of specifications or work products that has been formally re-viewed and agreed on, which thereafter serves as the basis for further development, and which can be changed only through change control procedures (See also "configuration baseline" and "product baseline.")

An association among two or more logical entities that is discernable in either direction (i.e., to and from an entity). (See also "requirements traceability" and "traceability.")

(See "organization's business objectives.")

An appraisal by a trained team of professionals used as a discriminator to select suppliers, for contract monitoring, or for incentives. Evaluations are used to help decision makers make better acquisition decisions, improve subcontractor performance, and provide insight to a purchasing organization. (See also "appraisal" and "assessment.")

Achievement of process improvement within an individual process area. A capability level is defined by the appropriate specific and generic practices for a process area. (See also "generic goal," "generic practice," "maturity level," and "process area.") 
capability level profile

\author{
capability maturity \\ model
}

capable process

causal analysis

change

management

CMMI Framework

CMMI model

CMMI model component
In the continuous representation, a list of process areas and their corresponding capability levels. (See also "achievement profile," "target profile," and "target staging.")

The profile may be an achievement profile when it represents the organization's progress for each process area while advancing through the capability levels. Or, the profile may be a target profile when it represents an objective for process improvement.

A model that contains the essential elements of effective processes for one or more disciplines and describes an evolutionary improvement path from ad hoc, immature processes to disciplined, mature processes with improved quality and effectiveness.

A process that can satisfy its specified product quality, service quality, and process-performance objectives. (See also "stable process," "standard process," and "statistically managed process.")

The analysis of defects to determine their cause.

Judicious use of means to effect a change, or proposed change, on a product or service. (See also "configuration management.")

The basic structure that organizes CMMI components, including common elements of the current CMMI models as well as rules and methods for generating models, their appraisal methods (including associated artifacts), and their training materials. The framework enables new disciplines to be added to CMMI so that the new disciplines will integrate with the existing ones. (See also "CMMI model" and "CMMI Product Suite.")

One from the entire collection of possible models that can be generated from the CMMI Framework. Since the CMMI Framework can generate different models based on the needs of the organization using it, there are multiple CMMI models. (See also "CMMI Framework" and "CMMI Product Suite.")

Any of the main architectural elements that compose a CMMI model. Some of the main elements of a CMMI model include specific practices, generic practices, specific goals, generic goals, process areas, capability levels, and maturity levels. 


\section{CMMI model tailoring}

CMMI Product Suite

common cause of process variation

concept of operations configuration audit

configuration baseline

configuration control

configuration control board
The use of a subset of a CMMI model for the purpose of making it suitable for a specific application. The intent of model tailoring is to assist an organization in aligning application of a model with its business objectives.

The complete set of products developed around the CMMI concept. These products include the framework itself, models, appraisal methods, appraisal materials, and various types of training. (See also "CMMI Framework" and "CMMI model.")

The variation of a process that exists because of normal and expected interactions among the components of a process. (See also "special cause of process variation.")

(See "operational concept.")

An audit conducted to verify that a configuration item, or a collection of configuration items that make up a baseline, conforms to a specified standard or requirement. (See also "audit," "configuration item," "functional configuration audit," and "physical configuration audit,")

The configuration information formally designated at a specific time during a product's or product component's life. Configuration baselines, plus approved changes from those baselines, constitute the current configuration information. (See also "product life cycle.")

An element of configuration management consisting of the evaluation, coordination, approval or disapproval, and implementation of changes to configuration items after formal establishment of their configuration identification. (See also "configuration identification," "configuration item," and "configuration management.")

A group of people responsible for evaluating and approving or disapproving proposed changes to configuration items, and for ensuring implementation of approved changes. (See also "configuration item.")

Configuration control boards are also known as change control boards. 
configuration identification

configuration item

configuration
management

configuration status accounting

\section{continuous representation}

\section{contractor}

corrective action

\section{COTS}

An element of configuration management consisting of selecting the configuration items for a product, assigning unique identifiers to them, and recording their functional and physical characteristics in technical documentation. (See also "configuration item," "configuration management," and "product.")

An aggregation of work products that is designated for configuration management and treated as a single entity in the configuration management process. (See also "configuration management.")

A discipline applying technical and administrative direction and surveillance to (1) identify and document the functional and physical characteristics of a configuration item, (2) control changes to those characteristics, (3) record and report change processing and implementation status, and (4) verify compliance with specified requirements. (See also "configuration audit," "configuration control," "configuration identification," and "configuration status accounting.")

An element of configuration management consisting of the recording and reporting of information needed to manage a configuration effectively. This information includes a listing of the approved configuration identification, the status of proposed changes to the configuration, and the implementation status of approved changes. (See also "configuration identification" and "configuration management.")

A capability maturity model structure wherein capability levels provide a recommended order for approaching process improvement within each specified process area. (See also "capability level," "process area," and "staged representation.")

(See "supplier.")

Acts or deeds used to remedy a situation, remove an error, or adjust a condition.

Items that can be purchased from a commercial vendor. (COTS stands for "commercial off the shelf.") 


\section{customer}

data

data management

defect density

defined process

derived measures

derived requirements
The party (individual, project, or organization) responsible for accepting the product or for authorizing payment. The customer is external to the project (except possibly when Integrated Product Teams are used, as in IPPD), but not necessarily external to the organization. The customer may be a higher level project. Customers are a subset of stakeholders. (See also "stakeholder.")

The meaning of the term "customer" in CMMI is context sensitive. Therefore, sometimes the narrow definition above is intended, but other times a more broad definition of customer is used that may include other relevant stakeholders (e.g., as in the phrase "customer requirements" used in the Acquisition Requirements Development process area).

Recorded information, regardless of the form or method of recording, including technical data, computer software documents, financial information, management information, representation of facts, numbers, or datum of any nature that can be communicated, stored, and processed.

The disciplined processes and systems that plan for, acquire, and provide stewardship for business and technical data, consistent with data requirements, throughout the data lifecycle.

Number of defects per unit of product size (e.g., problem reports per thousand lines of code).

A managed process that is tailored from the organization's set of standard processes according to the organization's tailoring guidelines; has a maintained process description; and contributes work products, measures, and other process improvement information to the organizational process assets. (See also "managed process.")

Data resulting from the mathematical function of two or more base measures. (See also "base measure.")

Requirements that are not explicitly stated in the customer requirements, but are inferred (1) from contextual requirements (e.g., applicable standards, laws, policies, common practices, and management decisions), or (2) from requirements needed to specify a product component. Derived requirements can also arise during analysis and design of components of the product or system. (See also "product requirements.") 
design review

development

developmental plan

discipline

discipline amplification

document

enterprise

entry criteria
A formal, documented, comprehensive, and systematic examination of a design to evaluate the design requirements and the capability of the design to meet these requirements, and to identify problems and propose solutions.

In the CMMI Product Suite, not only development activities but also maintenance activities may be included. Projects that benefit from the best practices of CMMI can focus on development, maintenance, or both.

A plan for guiding, implementing, and controlling the design and development of one or more products. (See also "product life cycle" and "project plan.")

In the CMMI Product Suite, the bodies of knowledge available to you when selecting a CMMI model (e.g., systems engineering). The CMMI Product Team envisions that other bodies of knowledge will be integrated into the CMMI Framework in the future.

Discipline amplifications are informative model components that contain information relevant to a particular discipline. For example, to find a discipline amplification for software engineering, you would look in the model for items labeled "For Software Engineering." The same is true for other disciplines.

A collection of data, regardless of the medium on which it is recorded, that generally has permanence and can be read by humans or machines. So, documents include both paper and electronic documents.

The full composition of companies. Companies may consist of many organizations in many locations with different customers. (See also "organization.")

States of being that must be present before an effort can begin successfully. 
equivalent staging

establish and maintain

\author{
evidence \\ executive \\ exit criteria \\ expected CMMI \\ components
}

\section{finding \\ formal evaluation process}

framework
A target staging, created using the continuous representation, that is defined so that the results of using the target staging can be compared to the maturity levels of the staged representation. (See also "capability level profile," "maturity level," "target profile," and "target staging.")

Such staging permits benchmarking of progress among organizations, enterprises, and projects, regardless of the $\mathrm{CMMI}$ representation used. The organization may implement components of CMMI models beyond those reported as part of equivalent staging. Equivalent staging is only a measure to relate how the organization is compared to other organizations in terms of maturity levels.

In the CMMI Product Suite, you will encounter goals and practices that include the phrase "establish and maintain." This phrase means more than a combination of its component terms; it includes documentation and usage. For example, "Establish and maintain an organizational policy for planning and performing the organizational process focus process" means that not only must a policy be formulated, but it also must be documented and it must be used throughout the organization.

(See "objective evidence.")

(See "senior manager.")

States of being that must be present before an effort can end successfully.

CMMI components that explain what may be done to satisfy a required CMMI component. Model users can implement the expected components explicitly or implement equivalent alternative practices to these components. Specific and generic practices are expected model components.

(See "appraisal findings.")

A structured approach to evaluating alternative solutions against established criteria to determine a recommended solution to address an issue.

(See "CMMI Framework.") 
functional analysis

\section{functional architecture}

\author{
functional \\ configuration audit
}

generic goal

generic practice generic practice
elaboration

goal
Examination of a defined function to identify all the subfunctions necessary to the accomplishment of that function; identification of functional relationships and interfaces (internal and external) and capturing these in a functional architecture; and flow down of upper level performance requirements and assignment of these requirements to lower level subfunctions. (See also "functional architecture.")

The hierarchical arrangement of functions, their internal and external (external to the aggregation itself) functional interfaces and external physical interfaces, their respective functional and performance requirements, and their design constraints.

An audit conducted to verify that the development of a configuration item has been completed satisfactorily, that the item has achieved the performance and functional characteristics specified in the functional or allocated configuration identification, and that its operational and support documents are complete and satisfactory. (See also: "configuration audit," "configuration management," and "physical configuration audit.")

A required model component that describes the characteristics that must be present to satisfy the institutionalization of the processes that implement a process area. (See also "institutionalization.")

An expected model component that is considered important in achieving the associated generic goal. The generic practices associated with a generic goal describe the activities that are expected to result in achievement of the generic goal and contribute to the institutionalization of the processes associated with a process area.

An informative model component that appears after a generic practice to provide guidance on how the generic practices should be applied to the process area.

A required $\mathrm{CMMI}$ component that can be either a generic goal or a specific goal. When you see the word goal in a CMMI model, it always refers to a model component (e.g., generic goal and specific goal). (See also "generic goal," "objective," and "specific goal.") 


\section{hardware engineering}

\section{higher level management}

incomplete process

\section{informative CMMI components}

institutionalization

integrated product

and process

development
The application of a systematic, disciplined, and quantifiable approach to transform a set of requirements representing the collection of stakeholder needs, expectations, and constraints using currently available techniques and technology to design, implement, and maintain a tangible product. (See also "software engineering" and "systems engineering."

In CMMI, hardware engineering represents all technical fields (e.g., electrical, mechanical) that transform requirements and ideas into tangible and producible products.

The person or persons who provide the policy and overall guidance for the process, but do not provide the direct dayto-day monitoring and controlling of the process. Such persons belong to a level of management in the organization above the immediate level responsible for the process and can be (but is not necessarily) a senior manager. (See also "senior manager.")

A process that is not performed or is performed only partially (also known as capability level 0 ). One or more of the specific goals of the process area are not satisfied.

CMMI components that help model users understand the required and expected components of a model. These components can contain examples, detailed explanations, or other helpful information. Subpractices, notes, references, goal titles, practice titles, sources, typical work products, discipline amplifications, and generic practice elaborations are informative model components.

The ingrained way of doing business that an organization follows routinely as part of its corporate culture.

A systematic approach to product development that achieves a timely collaboration of relevant stakeholders throughout the product life cycle to better satisfy customer needs. 
integrated team

interface control

lead appraiser

life-cycle model

managed process

manager

maturity level

memorandum of agreement
A group of people with complementary skills and expertise who are committed to delivering specified work products in timely collaboration. Integrated team members provide skills and advocacy appropriate to all phases of the work products' life and are collectively responsible for delivering the work products as specified. An integrated team should include empowered representatives from organizations, disciplines, and functions that have a stake in the success of the work products.

In configuration management, the process of (1) identifying all functional and physical characteristics relevant to the interfacing of two or more configuration items provided by one or more organizations, and (2) ensuring that the proposed changes to these characteristics are evaluated and approved prior to implementation. (See also "configuration item" and "configuration management.")

As used in the CMMI Product Suite, a person who has achieved recognition from an authorizing body to perform as an appraisal team leader for a particular appraisal method.

A partitioning of the life of a product or project into phases.

A performed process that is planned and executed in accordance with policy; employs skilled people having adequate resources to produce controlled outputs; involves relevant stakeholders; is monitored, controlled, and reviewed; and is evaluated for adherence to its process description. (See also "performed process.")

In the CMMI Product Suite, a person who provides technical and administrative direction and control to those performing tasks or activities within the manager's area of responsibility. The traditional functions of a manager include planning, organizing, directing, and controlling work within an area of responsibility.

Degree of process improvement across a predefined set of process areas in which all goals in the set are attained. (See also "capability level" and "process area.")

Binding documents of understanding or agreements between two or more parties. Also known as a "memorandum of understanding." 
natural bounds

nondevelopmental
item (NDI)

nontechnical

requirements

objective

objective evidence

objectively evaluate

observation
The inherent process reflected by measures of process performance, sometimes referred to as "voice of the process." Techniques such as control charts, confidence intervals, and prediction intervals are used to determine whether the variation is due to common causes (i.e., the process is predictable or "stable") or is due to some special cause that can and should be identified and removed.

An item of supply that was developed previous to its current use in an acquisition or development process. Such an item may require minor modifications to meet the requirements of its current intended use.

Contractual provisions, commitments, conditions, and terms that affect how products or services are to be acquired. Examples include products to be delivered, data rights for delivered commercial off-the-shelf (COTS) nondevelopmental items (NDIs), delivery dates, and milestones with exit criteria. Other nontechnical requirements include training requirements, site requirements, and deployment schedules.

When used as a noun in the CMMI Product Suite, the term objective replaces the word goal as used in its common everyday sense, since the word goal is reserved for use when referring to the CMMI model components called specific goals and generic goals. (See also "goal.")

As used in CMMI appraisal materials, qualitative or quantitative information, records, or statements of fact pertaining to the characteristics of an item or service or to the existence and implementation of a process element, which are based on observation, measurement, or test and which are verifiable.

To review activities and work products against criteria that minimize subjectivity and bias by the reviewer. An example of an objective evaluation is an audit against requirements, standards, or procedures by an independent quality assurance function. (See also "audit.")

As used in CMMI appraisal materials, a written record that represents the appraisal team members' understanding of information either seen or heard during the appraisal data collection activities. The written record may take the form of a statement or may take alternative forms as long as the information content is preserved. 
operational concept

operational scenario

optimizing process

organization

organizational
maturity organizational
policy

organizational process assets
A general description of the way in which an entity is used or operates. (Also known as "concept of operations.")

A description of an imagined sequence of events that includes the interaction of the product with its environment and users, as well as interaction among its product components. Operational scenarios are used to evaluate the requirements and design of the system and to verify and validate the system.

A quantitatively managed process that is improved based on an understanding of the common causes of variation inherent in the process. The focus of an optimizing process is on continually improving the range of process performance through both incremental and innovative improvements. (See also "common cause of process variation," "defined process," and "quantitatively managed process.")

An administrative structure in which people collectively manage one or more projects as a whole, and whose projects share a senior manager and operate under the same policies. However, the word organization as used throughout CMMI models can also apply to one person who performs a function in a small organization that might be performed by a group of people in a large organization. (See also "enterprise" and "organizational unit.")

The extent to which an organization has explicitly and consistently deployed processes that are documented, managed, measured, controlled, and continually improved. Organizational maturity may be measured via appraisals.

A guiding principle typically established by senior management that is adopted by an organization to influence and determine decisions.

Artifacts that relate to describing, implementing, and improving processes (e.g., policies, measurements, process descriptions, and process implementation support tools). The term process assets is used to indicate that these artifacts are developed or acquired to meet the business objectives of the organization, and they represent investments by the organization that are expected to provide current and future business value. (See also "process asset library.") 
organizational unit

\section{organization's business objectives}

organization's measurement repository

\section{organization's process asset library}

The part of an organization that is the subject of an appraisal; also known as the organizational scope of the appraisal.

An organizational unit deploys one or more processes that have a coherent process context and operates within a coherent set of business objectives. An organizational unit is typically part of a larger organization, although in a small organization, the organizational unit may be the whole organization.

Senior management developed strategies designed to ensure an organization's continued existence and enhance its profitability, market share, and other factors influencing the organization's success. (See also "quality and processperformance objectives" and "quantitative objective.")

Such objectives may include reducing the number of change requests during a system's integration phase, reducing development cycle time, increasing the number of errors found in a product's first or second phase of development, and reducing the number of customerreported defects, when applied to systems engineering activities.

A repository used to collect and make available measurement data on processes and work products, particularly as they relate to the organization's set of standard processes. This repository contains or references actual measurement data and related information needed to understand and analyze the measurement data.

A library of information used to store and make available process assets that are useful to those who are defining, implementing, and managing processes in the organization. This library contains process assets that include processrelated documentation such as policies, defined processes, checklists, lessons-learned documents, templates, standards, procedures, plans, and training materials. 
organization's set of standard processes

outsourcing

peer review

performance

parameters

performed process

physical
configuration audit

planned process

policy

process
A collection of definitions of the processes that guide activities in an organization. These process descriptions cover the fundamental process elements (and their relationships to each other, such as ordering and interfaces) that must be incorporated into the defined processes that are implemented in projects across the organization. A standard process enables consistent development and maintenance activities across the organization and is essential for long-term stability and improvement. (See also "defined process" and "process element.")

(See "acquisition.")

The review of work products performed by peers during development of the work products to identify defects for removal. The term peer review is used in the CMMI Product Suite instead of the term work product inspection. (See also "work product.")

The measures of effectiveness and other key measures used to guide and control progressive development.

A process that accomplishes the needed work to produce work products. The specific goals of the process area are satisfied.

An audit conducted to verify that a configuration item, as built, conforms to the technical documentation that defines it. (See also: "configuration audit," "configuration management," and "functional configuration audit.")

A process that is documented both by a description and a plan. The description and plan should be coordinated, and the plan should include standards, requirements, objectives, resources, assignments, and so on.

(See "organizational policy.")

In the CMMI Product Suite, activities that can be recognized as implementations of practices in a CMMI model. These activities can be mapped to one or more practices in CMMI process areas to allow a model to be useful for process improvement and process appraisal. (See also "process area," "subprocess," and "process element.")

There is a special use of the phrase the process in the statements and descriptions of the generic goals and generic practices. "The process," as used in Part Two is the process or processes that implement the process area. 
process action plan

process action team

process and technology improvements

process architecture

process area

process asset

process asset library

process attribute

process capability

process context
A plan, usually resulting from appraisals, that documents how specific improvements targeting the weaknesses uncovered by an appraisal will be implemented.

A team that has the responsibility to develop and implement process improvement activities for an organization as documented in a process action plan.

Incremental and innovative improvements to processes and also to process or product technologies.

The ordering, interfaces, interdependencies, and other relationships among the process elements in a standard process. Process architecture also describes the interfaces, interdependencies, and other relationships between process elements and external processes (e.g., contract management).

A cluster of related practices in an area that, when implemented collectively, satisfy a set of goals considered important for making improvement in that area. All CMMI process areas are common to both continuous and staged representations.

Anything that the organization considers useful in attaining the goals of a process area. (See also "organizational process assets.")

A collection of process asset holdings that can be used by an organization or project. (See also "organization's process asset library.")

A measurable characteristic of process capability applicable to any process.

The range of expected results that can be achieved by following a process.

The set of factors, documented in the appraisal input, that influences the judgment and comparability of appraisal ratings.

These include, but are not limited to, (a) the size of the organizational unit to be appraised; (b) the demographics of the organizational unit; (c) the application domain of the products or services; (d) the size, criticality, and complexity of the products or services; and (e) the quality characteristics of the products or services. 
process definition

process description

process element

process group

process improvement

processimprovement objectives

processimprovement plan
The act of defining and describing a process. The result of process definition is a process description. (See also "process description.")

A documented expression of a set of activities performed to achieve a given purpose that provides an operational definition of the major components of a process. The documentation specifies, in a complete, precise, and verifiable manner, the requirements, design, behavior, or other characteristics of a process. It also may include procedures for determining whether these provisions have been satisfied. Process descriptions can be found at the activity, project, or organizational level.

The fundamental unit of a process. A process can be defined in terms of subprocesses and/or process elements. A subprocess can be further decomposed into subprocesses and/or process elements; a process element cannot. (See also "process" and "subprocess.")

Each process element covers a closely related set of activities (e.g., estimating element, peer review element). Process elements can be portrayed using templates to be completed, abstractions to be refined, or descriptions to be modified or used. A process element can be an activity or task.

A collection of specialists who facilitate the definition, maintenance, and improvement of the process(es) used by the organization.

A program of activities designed to improve the performance and maturity of the organization's processes, and the results of such a program.

A set of target characteristics established to guide the effort to improve an existing process in a specific, measurable way either in terms of resultant product characteristics (e.g., quality, performance, conformance to standards) or in the way in which the process is executed (e.g., elimination of redundant process steps, combination of process steps, improvement of cycle time). (See also "organization's business objectives" and "quantitative objective.")

A plan for achieving organizational process-improvement objectives based on a thorough understanding of the current strengths and weaknesses of the organization's processes and process assets. 
process measurement

process owner

process performance

process
performance
baseline

process performance model

process tailoring

product
The set of definitions, methods, and activities used to take measurements of a process and its resulting products for the purpose of characterizing and understanding the process.

The person (or team) responsible for defining and maintaining a process. At the organizational level, the process owner is the person (or team) responsible for the description of a standard process; at the project level, the process owner is the person (or team) responsible for the description of the defined process. A process may therefore have multiple owners at different levels of responsibility. (See also "defined process" and "standard process.")

A measure of actual results achieved by following a process. It is characterized by both process measures (e.g., effort, cycle time, and defect removal efficiency) and product measures (e.g., reliability, defect density, and response time).

A documented characterization of the actual results achieved by following a process, which is used as a benchmark for comparing actual process performance against expected process performance. (See also "process performance.")

A description of the relationships among attributes of a process and its work products that are developed from historical process performance data and calibrated using collected process and product measures from the project and that are used to predict results to be achieved by following a process.

Making, altering, or adapting a process description for a particular end. For example, a project tailors its defined process from the organization's set of standard processes to meet the objectives, constraints, and environment of the project. (See also "defined process," "organization's set of standard processes," and "process description.")

In the CMMI Product Suite, a work product that is intended for delivery to a customer or end user. The form of a product can vary in different contexts. (See also "customer," "product component," and "work product.") 
product baseline

product component

product-component requirements

product life cycle

product line

product-related lifecycle processes

product
requirements

product suite
In configuration management, the initial approved technical data package (including, for software, the source code listing) defining a configuration item during the production, operation, maintenance, and logistic support of its life cycle. (See also "configuration item" and "configuration management.")

In the CMMI Product Suite, a work product that is a lower level component of the product. Product components are integrated to produce the product. There may be multiple levels of product components. (See also "product" and "work product.")

A complete specification of a product component, including fit, form, function, performance, and any other requirement.

The period of time, consisting of phases, that begins when a product is conceived and ends when the product is no longer available for use. Since an organization may be producing multiple products for multiple customers, one description of a product life cycle may not be adequate. Therefore, the organization may define a set of approved product life-cycle models. These models are typically found in published literature and are likely to be tailored for use in an organization.

A product life cycle could consist of the following phases: (1) concept/vision, (2) feasibility, (3) design/development, (4) production, and (5) phase out.

A group of products sharing a common, managed set of features that satisfy specific needs of a selected market or mission.

Processes associated with a product throughout one or more phases of its life (e.g., from conception through disposal), such as the manufacturing and support processes.

A refinement of the customer requirements into the developers' language, making implicit requirements into explicit derived requirements. (See also "derived requirements" and "product-component requirements.")

The developer uses the product requirements to guide the design and building of the product.

(See "CMMI Product Suite.") 
profile

program

project

project manager

project plan

project progress and performance

project's defined process
(See "achievement profile" and "target profile.")

(1) A project. (2) A collection of related projects and the infrastructure that supports them, including objectives, methods, activities, plans, and success measures. (See also "project.")

In the CMMI Product Suite, a managed set of interrelated resources that delivers one or more products to a customer or end user. A project has a definite beginning and end and typically operates according to a plan. Such a plan is frequently documented and specifies the product to be delivered or implemented, the resources and funds to be used, the work to be done, and a schedule for doing the work. A project can be composed of projects.

In the CMMI Product Suite, the person responsible for planning, directing, controlling, structuring, and motivating the project. The project manager is responsible for satisfying the customer.

A plan that provides the basis for performing and controlling the project's activities, which addresses the commitments to the project's customer.

Project planning includes estimating the attributes of the work products and tasks, determining the resources needed, negotiating commitments, producing a schedule, and identifying and analyzing project risks. Iterating through these activities may be necessary to establish the project plan.

What a project achieves with respect to implementing project plans, including effort, cost, schedule, and technical performance.

The integrated and defined process that is tailored from the organization's set of standard processes. (See also "defined process.") 
prototype

quality

quality and processperformance objectives

quality assurance

quality control

quantitative objective

quantitatively managed process
A preliminary type, form, or instance of a product or product component that serves as a model for later stages or for the final, complete version of the product. This model (e.g., physical, electronic, digital, analytical) can be used for the following (and other) purposes:

- assessing the feasibility of a new or unfamiliar technology

- assessing or mitigating technical risk

- validating requirements

- demonstrating critical features

- qualifying a product

- qualifying a process

- characterizing performance or product features

- elucidating physical principles

The ability of a set of inherent characteristics of a product, product component, or process to fulfill requirements of customers.

Objectives and requirements for product quality, service quality, and process performance. Process-performance objectives include product quality; however, to emphasize the importance of product quality in the CMMI Product Suite, the phrase quality and process-performance objectives is used rather than just process-performance objectives.

A planned and systematic means for assuring management that the defined standards, practices, procedures, and methods of the process are applied.

The operational techniques and activities that are used to fulfill requirements for quality. (See also "quality assurance.")

Desired target value expressed as quantitative measures. (See also "process-improvement objectives" and "quality and process-performance objectives.")

A defined process that is controlled using statistical and other quantitative techniques. The product quality, service quality, and process performance attributes are measurable and controlled throughout the project. (See also "defined process," "optimizing process," and "statistically managed process.") 


\section{rating}

reference

reference model

relevant stakeholder

representation

required $\mathrm{CMMI}$ components

requirement

requirements analysis

requirements elicitation

requirements management

requirements traceability
(See "appraisal rating.")

An informative model component that points to additional or more detailed information in related process areas.

A model that is used as a benchmark for measuring some attribute.

A stakeholder that is identified for involvement in specified activities and is included in a plan. (See also "stakeholder.")

The organization, use, and presentation of a CMM's components. Overall, two types of approaches to presenting best practices are evident: the staged representation and the continuous representation.

CMMI components that are essential to achieving process improvement in a given process area. These components are used in appraisals to determine process capability. Specific goals and generic goals are required model components.

(1) A condition or capability needed by a user to solve a problem or achieve an objective. (2) A condition or capability that must be met or possessed by a product or product component to satisfy a contract, standard, specification, or other formally imposed documents. (3) A documented representation of a condition or capability as in (1) or (2).

The determination of product-specific performance and functional characteristics based on analyses of customer needs, expectations, and constraints; operational concept; projected utilization environments for people, products, and processes; and measures of effectiveness.

Using systematic techniques, such as prototypes and structured surveys, to proactively identify and document customer and end-user needs.

The management of all requirements received by or generated by the project, including both technical and nontechnical requirements as well as those requirements levied on the project by the organization.

A discernable association between requirements and related requirements, implementations, and verifications. (See also "bidirectional traceability" and "traceability.") 
return on investment

risk analysis

risk identification

risk management

risk management strategy

root cause

senior manager

service
The ratio of revenue from output (product) to production costs, which determines whether an organization benefits from performing an action to produce something.

The evaluation, classification, and prioritization of risks.

An organized, thorough approach to seek out probable or realistic risks in achieving objectives.

An organized, analytic process to identify what might cause harm or loss (identify risks); to assess and quantify the identified risks; and to develop and, if needed, implement an appropriate approach to prevent or handle causes of risk that could result in significant harm or loss.

An organized, technical approach to identify what might cause harm or loss (identify risks); to assess and quantify the identified risks; and to develop and, if needed, implement an appropriate approach to prevent or handle causes of risk that could result in significant harm or loss. Typically, risk management is performed for project, organization, or product developing organizational units.

A source of a defect such that if it is removed, the defect is decreased or removed.

In the CMMI Product Suite, a management role at a high enough level in an organization that the primary focus of the person filling the role is the long-term vitality of the organization rather than short-term project and contractual concerns and pressures. A senior manager has authority to direct the allocation or reallocation of resources in support of organizational process improvement effectiveness. (See also "higher level management.")

A senior manager can be any manager who satisfies this description, including the head of the organization.

Synonyms for "senior manager" include "executive" and "top-level manager." However, to ensure consistency and usability, these synonyms are not used in CMMI models.

In the CMMI Product Suite, a service is a product whose primary value is delivered to a customer or end user in a form that is intangible, non-storable, and is dependent on the direct application of labor. (See also "product," "customer," and "work product.") 


\author{
shared vision \\ software \\ engineering
}

\section{solicitation}

solicitation package

special cause of process variation

specific goal

specific practice

stable process
A common understanding of guiding principles including mission, objectives, expected behavior, values, and final outcomes, which are developed and used by a project.

(1) The application of a systematic, disciplined, quantifiable approach to the development, operation, and maintenance of software. (2) The study of approaches as in (1). (See also "hardware engineering," and "systems engineering.")

The process of preparing a package to be used in selecting a supplier (contractor). (See also "solicitation package.")

A formal document delineating technical and nontechnical requirements that is used to request offers on invitations for bid (bids) and requests for proposal (proposals), or to request statements of capabilities and price quotations (quotes). It is otherwise used as a basis for selecting a supply source or sources to provide products or services.

A cause of a defect that is specific to some transient circumstance and not an inherent part of a process. (See also "common cause of process variation.")

A required model component that describes the unique characteristics that must be present to satisfy the process area. (See also "capability level," "generic goal," "organization's business objectives," and "process area.")

An expected model component that is considered important in achieving the associated specific goal. The specific practices describe the activities expected to result in achievement of the specific goals of a process area. (See also "process area" and "specific goal.")

In the continuous representation, every specific practice is associated with a capability level. The staged representation does not recognize capability levels, so all specific practices are treated equally.

The state in which all special causes of process variation have been removed and prevented from recurring so that only the common causes of process variation of the process remain. (See also "capable process," "common cause of process variation," "special cause of process variation," "standard process," and "statistically managed process.") 
staged

representation

stakeholder

standard

standard process

statement of work

statistical
predictability
statistical process
control

statistical techniques
A model structure wherein attaining the goals of a set of process areas establishes a maturity level; each level builds a foundation for subsequent levels. (See also "maturity level" and "process area.")

In the CMMI Product Suite, a group or individual that is affected by or is in some way accountable for the outcome of an undertaking. Stakeholders may include project members, suppliers, customers, end users, and others. (See also "customer" and "relevant stakeholder.")

When you see the word standard used as a noun in a CMMI model, it refers to the formal mandatory requirements developed and used to prescribe consistent approaches to development (e.g., ISO/IEC standards, IEEE standards, organizational standards). Instead of using standard in its common everyday sense, we chose another term that means the same thing (e.g., typical, traditional, usual, or customary).

An operational definition of the basic process that guides the establishment of a common process in an organization.

A standard process describes the fundamental process elements that are expected to be incorporated into any defined process. It also describes the relationships (e.g., ordering and interfaces) among these process elements. (See also "defined process.")

A description of contracted work required to complete a project.

The performance of a quantitative process that is controlled using statistical and other quantitative techniques.

Statistically based analysis of a process and measurements of process performance, which will identify common and special causes of variation in the process performance, and maintain process performance within limits. (See also "common cause of process variation," "special cause of process variation," and "statistically managed process.")

An analytic technique that employs statistical methods (e.g., statistical process control, confidence intervals, and prediction intervals). 


\section{statistically managed process}

strength

subpractice

subprocess

supplier

sustainment

systems engineering
A process that is managed by a statistically based technique in which processes are analyzed, special causes of process variation are identified, and performance is contained within well-defined limits. (See also "capable process," "special cause of process variation," "stable process," "standard process," and "statistical process control.")

As used in CMMI appraisal materials, an exemplary or noteworthy implementation of a CMMI model practice.

An informative model component that provides guidance for interpreting and implementing specific or generic practices. Subpractices may be worded as if prescriptive, but are actually meant only to provide ideas that may be useful for process improvement.

A process that is part of a larger process. A subprocess can be decomposed into subprocesses and/or process elements. (See also "process," "process description," and "process element.")

(1) An entity delivering products or performing services being acquired. (2) An individual, partnership, company, corporation, association, or other service having an agreement (contract) with an acquirer for the design, development, manufacture, maintenance, modification, or supply of items under the terms of an agreement (contract).

The processes used to ensure that a product can be utilized operationally by its end users or customers. Sustainment ensures that maintenance is done such that the product is in an operable condition whether or not the product is in use by customers or end users.

The interdisciplinary approach governing the total technical and managerial effort required to transform a set of customer needs, expectations, and constraints into a product solution and to support that solution throughout the product's life. (See also "hardware engineering" and "software engineering.")

This includes the definition of technical performance measures, the integration of engineering specialties toward the establishment of a product architecture, and the definition of supporting life-cycle processes that balance cost, performance, and schedule objectives. 
tailoring

tailoring guidelines

target profile

target staging

technical data package
Tailoring a process makes, alters, or adapts the process description for a particular end. For example, a project establishes its defined process by tailoring from the organization's set of standard processes to meet the objectives, constraints, and environment of the project.

Organizational guidelines that enable projects, groups, and organizational functions to appropriately adapt standard processes for their use. The organization's set of standard processes is described at a general level that may not be directly usable to perform a process.

Tailoring guidelines aid those who establish the defined processes for projects. Tailoring guidelines cover (1) selecting a standard process, (2) selecting an approved lifecycle model, and (3) tailoring the selected standard process and life-cycle model to fit project needs. Tailoring guidelines describe what can and cannot be modified and identify process components that are candidates for modification.

In the continuous representation, a list of process areas and their corresponding capability levels that represent an objective for process improvement. (See also "achievement profile" and "capability level profile.")

In the continuous representation, a sequence of target profiles that describes the path of process improvement to be followed by the organization. (See also "achievement profile," "capability level profile," and "target profile.")

A collection of items that can include the following if such information is appropriate to the type of product and product component (e.g., material and manufacturing requirements may not be useful for product components associated with software services or processes):

- product architecture description

- allocated requirements

- product-component descriptions

- product-related life-cycle process descriptions if not described as separate -product components

- key product characteristics

- required physical characteristics and constraints

- interface requirements

- materials requirements (bills of material and material characteristics) 
- fabrication and manufacturing requirements (for both the original equipment manufacturer and field support)

- verification criteria used to ensure requirements have been achieved

- conditions of use (environments) and operating/usage scenarios, modes and states for operations, support, training, manufacturing, disposal, and verifications throughout the life of the product

- rationale for decisions and characteristics (e.g., requirements, requirement allocations, design choices)

\section{technical requirements}

test procedure

\author{
traceability
}

trade study

training

typical work product

unit testing

validation

verification
Properties (attributes) of products or services to be acquired or developed.

Detailed instructions for the setup, execution, and evaluation of results for a given test.

A discernable association among two or more logical entities such as requirements, system elements, verifications, or tasks. (See also "bidirectional traceability" and "requirements traceability.")

An evaluation of alternatives, based on criteria and systematic analysis, to select the best alternative for attaining determined objectives.

Formal and informal learning options, which may include inclass training, informal mentoring, Web-based training, guided self-study, and formalized on-the-job training programs. The learning options selected for each situation are based on an assessment of the need for training and the performance gap to be addressed.

An informative model component that provides sample outputs from a specific practice. These examples are called typical work products because there are often other work products that are just as effective, but are not listed.

Testing of individual hardware or software units or groups of related units. (See also "acceptance testing.")

Confirmation that the product, as provided (or as it will be provided), will fulfill its intended use. In other words, validation ensures that "you built the right thing." (See also "verification.")

Confirmation that work products properly reflect the requirements specified for them. In other words, verification ensures that "you built it right." (See also "validation.") 
version control

weakness

work breakdown structure (WBS)

work product

work product and task attributes
The establishment and maintenance of baselines and the identification of changes to baselines that make it possible to return to the previous baseline.

As used in CMMI appraisal materials, the ineffective, or lack of, implementation of one or more CMMI model practices.

An arrangement of work elements and their relationship to each other and to the end product.

In the CMMI Product Suite, a useful result of a process. This can include files, documents, products, parts of the product, services, process descriptions, specifications, and invoices. A key distinction between a work product and a product component is that a work product is not necessarily part of the end product. (See also "product" and "product component.")

In CMMI models, you will see the phrase work products and services. Even though the definition of work product includes services, this phrase is used to emphasize the inclusion of services in the discussion.

Characteristics of products, services, and project tasks used to help in estimating project work. These characteristics include items such as size, complexity, weight, form, fit, and function. They are typically used as one input to deriving other project and resource estimates (e.g., effort, cost, and schedule). 


\begin{tabular}{|c|c|c|c|c|}
\hline \multicolumn{3}{|c|}{ REPORT DOCUMENTATION PAGE } & \multicolumn{2}{|c|}{$\begin{array}{l}\text { Form Approved } \\
\text { OMB No. 0704-0188 }\end{array}$} \\
\hline \multicolumn{5}{|c|}{ 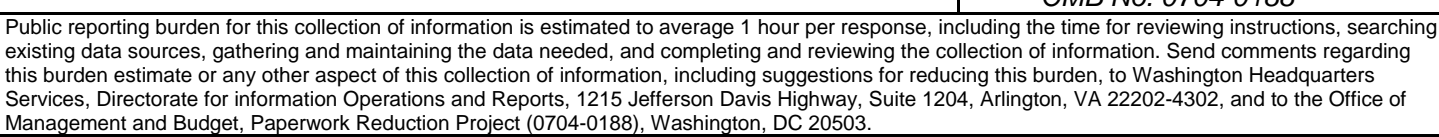 } \\
\hline $\begin{array}{l}\text { (Leave Blank) } \\
\text { 1. AGENCY USE ONLY, }\end{array}$ & \multicolumn{2}{|c|}{$\begin{array}{l}\text { 2. REPORT DATE } \\
\text { June } 2006\end{array}$} & \multicolumn{2}{|c|}{$\begin{array}{l}\text { 3. REPORT TYPE AND DATES COVERED } \\
\text { Final }\end{array}$} \\
\hline \multicolumn{3}{|c|}{$\begin{array}{l}\text { TITLE AND SUBTITLE } \\
\text { Adapting CMMI for Acquisition Organizations: A Preliminary Report }\end{array}$} & \multicolumn{2}{|c|}{$\begin{array}{ll}5 . & \text { FUNDING NUMBERS } \\
& \text { FA8721-05-C-0003 }\end{array}$} \\
\hline \multicolumn{5}{|c|}{$\begin{array}{ll}\text { 6. } & \text { AUTHOR(s) } \\
& \text { Kathryn M. Dodson, Dr. Hubert F. Hofmann, Gowri S. Ramani, Debc }\end{array}$} \\
\hline \multicolumn{3}{|c|}{$\begin{array}{l}\text { PERFORMING ORGANIZATION NAME(S) AND ADDRESS(ES) } \\
\text { Software Engineering Institute } \\
\text { Carnegie Mellon University } \\
\text { Pittsburgh, PA } 15213\end{array}$} & \multicolumn{2}{|c|}{$\begin{array}{ll}8 . & \text { PERFORMING ORGANIZATION } \\
\text { REPORT NUMBER } \\
\text { CMU/SEI-2006-SR-004 }\end{array}$} \\
\hline \multicolumn{3}{|c|}{$\begin{array}{l}\text { SPONSORING/MONITORING AGENCY NAME(S) AND A } \\
\text { HQ ESC/XPK } \\
5 \text { Eglin Street } \\
\text { Hanscom AFB, MA 01731-2116 }\end{array}$} & \multicolumn{2}{|c|}{$\begin{array}{l}\text { 10. SPONSORING/MONITORING AGENCY } \\
\text { REPORT NUMBER }\end{array}$} \\
\hline \multicolumn{5}{|c|}{ 11. SUPPLEMENTARY NOTES } \\
\hline \multicolumn{3}{|c|}{$\begin{array}{l}\text { 12A DISTRIBUTION/AVAILABILITY STATEMENT } \\
\text { Unclassified/Unlimited, DTIC, NTIS }\end{array}$} & \multicolumn{2}{|c|}{ 12B DISTRIBUTION CODE } \\
\hline \multicolumn{5}{|c|}{$\begin{array}{l}\text { CMMI }{ }^{\circledR} \text { (Capability Maturity Model Integration) is a collection of best practices that helps organizations im- } \\
\text { prove their processes. It was initially developed by a product team from Industry, U.S. government and the } \\
\text { Software Engineering Institute for application to process improvement in the development of products and } \\
\text { services covering the entire product life cycle from conceptualization through maintenance and disposal. Fol- } \\
\text { lowing the success of CMMI models for development organizations, the need was identified for a CMMI } \\
\text { model addressing the acquisition environment. This need was reinforced and gained further attention due to } \\
\text { similar needs expressed by General Motors (GM), which acquires information technology (IT) solutions. } \\
\text { Aligned with GM's strategy, GM projects or programs develop requirements and design constraints and over- } \\
\text { see multiple suppliers that develop IT solutions and then deploy the resulting products and services into one } \\
\text { or more of GM's business units. This approach parallels the acquisition processes used in many government } \\
\text { organizations. }\end{array}$} \\
\hline \multicolumn{5}{|c|}{$\begin{array}{l}\text { General Motors, in collaboration with the SEI and with approval of the CMMI Sponsors and Steering Group, } \\
\text { sponsored the development of an initial draft CMMI for Acquisition (CMMI-ACQ) constellation, which will lead } \\
\text { to a CMMI-based acquisition model formally accepted by both government and industry after piloting of the } \\
\text { initial draft CMMI-ACQ has been completed. This draft is based on the CMMI Version } 1.2 \text { architecture and } \\
\text { framework which incorporates the concept of constellations, which are groupings of components to support a } \\
\text { specific model application such as Development (DEV) or Acquisition (ACQ). }\end{array}$} \\
\hline \multicolumn{3}{|c|}{$\begin{array}{l}\text { SUBJECT TERMS } \\
\text { process improvement, version 1.2, CMMI, integrated CMM, } \\
\text { integrated model, reference model, CMM, supplier sourcing, } \\
\text { acquisition, supplier management }\end{array}$} & \multicolumn{2}{|c|}{$\begin{array}{l}\text { 15. NUMBER OF PAGES } \\
413\end{array}$} \\
\hline \multicolumn{5}{|c|}{ 16. PRICE CODE } \\
\hline $\begin{array}{l}\text { 17. SECURITY CLASSIFICATION } \\
\text { OF REPORT } \\
\text { Unclassified }\end{array}$ & $\begin{array}{l}\text { 18. SECURITY CLASSIFICATION OF } \\
\text { THIS PAGE } \\
\text { Unclassified }\end{array}$ & $\begin{array}{l}\text { 19. SECURITY CL/ } \\
\text { ABSTRACT } \\
\text { Unclassifie }\end{array}$ & SIFICATION OF & $\begin{array}{l}\text { 20. LIMITATION OF ABSTRACT } \\
\text { UL }\end{array}$ \\
\hline
\end{tabular}

